\title{
THE CITIZEN AND TRUST IN THE (TRUSTWORTHY) STATE
}

\section{ROBERT NEIL PALMER BROWN}

A thesis submitted in partial fulfilment of the requirements of the University of the West of England, for the degree of Doctor of Philosophy

Faculty of Health and Applied Sciences University of West of England

August 2018 


\section{Foreword}

This thesis is the result of reflecting on professional experience gained in different areas of public service reform. This includes working for a social enterprise providing services for people with learning difficulties, working for a reforming CEO of a local authority and, for many years, as a public sector management consultant working across most of the big departments of state as well as local government. A consistent theme running through this history of public sector change has been how to make public services more responsive to their users; a vital objective but one too often addressed from the point of view of public institutions rather than citizens. This thesis is an attempt to harness the experience to explore the issue from the perspective of citizens.

It is the result of a wide-ranging research process, and I should acknowledge the array of support and help I have received. This includes the management and participants of the research case studies, many friends and colleagues who have contributed debate and practical help in the course of the study (with particular thanks to $\mathrm{DC}$ and $\mathrm{JH}$ ) and of course the encouragement of family members. I should also make special mention of my supervision team (Professor David Evans, Dr Simon Thompson, Dr Andy Gibson and, for the first part of the study, Professor Paul Hoggett). They have gone beyond the call of duty in providing invaluable challenge and support. 


\begin{abstract}
Public sector modernisation has focused on achieving greater efficiency within the institutions and agencies of the state. In comparison the relationship between citizen and state as a basis for service improvement has received less attention. This study helps to redress this balance by exploring the role that trust can play as a mechanism of accountability of the state to the citizen, and as a consequence improving their mutual cooperation.
\end{abstract}

This poses a challenge for the state; to be trusted by citizens, the state must be trustworthy in the eyes of those citizens. Establishing the citizen's view of the characteristics of the trustworthy state, and how this differs from the norm of trust currently in use within the state, is the subject of the research. The question is addressed through a process of dialogic action research with users and frontline staff of two public services (a housing benefit service and a general practice). The output of the study is a relational diagnostic, applicable across the public sector, derived from a synthesis of the tests applied by citizens as they assess the trustworthiness of a public service. The diagnostic is structured around the essential elements of the citizen/state trust relationship; it tests citizens' perceptions of the respect with which they are held as 'trustor', the sense of responsibility they perceive in the state as 'trustee' and the degree to which their consent is important to the 'governance' of the trust relationship.

Applying these tests sets a demanding agenda for change in the management of the state and its agencies, in organising to create a more responsive and cooperative relationship with citizens. The diagnostic structure and tests are designed to be used by public services and citizen groups to improve relationships across the public sector. 
1. COOPERATION, PUBLIC VALUE AND THE TRUSTWORTHY STATE ... 6

1.1 INTRODUCTION 6

1.2 THE RELATIONAL MODEL FOR THE STUDY........................................................... 14

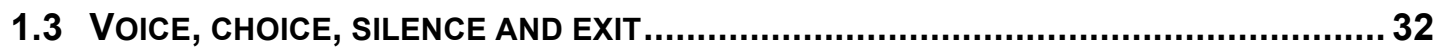

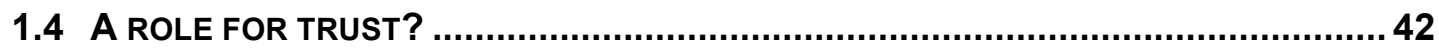

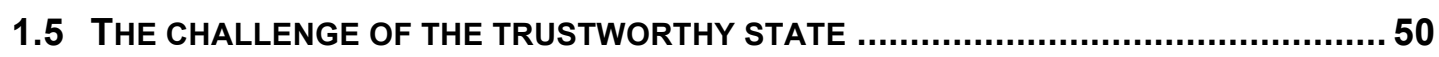

2. A THEORETICAL PERSPECTIVE - THE VARIETIES OF TRUST .........56

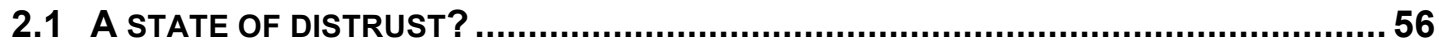

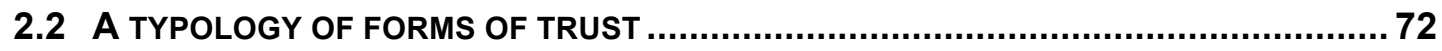

2.3 A HYPOTHESIS OF DIFFERING NORMS OF TRUST ............................................. 92

3. A RELATIONAL AND DELIBERATIVE RESEARCH METHOD ..............95

3.1 OVERVIEW OF THE KNOWLEDGE CHALLENGES AND STUDY METHOD......................95

3.2 THE DIALOGIC ACTION RESEARCH METHOD IN PRACTICE...................................104

3.3 THE EVALUATION FRAMEWORK FOR DATA ANALYSIS ...................................... 118

3.4 THEORY DRIVEN AND EMERGENT APPROACHES TO DATA ANALYSIS ...................129

4. KEY THEMES FROM THE INITIAL FIELDWORK .............................. 132

4.1 THE TYPES OF DATA GENERATED BY THE CASE STUDY .................................133

4.2 FINDINGS FOR 'CONNECTIVITY' ............................................................... 139

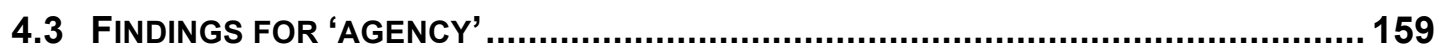

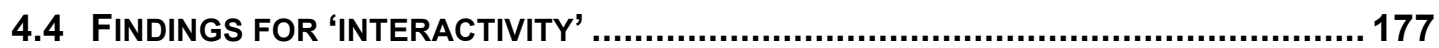

4.5 EMERGING THEMES FOR THE TRUSTWORTHY STATE ...................................... 197

5. THE DIAGNOSTIC TESTS OF A TRUSTWORTHY STATE .................202

5.1 THE RATIONALE AND STRUCTURE OF THE DIAGNOSTIC ..................................202

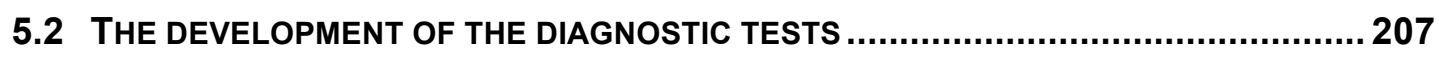

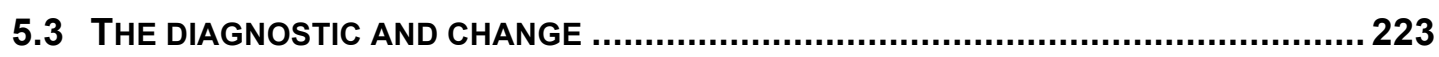

6. TESTING THE DIAGNOSTIC WITH A GP SURGERY .........................224 


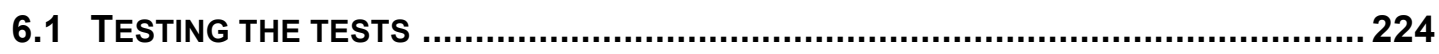

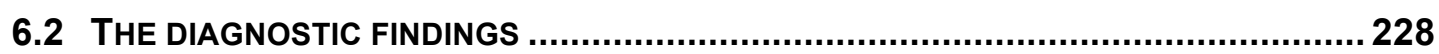

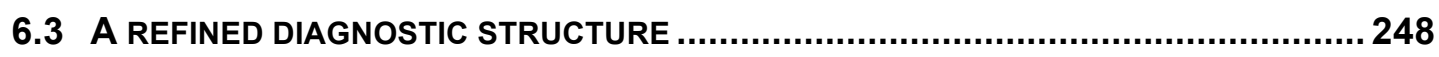

7. CRITICAL EVALUATION AND FUTURE LINES OF INQUIRY ............... 255

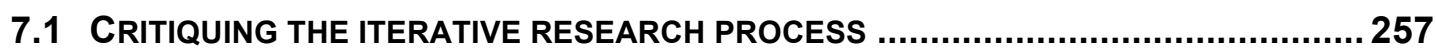

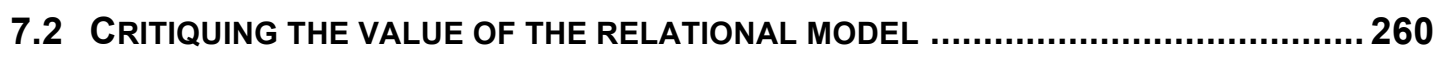

7.3 CRITIQUING THE PROPOSITION TO ENHANCE CITIZEN TRUST..............................263

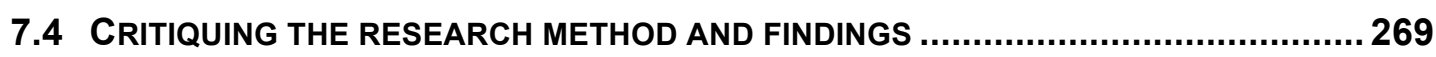

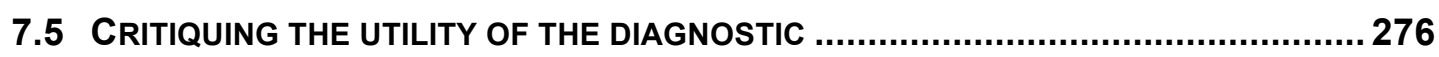

7.6 FINAL THOUGHTS AND FUTURE LINES OF INQUIRY ........................................ 282

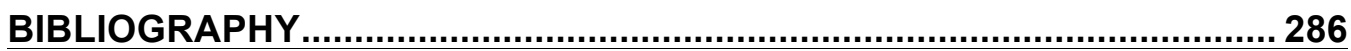

Appendixes [attached in separate document]

Contents

APPENDIX 1 GLOSSARY 2

APPENDIX 2. ETHICAL APPROVAL 3

APPENDIX 3. HB STUDY PARTICIPANT CONSENT FORM 6

APPENDIX 4. HB STUDY USER SURVEY QUESTIONNAIRE 10

APPENDIX 5. GP STUDY PATIENT CONSENT FORM 13

APPENDIX 6. GP STUDY PATIENT SURVEY QUESTIONNAIRE 17

APPENDIX 7. DRAFT ARTICLE SUBMITTED TO PPA 25 


\section{Cooperation, public value and the trustworthy state}

This chapter defines the problem addressed by the research, critiquing the effectiveness of the current citizen/state relationship. It also sets out the high-level proposition for addressing the problem, exploring the potential and challenges for enhancing citizen trust in the state.

The argument is developed in five stages. The first section (1.1) sets out the objectives, key methodological assumptions, and thesis structure. Subsequent sections analyse the citizen/state relationship from the perspective of cooperation in the creation of public value (1.2), and then discuss the nature of current relational mechanisms of voice and choice in managing the citizen/state interaction (1.3). The concluding sections explore the potential for trust to act as a mechanism of mutual coordination that encourages more active citizen/state cooperation (1.4), and then develop the challenge - that to be trusted by citizens, the state must be perceived to be trustworthy in their eyes (1.5).

\subsection{Introduction}

In this section I describe the objectives and key methodological assumptions for the study (1.1.1), and summarise how the thesis structure relates to the iterative process of inquiry (1.1.2).

\subsubsection{The goal is to empower citizens in their relationship with the state}

One of the key vehicles for collective social action is the modern state, using public resources to achieve social goals, whether by direct intervention or by facilitating individuals and groups to enhance social welfare. Over recent decades much effort has been expended on improving its effectiveness. Most reforms have aimed to make the state more efficient in generating collective benefits. Often grouped as 'New Public Management' (NPM) (Hood, 1991) or the creation of a 'post bureaucratic state' (Kernaghan, 2000), 'modernisation' has imported management techniques from the private sector to streamline the delivery machine of state institutions and agencies. 
By contrast this study starts from the premise that the relationship between state and citizens (individually or in communities) should also be a significant focus of reform. It contributes to a growing if still embryonic and fragmented debate on the changing role of citizens, as exemplified by the Behavioural Unit (The Behavioural Insights Team, 2015) within the Cabinet Office, as well as academic discussions of themes such as the relational state (Muir, 2014) and models of participation and citizenship (Barnes, Newman and Sullivan, 2009). The proposition it explores is that enhancing citizens' trust in the state can improve co-operation with state services and activities, offering the potential for a step change in effectiveness through more active citizen contributions, and reducing redundant and dysfunctional effort.

My interest in exploring this proposition is derived from both professional experience and personal values. I have worked on many aspects of the reform of public services. An early formative experience was managing a social enterprise that, prior to the introduction of 'care in the community', challenged the prevailing orthodoxy of institutionalised state provision for people with learning difficulties. Subsequent experiences included working for a county council chief executive who pioneered the introduction of 'devolved management' within the public sector, followed by many years as a public sector management consultant leading programmes of change using many of the techniques of NPM described above. In this role I have also been involved with a number of potent initiatives that help indicate the potential for a more radical reform of the citizen relationship, such as designing the first local authority customer service centre at Westminster City Council and developing a citizen-centric policy development tool - the Department for Education and Schools' system reform model. These and related projects provided the insight that contemporary attempts to make public services more responsive to their users were vital but limited by being initiated from within a dominant institutional paradigm. This thesis is an attempt to harness that experience to address the issue from the perspective of citizens.

The second and related driver for the investigation of this proposition is a personal commitment to forms of social collaboration and collective action, both in terms of individual relations and at the macro level of a social solidarity. Part of the motivation for pursuing a career in public service reform was to improve the capacity of the state to 
develop and implement effective collective action to mitigate social problems and create the conditions for better social collaboration. Thus whilst aspects of this thesis are profoundly critical of the current formations of the state, this criticism is offered in a spirit of optimism for the potential of the provision it can and should deliver on behalf of the collective. The goal of the critique is not to dispute the validity of state action, but to enhance its legitimacy by helping it to achieve a better return on the financial and behavioural investment citizens make in it. The conceptual hierarchy underpinning this endeavour is firstly that the optimisation of public value should be the overarching goal of the state, secondly that the cooperation of citizens is an important contributor to the creation of this value, and thirdly that trust plays an important role in enabling and structuring that cooperation.

The investigation necessarily touches multiple areas of academic discourse including public policy, political philosophy, sociology and the wide and burgeoning literature on trust itself. A number of perspectives underpin the integration of relevant contributions from all these areas. The first is that a relational emphasis, embracing the personal and institutional, requires a mode of analysis that is psychosocial: 'psycho' because citizen/state relationships exist partly in the subjective cognitive and emotional feelings of individuals, whether individually or as part of a community; and 'social' because these feelings arise partly in the context of broader social structures and forces.

In fact the citizen's individual and subjective relationship with the social institutions of the state embodies the rationale for combining these disciplines, as summarised by Simon Clarke:

"We all know there is a social construction of our realities as much as we know that we are emotional people who construct our 'selves' in imagination and affect. Neither sociology or psychoanalysis provides a better explanation of the world than the other, but together they provide a deeper understanding of the social world" (Clarke, 2006, p.1154).

As a result the study was open to all relevant forms and motives of human behaviour, including affect and emotion as well as reason. This is the terrain of fuzzy or bounded rationality (Simon, 1992), whereby human behaviour is understood to be motivated by a complex mix of calculation and mental and emotional heuristics. 
A related consideration is the agency/structure debate. Theories of structuration (Giddens, 1986) compliment the psychosocial perspective. According to this account social phenomena, such as trust, are the results of a dialectical interplay of individual agency with external systemic forces. This understanding of structure as a duality, both formed by and reflecting the actions of agents in an interaction with a social system, was a helpful backdrop to the initial analysis of the citizen/state relationship.

A final important part of the intellectual context for the study is the role of power as one of the key constraints on agency, particularly important given the asymmetry of power relations between citizen and state. In this respect the broad definition of power derived from Foucault's ([1977-78] 2009) analysis of disciplinary discourse, and the internalisation of structures of domination is useful. Foucault's investigation builds on Lukes' (1986) seminal description of the three faces of power. Lukes helped promote a more holistic understanding of power not just as a resource (such as the possession of force or authority) but also as a consequence of the distribution of knowledge - who has it, whose knowledge is defined as relevant and, in the third face of power, how the definition of what constitutes knowledge structures power in setting the agenda for discussion and political discourse. Foucault took this understanding of the subjective internalisation of power still further in recognising that power is constituted within the individual not just by the constraints of an external body or knowledge, but also by the voluntary acceptance of prevailing systems of thought themselves - a "power within shaped by one's identity and self-conception of agency as well as by "the Other" (Gaventa and Cornwell, 2006, p.75). It is this perspective that helps illuminate the potential for dominatory relations between citizen and state, and underpins the approach within this study to analysing the micro dynamics of the interactions within the relationship.

These considerations form the basis for describing the study objective in promoting better citizen state relations. The state is understood as a self-reproducing system that responds to its own internal needs and power structures as well as external demands. The main engine of change is hierarchic, whether from democratically elected or autocratic political leaders. Moreover, its relationship with citizens is necessarily characterised by an asymmetry of power. As a result change is slow and relatively unresponsive to bottom up pressure from citizens. Thus the normative objective of the study is to explore whether the 
mechanism of trust can play a more effective role in empowering citizens in holding the state to account, and shaping service delivery. So whilst the subject of the study is the mutual relationship between citizen and state, the dominant perspective in setting the agenda for change is that of the citizen.

The theoretical perspective that is tested in addressing this objective is that one explanation for what has been dubbed the 'delivery paradox' - whereby it seems that trust in the state is inexorably reducing just as services are improving (Coats and Passmore, 2008; Parker, 2008) - is that the state is operating to a different and more limited form of trust than that to which citizens aspire. If true, then articulating citizens' perspectives on trust could offer a potential practical tool for fulfilling the objective of empowering citizens.

Two research questions flowed from this. The first was to understand the tests in the mind of citizens when assessing the state's trustworthiness, and whether these were different in kind to the norm of trust and trustworthiness in use within the agencies of the state. The second question followed; once identified, could these tests help structure the citizen/state relationship to encourage more co-operative interactions?

\subsubsection{The study method was iterative and reflexive}

The study approach follows the tradition of critical theory (Barry, 2009) in starting from the idea for change summarised above, and iteratively developing and testing the theoretical and empirical components required for its application. In pursuing this objective for change the study seeks to provide a number of distinctive contributions to the emergent debates on the role of the citizen. The first is analytic: to provide a relational perspective in conceptualising and investigating the way citizens and state interact. The second is propositional: to explore the core nature and dynamics of trust as a mechanism for the coordination of social interactions, and its relevance to the citizen/state relationship. The third is methodological: to develop a repeatable way of tapping deliberative and relational knowledge of citizens and frontline staff in respect of their mutual trust. The final contribution is practical; to build on this theory and practice to synthesise the 'heuristic' or common sense tests by which citizens judge the trustworthiness of a state activity. The 
final chapter evaluates the success of the study by challenging the value of each of these contributions.

In synthesising the eclectic range of academic literatures germane to this endeavour sources have been chosen for several reasons. Firstly, because of their specific relevance to the argument being developed. Secondly, because they are the most influential contributions and debates. Thirdly, to test the thinking in the context of the normative traditions most relevant to current public service reform. These are the neoliberal school (sceptical of the role of state, and all collective organisation), a socialist perspective (if liberated from capitalist class structures the state can be an engine of social change), and what has been called the neo-institutionalism approach (the state is likely to be in the grip of the prevailing dominant power structures).

The spirit of critical inquiry is also reflected in the structure of the thesis. The first sections develop the description of the problem, proposition and hypothesis. The following sections describe how this thinking was tested and developed through two cycles of a customised form of dialogic action research (DAR) with groups of service users and frontline staff. The first case study with a busy urban housing benefit service gave rise to an initial formulation of the tests of state trustworthiness in the eyes of citizens. These were tested and refined through practical deployment in a second case study with a suburban general practice (GP) surgery.

Figure 1.1 illustrates the key stages of the process and how they relate to the structure of the thesis, and the subsequent text summarises the logic and contents of each chapter. 
Figure 1.1 The inquiry process related to thesis structure

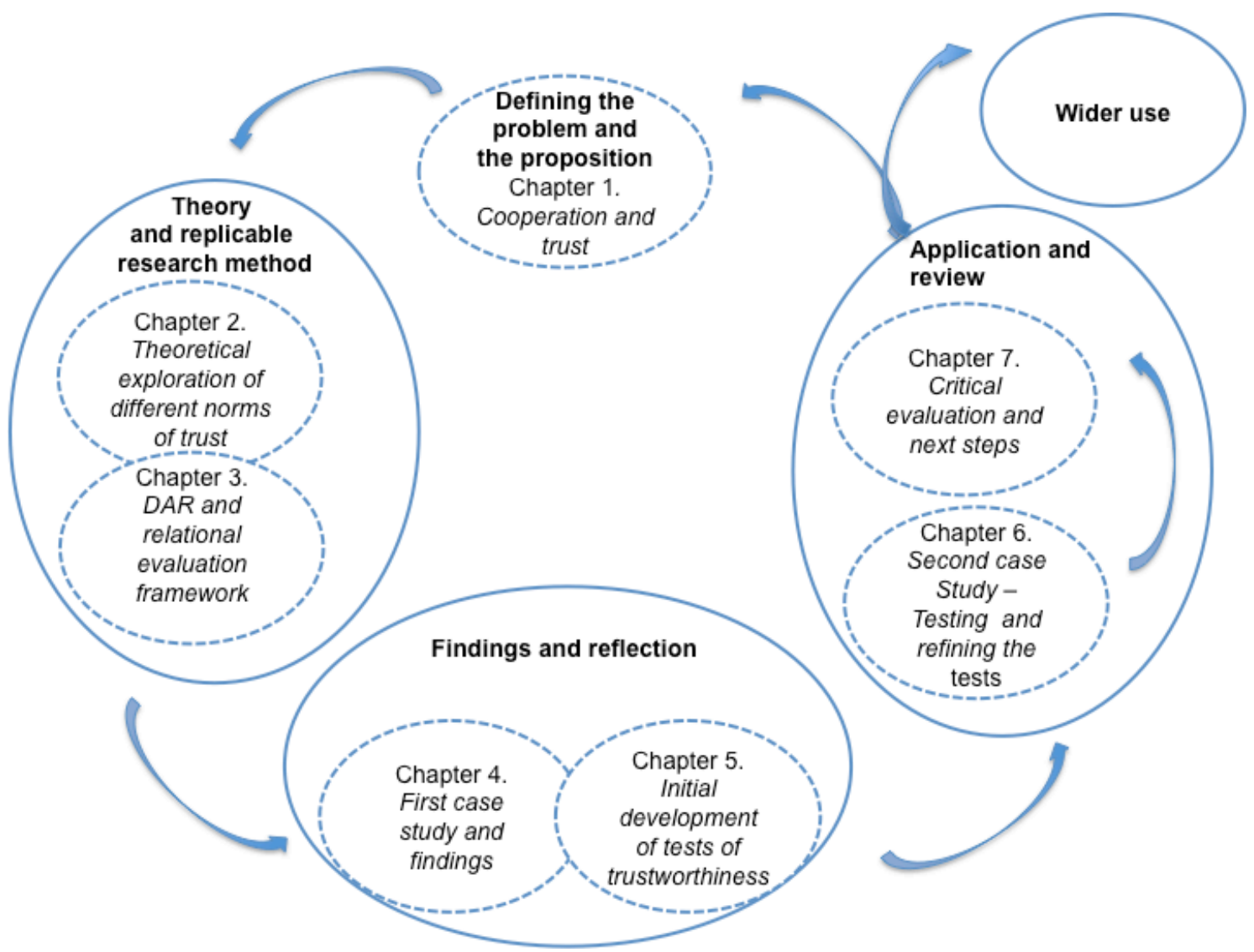

Chapter 1 - defining the problem and proposition

The starting point is to conceptualise citizen/state relationships from the point of view of the citizen rather than more traditional institutional and bureaucratic definitions. This provides an analytic basis for understanding problems in current citizen/state cooperation and developing the proposition for the potential role of trust in improving the relationship.

\section{Chapter 2 - developing the theoretical dimensions of the proposition}

Analysing current research relevant to trust in the state suggests that citizen and state are operating to different norms. A typology of forms of trust helps to understand the potential areas of difference. 
There are two key components for a relational research method to investigate the knowledge challenges posed by this definition of the problem. Firstly, designing a DAR process for the fieldwork. Secondly, developing an evaluation framework for coding data derived from the DAR.

\section{Chapter 4 - deriving the initial research findings}

The initial DAR case study was conducted with an urban housing benefit service. Service user representatives worked with frontline staff in a collaborative and structured analysis of their relationship. This chapter summarises the findings, analysing both the formal recommendations arising from the group and the coding of the transcript evidence. The evaluation framework provides insight into the relational dynamics at play.

\section{Chapter 5 - initial synthesis of the tests of trustworthiness}

Reflecting on the fieldwork findings in the context of the trust typology, the next step was to identify the core heuristic tests that may be applied by citizens in assessing whether a public service is trustworthy. These were formed into an initial version of a generic diagnostic tool designed to analyse any citizen/state relationship.

\section{Chapter 6 - testing the tests}

The second piece of fieldwork tested the tests in action, in a targeted version of the DAR process conducted with patients and staff of a suburban GP Surgery. This chapter describes the process and outcomes, and the refinements to the diagnostic structure that resulted.

\section{Chapter 7 - critical evaluation}

Chapter 7 evaluates the success of the project in addressing the research question. It is structured around an assessment of the value and wider validity of each of the four contributions set out in section 1.1.2 above. It concludes with a summary of the learning generated in the context of the research questions and the challenges this poses for the reform of the state and further research. 


\subsection{The relational model for the study}

The first step in analysing the citizen/state relationship is to conceptualise its intrinsic nature and components. In this section I use the framework of public value to probe the key dynamics of the relationship, especially the contribution of citizens to the workings of the state (1.2.1). This leads to the formulation of a public value relational model, starting (1.2.2) with the structure and scope of the model and then (1.2.3) considering the relational dynamics that inform its workings.

\subsubsection{Citizens and state co-create public value}

Describing and conceptualising the citizen/state relationship draws on several emerging strands of public policy thinking. These include recent discussions around the concept of the 'relational state' (Muir, 2014), the growing literature on 'co-production' (Boyle and Harris, 2009; Cahn, 2000; Ostrom, 1990), and the application of 'service value' (Grönroos, 2011) analysis to the delivery of public services.

Each approach offers insights and challenges. However, a particularly useful framework for integrating these insights is 'public value' (Moore, 1995). By starting from the existential question of what value is produced by the state, and how, it provides an analytic basis for investigating the practical contribution of citizens to that value in cooperation with the state.

However, the framework needs adapting for use in this way. Moore (1995) conceived the public value concept as an educational tool for public sector managers. His objective was to encourage greater innovation and entrepreneurialism within the public sector in pursuit of 'value', deliberately analogous to a private sector approach. As a result Moore developed an analytic framework for understanding both the nature of the value produced by the state, and the key processes for achieving it. Moore describes a 'strategic triangle' of factors relevant to managers that support or constrain the creation of public value. These factors are:

- 'Strategic goals' - what Moore calls the 'value circle', or the aims of a public service against which it should be measured. 
- 'Authorising environment' - gaining support and funding for action from all relevant stakeholders, including citizens.

- 'Operational capability' - the practical deployment of resources, and the capabilities of the public sector and its users.

The analysis that follows uses the same categories ${ }^{1}$, but replaces the public sector manager at the core of the triangle with the citizen, as a way of assessing the contribution they make to public value. Figure 1.2 illustrates the triangle and the main types of citizen contribution to public value. These are discussed more fully below.

${ }^{1}$ Others have attempted different formulations of this framework. Kelly Mulgan and Muers recast the three elements as 'outcomes', 'trust' and 'services'(2002). Coats and Passmore (2008) offer 'measure', 'authorise' and 'create'. These are interesting refinements but they are not necessary here, so I follow most commentators in sticking to the original descriptions. 
Figure 1.2 The citizen contributes value in all three aspects of the strategic triangle

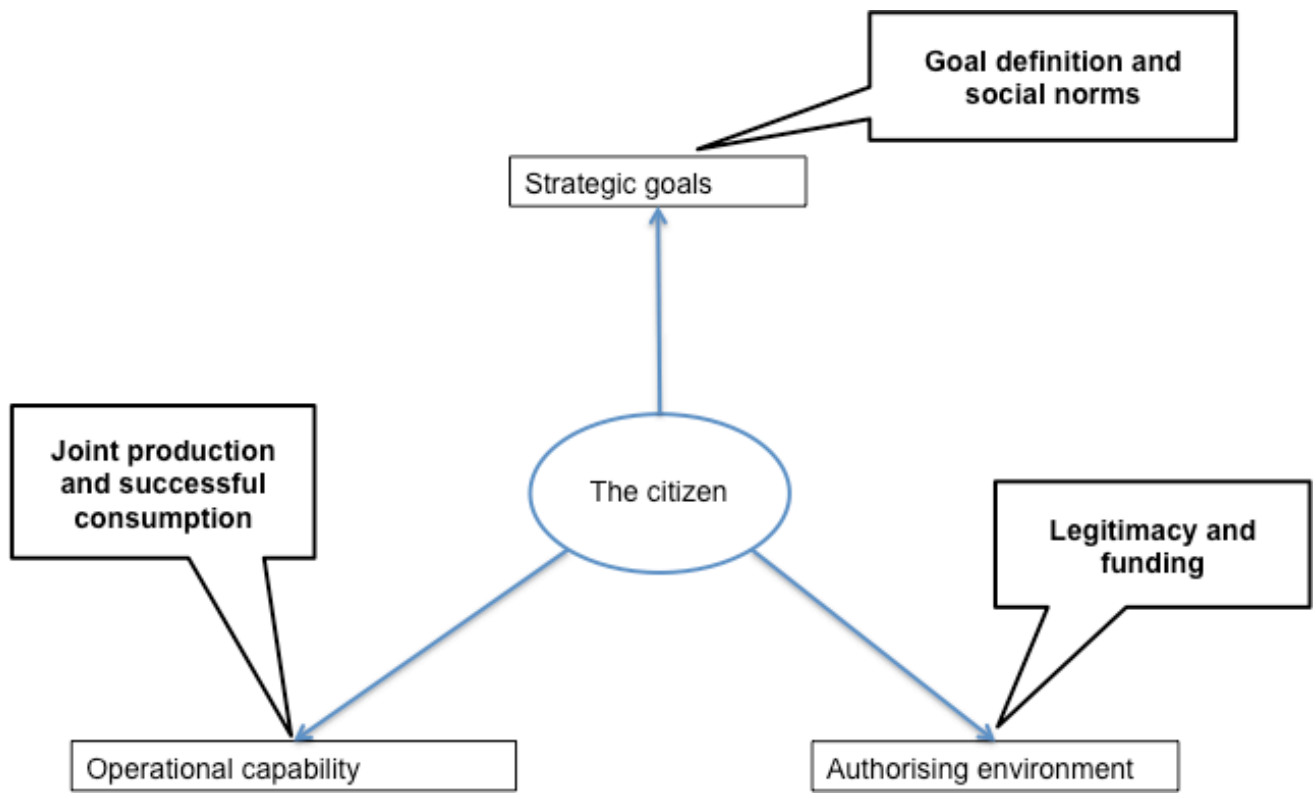

\section{Citizens and strategic goals}

The strategic triangle starts by defining the intrinsic value the state produces, so it can be understood and measured. The many debates this has spawned around the precise measures are less important to this study than how commentators define the citizen's role in the process. Moore unequivocally locates public value in the experience of both the individual citizen and the community:

"... partly in terms of the satisfaction of individuals who enjoy desirable outcomes... and partly in terms of the satisfactions of citizens who have seen a collective need, fashioned a public response to that need, and thereby participated in the construction of a community" (Moore, 1995, p. 45).

Whether individual or collective, the significant point for this study is that public value is measured by the state's success in satisfying defined public need (Kelly, Mulgan and Muers, 2002). This is itself shaped by the collective and subjective feelings of citizens. David Coats and Eleanor Passmore argue that: 
"Public services are characterised by claims of rights by citizens to services that have been authorised and funded through some democratic process" (Coats and Passmore, 2008, p.7).

If social needs and goals define public value, it can be measured by outcomes. For Kelly, Mulgan, and Muers the results of state activity form a "core part of the contract with government" (Kelly, Mulgan and Muers, 2002, p.15). Thus, citizens assess the value produced by the police service in term of safety in the streets more than the quality of operational procedures. Framing public value like this both demonstrates the importance of citizens in defining what is valuable, and the strategic contribution of civic society to public value. The authors argue "Government alone cannot deliver lower crime and better health: social norms of behaviour are critical" (Kelly, Mulgan and Muers, 2002, p.16). It follows that citizen/state relationships are necessarily symbiotic. It is the interaction between public services and citizens, and their social norms of behaviour, that help cocreate public value.

\section{Citizens and the authorising environment}

The second dimension of Moore's public value triangle is the 'authorising environment' (1995). This highlights the range of stakeholders whose support is required to achieve public value, including managers, staff, delivery partners, and the public(s) that fund and use the service. The importance of citizens' contribution to the 'authorising environment' is twofold. Firstly, it confers public legitimacy, the acceptance that the service is appropriate because of a shared understanding of the public outcomes it supports. Secondly, it enables funding and resources for the service, even where there is little personal benefit. The authorising environment combines with strategic goals to represent the relationship of citizens with the state in embodying the intent of the collective.

Perspectives from political philosophy and sociology echo the importance of this relationship. In 'A State of Trust', Levi argues that a key benefit of trusting the state is that it enhances the contingent consent of its citizens:

"Citizens are likely to trust Government only to the extent that they believe that it will act in their interests, that its procedures are fair, and that their trust of the state and of others is reciprocated. These are the conditions of contingent consent, 
behavioural compliance with government demands even when an individual's costs somewhat exceed her individual benefits ..." (Levi, 1998, p.88).

Levi adds that the other pre-condition for the contingent consent of citizens is the 'ethical reciprocity' amongst their fellows.

\section{Citizens and the operational capacity to achieve public value}

Moore's third dimension concerns how public sector managers should best deploy operational resources to maximise the production of public value. This reflects the relationship with the citizen as service user (individually or in communities), and the citizen role in this domain is more complex and contested. One can conceptualise the citizen contribution within the separate but complementary categories of production and consumption. Social care illustrates both the distinction and relationship between these categories. For example, the 'authorising public' funds dementia care because of the perceived social value of easing family and individual suffering. This value is then crystallised (or not) through the individual experience of the service and how far it succeeds in maintaining self-sufficiency (facilitating citizen co-production) and in attenuating suffering (successful citizen consumption).

Looking first at the process of consumption ${ }^{2}$, the citizen contribution has traditionally been underemphasised. This is perhaps partly because from a narrow supply side perspective consumption is, if anything, destructive of public value - a rationed good is no longer available to another. However, the dementia example demonstrates that a public service

2 By consumption, here I focus here on the use of a public service. Later I discuss consumerism as a delivery philosophy. 
is only valuable if it is successful, and that success - or lack of it - occurs within the citizen's lived experience of the service. Moreover, information from citizens on the successes or failures of services is vital to the public service agency to help create additional future value.

This is the perspective of 'service management theory' (Normann, 1991). This argues that the user creates service value through their engagement in the mode of consumption, whether that service is public or private. This moves beyond the traditional view of valuein-exchange (in the private sector the price achieved by the seller) to an understanding that the key currency is value-in-use, that a service is only of value insofar as it resolves a user need. Grönroos's summary is:

"Value-in-use means that value for the user is created or emerges during usage, which is a process of which the customer as user is in charge. In the same way as service quality is perceived throughout the service process (Grönroos, 1984; Parasuraman et al., 1985), value is accumulating, or destroyed throughout this process... Hence, value is created by the user, and moreover, also experienced by a user, who also uniquely determines what value is created" (Grönroos, 2011, p.287).

Service management theory also links consumption with production. Each is part of the other in the lived experience of any service, public or private. So, citizen and state are locked in an inescapable embrace as they co-create public value. Osborne, Radnor and Strokosch call this 'technical co-production', and describe it as intrinsic to the service experience:

"The user's contribution as a co-producer during service production is not only unavoidable (and can be unconscious or coerced) but is also crucial to the performance of a service. Such co production leads to the co-creation of value for the service user" (Osborne, Radnor and Strokosch, 2016, p.643).

For this study the term 'joint production' is preferred for describing this intrinsic and everyday reciprocity. The term embraces the weft and weave of the citizen role in most services, however transactional, in providing information, following process and participating in the production process. It also helps differentiate this perspective from the more traditional literature on co-production. This tends to conceptualise the citizen contribution as additive rather than inherent, running the danger of implicitly retaining the 
characterisation of citizens as predominantly passive consumers. It is this that explains the tendency of some co-production literature to focus only on public services seen as particularly 'relational' (Mulgan, 2012), such as social care. However, what both perspectives share is the analysis of the value citizens can bring to the process of production, as summarised by David Boyle and Michael Harris in The Challenge of CoProduction:

"Co-production means delivering public services in an equal and reciprocal relationship between professionals, people using services, their families and their neighbours. Where activities are co-produced in this way, both services and neighbourhoods become far more effective agents of change" (Boyle and Harris, 2009, p.11).

Boyle and Harris's examples illustrate the potential of better citizen/state co-operation, from Youth Courts where first offenders are 'tried' by their peers; to the expert patient programme, where patients suffering chronic illness support others similarly affected. This chimes with many other practical projects. For example, the 2020 public services trust study co-ordinated by the Royal Society of Arts (RSA) describes their goal as "social productivity" based on "social citizenship" and derived from "a culture of participation based on the joint creation of social value" (2010, p.17).

There are different ways of describing the distinctive importance of the participation of citizens in the process of production. However the main arguments include:

- Ownership - the motivation of citizens to follow advice or use a service in pursuit of the value outcomes; for example, the commitment of patients to rehabilitation, students to learning and prisoners to rehabilitation.

- Effort - the physical contribution of citizens to a service. For example, the willingness to offer extra support to other patients with the same disease in the Expert Patient Programme.

- Intelligence - the integration and guidance of public services, particularly in the so called 'wicked issues' like obesity or antisocial behaviour. Social issues with 
multiple causes and multiple interventions require the active management of citizens to be effective.

\subsubsection{Conceptualising a public value relational model}

The lens of public value reveals a dynamic picture of the citizen/state relationship, where citizens make three specific contributions when co-creating public value with the state. Citizens pose the social need that defines the nature of the value itself, legitimise and fund the activity required and finally participate with the state in operational activity by both consuming the service and playing a role in its production.

All three modes of value production occur within iterative interactions between state and citizen. Public value is constantly produced through a range of strategic, governance, and operational relationships between state agencies and citizens, individually or in communities. Better cooperation can enhance the co-creation of public value. Conversely a poor or uncooperative relationship can reduce or even destroy public value, for example by:

- 'Exit' - citizens choose private provision, and become unwilling to fund collective services through taxes.

- Non compliance - the converse of contingent consent, which may have a heavy price in causing re-work and sub-optimal results such as tax evasion.

- Operational conflict - clearly destructive of value, both in high profile cases like the long-running campaign to challenge the authorities over the cover up of police failings that contributed to the loss of life at Hillsborough (Scraton, 2013), as well as more prosaic maladministration.

- Skewed priorities, dysfunctional, or dominatory services - when for example the strategic or operational interests of the state as an entity become detached from those of its users and members, as for example with the systemic failings that led to the abolition of the Mid Staffordshire Hospital Trust (Francis, 2013). 
This analysis of co-creating public value holds true across most state activities. Table 1.1 provides an illustrative grouping of the most common public functions of the state using a typography derived from commonalities in the nature of, and access to, the service. The second column gives examples of the public value outcome and the third examples of citizens' contributions.

Table 1.1 Analysis of public value and the citizen

\begin{tabular}{|c|c|c|}
\hline Public service area & $\begin{array}{l}\text { Examples of public value } \\
\text { outcomes }\end{array}$ & $\begin{array}{l}\text { Examples of citizen } \\
\text { contributions }\end{array}$ \\
\hline $\begin{array}{l}\text { Universal services such as } \\
\text { health and education }\end{array}$ & $\begin{array}{l}\text { A healthy population } \\
\text { 'Capable' citizens }\end{array}$ & $\begin{array}{l}\text { Managing own health; } \\
\text { seeking and applying } \\
\text { medical advice } \\
\text { Developing own potential } \\
\text { by studying and gaining } \\
\text { qualifications/skills }\end{array}$ \\
\hline $\begin{array}{l}\text { Welfare services such as } \\
\text { benefits and social } \\
\text { services }\end{array}$ & $\begin{array}{l}\text { Protection of the vulnerable } \\
\text { Enabling universal social } \\
\text { participation }\end{array}$ & $\begin{array}{l}\text { 'Appropriate' use of } \\
\text { benefits and services to } \\
\text { encourage self-help and } \\
\text { reduce dependency }\end{array}$ \\
\hline Regulatory services & $\begin{array}{l}\text { Orderly markets for all to } \\
\text { use }\end{array}$ & $\begin{array}{l}\text { Compliance with } \\
\text { regulation and standards }\end{array}$ \\
\hline $\begin{array}{l}\text { Judicial and policing } \\
\text { services }\end{array}$ & $\begin{array}{l}\text { Community order and } \\
\text { reduction in crime }\end{array}$ & $\begin{array}{l}\text { Compliance with laws } \\
\text { Co-operation with } \\
\text { policing and judicial } \\
\text { processes }\end{array}$ \\
\hline Economic development & Economic prosperity & $\begin{array}{l}\text { Worker and business } \\
\text { production of economic } \\
\text { value }\end{array}$ \\
\hline Defence & $\begin{array}{l}\text { Maintaining internal order } \\
\text { and external boundaries }\end{array}$ & $\begin{array}{l}\text { Accepting state monopoly } \\
\text { of internal and external }\end{array}$ \\
\hline
\end{tabular}




\begin{tabular}{|l|l|l|}
\hline & & violence \\
\hline Taxation & $\begin{array}{l}\text { Financing collective } \\
\text { provision }\end{array}$ & $\begin{array}{l}\text { Paying taxes and } \\
\text { observing regulations }\end{array}$ \\
\hline
\end{tabular}

A generic 'relational model', illustrated in Figure 1.3 below, is another way of presenting this analysis, and it helps to structure this study. The state is on one side and citizens, individually or collectively, on the other. The multiple relationships described above and illustrated in Table 1.1 are conceptualised within a zone of interaction where public value is co-created.

The typical stages of the citizen's experience of the interaction are represented by the 'citizen journey' through a public service. For example, a health service 'patient pathway' usually tracks the journey from identifying patient need, through gaining access to the appropriate service, and then actual delivery. Each stage has its own relational parameters and dynamic.

Figure 1.3 A public value relational model

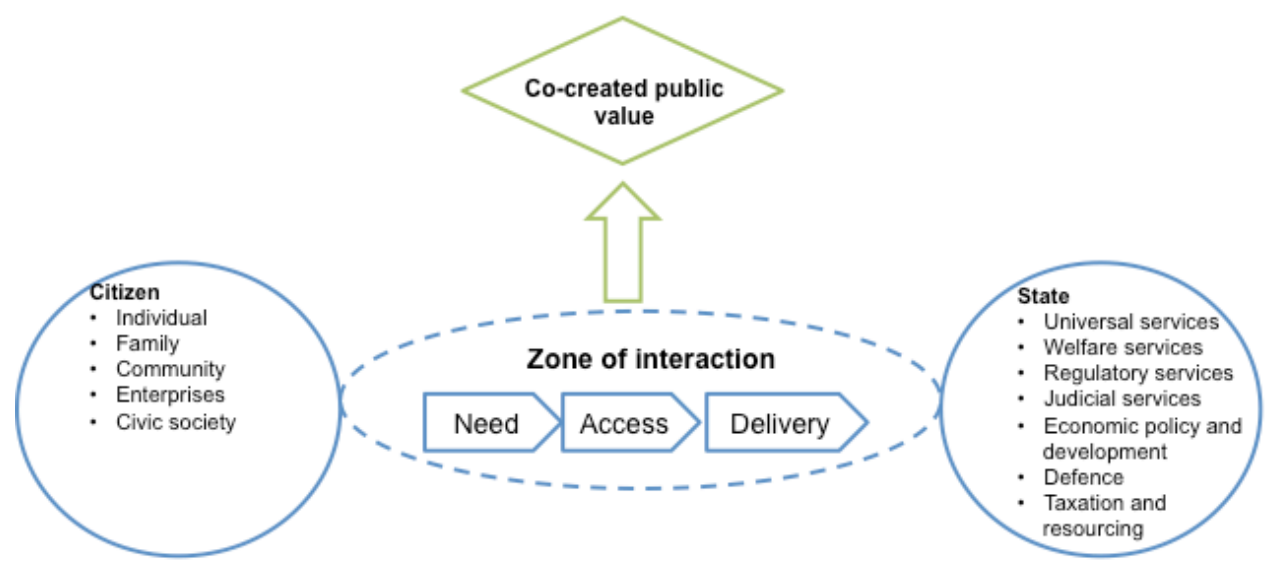

It is the focus on the zone of interaction that differentiates this model from previous conceptualisations. For example, traditional public policy models often assume a citizen waiting passively at the end of a state-managed production line (Doray, 1988). More 
recent formulations of the relationship acknowledge a strategic role for citizens in providing feedback on services (Cabinet Office, 2006), but give little concrete insight into making the proposition a reality beyond the action of voice and choice (which are critiqued in the next section). This is a shift of rhetoric but remains a fundamentally static depiction of the relationship. The public value relational model developed here is intended to capture a more dynamic, reciprocal, and iterative quality in the relationship between citizen and state. ${ }^{3}$

The sections below use the categories of the model to define the scope of the study, and bring some research issues into sharper relief. The first two define how the terms state and citizen are used within this model. The subsequent sections then explore in more detail the components of the zone of interaction and its relationship to public value outcomes.

\section{Defining the state}

Despite globalisation, the nation state ${ }^{4}$ remains the predominant political power. There is no single definition of the state, but it is generally understood as a historically contingent

${ }^{3}$ One clear articulation of citizen/state reciprocity is in the language of the social contract; a contract describes a reciprocal relationship in which parties agree mutual obligations. There are different views on the philosophic bases for the obligations of citizen and state, but they are agreed on the core mutuality. Whether the central purpose of the state is held to be the enactment of popular opinion (Locke, [1632-1704] 1993) or the maintenance of public order (Hobbes, [1651] 2013) the state is obliged to provide the function, and citizens have a corresponding duty to accept the sovereignty of the state.

4 The UK is sometimes referred to as 'countries within countries' (Cabinet Office, 2008) but nonetheless still conforms to the general definition of a nation state (Office for National Statistics, 2011). 
form of governance that conflates cultural identity with political structures. Common themes are an emphasis on sovereignty within hard borders, centralised administration, and a powerful state role in shaping and maintaining a common cultural, economic and military capacity (Jessop, 2002).

Most commentators trace its origins to the early city-states of Northern Italy in the twelfth and thirteenth century. It is here that Skinner (2012) amongst others identifies some of the earliest breaks with feudal forms of government, not least in the earliest use of state as a word. Derived from the Italian 'Stato,' it distinguishes between the current regime and the institutions of government that exist independently of any ruler. Over centuries of debate and evolution, the state became seen as the sovereign political authority in the land, with an existence separate from that of civil society and deriving its legitimacy by being itself subject to the rule of law.

These principles still apply to most modern states amidst the growth of capitalism and the related industrial and political evolutions of the eighteenth and nineteenth centuries. Many of these developments concerned new technologies of state control - for example police forces, the growth of mass surveillance, and bureaucratic structures of governance such as tax collection. There was also a tightening of the territorial definition of the state and its grip on the use of force. These developments prompted Weber's famous definition of the state as:

"A human community that (successfully) claims the monopoly of legitimate use of physical force within a given territory" (Weber, Gerth and Mills, 1970, p.78). 
If increasing control is one historical theme, then the other is the enhanced range of functions by which the state supports social solidarity. The emergence of these administrative systems provided the foundation for the remarkable growth in the scale and complexity of the 'social' state over the last century. In his study of the history of capitalism, Thomas Piketty makes the point that the scale of this enlargement is unparalleled:

"in other words, all the rich countries, without exception, went into the $20^{\text {th }}$ century from an equilibrium in which less than a tenth of their national income was consumed by taxes to a new equilibrium in which the figure rose to between a third and a half" (Piketty, 2014, p.476).

The growth of the state into all the areas of public value creation summarised by table 1.1 is the context for the working definition of the state for this study. The state includes any activity or function funded by public money, whether owned or delivered publicly, privately, or the third sector. For clarity, the term 'state agent' is used to describe any staff or other agent acting on behalf of the state and with whom citizens interact, however employed.

Subsequent sections review recent attempts at state reform (section 1.3), political philosophy and trust in the state (section 1.4), and a review of existing empirical evidence on the citizen/state relationship (chapter 2 ).

\section{Defining the citizen}

The concept of 'citizen' is also complex and contested. For the purposes of this study the term is used to cover all who interact with the state as defined above, whether as an individual or as members of collective entities.

'Citizen' has connotations that should be acknowledged and justified. Originally derived from the Roman distinction between an active member of the cives, or public life, and a slave or a woman, the term was appropriated by early republicans in the seventeenth and eighteenth century. They differentiated between the voluntary delegation of power to a ruler by an otherwise free born individual, and the model of a subject bound involuntarily to the natural authority of an imposed governor (Cudworth, Hall and McGovern, 2007). 
This is a normative assumption generally accepted within the UK. Most residents of Britain are technically citizens in this legal sense.

However the term is also used in the non-legal context of the Roman principle of quod omnes tangit, ab omnibus approbetur ('whatever touches all, must be approved by all'). The scope of what is meant by the citizen for this study follows the spirit of this definition by embracing anyone who encounters the requirements of the state, individually or collectively, whether taxpayer, resident, or stateless and penniless asylum seeker. Finally the term also embraces the different relational archetypes implied by more contested language such as 'customer', 'client' or 'subject'.

Subsequent sections consider the emergence of different models or discourses of citizenship and the current workings of voice and choice (section 1.3), and review existing empirical evidence on the citizen/state relationship (chapter 2).

\section{Defining the zone of interaction}

The 'zone of interaction', the relational space between citizen and state, is intended to be a unifying concept to capture the full range of transactions between citizens and the multiple embodiments of the state. Its parameters are defined by the subjective lived experience of the state in the consciousness of the citizen. It embraces all points of contact, whether formal actions such as voting, or more basic transactions such as a doctor's appointment or phoning for advice.

Within the zone are the relational dynamics of the interaction, with every moment potentially contributing to the experience - even a sign, gesture, or passing emotion. It embraces both actions and feelings, usually within an on-going and reciprocal exchange (with reciprocity used here in the neutral sense of any connected exchange between parties whether beneficial or hostile). As observed earlier, the interaction can either lead to the co-operative co-creation of public value, or its destruction.

The concept of intersubjectivity described by Atwood and Stolorow is helpful in conceptualising the zone and its workings: 
"Intersubjectivity theory is a field theory or systems theory in that it seeks to comprehend psychological phenomena not as products of isolated intrapsychic mechanisms, but as forming at the interface of reciprocally interacting subjectivities" (Stolorow and Atwood, 2002, p.1).

The importance of the focus on the interaction between citizen and state for this investigation is confirmed by Giddens' influential meditation on the additional demands modernity poses for the workings of trust (Giddens, 1990). He dates modernity to the emergence in Europe of a potent mix of capitalism and industrialisation combined with the development of the nation state in the eighteenth century. Giddens argues that a historically contingent aspect of modernity has been the move from the predominance of personal to impersonal relations between people. Twin processes of "distanciation" and "disembedding" of social relations are the cause. "Distanciation" describes the separation of time from space (time moves from being locally defined to becoming a universal measure based on Greenwich Mean Time) that permits productive relations across time zones. Space also becomes separate from and emptied of 'place' - communication is now possible at great distance. These conditions encourage the "disembedding" of social relations:

"By disembedding I meant the "lifting out" of social relations from local contexts of interaction and their restructuring across indefinite spans of time-space" (Giddens, 1990, p.21).

I will discuss Giddens' views on the implications of modernity more fully in the next section. What matters here is how he sees the function of trust evolving. Trust in modernity is no longer reliant on personal relations, as these are less effective at a distance. Instead trust is fuelled by "symbolic tokens" such as money and expert systems (for example, air traffic control is an expert system we all implicitly trust). Giddens collectively calls these 'abstract systems'.

Building on this terminology, citizens can perceive the state as a network of 'abstract systems' that citizens are asked to trust without knowing their internal workings. Giddens' description of how that trust is built stresses the mix of 'facework commitments' (direct personal encounters) with 'faceless commitments' (the workings of abstract systems), and how these two mechanisms come together at 'access points': 
"At access points the facework commitments which tie lay actors into trust relations ordinarily involve displays of manifest trustworthiness and integrity, coupled with an attitude of "business as usual," or unflappability. Although everyone is aware that the real repository of trust is in the abstract system, rather than the individuals who in specific contexts "represent" it, access points carry a reminder that it is flesh-and-blood people (who are potentially fallible) who are its operators. Facework commitments tend to be heavily dependent upon what might be called the demeanour of system representatives or operators. The grave deliberations of the judge, solemn professionalism of the doctor or stereotyped cheerfulness of the air cabin crew all fall into this category" (Giddens, 1990, p.85).

This is the theoretical core for this study, understanding the dynamics and relationships that inform the interactions of the citizen and the facework of government agents at the 'frontline' of state activities who are themselves representing the faceless commitments of the bureaucracies and systems at their back. As Giddens argues, studying frontline interactions will provide evidence on the factors that inform trust in the moment of the interaction, and on the system and hierarchical dynamics that drive the behaviour and processes of front-line workers themselves. The 'zone of interaction', comprising facework and faceless commitments, is a comprehensive setting to investigate trust between citizen and state, even where the pressures that drive those factors arise at a distance from the front-line, including the processes of policy development that gives rise to the service experience in the first place.

\section{Defining co-created public value}

This section began by claiming that few areas of public value are not co-created between state and citizen. The description of the relational model, and particularly the zone of interaction, reflects this. Within this model, public value outcomes concern overall measures such as public health, educational attainment, total taxation raised, community law and order, or the amelioration of poverty. As argued above, the majority of these are the result of iterative interactions between citizen and state. This is the basis for the proposition that if the relationship with citizens is a significant contributor to public value, then a cooperative relationship will co-create more public value (better outcomes) than a passive or conflictual engagement. 


\subsubsection{Introducing relational dynamics within the model}

The final stage in the development of the model in providing the analytic scope for the study is to conceptualise the key dynamics that energise its workings. This entails the identification and categorisation of the main relational variables brought into play in the variety of citizen/state interactions, in order to understand which are important to trust. They function as a map of the relational terrain; in themselves they do not offer solutions or priorities, but rather the means for the identification of the factors of importance within the data.

The categories work with the grain of the subjective and intersubjective dimensions of the relational model presented thus far. Starting with the subjective aspect, the analysis builds on Bakan's formulation of agency and communion as two competing relational modes:

"I have adopted the terms 'agency' and 'communion' to characterize two fundamental modalities in the existence of living forms. Agency for the existence of an organism as an individual, and communion for the participation of the individual in some larger organism of which the individual is part" (1966, pp.14-15).

This appeals as a basic bifurcation of relational approaches that helps expose a difference in view between the state and citizen on the instrumentality and emotional qualities of the relationship. However, to be useful in this regard the terms need to be adapted in a number of ways. This study follows those commentators such as Leonard (1997) who have adapted Bakan's thinking in seeing the two relational modalities as a duality (both present in some form) rather than a dualism (alternative and mutually exclusive types of relationships). It follows that whilst the basic categorisation is useful, the normative implications of the original are not. In order to understand the full range of potential factors and how they work together it is more helpful to view each category as descriptive. Thus, the question is what form of agency and communion participants espouse, and how these relate to trust. It is for this reason the latter category is renamed 'connectivity' rather than communion, in order to capture this more analytic intent.

Building on this separation, the category of 'agency' is used to probe the attitudes of the participants to the material aspects of the interaction, examining issues such as their motivation, their perception of their role in an interaction and their capacity to enact that 
role. The category 'connectivity' investigates issues associated with the emotional and social nature of the relationship, summarised as the capacity of the participants to connect with the other. The premise is that all citizen/state relationships contain elements of both agency and connectivity. This conceptualisation helped illuminate the core issue of whether trust is driven primarily by factors to do with performance and efficiency, identified within the agency category; or alternatively whether factors to do with how a service is delivered, for example emotion and affect, are also important. This is what the connectivity category was intended to expose.

Thus 'agency' and 'connectivity' are conceived as the subjective attitudinal terrain on which the behavioural and intersubjective actuality of the citizen/state interaction sits. Understanding the dynamics of this reciprocal 'interactivity' is the third dimension of the model. This leads to questions about the nature and importance of how citizen/state interactions are structured, the impact of process they follow and on the significance of the perception of the outcomes they produce. It is informed by a variety of academic contributions on the nature of intersubjectivity in addition to that of Stolorow and Atwood referenced earlier (Grönroos, 2011; Hoggett et al., 2010; Stolorow and Atwood, 2002; Habermas, 1987). It also embraces Benjamin's intersubjective conceptualisation of the "space of thirdness" as the "capacity to identify, to get inside the other's mind and let the other inside us..." (2005, p.449).

Thus the three analytic relational categories combine in a specific way. The interaction is influenced by, and influences, the subjective attitudes and thoughts of the participants. 'Agency' and 'connectivity' are inputs to, and consequences of, 'what happens' in the 'zone of interaction'. In this way the categories fit within the relational model and can be used to analyse the dynamics of its workings, providing the means of probing what attitudes, structures and patterns of reciprocal behaviour affect trust. Building this thinking into the model can be illustrated graphically as in Figure 1.4 below. The relational model, embracing the 'zone of interaction' and the category of 'interactivity', is structured by the participants' positions in terms of the dimensions of 'connectivity' and 'agency'. 


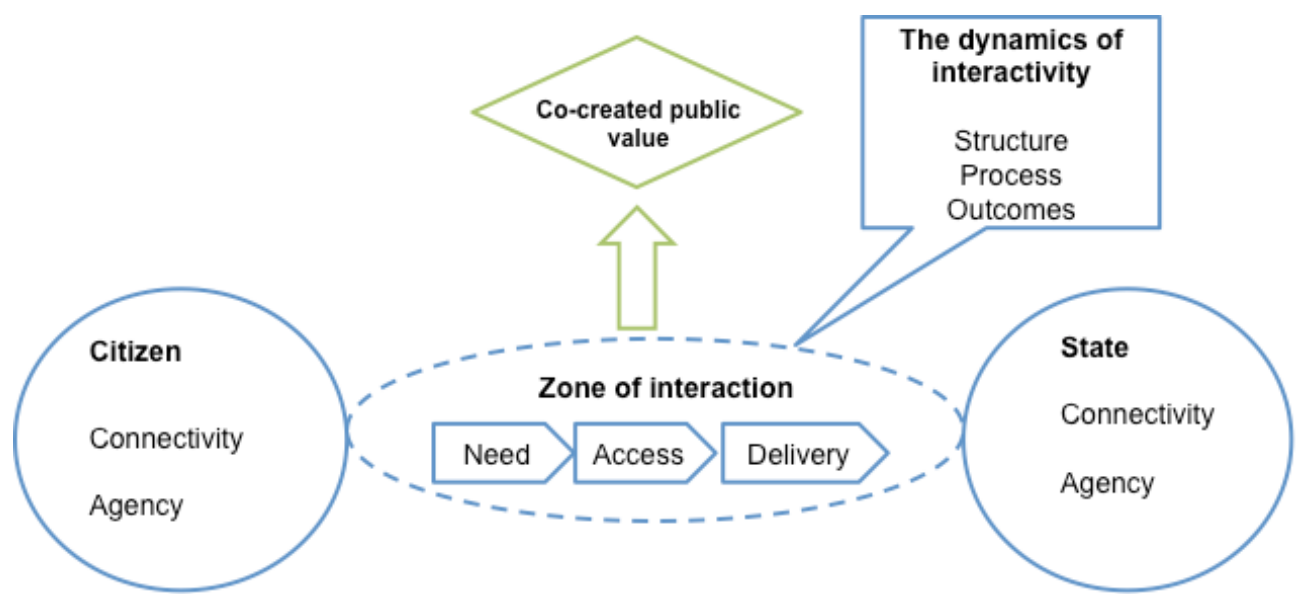

This model including the relational categories is used as a tool in helping to analyse a range of contemporary published research relevant to trust in the state and in the development of the trust typology. It is also used to interrogate the data from the fieldwork.

\subsection{Voice, choice, silence and exit}

This section builds on the conceptualisation of the relational model to investigate the current citizen/state relationship in the context of the collaborative co-creation of public value. I start by summarising the impact of the main recent reform agendas of on the structures of the state (1.3.1). I then consider their impact on prevailing mechanisms of relational coordination (primarily voice and choice) and associated models of citizenship (1.3.2). This reveals a current relational paradigm based more on citizen compliance than cooperation.

\subsubsection{Public sector reform has changed aspects of the citizen/state relationship}

There have been many efforts to reform the state over the last few decades, in the UK and most developed countries. This section surveys the main structural shifts of the UK experience, arguing that they have had more impact on the structures of the state than on relationships with citizens. 
The dominant political philosophy of these reforms has been neo-liberalism. Famously championed by Thatcher and Reagan in the eighties, with many principles also adopted by New Labour Governments of 1997 - 2010, neo-liberals regard the state with intrinsic suspicion. They argue that attempts to create a collective vehicle inevitably end in the limitation of individual economic and social freedom (Hayek and Caldwell, 2014; Friedman, 1977).

This scepticism is illustrated by the literature around the so-called knight/knave characterisation of the principal/agent analysis (Le Grand, 2003). This argues that the state may have good intentions but these will be thwarted by the self-interest of its agents - the knaves. Without the discipline of the market and its structuring of information and incentives, the prime motive of state employees is a quiet life, not the common good. Opting for a quiet life means a dampening of responsiveness to public service users, and inertia in adopting new and more efficient means of production.

In practice the neo-liberal critique has focussed more on the latter problem than the former. I shall demonstrate this through a brief analysis of the two dominant and related reform strategies that have been used, the managerial philosophy of the so called New Public Management (NPM) (Hood, 1991), and the use of markets and competition.

Summarising the components of NPM, Newman and Clarke (2009) describe an 'assemblage' of complementary propositions around the concept of 'good management', amounting to a normative and disciplinary discourse in its own right. NPM seeks wholesale adoption of modern management techniques and information technology primarily drawn from the private sector, because of the apparent contribution to productive efficiency and also their value as a countervailing force to the 'professional' control of service definition and delivery. Typical components include target setting, league tables and looser labour laws to create a more malleable and flexible labour force.

Controversially, neo-liberal inspired change has also increased the use of competition and markets in public services delivery. The aim has been partly to increase citizen choice of service provider, for example in schools, GP surgeries and hospitals. I discuss this more fully below. Other examples include privatisation, the sale of state bodies and contracting 
out - where non-state, often private sector, agencies take over work previously done by a public sector bureaucracy. The Private Finance Initiative (PFI) is a variant in which the private sector also funds capital investment in public assets such as hospitals or roads (Wang, 2014).

A final theme has been replacing state agencies with other forms of collective organisation with social objectives, such as voluntary or charitable groups. Examples include housing associations, as well as religious, voluntary, and community groups. Politically, some see this as community or individual empowerment. Others see an opportunity to reduce the role of the state. Whether or not this is a good idea is outside the scope of this study. What matters here is that they play a vital role in enabling citizens to voice and communicate their needs to the state. But there are limits to this. Young (2002) argues:

"Despite the vital role of civil society in promoting inclusion, expression, and critique for deep democracy, I argue against those who suggest that civil society serves as a preferred alternative to the state today for promoting democracy and social justice. State institutions have unique capacities for co-ordination, regulation, and administration on a large-scale that well functioning democracy cannot do without. Though civil society stands in tension with state institutions, a strengthening of both is necessary to deepen democracy and undermine injustice, especially that deriving from private economic power" (Young, 2002, p.156).

She likens this citizen/state cooperation to the workings of a political thermostat alerting the state to the issues that need regulation.

\subsubsection{The impact of reform on the citizen relationship}

This section turns to examine how far these reforms have changed citizen/state relationships by analysing their impact on the mechanisms and related citizen discourses that govern the relationship. It starts by defining the range of mechanisms, and then examines each in turn.

Hirschman's Exit, Voice, and Loyalty (1970) offers voice and exit as the two main ways of coordinating citizen/state relationships. With the addition of choice (to reflect the changes described above) this remains the dominant public policy framework of relational mechanisms. For the purposes of analysis I also suggest adopting a fourth mechanism of 
'silence', as a way into understanding citizen/state interactions where citizens have no means of influencing the relationship. The argument developed below is that, despite some genuine advances, the dominant citizen/state relational paradigm remains securing citizen compliance rather than active collaboration.

The great strength of Hirschman's original development of the Exit, Voice, Loyalty (EVL) framework was that it represents a 'bottom up' view of how citizens and customers of public and private bodies can influence public 'producers'. Hirschman added the concept of 'voice' to the prevailing orthodoxy that 'exit' (taking your custom elsewhere) was the only effective response to an unsatisfactory situation - an orthodoxy that embraced both state bureaucracy and capitalist relations between companies and customers. Hirschman described his objective as:

" In the large portion of my book, which was an essay in persuasion on behalf of voice, I argued that voice can and should complement and occasionally supersede exit as a recuperation mechanism when business firms, public services, and other organisations deteriorate" (Hirschman, 1973, pp.7-8).

In Hirschman's original formulation, citizens occasionally need to signal dissatisfaction to the state to maintain an efficient machine of economic distribution. Voice and exit are potential mechanisms to express their views. Which they use depends partly on how loyal they feel to the state. Hirschman's objectives were normative as well as analytic. He feared that the disenchanted affluent would exit state provision, and that would weaken the 'voice' of those that remain. He wanted to understand how voice and loyalty could work together to optimise feedback to the state, and therefore minimise exit. He hoped that if citizens were loyal to public services, dissatisfaction would be expressed by voice not exit. Adding 'choice' reflects the policy developments described earlier. For clarity this should be understood as 'internal' choice to differentiate it from the original conception of 'exit', representing the option of choosing to move beyond the public system entirely.

As a further test of the categorical clarity of the terms and of the comprehensiveness of the model, it is useful to consider a rival framework inspired by Hirschman's work but taking it forward with a revised formulation. This is the Exit, Voice, Loyalty and Neglect (EVLN) framework (Lyons, Lowery and Hoogland De Hoog, 1992). The language is similar to Hirschman but the concepts are different. Here, EVLN are conceived as 
equivalent, mutually exclusive, and comprehensive potential behavioural responses to dissatisfaction in a relationship (any relationship, from marriage to dissatisfaction with public services).

This perspective is interesting but differs from the objective of this analysis in conflating mechanisms and outcomes. Moreover, the EVLN categories carry more normative overtones than Hirschman's more neutral mechanisms; voice and loyalty are described as positive responses to dissatisfaction, exit and neglect as destructive. So at a categorical level, Hirschman's conceptualisation of voice and exit as mechanisms separate from but influenced by attitudes (loyalty) is more analytically useful for the purpose of this study.

However, the EVLN approach is helpful in that 'neglect' poses the issue of passive responses to dissatisfaction. Arguably there is a mechanism of communication and influence that frames this sort of relationship, and it is called silence. Dowding and John's analysis of the differences between EVL and EVLN makes just this point:

"Exit and voice are clearly not exclusive of each other. The poles opposite voice and exit are silence and non exit or stay rather than loyalty and neglect" (Dowding and John, 2012, p.73).

This is an important insight in the context of the present endeavour of creating a comprehensive understanding of how the current citizen/state relationship is managed. Some interactions between citizen and state are not subject to voice, choice or exit. For this study, I suggest silence best describes this passive acceptance.

Below I use this formulation of the citizen/state relational mechanisms to develop a critique of the effectiveness of the current relationship grounded in the means available to influence events. Each mechanism is assessed through the lens of cooperation, and in the context of the models of citizenship they imply. For this purpose Barnes, Newman and Sullivan (2009) helpfully document a number of different 'citizen discourses'. They identify relational archetypes or 'publics' such as the 'consuming public', the 'empowered public', the 'stakeholder public', and the 'responsible public'. To this I add the discourse of the 'dependant public' as a way of analysing the mechanism of silence. 
Hirschman's description of voice actually includes dialogue, not just registering discontent. Hirschman argued that voice was appropriate to relationships containing an asymmetry of information that, he believed, makes a pure market relationship problematic. This asymmetry is ubiquitous across the public sector so it is worth repeating his analysis in the context of health:

"When the delivery of health services can proceed along standard lines within well charted territory as, say, in the case of minor dentistry, consumer dissatisfaction with one dentist is likely to take the form of exit. But the individual who has some as yet poorly articulated complaint with respect to his general physical or mental health is probably well advised not to abandon his family doctor or psychiatrist at the slightest disappointment, but to help them grope on his behalf and to collaborate intensively with them through active use of voice" (Hirschman, 1973, p.10).

Instruments that support voice have developed considerably since Hirschman's original formulation. Rowe and Frewer (2005) document 31 different methods of public consultation and engagement, from citizen juries to direct budgeting exercises. They show three broad approaches: communication (one way distribution of information to the public), consultation (one way distribution of information to the state) and participation (often involving 'expert' lay representatives in dialogue with professionals) as for example on the board of the National Institute for Health and Care Excellence (NICE).

One way to assess the impact of the development of voice is to consider the relevant participation orientated discourses from Barnes, Sullivan and Newman's typography, and whether these represent a relationship of cooperation or compliance. Most relevant to voice are 'the responsible citizen', 'the empowered citizen', and the 'stakeholder citizen'.

The 'responsible citizen' carries echoes of both New Labour and the UK Coalition Government's 'Big Society' modernisation projects. It stems from the communitarian movement's emphasis on the duties of citizenship (Etzioni, 1995). This is usually conceived as individuals or communities taking additional responsibility for a particular public service, for example faith-based schooling. There is a disciplinary quality to this narrative with the identification and punishment of the converse of (sometimes literally) anti-social behaviour. Stronger citizen/state cooperation is certainly a feature, yet it is not 
conceived reciprocally. It encourages citizens' efforts but with little corresponding insight into what the state should do differently to encourage greater participation or how to strengthen the mechanism of voice.

The 'empowered public' discourse is rooted in the later $20^{\text {th }}$ century. It argues for communities of interest 'taking over their' services, or at least having an important role in their definition and control. These communities are often spatially defined. For example in the UK Community Development Projects (CDPs) were intended to be 'community led', and Local Strategic Partnerships between local government and other local public services had mandatory councillor representation. Though interesting experiments, their influence has arguably been at the margins. Their scope was wider than their impact, and more generally few mainstream services have been turned over to citizen management (free schools may be an example, but they are few in number and must still conform to national curricula). A further tension between the empowerment movement and citizen cooperation is that the final rung of Arnstein's famous ladder of participation (1969) is citizen control, not mutual collaboration.

The stakeholder citizen, the final category relevant to voice, focuses primarily on innovations in types of democracy. Examples include experiments in participatory democracy, often at neighbourhood level within progressive local authorities, and citizen and user representatives in service delivery structures such as hospital trusts. This discourse is more valuable in the context of cooperation. Conceptualising the citizen as a 'member' of the state takes the relationship into the micro-delivery of public service and suggests a stronger voice on policy priorities. Hirst summarises the vision thus:

"A stake implies a voice, and the right to voice implies the obligation to use it, to steward our own assets. In that sense the concept helps us to restore the robust democracy of free people governing themselves" (Hirst, 1994, p.241).

The critique of this is about impact rather than philosophy. For example, an often quoted stakeholder inspired reform is the Number 10 web-based petition, where enough signatures guarantee a parliamentary discussion. This is an additional articulation of voice; but only within existing decision-making structures and with little evidence of major impact. By the beginning of 2018 there were 3,455 petitions on the Government website 
of which 51 received a government response and a mere 6 debated in Parliament (Cabinet Office, 2018).

The conclusion to draw from this brief survey of the citizen discourses around voice is of both change and continuity. There has been a genuine widening of the policy process and real gains in making the barrier between state and public more permeable. However, there is little evidence of politicians or policy makers interest in making voice an effective and structured reality. Moreover the profusion of different instruments and initiatives indicates that voice is currently insufficiently conceptualised to provide a basis for creating systematic cooperation in the delivery of a public service.

\section{Choice}

A key development in public policy since Hirschman's book is the growth of markets to coordinate and control public service delivery, ostensibly to nurture competition and citizen choice. The market options usually remain publicly funded so this should be understood as internal choice, as distinct from exit. It also differs from contracting out, which replaces an existing provider with different one but does not itself extend citizens' choices.

The most common form is a choice between different providers of the same stateordained service, such as health and education. There can be also choice over the nature of the provision. This is more radical as it delegates authority over the nature of the service to the citizen as customer. Personal budgets for social care are one example; citizens receive a budget according to some objective measure of need, which they can spend broadly as they wish.

There is considerable academic work around the limitations of public sector markets (Greener, 2008). The service is still collectively funded, and usually free at the point of delivery. Apart from elements of social care choice is often prescribed to a few accredited suppliers. Nonetheless, it gives citizens some market power to choose, transferring to them a role and rights that demand greater respect from state providers. Such quasi markets can also help expose poor performance. 
The narrative of citizen as 'customer' is one that politicians have consistently embraced for decades. However, in the context of cooperation, choice occupies an ambiguous position. There is some evidence that treating citizens as customers can improve satisfaction levels for example by raising service and care standards. However, it can introduce competitive behaviour as well as cooperation, and even in a limited form it is only appropriate to a discrete number of services. Where it has been introduced, such as around schools and hospitals, it has not been accompanied by investment in redundancy in the system necessary for genuine choice and competition between several providers (Jilke, 2015; Le Grand, 2007).

\section{Silence}

I argued above that some citizen/state relationships are not subject to voice, choice or exit. These passive relationships are instead characterised by bureaucratic state prescription and citizen 'silence'. Silence can denote acquiescence. The service or interaction proceeds without great upset, along standardised lines. This will often be true if the interaction has no great importance to the individual and there is limited discretion to opt out. The benefits of a deeper co-operative relationship are not important.

However, silence can also denote domination. Citizens may be unhappy or distrustful of the interaction but unable to use voice, choice or exit. This may be out of loyalty, or it may be because they have no options, or lack the capacity or means to secure change in the face of institutional indifference. The Francis Inquiry identified one of the main contributory factors to the catastrophic service failures at the South Staffordshire NHS Trust as "Trust management had no culture of listening to patients" (Francis QC, 2013, p.44).

A phrase that describes this is "bureaucratic dependency" (Breiner, 1996). In its day bureaucracy was considered progressive (Waters and Waters, 2015), offering an objective technology of 'control' that enabled the state to finance and manage the enormous growth in its functions. Bureaucracies value equity and standardisation, and emphasise process control to reduce the risk of error. This emphasis on order and coherence banishes the arbitrary, as perceived by the bureaucracy or citizens. 
However the corollary is a relationship based predominantly on state power. In this world, citizens are often conceived as waiting passively at the end of the state production line awaiting the benefits or interventions decreed by a distant authority. In the 1980s Gyford described the combination of bureaucratic organisation and powerful professionals in some public services as creating an "infantilised public" (Gyford, 1991). Some writers still look back at this as a golden age of public service characterised by citizen trust (Fotaki, 2014; Coats and Passmore, 2008). The alternative view is that a form of trust may have been present, but in a dominatory form. I discuss this more fully later in this chapter.

\section{Exit}

As discussed earlier a fear driving public policy over many years is that the affluent middle classes especially will stop using (and paying for) many public services. Services might then become an impoverished safety net for the poor and vulnerable. Fear of exodus drove many elements of the New Labour project led by Tony Blair and Gordon Brown. However, the public value perspective highlights other forms of exit - passive or active resistance. Resistance may be the only available option, particularly for state functions from which exit is not permitted like policing. The long battle over Hillsborough is an example where voice failed to achieve accountability and resulted in outright conflict, an example of public value destroyed.

\section{Conclusion - cooperation or compliance?}

This survey of the variety of current state and citizen/state relational mechanisms presents a mixed picture. The discourses of participation and associated developments of voice and choice have prompted some innovation, but their adoption by politicians and policy makers has been half hearted at best. As a result there has been insufficient theorisation of the relational forms and the interactions they suit, and as mechanisms they have not fully emerged from the legacy of bureaucracy, or alternatively are largely appropriated from private market models. In either case citizens' roles are largely restricted to quiet consumption, taken to imply satisfaction, or 'customer' type feedback on dissatisfaction. The implication is an underlying relational paradigm based on the state prioritising citizen compliance more than active cooperation. 


\subsection{A role for trust?}

This section introduces and defines the concept of trust used in the rest of the study, focussing in the first instance on its characteristics and function as a mechanism for the coordination and governance of social interactions in order to demonstrate its potential relevance to the citizen/state relationship. It starts (1.4.1) by relating trust and control, and then (1.4.2) compares trust to other coordinating mechanisms such as power and markets. This helps delineate trust as a mechanism particularly appropriate for relationships of voluntary cooperation (1.4.3). I also describe a dark side to trust, and that it is particularly unwise to trust the untrustworthy (1.4.4). A fuller exploration of different forms of trust relationships follows in chapter 2.

\subsubsection{Trust and control}

That "trust arrives on foot but leaves on horseback" ${ }^{5}$ rings true both in the workings of trust, and for scholars trying to peel back the layers to a core definition of how it works. Trust often appears broadly benign and passive. The Concise Oxford English Dictionary (Stevenson and Waite, 2011) defines trust as 'the firm belief in the reliability, truth, ability or strength of someone or something'. This seems straightforward; a simple relationship between $A$ and $B$ in which the former anticipates a beneficial attitude from the latter. ${ }^{6}$

${ }^{5}$ Attributed to nineteenth century Dutch statesman Johan Thorbecke (Anon., 2011)

${ }^{6}$ The word trust is said to be derived from the Middle English of medieval times and referred to a specific form of collaborative hunting in which one group of villagers would work through a field or wood driving small game towards their fellows 'standing tryst', ready to capture the prey (Hardin, 2006). 
Modern scholarship challenges this simple definition, primarily because it is silent on the context for the act of trust. Probing further rapidly reveals a more dynamic, emotional and potent mechanism. There is relative consensus around Blackburn's description of trust as a tripartite relationship:

"What is our concept of trust, and what are its principal divisions? I think the obvious point of entry is a tripartite relationship: one person trusts another to do something ( $X$ trusts $Y$ to do $Z$ ). This formula allows, rightly, that one might trust one person to do things that one would not trust another to do. And it allows, equally rightly, that one might trust the person to do some things but not others..." (Blackburn in Braithwaite and Levi, 1998, p.30).

Others echo this three part definition. In what they call a 'grammar' of trust, McKnight and Chervany compare trust to a sentence:

"with a subject (trustor), verb (trust) and direct object (trustee). It is the direct object that determines many of the types of trust in use. If the direct object of trust is a person, the construct is interpersonal trust; if the object is an institution, the construct is institutional trust..." (McKnight and Chervany, 2001, p.42).

The interest at stake can also vary, from trusting institutions or people to do things, with things, or even to adopt an attitude ('I trust the teacher to be fair with my child'). Simmel (1964) also echoes the three part understanding of trust with his influential description it as an 'expectation' (of the trustee), an 'interpretation' (the trustor's analysis of whether this expectation is sound) and a 'suspension of doubt' (the act of trusting). This description also highlights the subjective nature of acts of trust; for Simmel the central questions were 'why does the trustor have an expectation and an interpretation'? and 'why are they prepared to suspend doubt'?

Analysing trust from this perspective raises the question of the function of trust as a mechanism of social coordination. A trust transaction starts with the trustor needing something that they cannot themselves provide. This opens them to the complexity of selecting the best options for achieving their interests, and to risk because the means for achieving their interests are out of their control. Trust reconciles the trustor to this complexity and risk by placing them as an expectation on another. By fulfilling these expectations the trustee resolves the complexity satisfactorily. How much risk and vulnerability the trustor accepts depends on the strength of their trust in the trustee. 
This focus on vulnerability and risk chimes with much of the literature. To quote Möllering:

"I define trust as a reflexive process of building on reason, routine and reflexivity, suspending irreducible social vulnerability and uncertainty as if they were favourably resolved, and maintaining a state of favourable expectation toward the actions and intentions of more or less specific others"(Möllering, 2005, p.5).

This 'suspension of vulnerability' leads to a further key observation. The engine that powers trust is reciprocity. The trustor exchanges vulnerability for a reciprocal benefit. The trustor's willing suspension of doubt is conditional, maintained by the successful fulfilment of the trustor's expectation. If the trustee fails this expectation, the trustor may seek redress, and be less likely to suspend doubt next time.

There can be a strong emotional quality to this exchange. Commentators explain the cultural ubiquity and emotional potency of trust by locating it in the formative experiences of early childhood. Giddens summarises it thus:

"A fundamental feature of the early formation of trust is trust in the caretaker's return. A feeling of the reliability, yet independent experience, of others - central to a sense of continuity of self-identity - is predicated upon the recognition that the absence of the mother does not represent a withdrawal of love. Trust thus brackets distance in time and space and so blocks off existential anxieties which, if they were allowed to concretise, might become a source of continuing emotional and behavioural anguish throughout life" (Giddens, 1990, p.97).

The deep psychological and emotional roots of trust helps to explain one of the more baffling aspects of the phenomenon for rational theorists - the lengths to which betrayed trustees will go to exact revenge for defection from trust, often out of proportion to the interest at stake or the hurt suffered (Zeckhauser and Bohnet, 2004). This is discussed further in Chapter 2.

This analysis helps differentiate trust from related phenomena such as confidence and faith. For example, A may have confidence in the way a colleague B will behave in any given circumstance. But if there is nothing at stake, that confidence is closer to a probabilistic estimate rather than an act of trust. Trust also differs from faith (as the term is used in most religions for example) in respect of doubt. For trust to be present it is inherent that there must also be doubt. Faith on the other hand has a more distant 
relationship with doubt, striving for belief without it. Someone who professes faith may also have doubts, but these are not inherent in the concept of faith itself.

\subsubsection{Trust works with and alongside power and markets}

These distinctions bring us back to the main argument of this section. Having something at stake makes trust a mechanism for the governance of social interaction around a need (Bijlsma-Frankema and Costa, 2005). Bachmann summarises the importance of trust in this respect:

"Trust ... may be understood as a fundamental social mechanism that allows for co-ordinated interactions and thus indeed for the possibility that highly differentiated social systems can emerge in the empirical world. Power, significance, incentives or legitimacy may be seen as other mechanisms..." (Bachmann in McEvily et al., 2006, p.394).

Several sociologists offer similar typologies. In the context of organisational control, Bradach and Eccles offer a simple yet influential formulation in their article 'Price, authority and trust: from ideal types to plural forms' (1989). They argue that the three main mechanisms by which intra- and inter-organisational affairs are co-ordinated and common interests resolved (or not) are authority, prices, and trust. All three mechanisms are alternative answers to the same issue; the ability of $A$ to influence actor $B$ to do $C$. Price informs the exchange of goods or services through the raising or lowering of cost to the purchaser. Authority influences behaviour by power, rules and hierarchy. By contrast, as discussed above, trust coordinates social transactions through expectation and obligation. This is a useful tripartite framework. However, to broaden the concepts beyond organisational analysis we need to follow most other commentators in linking authority to power, and price to the more general use of markets to coordinate exchanges.

While the mechanisms of power, markets and trust are distinct, there is a complex relationship between them. For example, Bachmann points out the many similarities between trust and power, along with the key difference:

"Both mechanisms (trust and power) largely seem to operate on the basis of the same principle... Both mechanisms allow social actors to link their mutual expectations with each other and to co-ordinate (re)actions between them. However, there is also a slight difference between trust and power as regards the 
mode of selection of expectations. While in the case of trust, the actor who considers to invest trust in his assumptions selects the possibility that the potential trustee will behave the way he prefers, the powerful actor selects a possibility of behaviour which he suggests to the subordinate actor as an undesirable behaviour that should be avoided" (Bachmann, 2001, pp.349-350).

In this abstract analysis trust and power have a similar function but use different influences, and apply in different circumstances. However, in situations of any complexity they are likely to be operating together, combining in a multitude of different ways. An agreement negotiated within an environment of high trust will look different to one forged between wary partners. So while power and trust may be conceptually separate mechanisms, they almost always occur as a hybrid.

Bachman suggests that most complex relationships will inevitably reflect aspects of both mechanisms. Trust oils the wheels of power and, he argues, power provides a 'precondition' for trust. Bachman identifies at least two hybrids of trust and power - one where power predominates and one where trust predominates. He describes the structure of business relations in the UK and Germany respectively as examples of each style. An important inference of this observation is that trust is a malleable and contingent mechanism, taking different forms in different circumstances. In chapter 2 this issue is explored more fully to develop a typology of forms of trust.

There is a final and important aspect to this discussion. Trust may be influenced by power, but it is also can also mediate power. It is difficult to force someone to trust. One of the particularly interesting aspects to trust for this study is whether it can provide a way of ameliorating the asymmetry of power between citizen and state.

\subsubsection{Trust is the oxygen of cooperation}

I now describe briefly the attributes and strengths of trust as a mechanism of governance, especially for cooperative relationships. Arrow summarises the practical value of trust in The Limits of Organization (1974):

"Trust is important lubricant of a social system. It is extremely efficient; it saves people a lot of trouble to have a fair degree of reliance on other peoples' word" (Arrow, 1974, p.23). 
The 'efficiency' offered by trust is worth analysis. Several elements differentiate trust from the mechanisms of power or markets. Firstly, the process by which trustor and trustee arrive at a shared understanding of the expectation on which trust is based can be a more fluid and intuitive exercise compared, for example, to the preparation of contracts.

Secondly it can encompass more ambiguity and dynamism than the rigidities of hierarchy or market transactions. Finally, the motive to fulfil the transaction is voluntary, and the mechanism of coordination consent to vulnerability, so both parties expend far fewer resources to ensure each other's compliance compared to most uses of power or market. For example, costly external monitoring is avoided because participants themselves regulate the direct relationship.

This is why economists have long thought of trust as the oxygen of co-operation. Trust is vital but mostly invisible in hundreds of large and small informal daily acts of co-operation (Axelrod and Dion, 1988; Dasgupta, 2009). Without it, normal social life would grind to a halt in a miasma of paperwork, energy sapping defensiveness and inefficient processes. Cook, Hardin and Levi argue that trust is most important at the micro level:

"We argue ... that trust works primarily at the interpersonal level to produce microlevel social order and to lower the costs of monitoring and sanctioning that might be required if individuals were not trustworthy" (Cook, Hardin and Levi, 2005, p.1).

The link between trust and voluntary cooperation can be evidenced in the context of the citizen/state relationship. Scholz and Pinney (1998) reviewed taxpayer attitudes and behaviour in a study following the Tax Reform Act 1986. They used statistical and qualitative methods to analyse the impact of trust on taxpayers' compliance, asking whether trust or fear (of detection) was the most powerful driver of co-operation and honesty. The results of their analysis are startling:

"As trust in government moves from its minimum to its maximum value, the probability of full compliance changes from .29 to 0.99 , or almost unanimous compliance, for a remarkable change of .70 in the proportion of full compliance" (Scholz and Pinney, 1998, p.149).

The link between trust and effectiveness, particularly on the behaviour of citizens as service users, is further supported by an Audit Commission study (Duffy, Downing and Skinner, 2003). Focus group respondents gave multiple examples of how mistrust gave 
rise to more challenging customer behaviour in establishing rights and keeping cumbersome paper trails, or, worse, refusing to engage at all. "You don't bother calling them [the police] because you know they are going to take ages or are not going to turn up' [Asian male, 18 - 35 Birmingham]" (Duffy, Downing and Skinner, 2003, p.10).

Trust in the state is also a major contributor to social capital (Putnam, 1995). The argument that trust in the state encourages civic co-operation is made particularly strongly by Fukuyama (1995). He emphasises the informal regulatory role of the state in providing institutions and norms that lower the cost of voluntary co-operation. A common example is state enforcement of contract law (North, 1990). As Levi observes, in effect the role of the government here is to help transfer trust from one domain to another (Levi, 1998). Others talk of the role of government in validating the trustworthiness of civic institutions, "lending" (James Jr, 2002) the trust in government to the institution.

\subsubsection{Trust only the trustworthy}

These examples illustrate the potential for trust to enhance co-operation between citizen and state in co-creating public value, and militate against its diminution. However, there are dangers if trust is misused or abused. Relationships that disproportionately benefit one of the participants can entail an abuse of trust. Such relationships can be exploitative or even dominatory, and can be observed when trust works alongside asymmetric power relationships, as with the majority of citizen/state transactions (Dasgupta, 2009).

Figure 1.6 below clarifies the high-level conceptual options for relationships of trust viewed as a mechanism of social co-ordination. The first key variable is the strength of trust in the trustee, which may be weaker or stronger. The second key variable is the trustworthiness of the trustor to deliver. This gives rise to six broad possible types of trust relationships:

- full co-operation; strong commitment and delivery from both parties

- betrayal; strong trustor commitment, but the trustee actively exploits that vulnerability 
- compliance; weak trustor commitment, as expectations are met but with little at stake

- domination; weak trustor commitment to a untrustworthy trustee; the trustor remains passive in the face of low expectations or unfulfilled delivery

- conflict; strong trustor distrust in an untrustworthy trustee (in political terms, one of the conditions for revolution)

- passive resistance; weaker trustor distrust in a untrustworthy trustee can also lead to passive resistance.

Figure 1.6 Trust only the trustworthy

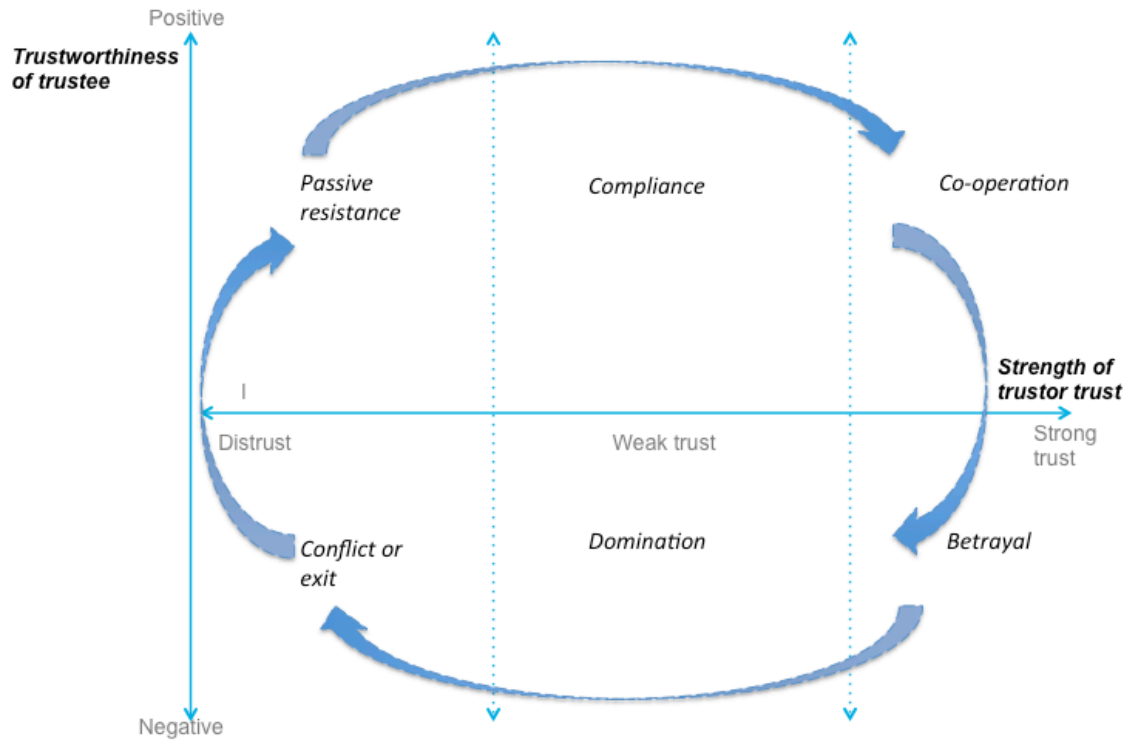

In the words of Hardin, "you should not trust the untrustworthy" (2006, p.1). Trusting the untrustworthy can lead to abuse, or worse - in the case of a trustee who is more powerful it can lead to domination. This dark side of trust is an important consideration for the public sector. It is apparent in high profile instances of trust abused such as with the patients of the Mid Staffordshire Health Trust (Francis, 2013). But the perspective of this 
study is that such scandals may be the visible tip of a more systemic issue. In the next chapter the argument is developed that many more citizen/state trust relationships fall into a category of dependent, no choice, sort of trust; a type comparatively immune to citizen dissatisfaction (Robb and Greenhalgh, 2006).

\subsection{The challenge of the trustworthy state}

Thus far this chapter has developed a description of trust as a mechanism of social coordination appropriate to voluntary cooperation. Whether this conceptualisation can be applied to the citizen relationship with the state, and whether the state can in principle aspire to be trustworthy, is discussed in this final section of chapter. It starts with a summary of the main theoretical and practical challenges (1.5.1), and concludes with a description of how these are reflected in the research question for the study fieldwork (1.5.2).

\subsubsection{The challenge of trusting the state}

Trust might be a mechanism of accountability between citizen and state, guiding a more co-operative co-creation of public value. However, there are powerful theoretic arguments that trust in the state is problematic. These are briefly considered below, seeking to distinguish whether the arguments challenge the goal of trust in itself, or rather point to the practical challenges in making it a reality. The recurring theme from the variety of perspectives is that the state cannot be considered trustworthy if it operates in support of interests that are not those of citizens. This helps frame the challenge for trust as a mechanism of governance, and whether it can be effective in aligning the interests of state and citizen.

Neo-liberals, Marxists, and some post-structuralists, all find reasons to distrust the state. Stears (2012) takes a sceptical view in his critique of Mulgan's (2012) essay. Mulgan advocates a 'relational state' that works 'with' citizens rather than 'to' or 'for' them. Stears counter-argues that the role of the state is inevitably one of standardisation, and conflict when taking on some vested interests; it will therefore always struggle to have a human and holistic relationship with citizens. Stears advocates a relational state that focuses on creating better relationships between citizens. This debate crystallises an issue for this 
study; can we apply the concept of trust to the impersonality and standardisation inherent in the state?

Others support Stears' scepticism. For example, from the neoliberal and rational choice schools, Hardin argues that the only way of establishing this trust is either to know that every individual within an institution is well intentioned and honest, or to know that the organisation has sufficiently well designed incentives that align interests with our own. Since neither is feasible for something as complex as the state, then trust is surely impossible. The best we can hope for is an absence of distrust (a formulation close to the 'paradigm of compliance' described earlier):

"Very often, all that is needed for government to work is for citizens not actively to distrust it" (Hardin, 1998, p.11).

This 'information gap' leads most neo-liberals to view any collective entity as prone to distorting the interests of the individual, because it will tend to develop a self-serving imperative to respond to its own needs. This is opposed to their view of the market as the mechanism whereby individuals have full control over their own decisions. The challenge that commentators from this tradition pose for this study is whether the factors that are important to state trustworthiness in the eyes of citizens are sufficiently robust that they can drive internal performance systems and incentives.

The traditional Marxist critique of the state also argues that the workings of the nation states of late capitalism are unlikely to be aligned with the interests of citizens, but in this case because the state will be captured by dominant class interests rather than bureaucratic officials. Contemporary states will reflect the prevailing dominant economic interests of the owners of capital and the means of production, to the detriment of those whose surplus value is appropriated (Jessop, 2008). There is ambivalence in Marxist thought as to how this contraction should be resolved, with Marx and Engels predicting, in some texts at least, that communism would mean the "withering" of the state (Engels, 1959). Most contemporary Marxists however take a more pragmatic view, with the objective of modern communist parties - in the developed world at least - being to take control of the state in order to use it as a weapon in overcoming the hegemony of the bourgeoisie. Thus the state can and should be trusted, but only once within the control of 
progressive forces. The test for this study from this tradition is therefore along similar lines as that of the neo-liberal but with a nuance - it will be necessary to show that citizens' definition of state trustworthiness can not only hold the state to account, but in themselves also promote equitable public policy that genuinely challenges social need and inequality.

Perhaps the most profound scepticism of the trustworthy state is to be found in the later writings from Foucault. He identifies is what he calls 'governmentality', the logic and means by which the state exercises power. Governmentality involves:

"The ensemble constituted by the institutions, procedures, analyses, and reflections, the calculations and tactics that permit the exercise of this quite specific, albeit very complex form of power, which has, as its principal target, population; as its main form of knowledge; political economy, and, as its essential technical means; apparatuses of security" (Foucault in Burchell, Gordon and Miller (eds.), 1991, p.102).

For Foucault the defining feature of modern states is that techniques of control have evolved from those enabling it to rule over a territory, to ruling over the population in a territory. The key tool is the 'disciplinary' use of liberalism. The modern state exercises its potentially dominatory authority through the internalised sense of individual responsibility derived from the liberal conception of autonomous individuals. State power is legitimised and enhanced when citizens voluntarily adopt the fiction of active citizenship. This is what enables the modern state to "govern at a distance" (Rose, 1996), operating in the interests of current power formations. Like the Marxist and neo-liberal critique it hinges on the state being inherently untrustworthy because it will be captured by interests separate from those of citizens. This tradition will want to know whether the factors that encourage citizen trust are sufficiently potent genuinely to enlarge the agency of citizens in their relational discourse with the state.

These arguments carry considerable force. However for this thesis they represent the starting point, not the conclusion. The common thread is pessimism in the ability of the state to act objectively and equitably because it will be captured by privileged interests (respectively in the analysis above bureaucrats, the ruling class or the dominant prevailing disciplinary powers). The question is whether a form of trust can empower citizens sufficiently to wrest the state from control by a dominant and self re-producing power 
structure' both in how it operates and the goals which it promotes. Returning to Stears' critique (2012), the challenge extends to those functions where the role of the state is to 'standardise' or resolve conflict. A key question for the study is whether trust and trustworthiness can thrive even amidst competing interests.

A final argument for the normative importance of a trustworthy state can be drawn from the political philosophy of legitimacy and sovereignty. This argues that the enforced nature of citizens' subjection to the state allows no choice in whether to trust or distrust. Pettit, in his essay 'Republican Theory and Political Trust', observes:

"Wherever I choose to live, I will find myself subject to a government and in the position of vulnerability to government agents. I may trust or distrust the government, of course, but I have no choice about whether to put myself in a position where those are the only alternatives" (Pettit, 1998, pp.299-300).

Given the state's dominant and enforced position, it is ethically incumbent on the state to use its asymmetric power in a trustworthy way. The corollary of the asymmetry is that the sensible position for citizens is to distrust the state until evidence of trustworthiness is clear. The question for this study was what sort of evidence citizens might require, and to what extent this is structured by the context and situation of each interaction.

\subsubsection{The research question - the citizen perspective on the trustworthy state}

The questions explored by this study are twofold. The first is to understand the tests in the mind of citizens when assessing the state's trustworthiness, and whether these are different in kind to the norm of trust and trustworthiness within the agencies of the state. The second question follows; once identified, can these tests help structure the citizen/state relationship to overcome the challenges described above, encouraging more co-operative interaction?

If useful answers are found, then the study could contribute to developing the use of trust as a mechanism of governance for the relationship, working alongside voice and choice in creating a relational paradigm of cooperation rather than compliance. The scope of this question can be illustrated with a 'trust version' of the public value relational model, incorporating the three-part definition of trust described earlier and illustrated in Figure 1.7. 
The citizen as trustor (1) needs reasons to trust the state as trustee (2) in the pursuit of the trust transaction within the zone of interaction (3).

Figure 1.7 The research question and trust version of the public value relational model

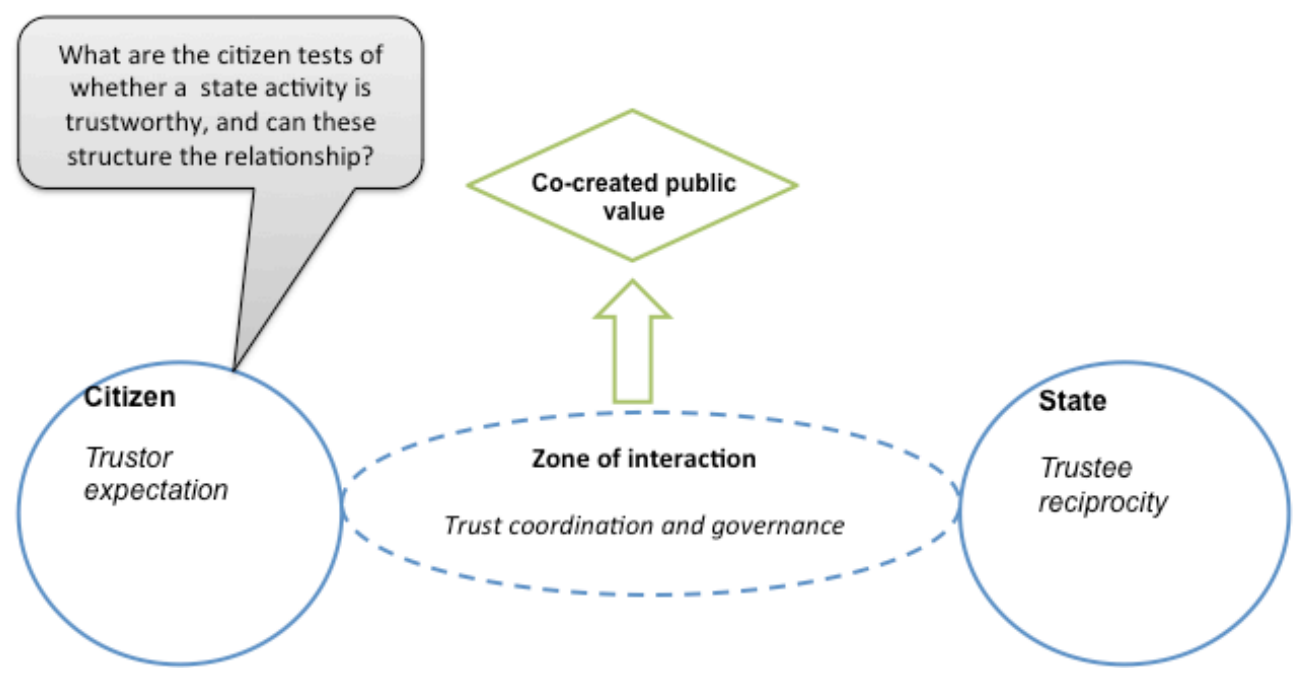

Posing the research questions in this way suggested several lines of inquiry for the study. It confirmed the site of the study as the 'zone of interaction' between citizens and state. Trust and trustworthiness are subjective judgements, arrived at in the course of the individual lived experience of interacting with the state. The research required openness to all potential issues that might shape that experience, including relational issues of affect and emotion as well as the traditional focus on actions and roles. It also meant understanding the governance mechanics by which trustworthiness could be maintained.

This also meant being alive to the workings of trust at a number of different dimensions and levels. Firstly there are the twin dimensions of the citizen relationships identifiable from the public value analysis with which the chapter started. The first of these is the trustworthiness of the state in respect of the citizen as the 'authorising environment'. This is the state acting on behalf of the collective. Secondly there is the trustworthiness of the state in translating the policy goals of the collective into the experience of the individual user of public services. 
These two dimensions of the citizen/state relationship themselves operate at a number of conceptual levels. For example in the earlier narrative on the importance of the 'zone of interaction' I discussed Giddens' description of trust in abstract systems working at two levels; system trust (through mechanisms such as codes of ethics or quasi-judicial sanctions) and trust derived from the reassurance in the system offered by facework operators at access points to the state. Other commentators conceptualise this facework interaction between citizen and state as itself having two distinct facets, institutional trust and interactional trust. Currall and Inkpen (2006) make this distinction in their study of trust in the police in the Netherlands. They argue that in addition to system trust, citizens assess the police both at the level of the individual interaction, and at the level of the police force as an institution. Zucker (1987) also makes this point in her description of institutional trust (which she differentiates from process and characteristic based trust). The importance of the institutional level of trust is that it turns organisations from being simply a guarantor or umpire of the trust relations of others to being objects and sources of trust in themselves. Thus the study needed to look for evidence of the characteristics of trustworthiness at three levels - system, institutional and interactional. 


\section{A theoretical perspective - the varieties of trust}

The previous chapter outlined the proposition that a form of trust can act as a mechanism for strengthening cooperation in the citizen/state relationship. This proposition poses the questions for the research: to establish the tests by which citizens assess state trustworthiness, and whether these can be used to improve the relationship.

This chapter develops the theoretical perspective that informed the process of research into these questions; that trust is a malleable and contingent phenomenon, taking different forms in different situations. This perspective opens up the possibility that citizen and state are operating to different norms of trust, and that it is possible to conceive of a form of trust that could - from the citizen's viewpoint - be more potent than the prevailing norm.

The first section (2.1) reviews the main findings from relevant current research. The next section (2.2) builds on this by investigating academic work on trust to describe a typology of different forms of trust. This helps to anticipate how different norms in use by citizens and state might manifest themselves in the research data derived from the fieldwork. The final section (2.3) brings the argument together in a hypothesis for the difference in trust norms, and its relevance to the study.

\subsection{A state of distrust?}

This section reviews the evidence and issues for trust in the state from the main strands of contemporary research. Despite different starting points and methods, many commentators conclude that a significant issue for public trust is a difference in relational values between citizen and state. In reviewing this evidence the section concludes by categorising the range of issues and explanations posed by contemporary research within the three broad dynamic dimensions of the relational model described in the previous chapter ('connectivity', 'agency', 'interactivity'). These form the basis for the formulation in chapter 3 of an 'evaluation framework' used to probe the data derived from the fieldwork for this study.

The analysis considers the insights from three main families of empirical methods commonly applied to this area: 
- Firstly, large-scale quantitative surveys of opinion on trust in government, some providing broad indications of opinion trends across the population and some testing for the relevance of preconceived factors such as demography or partisanship. These attitudinal insights map predominantly to the connectivity and agency dimensions of the relational model (2.1.1).

- Secondly, the range of existing evidence from more qualitative studies, for example those using focus groups to discuss trust, enabling direct insight to the minds of citizens. Insights from this strand are both attitudinal and behavioural and contributed to all three of the relational model dimensions (2.1.2).

- Lastly, laboratory-type experiments using highly structured tasks derived from games theory, usually with a view to establishing quantifiable measures and explanations of trusting behaviour, including that between individuals and collectives. These behavioural insights mainly map to the interactivity dimension of the relational model (2.1.3).

The final sub-section, (2.1.4), summarises the analysis in the context of the dynamic dimensions of the relational model, and discusses how these inform the interrogation of the research fieldwork data through incorporation in the evaluation framework.

An important methodological consideration for this analysis is that much of the work in this field is targeted at political trust. This is one component of trust in the state, but the scope of this study extends to the broader institutional tableau of state agencies, and to trust over time. To test if this difference was significant, the fieldwork evaluation assessed the potential importance of all issues arising from the studies analysed below, whether the focus was political, institutional, personal, or impersonal.

\subsubsection{Quantitative surveys of public trust}

Quantitative surveys of citizen opinion are common research techniques in this field. Two types are relevant here. One tracks levels of trust over time, and can be used to analyse broader trends in public opinion. The second type includes questions about potential 
drivers of opinion (satisfaction, perceived competence, honesty etc.). Both offer insights for incorporation within the evaluation framework.

\section{Surveys of trends in levels of public trust}

Starting with the first type, contemporary surveys of levels of political trust have raised the fear that society is facing a "crisis of trust" (Van de Walle, et al., 2008). There is an apparent long term and inexorable global decline in trust in government. The Edelman Annual Global Trust Barometer survey is indicative of this. Since 2001, the Edelman survey provides a snapshot in 28 countries of the state of trust in four sectors - business, Non Government Organisations (NGOs), media and government. The headline for the 2017 survey is that there has been an "implosion" of trust generally, and especially for "world governance systems" which are now the least trusted of the four sectors they compare. A global average of $41 \%$ of respondents say they trust their national government $^{7}$. Interestingly China's Government tops the list, trusted by $76 \%$ of respondents, whilst the UK's was below the average with the trust of just $36 \%$ of respondents (Edelman Trust Barometer, 2017).

A check on this result, and a more reliable source of longer-term trends, can be found in the EU commissioned biannual opinion survey, the Eurobarometer. This involves a large citizen sample and has been asking consistent questions about trust in government

\footnotetext{
${ }^{7}$ The question posed is 'Below is a list of institutions. For each, please indicate how much you trust that institution to do what is right on a nine-point scale, where one means that you "do not trust them at all" and nine means that you "trust them a great deal".
} 
(amongst a number of institutions) since $2001^{8}$. In October $2001,42.80 \%$ of UK citizens said they tended to trust government. By May 2016 this had fallen to $33.95 \%$ (Standard Barometer 85 , Spring 2016). However, the pattern is volatile, with the low point of $20.71 \%$ in May 2009. Indeed, most surveys of political trust are often volatile, for example strongly correlating with elections in democracies; trust goes up immediately afterwards and then falls away.

An even longer-term perspective is offered by the annual British Social Attitudes Survey (BSAS). Since 1986 BSAS has asked respondents 'How much do you trust British Governments of any party to place the needs of the nation above the interests of their own political party?' In 1986, 38\% responded 'just about always' or 'most of the time'. In 2013, the last period for which there is data, this had fallen to $17 \%$ (BSAS, 2013).

However, an interesting aspect of the BSAS is that most of the downward trend was from 1987 to 1996 where it hit just above 20\%. This echoes data from America and elsewhere. While there has been a long-term decline, most of it occurred in the late twentieth century and the trend has bottomed out more recently (Barclay, 2010).

The few surveys that go beyond the immediately political in asking opinions of the state 'system' present a similar pattern (though with less volatility) of steep decline in the latter part of the last century, followed by a continued but more gradual erosion or at best a flatlining of trust. Ipsos Mori have been asking the same question about levels of satisfaction

8 The question reads 'I would like to ask you a question about how much trust you have in certain institutions. For each of the following institutions, please tell me if you tend to trust it or tend not to trust it?' (These, and do not know, are the only permissible answers). 
"with the system of governing Britain" since $1973^{9}$. Whilst satisfaction is different to trust (the link is discussed more fully later in this chapter) the results are indicative. In 1973 the proportion of people answering positively (works 'extremely well' or 'mainly well') was $48 \%$ of respondents. When the same question was asked again on behalf of the Hansard Society for the Audit of Political Engagement (Fox and Blackwell, 2016), the figure fell to $33 \%$ (which was itself up $7 \%$ from a low of $26 \%$ from the previous year, almost certainly because of the election bounce described earlier). Once again, most of this overall decline in satisfaction with the system had occurred by 1997 when it hit $28 \%$. It rose to $37 \%$ in the following election year and has declined steadily thereafter apart from election years.

However, the final exhibit for this section - the long running Ipsos Mori veracity survey ${ }^{10}-$ suggests that the picture is more complex at the frontline of service delivery. From its start in 1983 until the most recent survey in 2016, the scores for public sector professions have remained broadly the same or improved. Doctors and teachers remain amongst the professions most trusted to tell the truth ( $91 \%$ and $88 \%$ of respondents respectively) (Ipsos Mori, 2016). Police, civil servants and public service managers remain mid table professions, but they have held or improved their results over the years. Even the poor results for politicians (ministers are trusted by $20 \%$ of respondents) have at least not got worse.

${ }^{9}$ The question is: 'Which of these statements best describers your opinion on the present system of governing Britain. 1. Works extremely well and could not be improved. 2. Could be improved in small ways but mainly works well. 3. Could be improved quite a lot. 4. Needs a great deal of improvement. 5. Don't know.' ${ }^{10}$ The question posed is 'Now I will read out a list of different types of people. For each, would you tell me whether you generally trust them to tell the truth or not?' 
This analysis confirms the contemporary importance of exploring trust in the state and suggests several issues relevant to the study. Firstly, the consistent long decline in trust in government (and the system of governing) over the same period of modernisation described in Chapter 1 illustrates the deep malaise in the relationship. The distinction between responses to institutional trust and that in specific public professions also suggests the need to explore how citizens distinguish between their perception of the particular public service agent before them, and the system the agent is perceived as representing.

\section{Causal surveys of public trust}

Surveys that explore causal explanations for these results have used many different research methods. Two broad approaches are discernable:

- Model-driven investigations starting from an overarching theoretical framework, such as differentiating between factors derived from public policy rather than the process of service delivery.

- Investigations into the importance of specific preconceived issues such as corruption.

Starting with the first of these approaches, the dominant model of trust looks to 'performance' as the key variable. The logic is summarised by Van de Walle and Bouckaert as "... better performing public services will lead to increased satisfaction among their users, and this, in turn, will lead to more trust in government" (2007, p. 892). Their scepticism of this argument starts from the observation that the alternative may also be true - dissatisfaction with public services may be driven by a prior image of government that is "negative". They also point to methodological weaknesses in demonstrating causal connections between performance and trust. These include difficulties in clarifying what a public service actually is and whether frameworks of analysis should assume a general view of government, or whether each interaction should be evaluated separately. They also point to ambiguity about the criteria for good performance and the inevitable subjectivity of studies. They conclude that this line of analysis runs the danger of 
discounting the changing values of citizens, and the impact for example of a "culture of distrust" (Van de Walle and Bouckaert, 2007, p.905).

This is a salutary backdrop to other studies for two reasons. Firstly, it exposes the intellectual and methodological issues when discussing causality in this area. Secondly, it raises the issue of what constitutes good performance. This is significant since some studies suggest that by many objective measures including economic growth, pollution control, social integration, and combatting discrimination, the performance of the state has improved over the last decades - confirming the puzzle of the decline in trust described above. It is this 'delivery paradox' (Coats and Passmore, 2008) that has led several commentators to conclude, along with De Walle and Bouckaert, that it is citizens' values in judging what constitutes trustworthiness that have changed (Taylor-Gooby, 2008; O'Neill, 2002).

In response, several commentators have developed models that probe the components of performance in the context of trust in a more structured manner. Among these is the Hibbing and Theiss-Morse framework for measuring attitudes in both the 'policy space' and the 'process space' (2001), developed for their study of American political attitudes. The policy space comprised issues related to social conditions, service outputs, and overall public value outcomes. The process space addressed issues about how government works, and the mechanics of production. This provides a helpful first step in unpacking what might be important to citizens, and has subsequently been used by several UK academics exploring contemporary British attitudes.

For example, Allen and Birch (2015) use the framework for a major survey of the comparative importance to citizen satisfaction of policy issues (measured by respondent perception of political leanings of government compared to their own) or process (measured by respondents' desire for direct involvement in political decision-making compared with the perception of involvement on offer). Their conclusions, based on a detailed statistical analysis of 1,382 responses to a YouGov administered poll conducted in 2011 , support the analytic validity of the categories whilst also pointing to the opacity of the issues these broad categories embrace. The dissatisfaction 'gap' between 
respondents' perception of the government's position on both policy and process were found to be similar and statistically significant.

As with the original Hibbing and Thieiss-Morse study, factors associated with policy dissatisfaction included issues such as political partisanship and interest in politics. However, the issues driving process dissatisfaction were harder to quantify and deviated more from the US results. One factor was understanding of politics, but the strongest drivers of process dissatisfaction were perceptions of politicians' integrity and responsiveness. They conclude that more research is needed:

"For interested political scientists, future survey-based studies of process evaluations need to go beyond citizens' preferences for and perceptions of popular participation and include judgements about politicians' traits, such as their integrity and honesty. If policy space is multi dimensional, so is process space" (Allen and Birch, 2015, p.408).

Other contemporary studies follow the same broad distinction between policy and process, but explore different themes within them. One consistently cited is a study by Whitely (2016) that tests the association of 'valence' (the perception that government is achieving generally accepted policy goals, particularly economic improvement) and equity (the perception of fairness in the decision-making process). This study offers more nuance as it investigates trends in UK public opinion through a monthly data set (an internet and phone survey conducted from July 1997 to December 2013). The results confirm a slow erosion of perceived government honesty over this period (a characteristic the authors associate with trustworthiness). They also confirm a positive correlation between this decline and perceptions of a failure of competence in achieving policy outcomes, and the perception of unfairness or lack of integrity in political decision-making.

Other research helps illuminate some more specific issues that relate to these categories of analysis. A study by Tom Christensen and Per Laigreid (2005) used data from a mass survey of 2,297 respondents within the Norwegian Power and Democracy study of 2001. They tested the relative importance of three independent variables to trust in the government - satisfaction with services, political/cultural factors and demographic factors. They concluded that a process factor - 'satisfaction with democracy' - was the most important by some distance. However, they also report a smaller but positive correlation 
between service satisfaction and trust. The most significant demographic factor was whether the respondent was a public service employee, whilst other factors such as gender or education had only weak or non-existent correlation.

More targeted studies highlight the perception of corruption and lack of integrity as being particularly corrosive of trust. Analysing UK survey datasets from 2003 to 2011 (years that included the UK MP expenses scandal), Jonathan Rose (2014) comprehensively demonstrates the importance of the perception of probity to citizens' sense of trustworthiness in government. Allen and Birch, using data from a broader study of attitudes conducted by the British Cooperative Campaign Analysis Project (BCCAP) and a survey conducted by YouGov in April 2009, support this. This was just before the MP expenses scandal of that year reported by the Daily Telegraph. Their finding is that scandals have a significant effect on public trust and that "most people, when forced to choose, seem to prize honesty in their politicians above competence" (Allen and Birch, 2011, p.61).

Other studies approach the issue differently; they focus on the type of evidence to investigate, rather than where to look for evidence. A key strand of contemporary thinking in this respect is a growing understanding of the importance of issues of affect as well as cognition (Hoggett, 2000). Taylor-Gooby's (2008) statistical analysis of data on trust in the NHS from the 2001 British Social Attitudes Survey offers significant empirical support for this perspective. Taylor-Gooby identified two considerations with a statistical correlation to levels of trust. The first was broadly cognitive, assessing the 'objective quality of care' (responses to questions around issues such as staffing levels as well as satisfaction with service quality). The second represented more affective reasoning summarised as "Values: care and respect", in response to questions investigating issues such as the provision of information and taking patients' views into consideration.

Taylor-Gooby echoes others in placing these findings in the context of citizens' changing values as much as changes to service delivery. He points to the growth of what he terms 'critical trust', tracing the decline in trust in public institutions to the erosion of traditional values of deference. This elevates the importance to trust of subjective and relational 
issues of affect, as well as a growing willingness to challenge the received relationship and the power relations within it.

This insight into the contingent and variable nature of trust judgments is shared by other related research. Working within the NHS, Rowe and Calnan describe differences between "felt and enacted trust" (which resonates with the research framework's separation of interaction from the attitudes of the participants) and the growth of what they call "informed or conditional trust":

"The shift towards more informed patients willing to participate in decision-making we would argue has produced greater inter-dependence between patient and clinician. This has not removed the need for trust in clinical encounters, rather trust is now more conditional, negotiated and depends on communication, provision of information, and the use of 'evidence' to support decisions" (Rowe and Calnan, 2006, p.5).

Robb and Greenhalgh (2006) are even more radical in overtly relating the changing nature of trust to the issue of power, discussing three distinct concepts of trust: voluntary, coercive and hegemonic. Fisher, Heerde and Tucker (2010) pursue different forms of trust in their survey of opinions of parties and politicians (questions within the YouGov weekly online British Omnibus survey July 2007 and the British Election Study Continual Monitoring Panel March 2009). They conclude that in different situations citizens assess whether to trust government on the basis of: strategic trust (the largely cognitive assessment of the qualities of the trustee); deliberative trust (defined as the belief that there are mechanisms in place to protect the trustor from betrayal); and moral trust (the willingness of the trustor to believe in the norm of trustee goodwill) - in many ways similar to Uslaner's description of the importance of generalised trust (Uslaner, 2005).

This discussion reflects the broad trends within research models that underpin quantitative research into trust in government, including issues of both where to look (process and outcome) and what to look for (issues of affect as well as cognition and the role of power). Both dimensions are included within the evaluation framework. The analysis also identifies several more considerations that may be in the mind of citizens that need to be located within these broad headings, including issues of competence, probity, fairness, communication of information and influence over decision-making. 


\subsubsection{Qualitative studies}

A second body of research of particular importance to this study greatly enriches the list of specific potential qualitative factors for the evaluation of the fieldwork. Recent studies have adopted more open qualitative methods in testing the views of respondents, with no preconceived agenda but rather allowing the research participants themselves to identify the issues of importance. The methods vary from open interviews to focus groups. The questions posed vary, and this leads to different studies using different language, focussing on different priorities. However, there is a common thread - that the nature of the relationship is an important factor to both satisfaction and trust, in addition to competence in service delivery.

One comprehensive study conducted on behalf of the think-tank Demos investigated how to build "better relationships" in local government (Parker, 2008). Data from twenty focus groups with the public and eight with council staff perhaps explains why trust has apparently declined as services have improved:

"Our research provides a compelling explanation for this problem: trust is not built solely through services. At the institutional level, the public also takes into account the quality of personal interactions with council staff - particularly whether those interactions are emotionally satisfying" (Parker, 2008, p.11).

The study found that trust in local government depends on the quality of people's personal interactions, a judgement on the actual outcome of the service, and also on the "fairness" of council decision-making such as priorities for spending.

Other evidence confirms that the relationship at the frontline of service delivery is important in generating citizen trust as well as what is actually achieved. A MORI report exploring trust in public institutions for the Audit Commission (Duffy, Downing and Skinner, 2003) supplemented focus group discussions with quantitative surveys. This identified twelve factors that influence citizen trust. Only two refer to what is done in a service transaction ("expectations of the service" and "confidence in service delivery") whilst most of the others are about different aspects of the way the parties engage with each other (e.g. "way service is delivered", "response to mistakes", "dialogue: being listened to rather than talked at", "honesty, openness and telling the truth", "independence: information and 
audits" etc.). The report suggests four priorities for building citizen trust: the availability of information, the perception of independence in the service provider, friendly and helpful direct contact with frontline staff, and the perception of honesty in the leadership.

Finally, the UN $7^{\text {th }}$ Global Forum on Reinventing Government, 'Building Trust in Government in the Twenty-first Century', also emphasised 'process and relationship' as much as competence in service delivery (Blind, 2007). Most recommendations concerned the operational relationship with citizens, emphasising the need for consent, decentralisation of activities and decisions closer to citizens, transparent and accountable governance and an independent judiciary.

These studies start to offer direct evidence for the potential difference in values in the relationship between what is on offer from the state, as articulated by the performance model at least, and those prized by citizens. The performance model emphasises competence as the key to citizen trust. Many of the findings reported above echo the conclusion that citizens also value a relationship that is "emotionally satisfying". All the issues raised above were taken forwarsd for inclusion in some form within the evaluation framework, and it is revealing that most were grouped within the 'connectivity' category.

\subsubsection{Games theory and laboratory experiments on public trust}

This section reviews a selection of games theory studies. These are interesting because their orientation is toward actual behaviour, rather than the attitudinal studies above. As a result they offer particular insight into the parameters and issues to consider within the 'interactivity' dimension of the relational evaluation framework.

Economists often use games theory when discussing trust, usually to explore the tension between the dominant economic model of utility-maximising individuals, and the notion of trust and co-operation leading to behaviour apparently against the individuals' immediate interest (Williamson, 1993). Three classical games in the field particularly illustrate this tension: the Prisoners Dilemma (PD), the public good game and the ultimatum game. 
The PD game encapsulates the dichotomy between personal and collective utility. Two prisoners have been arrested for their joint crime. They are interrogated in different cells and unable to communicate between themselves. In the classic version (Axelrod, 2006; 1988), there are three scenarios. If both prisoners maintain silence, each receives one year's gaol for a more minor offence. If one agrees to testify against the other, she goes free and the other gets ten years. If both testify against the other, both receive five years. The dilemma is that the optimum overall collective benefit (the 'Pareto-efficient' outcome) is for both to cooperate in silence and therefore receive one year in goal each. But the rational strategy for each individual (the 'Nash equilibrium') is to blame the other, thus avoiding gaol completely.

The Prisoner's Dilemma replicates many 'social dilemmas' (Thaler, 1992). The outcomes are asymmetric between individual and collective interest, there is vulnerability to the actions of the other, and imperfect information on which to base a decision to trust or not. Research shows that if the game is played only once, most people blame the other (the Nash equilibrium). But if the game is played repeatedly, the outcome is different. This became a particularly influential demonstration of 'reciprocal altruism' (Fehr and Gächter, 2000). Axelrod (1997) demonstrated that the strategy that produces the best return for any one player was Tit For Tat (TFT). This calls for the player to be cooperative in the first move, and thereafter always to replicate the previous choice of the other player. This held true even with the introduction of a group of deliberately non-cooperative participants (Axelrod, 2012).

Both mode of analysis and conclusion have implications for the development of the evaluation framework for this study. The first observation is that this study, in common with all the games theory simulations, is measuring trust in behavioural units of cooperation. These are produced in the course of an intersubjective interaction in which anticipating the attitude of the other is key. This illustrates some of main parameters of the zone of interaction, such as the payoffs for cooperation or defection. Moreover, the experience of similar transactions in the past is a key component of the cognitive and affective attitude the participants bring to the exchange - demonstrating the importance of reciprocity for trust and cooperation. 
The 'public good' game considers how individuals relate to collectives. A typical game involves between four and ten randomly selected individuals. Each participant is given a sum of money that they can either keep, or some or all can be 'invested' in a 'group exchange'. The money invested is then multiplied by 2 or more, but less than the number of players, before being redistributed equally among players. Thus, any investment increases the total pot for the group; but the return for the individual for their investment is less than their contribution. This replicates the social dilemma of the Prisoner's Dilemma, but this time in relation to a collective.

Once again, the mathematically rational strategy for an individual to maximise their utility in a single play of this game is always not to co-operate - to keep the full value of their payment while hoping to benefit from the generosity of others who do cooperate. This is not what happens in practice. In one major study the game was played in many different formats (numbers in the group, amount of money at stake, different cultural groups, using groups who had played before, etc.). Almost always, the amount invested in the group exchange was between $40-60 \%$ of the starting funds ${ }^{11}$. Ironically, the different results were with economics students at Wisconsin University, whose contribution rate fell to $20 \%$ (Ames and Marwell, 1981).

The conclusion most games theorists draw is that the strategy of reciprocal altruism is supplemented by a social norm of cooperation (Frank, 2011). This suggests that cooperation is embedded in our cognitive and social processes as the default starting position, maintained until it becomes clear that others are not reciprocating (Dawes and

${ }^{11}$ Co-operation tended to decline over subsequent plays but still remained higher than explained by rational self interest (Mark Isaac, McCue and Plott, 1985). 
Thaler, 1988). The search for the elements of this social norm helps to substantiate and define the scope of the 'connectivity' dimension of the evaluation framework; issues of social identity are potential powerful influencers on behaviour. One other suggestive result from public good games is that the single most important condition for improving rates of cooperation - doubling them in some experiments - was for the participants to discuss their choices before making them. An instructive observation in the context of political processes, and further confirmation that establishing a group norm of cooperation is of significance.

The final game illuminates the workings of distrust and negative reciprocity, and shows the instinct for revenge as a powerful force for regulating trust relations. These are usually called ultimatum, dictator, or investment games. Players work in pairs. One $(A)$ is given some money, and then invited to share it with $(B)$ in a proportion that is entirely at A's discretion. B can accept this money or reject it, in which case all the money is lost. Rational self-interest is that B should always accept whatever is on offer, because that is better than nothing. In practice, across different cultures and different amounts of money, the average result is that any offer less than $33 \%$ of the total has a $50 \%$ chance of rejection (Güth and Kocher, 2014; Gale, Binmore and Samuelson, 1995).

It appears that in the face of perceived unfairness or betrayal there is a strong instinct to punish the perpetrator, even at a high personal cost. B would prefer that they both go without rather than allow what is felt as unfairness. This suggests that one of the forces maintaining trust is the mutual understanding that betrayal can incur consequences later. This has implications for the interactivity category of the evaluation framework, posing the need to investigate processes of fulfilment of expectations, and the consequences of any perceived defection from trust by the state.

\subsubsection{Populating the evaluation framework}

Concluding this review of current research, table 2.1 relates the key concepts and issues raised from the analysis to the three main categories of the relational model to take forward for inclusion within the evaluation of the fieldwork data. This was the starting point for shaping each category and the sensitivities to which the evaluation of evidence should 
be open. This process informed the categories of the framework and the relationships between them. Factors or issues that related to citizen or staff attitudes to the relationship itself were mapped to the connectivity theme. Citizen or staff attitudes to the nature of their role and contribution were mapped to the agency theme. Finally issues that occur in the course of an actual interaction were located within the interaction theme.

\section{Table 2.1 Summary of factors for evaluation framework from review of existing}

\section{research}

\section{Factors related to \\ 'Connectivity'}

The perception of how the parties relate to each other in a citizen/state interaction
Factors related to 'Agency'

The perception of the roles and competence of each party in the execution of a citizen/state interaction

Competence

Motivation

Incentives

Fairness

Equity

Legitimacy

Personal contact

Role

Commitment

Service quality

Empowerment

Authority

Resources

Predictability

Consistency

Efficiency

Access

Responsibility

Intention

Continuity of relations
Factors relating to 'Interactivity'

The perception of the coordination and governance of what happens in a citizen/state interaction

Policy outcomes

Valency

System drivers

Process trust

Reciprocity

Consent

Entitlement

Power, and its abuse

Coordination/control

(Inter) dependency

Influence

Accountability

Redress

Fulfilment

Betrayal and revenge

Response to mistakes

Proximity

Discrimination

Integrity

Collating the issues in this way was a useful step in the study process. It cannot determine causality or their comparative importance, but as an inclusive summary of the main factors put forward by current research they provided the raw material for the development of the evaluation framework described in the next chapter. The goal was to test their relative significance through the fieldwork for this study. The analysis also supports the practicality 
of the dynamic dimensions of the relational model as categories of analysis. These provide the backdrop to the theoretical discussion below of a trust typology.

\subsection{A typology of forms of trust}

The research discussed above demonstrates that trust is multifaceted. This opens the possibility that citizen and state are operating to different norms of trust. This section provides a theoretical exploration of this possibility through a review of the relevant academic literature on trust. The vehicle for the analysis is to develop a typology of different forms of trust derived from identifying the main variables relevant to the citizen/state relationship.

The first section (2.2.1) provides an overview of the literature addressed, and the rationale for the three-fold structure of the typology linking to the dynamic dimensions of the relational model. The subsequent three sections take each aspect of the typology in turn to address trust and connectivity (2.2.2), trust and agency (2.2.3), and trust and interactivity (2.2.4).

\subsubsection{An overview of the typology}

Considerable contemporary scholarship and intense debate focuses on trust. Trust, and particularly its relationship to cooperation, lies at the heart of conflicting cultural and political visions of social organisation, bringing into play powerful assumptions about human nature and the potential for political action. Making sense of these debates is made more problematic by the range of academic disciplines that have a perspective on the issue. These include philosophy (what is trust?), sociology (how trust structures macro and micro social relations, also including political philosophy and organisational analysis), psychology (how trust structures personal relations), and economics (how trust structures material relations). These different schools bring to bear different concerns and methods, and they examine different contexts such as the difference between personal trust and impersonal or institutional trust.

In examining a social phenomenon like the relationship of citizen to the state, the main literature relevant to this study is the sociological perspective, though at relevant points 
also touching on the psychological and economic dimensions. The primary and passionately argued fault line running through this literature concerns the motivational basis for trustworthiness; addressing the apparently perplexing issue of why people voluntarily put their prospects in the hands of others who may not share those interests. And, just as puzzling for some, why do trustees comply with such voluntary vulnerability rather than exploit it for their own individual benefit?

Jones (1999, p.68) offers a persuasive explanation by differentiating between "risk based" and "will based" accounts of trust. In the former, the trustor decides the risk of trustee defection is low, usually because it is in their self-interest not to defect (Coleman, 1990). This appeals to rational-decision theorists because it is founded on the assumption that people are naturally self-interested. By contrast, will based accounts emphasise the importance of social or normative forces in maintaining trustworthiness of the trustee (Baier, 1994; Holton, 1994). This account is more sympathetic to commentators concerned with social solidarity and collective action.

This basic fissure informs most of the debates of what constitutes trust, from the cognitive basis of trust decisions, its relationship with ethics, and how it is enforced. It permeates all that follows in this section. However the position taken here is distinctive in that it follows those commentators such as Simpson (2012) in recognising that trust can take different forms. Rather than arguing that one or other conceptualisation is the only proper form of trust, the perspective developed below is that both forms of trust can and do exist in different contexts. This perspective allows the possibility that citizen and state are operating to different norms.

The range of possible literature sources was vast, so to prioritise the most important texts the literature review was informed by the dynamic dimensions of the relational model. These provided key lines of inquiry for the theoretical exploration of the literature, and gave rise to the dimensions of the typology. The result is a typology with three separate but intertwined aspects that collectively expose the main variables in the structure of a trust transaction: 
- 'Connectivity' and trust - the reasons that participants to a trust transaction might have to trust the other, including examining the mutual 'interest' at stake and different rationales for trustors to have faith in trustees. This is defined as a continuum between social and instrumental trust.

- 'Agency' and trust - the psychic basis of the act of trust in the reflexivity and commitment invested by trustor and trustee. This is defined as a continuum between passive and active trust.

- 'Interactivity' and trust - trust as a mechanism of mutual coordination and governance within a trust transaction - defined as a continuum between dependent and interdependent trust.

The typology covers the three elements of the trust transaction described in the previous chapter - the trustor's expectation for the act of trust, the reasons they might have for the compliance of the trustee, and the enactment (or not) of the exchange. Figure 2.1 illustrates this structure, and its relationship to the relational model described in Chapter 1. Citizen and state bring assumptions and attitudes to the relationship depending on their position on the social/instrumental and the active/passive dimensions. These assumptions and attitudes inform the coordination and governance of the interaction, which is itself analysed in terms of dependency and interdependency. At this stage the positioning of citizen and state on the graphic is purely illustrative. The purpose of the fieldwork was to establish these positions from the evidence. 
Figure 2.1 The trust typology and the relational model

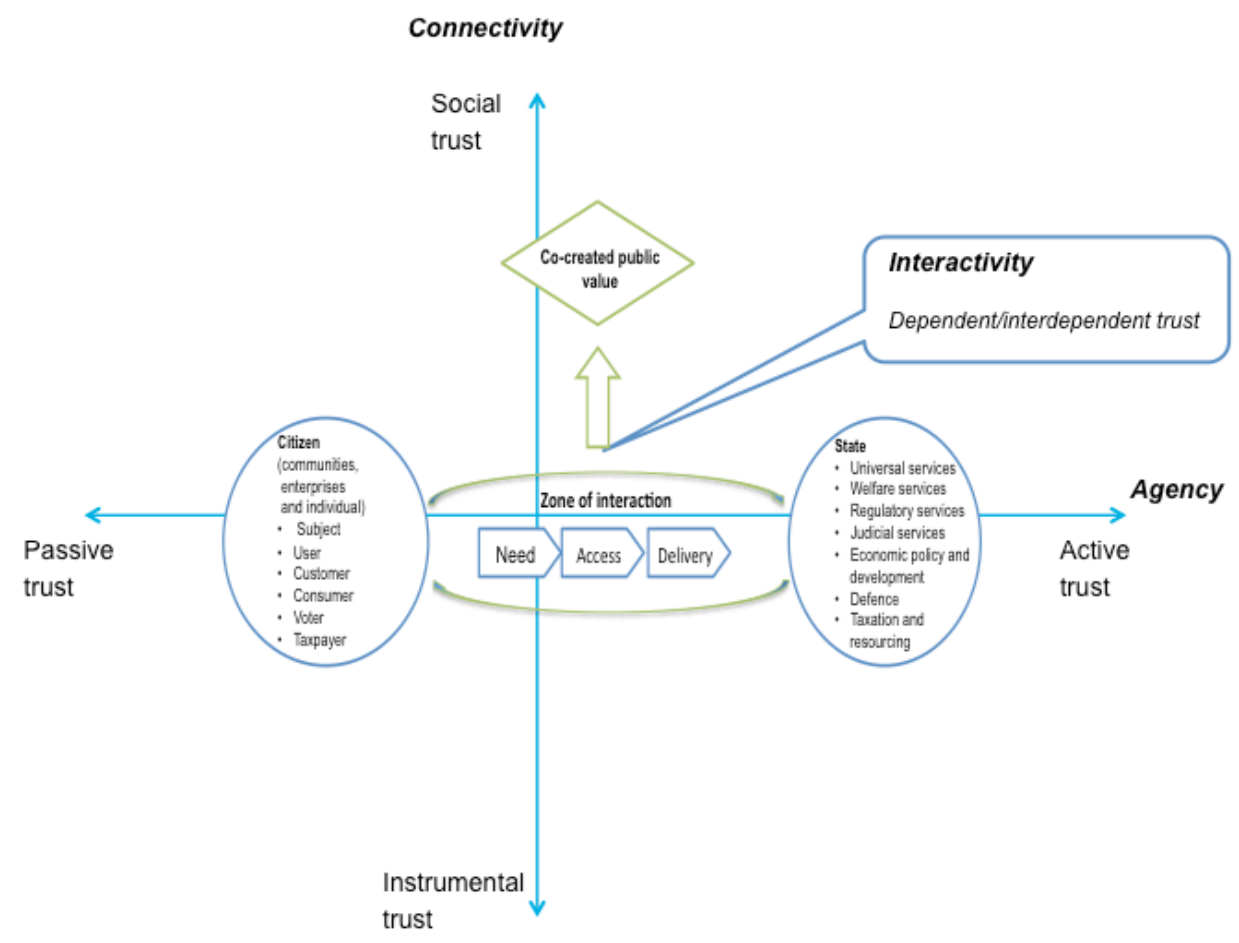

The different aspects of each continuum are not mutually exclusive. They offer 'idealised' ends of a relational spectrum that is mixed in different proportions in different real world situations. For example, most trust relationships of any complexity are likely to contain both social and instrumental elements. The question is, which predominates?

\subsection{2 'Connectivity' and social/instrumental trust}

The first dynamic dimension of the relational model, 'connectivity', investigates the perception of how the parties relate to each other in a citizen/state interaction. The analysis in 2.1 identifies potentially relevant issues in topics such as respect, affect, and communication. 
Applying this category of analysis to the literature on trust directs the study to the issue of the rationale for trust - the reason for the trustor and trustee being in an interaction in the first place. There are two aspects. The first is about the utility of the trusting relationship what is the 'interest' at stake. The second is the reason for believing in the trustworthiness of the other in advancing this interest.

This dimension goes directly to the heart of the academic divide discussed above. In the literature, this debate is often portrayed as an argument between commentators that use economic models (self-interested individuals seeking their own benefit (Cook, Hardin and Levi, 2005; Khalil, 1999)), and more sociologically orientated perspectives (where social bonds and goals are key (Taylor-Gooby, 2008; Banerjee, Bowie and Pavone, 2006)). This antithesis emerges often, with various nuances. For example, is the dichotomy best understood as differences in values, or information, or alternatively the type of reasoning or affect between the parties? Below I summarise the main strands of this debate to establish the importance of both forms of trust, and why characterising the key difference as that between an instrumental and social trust offered the most useful terminology within this dimension of the typology.

Braithwaite offers a values-based view with her description of the contrast between 'exchange' and 'communal' trust (1998b). Exchange trust can be summarised as the belief that trust rests on knowledge of the competence and motives of the other, and therefore the confidence they will fulfil the expectations placed on them. This is the territory of rational choice theorists who, following Williamson (1993), often identify trust as a form of calculation, where the trustor balances their risk against the potential reward from cooperation.

By contrast communal trust is usually held to be a function of social bonds. Information counts, but so do shared identities and an ethical requirement for compliance with trust derived from the act of becoming vulnerable. Braithwaite's links these two forms of trust to two distinct sets of values, with exchange trust representing values of 'security' and communal trust associated with 'harmony':

"The security value system brings together personal and social goals and modes of conduct that are considered important for protecting oneself or one's group from 
oppression from others. At a personal level, security values include having social recognition, economic prosperity, authority, and competitiveness... In contrast, the harmony value system brings together social and personal values with goals of furthering peaceful coexistence through a social order that shares resources, communicates mutual respect, and co-operates to allow individuals to develop their potential to the full" (Braithwaite, 1998b, p.49).

For Braithwaite both sets of values and forms of trust are valid for different people and situations. The distinction between the two value systems is how people infer the trustworthiness of the other. Security values emphasise the anticipation of likely outcomes, and harmony values look to "social connectedness" for assurance.

Blau (1964) uses an information based explanation for the difference between what he calls economic and social exchanges. Blau argues that economic exchanges leave little to trust. The process of bartering and contracting (a formal description of the exchange) removes the discretion that presages trust. In contrast 'social exchange entails unspecified obligations':

"[It] involves the principle that one person does another a favour, and while there is a general expectation of some future return, its exact nature is definitely not stipulated in advance." (Blau, 1964, p.93)

For Blau the intangibility of these 'diffuse future obligations' open the way to trust being present in social exchanges as opposed to economic transactions. Blau and Braithwaite locate economic trust in information on the other, but Blau also explains social trust on information - or rather on the lack of it, due to the diffuseness of the future obligation of the trustee.

In addition to values and information there is a third way of thinking about the different forms of connectivity that give rise to trust. In "A Genealogy of Trust" Faulkner (2007) follows Hollis (1998) in differentiating between predictive and affective trust. Predictive trust puts the role of information into a neutral context, and Faulkner identifies it as related to the 'game theoretic' trust in which rational calculation of probability (usually but not necessarily in the pursuit of self-interest) dominates decisions. By contrast affective trust implies a trust in the other person, not what they are saying. Here, the trustor trusts the trustee to be trustworthy because they are trusted. Affective trust widens the role of trust in the face of what might otherwise appear irrational calculation. To quote Faulkner: 
"When I expect my car to start, or other drivers to stick to their side of the road, my expectation is simply grounded by those observations that support my belief that things are reliable in this respect. But in expecting it of you that you do something because I depend on your doing so, my expectation is not grounded by any belief in your reliability but by the belief that you can recognise my dependence and by the presumption that this dependence gives you a reason for acting in the way I expect" (Faulkner, 2007, pp.312-313).

Conceptualising an antithesis between predictive and affective trust adds an emotional dimension to a social perspective on trust. It also helps explain the moral power of social trust in placing an obligation on the trustee. Placing the trustee as the subject of trust (rather than the trustee's competence, as with predictive trust), Faulkner introduces compassion as a source of trust. His example is a reformer choosing to employ a discharged ex-offender despite his unreliability:

"Moreover, the reformer could continue to trust her new employee, at least up to a point, even if this evidence was salient through his stealing from her; in such a situation, she could choose to give him 'one last chance'. This suggests that affective trust is an attitude that is comparable to intention in that it is an attitude that, with certain limitations, one can choose to adopt" (Faulkner, 2007, pp.314).

This points to the importance of the reciprocity of trust itself. Alan Fox says in "Exchange and Trust Dynamics":

"The more $X$ is perceived as manifesting a trust in $Y$, the easier $Y$ will find it to trust $X$, for $X$ 's behaviour suggests to $Y$ a belief that they share certain relevant values or interests" (Fox, 1974, p.67).

Other commentators also categorise trust by the type of reciprocity that they perceive in different types of trust exchanges, offering a number of explanations. The first focuses on the disposition of the trustor. This roots social trust in a natural human propensity for altruism and co-operation. Behavioural economists like Kahneman (1986) point to an innate sense of 'fairness' as a driver for human co-operation. A related concept from the literature is "strong reciprocity" (Gintis, 2000) in which individuals trust because they believe it will advance the interests of their social group even if not them personally. $A$ weaker form of altruism sits closer to a more predictive and instrumental conception of trust. This is reciprocal altruism where there is an expectation of a direct return to the trustor. The calculation is that mutual altruism repeated over time will bring more benefits to the participants than the short-term benefit of defection. 
The second discussion around reciprocity looks instead at the dispositional characteristics of the trustee. For example, altruism, both the strong and the reciprocal sort, also explains trustee compliance with the trustor mirroring the social and instrumental divide offered above. For the trustee, a key component of such reciprocal altruism is reputation, where the benefit of co-operating is being seen to be trustworthy, thereby encouraging others to trust. Another explanation for trustee trustworthiness tending towards the social form of trust is ethical reciprocity. Faulkner's exposition of affective trust outlined above provides a moral context to the trustee's trustworthiness; the trustor's assumption that placing themselves in a position of dependence is in itself reason for the trustee to comply. This act of vulnerability relies on the trustee reciprocating fully because of the moral obligation this dependence creates. Some argue that "being trustworthy is, in essence, a moral concept" (Banerjee, Bowie and Pavone, 2006, p.304). As a final example, the trust building model of McKnight and Chervany (2006) identifies four trustee characteristics as potential bases for trust. These are competence and predictability, which broadly align with the economic model of trust described above, and benevolence and integrity, which speak more to social models.

Thus far I have described several conceptualisations for the relational basis for trust that in various ways present differences between an economically based self interested trust at one extreme, and more affective and communitarian basis at the other. I conclude this section with a formulation for this antithesis offered by Tyler (1998) in his article "Trust and Democratic Governance". He also describes an "instrumental' trust", based on selfinterest and driven by rational calculation. He opposes to this a "social trust" that can embrace the issues described above of affect, harmony, values, and diffuseness of information through locating trust in the higher order category of recognition and identity:

"In contrast to the calculative or instrumental models of trust that have been outlined, recent approaches to studying authority relations have suggested an alternative perspective, which has been labelled the "relational perspective on authority" (Tyler and Lind, 1992). This model proposes that trust is linked to the sense of identity people derive from their relationships with the authorities. I will call such trust social trust" (Tyler, 1998, p.281). 
Tyler's argument is that people want to feel good about themselves, and one source of such feelings is information from others that confirms self worth. Therefore, in dealings with authority we are concerned about two issues:

"First, we are concerned about our social status. That status determines the pride we take in the groups of which we are members... Second, we are concerned about our social reputation. That reputation reflects the degree to which we think that we are respected by others within the group. Pride reflects our feelings about the status of the groups to which we belong, respect our status within these groups" (Tyler, 1998, pp.281-282).

In several empirical studies, Tyler demonstrates a direct correlation between people's subjective sense of pride in a group, levels of respect they feel from within the group, their willingness to accept group decisions, and the obligation they feel to obey group rules. For example, one study explored feelings of obligation to obey federal laws among citizens of Chicago interviewed about their experiences with police officers and judges. The key factors that encouraged deference to laws were outcome favourability (an instrumental measure), and two relational factors - perceived trustworthiness and status recognition (Tyler, 1998).

Defining social trust in terms of the 'identity' implied by the relationship for each participant offers a powerful unifying frame for the discussion so far. It embraces the other definitions discussed, such as affect, communal, or social exchange-based trust. It offers concrete tools for examining the issue around people's sense of respect and status. It provides an analytic tool for differentiating the different forms of trust, as it returns to the starting point for this dimension of the typology in the nature of the interests of trustor and trustee.

One final description of how trust works helps to illuminate how the continuum can be used. The idea of trust based on 'encapsulated interests' is a way of explaining trustors' belief in trustees. Hardin's summary is:

"First, I trust someone if I have reason to believe it will be in that person's interest to be trustworthy in the relevant way at the relevant time. My trust turns, however, not directly on the Trusted's interests per se, but on whether my own interests are encapsulated in the interests of the Trusted, that is, on whether the Trusted counts my interests as partly his or her own interests just because they are my interests... I may encapsulate your interests in my own, but this does not mean that your interests trump mine for me. Hence, there is some risk that my interests will trump 
yours and that I will therefore not fulfil your trust in me: and your trust will be limited to the degree to which you think my encapsulation of your interests gives them enough weight to trump other interests I have" (Hardin, 2006, p.19).

The emphasis on 'interests' reflects Hardin's origins in the rational choice school of thought, which accommodates an instrumental world-view. However, if we understand that interests are derived from identify and can include social as well as instrumental dimensions, then the formulation encompasses both forms of trust.

This analysis of current research suggests the potential for differences in the norm of trust adopted by state and citizen on this dimension. As a mode of organisation the logic of bureaucracy will tend towards more instrumental forms of trust because of the priority of maintaining order and equity in the interaction with the user. By contrast, if the findings described in section 2.1 that identified a citizen aspiration for a more "emotionally satisfying" relationship hold true, this would indicate a more social form of trust. The implication for the research process was to seek understanding of the nature of the interests articulated by citizens, and the basis they have for thinking that those interests will (or will not) be significant to the state.

\subsection{3 'Agency' and active/passive trust}

The typology's second dimension, also derived from the relational model, is the 'agency' that participants feel they invest in the trust transaction. Whereas 'connectivity' addresses the relationship between participants to a trust transaction, 'agency' concerns the consciousness of the act of trust itself - the psychic commitment trustor and trustee feel they are making to each other.

This aspect of the typology is constructed around an insight from Giddens (1994), with the continuum conceptualised between 'active' and 'passive' trust. There are two pertinent debates in the literature. The first is the degree and nature of reflexivity accorded to a trust transaction by its participants, the extent to which it is consciously articulated and understood. The second is the cognitive nature of that reflexivity, whether the act of trust is best understood as the involuntary consequence of a set of beliefs, or a voluntary decision to accept the terms of the transaction. 
Giddens presents 'active trust' as a corollary of his argument summarised earlier that the 'distanciation' and 'disembedding' of modern social relationships makes new demands on the social function of trust. Giddens' 'active trust' distinguishes a conscious and energetic form of trust more appropriate to this view of modernity. Möllering locates it in the agency of the trustor: "Active trust therefore recognizes the autonomy of the other, that is, the freedom to honour or exploit the trust' (Möllering, 2005, p.22). Giddens also points out this this contingency applies to the trustee. Trust "has to be worked at - the trust of the other has to be won" (Giddens, 1991, p.121). Thus, as Möllering concludes, "active trust reflects contingency and change in an on-going process of reflexive constitution" (Möllering, 2005, p.22).

The importance of reflexivity to active trust exposes several characteristics. Reflexivity is a process of directing something back on itself, in this case describing a level of mutual consciousness in the construction of the trust transaction. Both parties must be self-aware in shaping their role in the interaction. This implies a level of autonomy in both trustor and trustee in the interaction. It also suggests a complementary view of the consciousness of the other; reflexivity takes account of both the subject on themselves and their recursive impact on the other.

This is a view of a form of trust deliberately and consciously constructed. It is made clearer by following the logic of the insight in investigating the implied corollary of a more 'passive trust'. The term is my own, intended to help explore the antithesis of active trust. However the observation that much trust is unreflexive arises in several schools of thought. It helps explain both the ubiquity of trust in different contexts, and provides some explanation for the apparently sub-optimal trust relationships of compliance and domination already touched on.

The roots for an understanding of a more un-reflexive or passive trust lie in phenomenology, and the insight that individuals make sense of the diverse components of human condition by adopting a 'natural attitude':

"Born into a social world, he comes upon his fellow men [sic] and takes their existence for granted without question, just as he takes for granted the existence of the natural objects he encounters" (Schutz, 1967, p.98). 
Part of this natural attitude is that others have a world view that is broadly similar and that social reality is in essence a "world known in common with others" or a "common sense world" (Garfinkel, 1967, p.36). Thus, as Möllering summarises, "trust in the natural attitude means interacting with others on the basis that everyone knows and accepts the basic rules for the interaction" (Möllering, 2005, p.10).

Several writers on trust within the neo-institutionalist school identify sources of apparent common sense that govern many of our social interactions at the level of "taken for granted-ness" (Garfinkel, 1967, p.35). One, Zucker, defines trust as "a set of expectations shared by all those involved in an exchange; these expectations are structured by social rules and by pre-defined processes" (1986, p.54). By this account a function of institutions is to define many aspects of social reality including norms of legitimate and non-legitimate expectations of others. Many of our myriad daily social exchanges and interactions are conducted with an unconscious taken-for-granted-ness because they reside within these unquestioned norms and processes.

Other writers identify similar forces subliminally structuring our expectations of others in trust based exchanges. For example, Möllering points to isomorphism, the human instinct for conformity:

"[...] to argue further that manifestations of trust maybe explained to a considerable degree by institutionalization: the trustor $A$ trusts (or distrusts) the trustee $B$ in a certain matter because it is a natural and legitimate thing to do and 'everyone would do it" (Möllering, 2005, pp. 10-11).

Di Maggio and Powell (1991) identify three main types of institutional isomorphism. These are coercive isomorphism (external pressure to conform and achieve legitimacy), mimetic isomorphism (conformity derived from copying an influential other) and finally normative isomorphism (the power of socialisation, or the internalising of rules and norms, generating a shared common sense that might inform a relationship of trust). All three can contribute to a passive, un-reflexive trust. A final source of taken-for-granted trust is trust in systems. An influential study in this respect is Luhmann's (1979) analysis of trust and money, which argues that people trust such systems not just because they work experientially but also because they are impersonal, diffuse, and abstract, and therefore do not need to be questioned with every use. 
The second debate on trust that illuminates the active/passive continuum concerns the nature of the cognitive processes at play within different forms of trust, and whether these are best understood as rooted in beliefs, a conscious decision or an action. From the rational choice school, Hardin differentiates the first two categories from the third:

"[Many writers] conflate trusting with acting on the trust. But there might be no occasion for me to act on my trust by entrusting some matter to you. Hence, my action and my knowledge of your trustworthiness - which constitutes my trust are different" (Hardin, 2006, p.33).

According to this account trust should be understood primarily as a set of beliefs in the trustee. This is important to instrumental schools of trust, as beliefs offer an explanation for acts of trust even when the trustee's compliance is uncertain. Belief can fill the gap left by imperfect information on which to base a rational decision.

Other commentators focus more on trust as a decision, including questioning the separation of beliefs from behaviour. Their argument is that the statement 'I trust person or institution x' must be understood as a short hand for 'I trust person or institution $\mathrm{x}$ to do $y$ '. For them, all trust is context specific, and is only appropriate if some specific vulnerability is in question. As an example, in Luhmann's analysis of money quoted above, the efficacy of the medium of exchange derives from the general assumption that everyone will respect it. This assumption often remains unquestioned, until that is there is a run on the banks.

In the context of the typology, 'active trust' was primarily seen as an act of will or choice, which may or may not also be associated with beliefs. Möllering approvingly summarises the Simmellian (1964) conception of trust. “... Trust can be imagined as the mental process of leaping - enabled by suspension - across the gorge of the unknowable from the land of interpretation into the land of expectation" (Möllering, 2001, p.413). Simmel emphasises an irreducibly ineffable aspect to trust, that it requires some sort of "leap of faith" from the trustor towards the trustee. Giddens uses similar language for this suspension of doubt; it "presumes a leap to commitment, a quality of faith that is irreducible" (Giddens, 1991, p.19). 
This is a challenging idea. It runs counter to the calculative and instrumental accounts already described. But such a leap of faith is also hard to reconcile with the reflexivity I argue is associated with 'active trust', both chosen and capable of being withdrawn if abused. However, there are ways of reconciling this. For example, the earlier discussion of social trust locates trust in the person, not the immediacy of the transaction. The leap of faith in accepting immediate vulnerability is because of the trustor's broader trust in the trustee, and because the mere fact of this trust imposes a reciprocal obligation.

Another answer lies in the association of agency with active trust. This suggests that trust can be characterised as acceptance based on a conscious decision to suspend doubt. Differentiating acceptance from belief creates the space for a decision to trust. It also provides the mechanism for the trustor to retract their leap of faith in the event of failure. According to this account the trustor - aware both of their vulnerability as well as the potential benefit from trusting co-operation - decides to 'suspend' their doubt in order to initiate the act of trust (Möllering, 2001). They do this reflexively, knowing that there is a chance of the trustee reneging. The act of trust is therefore made conditional on not being abused. Doubt is suspended until it is shown to be false. This accords with the tit for tat strategy that emerges from the game theory analysis of trust.

The distinction between active and passive trust described here also resonates with aspects of the critique of voice and choice in the previous chapter and the empirical research discussed in 2.1. One inference of a relational paradigm centred on citizen compliance is that in the absence of active dissent the agencies of state will tend to assume trust. By contrast empirical findings of a decline of deference and associated emergence of a more 'critical trust' amongst citizens points to the possibility of citizens adopting a more active form of trust. Data from the fieldwork were investigated in this light, for example assessing the importance of the perception of the commitment of the state to an interaction.

\subsection{4 'Interactivity' and (inter)dependency}

Analysing the dynamics of the interactivity dimension of the relational model - exploring the processes of reciprocal cooperation (or not) between citizen and state - goes to the 
heart of trust as a mechanism of coordination and governance. Given the asymmetric power relationship between citizen and state, this requires a deeper understanding of how trust and power relate, and how they mediate each other.

This section develops this understanding in describing the final dimension of trust as a continuum between relationships that are dependent (in which the trustor has little choice but to trust the trustee) or interdependent (where success requires the active engagement of both parties). It then discusses the implications for the mechanisms that govern the interaction - touching on accountability, consent and redress.

Bachmann's description of the trust/power hybrid summarised in Chapter 1 (Bachmann, 2001) starts this discussion. He believed most complex relationships will inevitably reflect aspects of both mechanisms with trust oiling the wheels of power and, he argues, a form of power providing a 'pre-condition' for trust. In fact, power is a permanent backdrop to any discussion of trust because the very act of trust involves the trustor offering a 'gift of vulnerability' in return for an expectation of a reciprocal good. In the context of the citizen/state relationship this vulnerability is considerable - the obligation to comply with wide-ranging rules and requirements imposed by the state.

This vulnerability has considerable potential value to the state as trustee, reducing its need to expend resources in enforcing compliance. The corresponding issue crystallises around the citizens' capacity to hold the state to account in delivering on their reciprocal expectations in return for vulnerability. Thus, power is woven into the very fabric of trust in the balance of forces that construct and maintain trustor vulnerability and trustee integrity, and this is particularly the case for the relationship between citizen and state.

The first step in analysing how citizen and state may differ in approach to this dimension of trust was to conceptualise the spectrum of options. One was simply to reflect the degree to which there was a balance of power between trustor and trustee. However, as most trust relations operate with an asymmetry of power, this continuum offered little explanatory power. Instead a continuum of trust and power based on dependency and interdependency proved a better way of conceptualising the opposing ends of the spectrum. In this respect Foucault's approach to power described earlier in the thesis 
(Foucault, ([1975] 1997) is helpful. It located power in both the subjective internalisation of disciplines as well as in the operation of external rules. So, in relationships, it was not the absolute power of each party that matters, but the power relationship between the two.

This leads into the territory of reciprocal influence and control. Ultimately the efficacy of a mechanism of co-ordination of a transaction lies in whether it is successful in influencing the mutual behaviour of the parties; power only works if it has traction on the counter-party. As a dramatic example, overwhelming force is irrelevant if someone has decided on martyrdom. Different forms of trust/power have more or less influence on behaviour. So we can assess whether citizens require a more effective form of trust to that on offer from the state. A useful means of analysis is the mutual (inter)dependency of trustor and trustee. This offers the most useful explanation for how trust can exert mutual influence (or not) across asymmetric power relationships. McEvily et al. (2006) define a key condition for trust as:

“... for trust to arise, interdependence and uncertainty are necessary conditions. Interdependence means that the interests of one party cannot be fulfilled without reliance on another party" (McEvily et al., 2006, p.54).

In this formulation interdependence is understood as the mutual dependence of the trustor on the trustee, and vice versa. Both parties must fulfil their part of the trust transaction for the mutual benefit to arise, irrespective of the power relations between them. This binds the parties together in an effective and collaborative embrace. Interdependence ameliorates power asymmetry, because if an exchange requires the active participation of both parties irrespective of their relative power, domination can be challenged. One party may be more powerful, but this can be ameliorated if the weaker party can (for example) withdraw from the exchange if dissatisfied.

However, this study parts company with McEvily et al. (2006) in their assertion that interdependence (as opposed to uncertainty) is a necessary condition for all forms of trust. The lack of wisdom in trusting an untrustworthy trustee (discussed in chapter 1) demonstrates that trust can also occur in situations of profound dependence for the trustor. Such dependence can arise for a variety of reasons. There are situations of "no-choice" trust. For example, sick patients may have little choice but to trust their doctor; there is 
little or no genuine interdependence here for the state. As Mid Staffordshire (Francis, 2013) shows, a dominatory trust can then emerge that allows exploitation and abuse.

At one end of the continuum, interdependence creates the conditions to mediate asymmetric power relations since the joint enterprise cannot succeed without both parties. By contrast, dependence can reflect a one-sided relationship, predicated on the compliance of the less powerful party. Domination is not inevitable, but clearly it is a risk. This is why this study defines the continuum of trust types related to power as that between the citizen as trustor perceiving their relationship to the state as trustee as one of dependent or interdependent trust.

To understand the practical mechanisms by which (inter)dependence is structured it is useful to return to Bachmann's (2001) argument that some forms of power are necessary preconditions for trust. This is germane to citizen/state relationships because, he argues, institutional forms of power - the rules and regulations formulated and used by collective bodies - are essential to trust production. Bachmann bases his argument on Luhmann's (1979) earlier work on trust and power. Like others, Luhmann starts from the premise that trust involves vulnerability, and therefore of necessity the trustor needs "good reasons" for accepting that vulnerability and the risk entailed. Citing trust in money as a system, Luhmann concludes that legal norms are amongst the most potent sources of trust. Legal regulations and possible sanctions reduce risk by creating a commonly observed and understood system of behavioural norms. Luhmann reconciles this with the voluntary nature of trust by arguing that their value is in the way they implicitly guide behaviour, not in their actual use:

"The structure of the trust relationship requires that such calculation should remain latent (...) purely a reassuring consideration" (Luhmann, 1979, p.36).

Bachmann develops this insight in analysing the role of trust within business relations in the UK and Germany. To the law, he adds the role of trade associations, systems of technical standards, and government policy, all contributing to a tightly knit framework of institutional norms. This common world creates trust through consistency and the expectations and actions of participants. 
Bachmann argues that this sort of institutionalised trust is particularly important for trust in large complex systems such as states:

"...system trust is likely to be the prevailing social co-ordination mechanism under these conditions. At the same time, however, one should see that power is not generally absent in this case. Rather, it appears as system power in the form of law, powerful trade associations, inflexible business practices, technical standardization, and rigid structures of hierarchy. It is precisely this depersonalised form of power - or 'Herrschaft' to use Weberian terminology - which can mass produce trust and thus can be seen as the central precondition of, rather than alternative to, system trust" (Bachmann, 2001, p.352).

He suggests that where there is low institutional regulation, people and organisations are liable to use power as their default co-ordinating mechanism, or perhaps personal trust if they have had the time and opportunity to invest in such a specific relationship.

Building on this insight, the final part of the analysis addresses how the rules and norms of the citizen/state relationship are configured to manage trust in the context of (inter)dependence. Three aspects are analysed. The structure of coordination is examined in the context of the nature of the clarity of the mutual expectations of citizen and state.

The governance of the process of the interaction is considered though the lens of conflict and consent. Finally, the management of outcomes gives rise to the analysis of accountability for performance and redress for failure.

\section{Trust and mutual expectations}

Investigating trust as a mechanism of mutual co-ordination and governance illustrates the importance of power in structuring the mutual expectations by which the mechanism operates. This can be understood as the responsibility that each party carries for the successful fulfilment of reciprocal exchange. In the public service such expectations come in a number of forms. One of the most explicit is precise service agreement with individuals, such as the care plans and 'contracts' used to define some social care arrangements. Other services operate to more general statements of the standards and procedures for services, such as for example the NHS statements of patient rights. Sometimes expectations are built into the very logic of the service, such as with school curricula on which the qualification system is based. 
One question for trust between citizen and state is how far these service definitions, and the mutual roles of participants, provide a clear and equitable statement of the interaction from the citizen's point of view. This question could arise in a number of contexts. Firstly, do citizens feel they understand the production process, and their role within it? Secondly, who owns and defines the measures by which the success of a trust transaction is assessed? This may seem a rather technical point, but any performance management system or service standard that cannot be assessed by the service user - such as the widely prevalent bureaucratic measures of targets to achieve certain outcomes a percentage of the time - could suggest a relationship weighted towards dependence. For example, a commitment to treat $95 \%$ of A\&E patients within 4 hours may be a useful management target, but is of limited value to an individual patient waiting longer than this. It does not provide any basis to challenge the service since they maybe part of the unlucky $5 \%$.

\section{Trust and consent}

If clear and legitimate mutual expectations are the first aspect of the coordination and governance regime then the question arises: by what mechanism is a transaction agreed and maintained? For example, in a marketplace the exchange of money is a mechanism, as it signals mutual agreement between buyer and seller on the deal.

By contrast, as argued in Chapter 1 the currency of trust is consent; the trustor accepts their vulnerability in return for the benefit expected from the trustee's cooperation. Mutual interdependence implies an active, conscious, and chosen consent - the participants accept the basis on which it is structured and their role in the co-operation required. Conversely transactions predicated on dependency may be characterised by more passive (or grudging) 'compliance'.

Chapter 1 suggested that prevailing instances of voice (and to some extent choice) provide only partial and often symbolic means for citizens to signal acceptance of the transaction. Whether citizens require more definite consent was another issue for the fieldwork to probe. A related issue was the substance of consent; whether citizens were most concerned about the allocation of resources, the process of production, or service outcomes. One line of inquiry prompted by the empirical evidence in 2.1 and political 
philosophy was the importance of citizens' perception of fairness in state decision-making, a point made strongly by Levi:

"...individuals need to have evidence that government is relatively fair and not just credible if they are to have confidence that the State will harmonize the interests of otherwise competitive parties. The belief in government fairness requires the perception that all relevant interests have been considered, that the game is not rigged" (Levi, 1998, p.90).

This questions whether the perception of state trustworthiness derives from the result fitting the individual interest, or the validity of the process.

\section{Trust and accountability}

The corollary of investigating consent and trust is to understand the role of non-consent and distrust. This takes the discussion into the topic of accountability, the governance regime that maintains the commitment of trustor and trustee to the terms of their interaction. Braithwaite (1998a) describes two broad options for structuring accountability between citizen and state. The traditional model he calls hierarchic, "in which a regulatory body can be conceived as guarding citizens, a minister guarding the regulatory authority, and Parliament the minister" (Braithwaite, 1998a, p.353). This accountability can feel remote from citizens, and prone to infinite regression, a never-ending need for a guardian of the guardians. Hierarchic regulatory regimes can offer only limited systematic challenge to dependency, since citizens are largely dependant on the 'goodwill' in the regulatory system for its efficacy.

Instead Braithwaite proposes a 'republican' view of trust guardianship in which the lines of accountability are arranged in a circular model where 'everyone becomes a guardian of everyone else.' This model epitomises interdependence. He cites the effective working of nursing home resident committees who have a key role as part of the formal inspection regime in Australia. He concludes:

"Management more often than not responds in a trustworthy way to the climate of trust, because managers can see that the very process of dialogue empowers the other participants with dangerous knowledge they could use against management.... by getting the structural conditions of Republican regulation right, it is possible for regulatory encounters to be based on trust, with deterrence 
always threatening in the background but never threatened in the foreground" (Braithwaite, 1998a, p.355).

The mutual ability immediately to hold the other to account offers instant feedback and regulation of the interaction, creating interdependence through mutual policing. According to this account more often than not the challenge is to empower citizens to articulate their distrust:

"....we need enough distrust in institutions for the vigilance ..... [in the circular accountability model described above] to work. Whatever we do, the required level of distrust will usually exist; it is difficult to conceive of a sociologically possible world where absence of distrust is a problem. The problem is getting people to act on their distrust, the democratic challenge of channelling distrust into active citizenship" (Braithwaite, 1998a, p. 357).

If one challenge is "getting people to act on their distrust", the corollary is getting the state to acknowledge and resolve the distrust. This leads to some interesting reflections on how to institutionalise the role of distrust. In an interaction with high interdependence, distrust is likely to manifest in dissent. This should be valued as a chance to restore trust. By contrast, in interactions characterised by dependency the priority may be to ignore or neutralise distrust, perceiving it as a source of disorder and irritation. A related issue is redress. In addition to acknowledging distrust one way the trustee can regain trust is by rectifying the harm that damaged it. Redress is complex for the public sector. For example, financial compensation to one individual reduces the resources available to the rest. Yet the willingness of the state to make good a perceived error may be important in (re)building trust.

One of the research themes investigated in 2.1 was the importance to trust of the state admitting to, and rectifying, mistakes. This was an important issue for the fieldwork to assess. If significant the discussion above implies that this would manifest itself in a desire for a direct sense of accountability in the interaction with the frontline staff, accompanied and supported by a sense of the importance of consent and redress.

\subsection{A hypothesis of differing norms of trust}

The review of the empirical evidence, and theoretic articulation of a trust typology, helps to delineate the proposition that trust is a contingent and malleable phenomenon that can 
take on different forms in different situations. This chapter started with the observation that such malleability opened up the possibility that state and citizen are operating to different norms of trust. So by way of conclusion this section brings the threads together as a more precise hypothesis that was partially tested in the course of the fieldwork.

This hypothesis is that one explanation for the apparently inexorable decline of trust in government despite major reform and apparent improvement in social outcomes such as economic growth is that the values of citizen and state in respect of what constitutes trust and trustworthiness have diverged. The description of the typology in conjunction with the empirical evidence is at least suggestive that citizens are aspiring to a more social, active and interdependent trust, compared to that in use by the state.

This hypothesis can be illustrated using a simplified but more precise version of the relational model combined with the trust typology as in figure 2.2. 


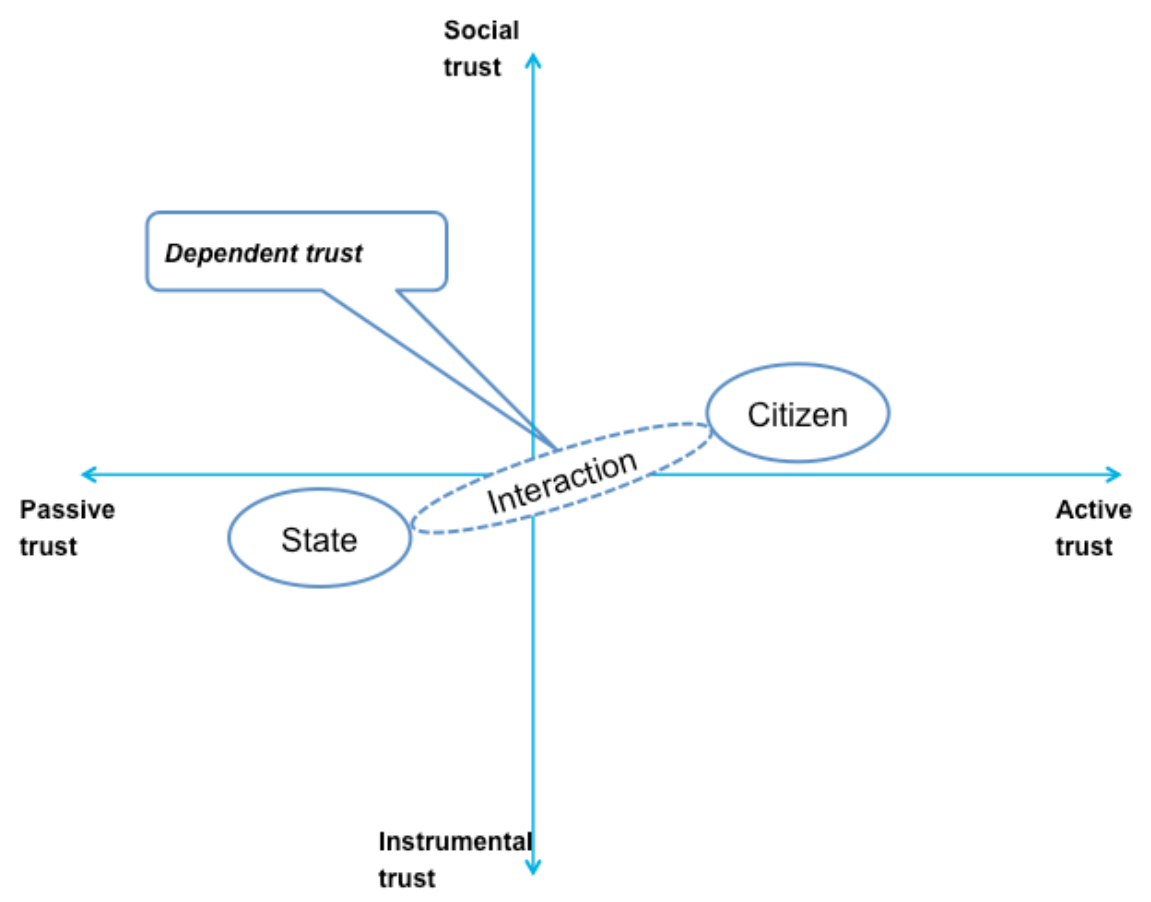

The research process responded to this analysis in a number of ways. Firstly, the fieldwork was designed to generate evidence capable of differentiating different norms of trust in use by citizen and state along the dimensions of the typology. However the goal of the first research question was not to focus on the differences in themselves but to explore the citizens' perspective. The priority was to establish the key factors in the citizens' mind rather than a detailed comparison with the state norm.

However the gap was partially addressed by virtue of the second research question, addressing whether citizen views on what constitutes state trustworthiness can be used to structure the future relationship. Answering this question did not entail scoping the precise gap in norms, but it did require assessing whether the citizen norm can take precedence over a state norm, and the extent that the elements of the typology are relevant to the variety and 'messy reality' of citizen/state interactions. This is discussed further in chapters 6 and 7 . 


\section{A relational and deliberative research method}

Chapter 1 concludes with the two questions addressed by the research. The first is to understand the tests in the mind of citizens when assessing the state's trustworthiness, and whether these were different in kind to the norm of trust and trustworthiness within the agencies of the state. The second question follows; once identified, can these tests help structure the citizen/state relationship to overcome the challenges described above, encouraging more co-operative interaction. Chapter 2 developed the theoretical context for this investigation by exploring the potential for citizen and state to be operating to different norms of trust. This chapter now turns to a discussion of the method for the fieldwork designed to address these questions within this context.

Such relational questions require a relational research method, which is described in four sections within this chapter. The first (3.1) discusses the key 'knowledge challenges' for the study and demonstrates why a specific form of Dialogic Action Research (DAR) was considered the most appropriate approach. The second (3.2) describes in more detail the protocol for the structure and management of the DAR process. The third section (3.3) builds on the analysis of existing empirical research in the previous chapter to develop the evaluation framework used in the interrogation and coding of the fieldwork data. The final section (3.4) concludes by summarising the different classes of research data that arises from the method and how each contributed to the evaluation of the case study.

\subsection{Overview of the knowledge challenges and study method}

This section describes the rationale for adopting a customised form of Action Research assembled from a number of AR traditions and termed Dialogic Action Research (DAR) as the appropriate research method for investigating the research questions(Heron, 2014; Montoya and Kent, 2011; Shotter, 2010). It starts (3.1.1) by analysing the nature of the knowledge challenges posed by the research questions. Resolving these challenges leads to development of the key design principles of the DAR method (3.1.2). It concludes by discussing the need for, and implications of, the repeatability of the approach to achieve robust and generic results (3.1.3). 


\subsubsection{The knowledge challenges}

In Chapter 1 the citizen/state relationship is conceptualised within a 'public value relational model' that identifies the 'zone of interaction' between citizen and state as the site of the co-creation of public value. The focus of the research questions are the dynamic, iterative, and reciprocal exchanges within the zone of interaction, and the attitudes and capacities that both citizen and state contribute to the processes of public service consumption and production. The research method needed to reflect this model, in the context of the research questions. The graphic is reproduced in figure 3.1 .

Figure 3.1 The research questions and scope defined by the relational model

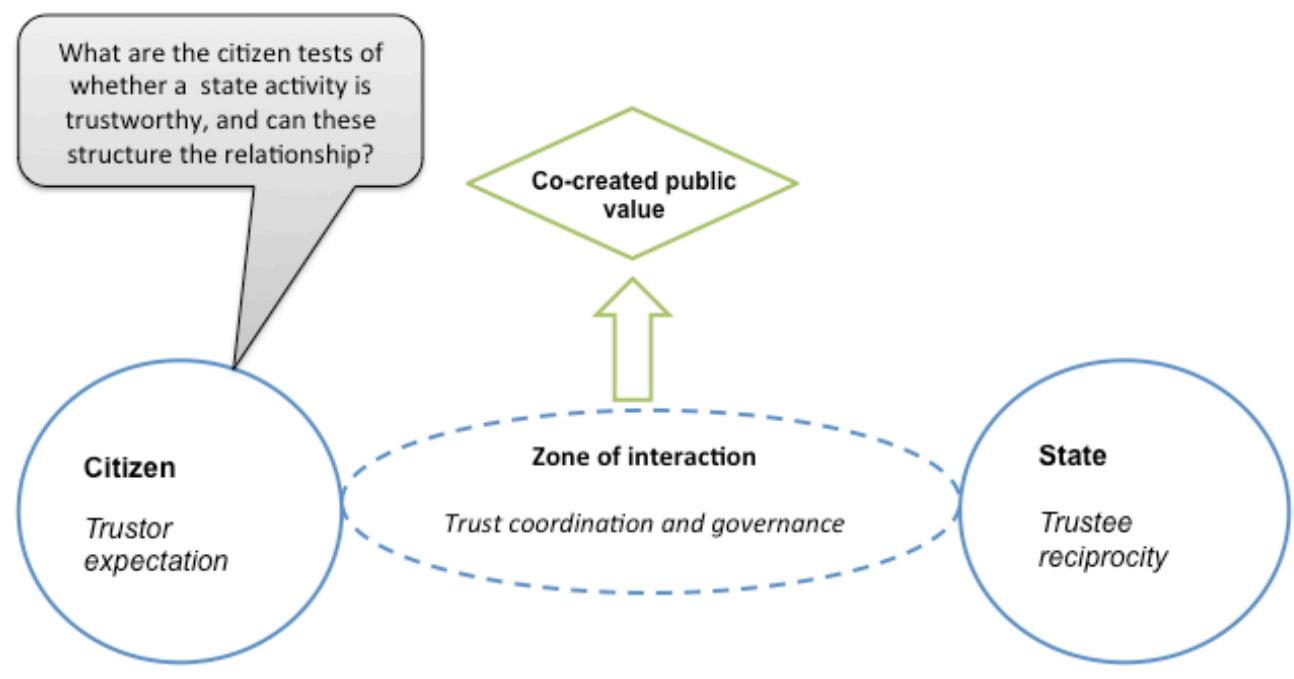

This framing of the problem helps to shape structure and knowledge challenges for the study in a number of separate but complementary ways. Firstly, the questions could only be resolved through the testimony of citizens, and people working for the state, on the quality of their relationship and mutual engagement within a 'zone of interaction'. The implication is that the type of knowledge required is both subjective and intersubjective. It comprises both the behavioural reality of what happens in the interaction between citizen and state, and the subjective attitudes, capabilities, and feelings that both citizens and agents of state perceive themselves and each other to be bringing to the interaction feelings that are themselves influenced by the interaction. 
This is the first knowledge challenge - trust, and the citizen's perception of the factors that indicate the state is trustworthy, is located in the subjective feelings and attitudes of citizens as mediated by actual intersubjective experience of the relationship in practice.

The second knowledge challenge concerns the substance of the required knowledge. The evidence should be able to differentiate between different norms of trust in use within the agencies of state compared to that applied by citizens, as articulated by the trust typology described in the previous chapter.

These challenges resonate with Park's (1999) typology of understandings required for complex social investigations, in contrast to what he calls the "empirical-analytic" approach of the traditional positivist method. Park's typology describes three distinct categories of knowledge. The first is "representational", embracing the traditional "functional" knowledge generated by the empirical analytic scientific method. However, in the setting of a social investigation it also requires an "interpretive" dimension:

"Although interpretive knowledge is different from the functional version of representational knowledge, it is still representational, in that it is a portrayal of reality in terms of the meaning that is intersubjectively rendered" (Park, 1999, p.147).

The second category within Park's typology is termed "relational". Park argues that it "resides in the thick of the relationship itself" (Park, 1999, p.147) rather than depicting the other as an "object of scrutiny". Thus, representational knowledge separates the knower and the known, whereas relational knowledge unites the knower and known in a union in which both partake. It is this sort of intersubjective knowledge that is the foundation of community life. Park's final category is "reflective". Park relates this to Habermas's (1987) description of critical and communicative rationality and also Paulo Freire's term of "conscientisation" - embracing both a sense of consciousness and conscience (Freire, 1972). This brings to the surface a form of moral knowledge that guides action. This typology is helpful in bringing some methodological clarity to the selection and design of the research process. The knowledge challenges described earlier require all three of these categories of knowledge if the study is to generate proposals to improve the citizen/state relationship. 


\subsubsection{A customised form of dialogic action research}

Park's endeavour in describing this typology is to demonstrate the potential knowledge claims that can arise out of forms of action research- covering all three forms of knowledge - in comparison to other qualitative and quantitative research methods. As a starting point for this research, AR has many attractions. It offers a dynamic research method that investigates phenomena by bringing together a group charged with changing a practice or way of thinking by actively developing alternatives (Reason, 2003). This would align with the most direct way of addressing the research questions - convening groups of citizens and state agents in a dialogue about the factors that contribute to the citizen perception that the state is trustworthy.

This would enable the research process to take place within a 'zone of interaction', involving the two groups who constitute the 'lived experience' of the service and able therefore to discuss with authority and understanding the different forms of trust actually in use. Such an approach would satisfy all three aspects of Park's typology of knowledge. It would provide representational knowledge (the outcome of the discussions on the factors of importance to trust) based on a relational analysis (the central theme under discussion is the citizen/state relationship) in way that invited reflective knowledge (deliberative and agreed prescriptions for action in the future conduct of the relationship).

The benefits of AR are made evident when it is compared to the research methods analysed in the previous chapter. For example the surveys of citizen opinion described in 2.1 target only subjective knowledge, capturing a static snapshot of the attitudes, views, or feelings of the research participants. These can reach many people, and give quantitative evidence, but are limited to testing views on preconceived issues. Such an approach would offer only a limited response to the research questions, as it would be impossible to probe the reasons behind participant's views, or debate the differing perspectives of citizens and state agents.

The more qualitative methods discussed in the previous chapter would be more productive in the context of the research questions. In depth interviews and focus groups, such as those used for the Audit Commission study (Duffy, Downing and Skinner, 2003) 
on trust in public institutions would enable a deeper and more discursive exploration of the issues. Focus groups especially would potentially enable new and shared insights as debate stimulated insight and creativity. However such approaches on their own would be unable to generate intersubjective knowledge, for example in differentiating and integrating the views of citizens and frontline agents. Nor would they have the same focus on promoting real change as DAR.

There are methods in addition to AR that could potentially take the study into the territory of intersubjective knowledge. One is the behavioural games described in the previous chapter. As already discussed these can produce interesting results but suffer from the same limitation as the quantitative survey, in that they can only test for a small number of preconceived variables. This has limited application for this study, where it is the nature of the variables themselves that are under investigation.

Another approach might be observation - the researcher stands within, but at one remove from, a social event or phenomena and opens themselves up to their perceptions seeking to absorb and describe the key parameters of the subject under investigation.

This can offer useful behavioural insight. However, for this study it would lack the focus on the specific topic of trust that a dialogue would provide. None of these methods alone could create a dialogue of citizen and state in pursuit of both the behavioural and attitudinal evidence required.

Thus a form of AR embracing both citizens and state agents analysing their mutual relationship was the method that showed most promise in addressing the research questions in a way that reflected the intent of the relational model. It also shared the research objective in using the study to promote active change, as Reason's definition of AR aptly summarises:

"It seeks to bring together action and reflection, theory and practice, in participation with others, in the pursuit of the practical solutions to issues of pressing concern to people, and more generally the flourishing of individual persons and their communities" (Reason and Bradbury, 2006, p.3). 
Reason draws out five key dimensions of action research that helps shape the parameter and principles of how the method could bring together groups of service users and service staff to discuss and improve their mutual trust. These are summarised in table 3.1.

Table 3.1 The dimensions of action research applied to a dialogic process

\begin{tabular}{|c|c|}
\hline Key dimension of action research & $\begin{array}{l}\text { The dialogic process with service users } \\
\text { and staff should.... }\end{array}$ \\
\hline $\begin{array}{l}\text { Knowledge in action - 'creating new } \\
\text { forms of understanding, since action } \\
\text { without reflection and understanding is } \\
\text { blind' }\end{array}$ & $\begin{array}{l}\text {...be deliberative, sharing of ideas and } \\
\text { analysis between them }\end{array}$ \\
\hline $\begin{array}{l}\text { Human flourishing - 'providing important } \\
\text { guidance and inspiration for practice' }\end{array}$ & $\begin{array}{l}\text {...find general lessons to improve value } \\
\text { from public services }\end{array}$ \\
\hline $\begin{array}{l}\text { Participation - 'human community } \\
\text { involves mutual sense-making and } \\
\text { collective action' }\end{array}$ & $\begin{array}{l}\text {... be driven by the insights and } \\
\text { conclusions of the participants }\end{array}$ \\
\hline $\begin{array}{l}\text { Practical issues - 'producing knowledge } \\
\text { useful to people in the everyday conduct } \\
\text { of their lives' }\end{array}$ & $\begin{array}{l}\text {... develop practical measures to improve } \\
\text { the relationship in the specific context of } \\
\text { a shared service experience }\end{array}$ \\
\hline $\begin{array}{l}\text { Emergent developmental form - 'Action } \\
\text { research is emancipatory, it leads not } \\
\text { just to new practical knowledge but to } \\
\text { new ways to create knowledge' }\end{array}$ & $\begin{array}{l}\text {...be useful more generally as a way of } \\
\text { assessing the effectiveness of the } \\
\text { citizen/state relationship across the } \\
\text { public sector }\end{array}$ \\
\hline
\end{tabular}

The conceptual fit of AR as described above with the research objectives and questions is clear. However AR encompasses a myriad of different specific traditions, and the design 
of a method specific to creating a dialogue between citizens and state agents needed to absorb aspects from a number of these.

An important starting point was the various schools that focus on the use of dialogue as the means of knowledge development. There are a number of articulations of this strand of AR (Montoya and Kent, 2011; Hoggett et al., 2010; Shotter, 2010; Ripamonti et al., 2016), but they share a number of principles significant to this approach, as well as one distinctive difference. One key assumption they share is that knowledge resides in the participants. They, not the researcher, are the "agent of change" (Mårtensson and Lee, 2004, p.515); the researched are the researchers (Montoya and Kent, 2011). Furthermore this knowledge is made explicit and enhanced by the process of interaction: "Dialogism conceptualizes the production of meaning through the situated interactions of actors" (Lorino, Tricard and Clot, 2011, p.769). A significant design principle for enabling this dialogue to break free of inherited and constraining modes of thought is to "situate" the discussion in the problem, "within the intertwined nexus where all those involved in a situated difficulty interact with each other" (Shotter, 2010, p.281). These considerations were central to locating the AR process directly in the research problem - asking citizen and state participants to work together to formulate recommendations on how to improve their trust.

Whilst these sources and principles were helpful to the design of the process they were not sufficient, for the reason that they all conceive the primary dialogue as occurring between the participants and the researcher. In contrast the intention in this research was the deliberate creation of a dialogue between the groups of participants. The research question requires the deliberate differentiation of the interests of citizen and state, in order to conduct a dialogue between these interests. For the design of this aspect of the process a number of other strands of AR were relevant. Somewhat paradoxically the first of these lies in the experience of using AR techniques' in pursuit of conflict resolution (Gozzoli and Frascaroli, 2012; Pettigrew, 2003). There is a considerable background to this technique, for example in helping to resolve disputes over resources between communities in development projects (Bavinck, Pellegrini and Mostert, 2014; Moeliono, 2005). One useful principle adopted from these approaches is that successful conflict resolution starts from the parties being satisfied that their differences were properly 
understood. The second principle is that an iterative process that allows for the evolution of mutual recognition and the development of collaborative analysis is vital (Coleman, Deutsch and Marcus, 2014). These considerations were significant in the design of a staged approach to the DAR, starting with each group meeting first on its own to help form its identity before going into dialogue with the other.

Another strand of AR associated with 'cooperative inquiry' (Heron, 1996) is also apposite in guiding the style of discussions designed to resolve difference. Cooperative inquiry emphasises a number of techniques in the collaborative resolution of differing perspectives: these are openness in setting the agenda, clarity in structuring the terms of the debate, allowing for an element of intuitive disruption in the discussions, and setting a concrete objective - in this case making practical recommendations on how to improve the citizen/state relationship (Shotter, 2010). The second and related element is to emphasise the role of the researcher as a facilitator of the workings of the group, not just the reporter of discussions. For a successful process of collaborative problem solving such as this the researcher/facilitator would need take an active role in helping the group to articulate problems and negotiate solutions.

The final strand of AR thinking relevant to the design of the process builds on this last point. It is the broader category of Participative Action Research (PAR) (Brydon-Miller, 1997). PAR is more of an umbrella term for all action research aimed at creating "communities of inquiry" that empower the participants (Reason and Bradbury, 2006). The design principles described above do not conflict, and the points articulated in table 3.1 above are largely derived from a PAR perspective. The additional significance of this tradition to this study lies in the emphasis on creating an inquiry process that drives towards the 'concrete objective' of change. The design of the AR process reflected this determination by adopting a structured process of problem solving - taking the participants through a cycle of diagnosis and analysis before moving into solution design.

All these strands of AR are key to the detailed design of the protocol for the research described more fully in section 3.2. However the most innovative and important aspect is the process of deliberative debate between citizen and state agent, and it is for this 
reason that the term Dialogic AR was adopted, defined by the characteristics summarised above.

\subsubsection{The process was designed for repeatability}

Having formulated a type of DAR as the appropriate method of research, the next challenge was to ensure the results it produced were as generally applicable as possible. Reason's identification of the importance of seeing AR as an emergent form of knowledge was key to this. The perspective of this study, described in chapter 1 , is that the whole arena of the citizen/state relationship is also emergent. It is important that the results of this study can make a contribution to this growing body of knowledge, but in a way that permits the assumptions and conclusions to be challenged and built upon.

The solution adopted was to design a 'recoverable' research process. This is the major insight from the work by Checkland and Holwell (1998) in toughening the methodological rigour of action research and the knowledge claims it produces. Drawing on 25 years of action research, they offer a systems-based model that "presents an argument for an appropriate form of validation which, though it does not match the magic of the replicability criterion in natural science, can sustain AR as a legitimate form of inquiry..." (Checkland and Holwell, 1998, p.10). They argue the positivism of the natural sciences is such a powerful paradigm because of the hypothesis-testing processes of "reductionism, repeatability and refutation", applied to phenomena that are "homogeneous through time" (they reference this description to Keynes, quoted in Moggridge (1976)).

Their reasoning is that all research entails applying a body of ideas, with a method, to an area of concern to generate learning. In positivist models the process is linear, with findings then contributing back to the original body of ideas (which usually takes the form of a precise hypothesis that can be proved or disproved). However the distinctive but also problematic issue with $A R$ is that by its nature it throws up simultaneous challenges in all these areas. The social situations investigated by AR tend to have many moving parts and cannot be homogeneous through time.

Their solution emphasises the recoverability or repeatability of the research process, enabling the development of a family of results that increases confidence overall. 
Achieving repeatability requires the prior declaration of the key themes under investigation; the method for investigation; and also the "body of ideas" that in conjunction with the method are applied to the area of concern to generate learning. Outlining these elements in advance provides the basis for a study and findings that can be replicated, or not, by others; "the absence of an insistence on this is the greatest lacuna in the literature on AR" (Checkland and Holwell, 1998, p.18).

As illustrated by the diagram used in chapter 1 to illustrate the iterative development of the study the entire approach to this thesis follows this paradigm. To be explicit chapters 1 and 2 have developed the "themes for the study" in the form of the research questions and theoretical perspective. This chapter addresses the method and, in the form of the relational evaluation framework, the "body of ideas" applied to derive learning from the fieldwork. This study is itself based on two iterations of case studies. The first, with an urban housing benefit service, helped to develop some initial tests of trustworthiness. The second tested these findings in use with a case study with a suburban GP practice. Moreover the intention is to make the method available to others for wider application within the public sector, enabling an inclusive community of inquiry to generate a growing body of evidence across a broader range of service contexts.

\subsection{The dialogic action research method in practice}

In this section I build on the principles identified above to describe more fully the specific design of the DAR method used for the fieldwork. The first part (3.2.1) discusses the detailed protocol and the second (3.2.2) describes the rationale for the selection of the case study sites. The section concludes (3.2.3) with a description of how the protocol was applied in practice for the first case study with an urban housing benefit service.

\subsubsection{The design principles for the DAR}

The sections above describe the key principles underpinning the specific form of DAR designed for the study. However at the more detailed level there remains a considerable number of issues and variables to resolve to make the approach operational. These include such practicalities as the scale and nature of the participant group, the structure of the process and the nature of the output. 
In his much-referenced essay on how to ensure quality in AR, Reason (2006) describes four key areas where choices have to be made in order to maximise the chances of success and ensure the welfare of the participants. These are clarity of purpose, participation (including research ethics), knowledge investigated and contribution to emergent knowledge. The precise DAR method was constructed to navigate these decisions in a way compatible with the research intent, and to embody the principles previously articulated in encouraging and containing open debate amongst multiple participants. These headings are used below to formulate the more detailed aspects of the dialogic process.

\section{Purpose}

Reason describes the objective of action research as "a means of using reality" (Reason, 2006 , p.191) rather attempting to represent reality. So, the first test of purpose is whether a project is designed to yield real insight that, in the words of Rorty, relates to the world in way that is "causal rather than representational" (Reason and Bradbury, 2006, p.191). In other words, will it effect real change to a real problem? However, Reason also counsels that a quality approach to AR will want to define whose purpose is being achieved in making a change, and whether the project has struck a proper balance between analysis and action.

These were important considerations for this study, partly because the central purpose, topic and process for the study were preconceived and imposed on the participants. Thereafter it was important to be as open as possible to the insight and deliberations of the participants. A number of points derived from the DAR principles were adopted to ensure this balance. The first was relatively obvious - to target a case study on a public service of which the participants would have a common experience - either as users or as service agents - and start the dialogue with an open question; simply asking the participants what factors they believed would improve the mutual trust and cooperation of users and agents of that service.

The core objective for the process was also formally agreed with the participants and senior management of the service, and was summarised in the participant consent form as: 
"The aim of the research is to explore ways of improving cooperation and trust between service users and staff of [case study organisation] in the delivery of the Council's Housing Benefit Service. The study involves groups of service users and front-line staff coming together to discuss how well the relationship works, and what actions might improve it" (Participant consent form p.1).

To underpin the creation of dialogue, the Habermassian conceptualisation of communicative action (Habermas, 1987) - of action arising from intersubjective discussion and agreement - proved useful. This captured the spirit of the study as described earlier, and also emphasised the practical importance of the "communicative space" that the study needed to create. This is the perspective offered by Stephen Kemmis in his discussion linking Habermassian critical theory to the practice of AR. Kemmis argues that creating "communicative spaces" is key to achieving the "inclusive, collective, transformative" (Kemmis, 2008, p.127) aims of AR designed to create change. Kemmis emphasises that communicative space is inherently dialogic - existing "between and beyond individual participants" (Kemmis, 2008, p.128). This account echoes those of the previous descriptions of DAR (Lorino, Tricard and Clot, 2011) in emphasising the importance of the interaction, where we encounter each other and where mutual discourse enhances the possibility of discerning truth and moral guidance.

These abstract considerations led to a number of practical steps in encouraging the creation of a productive communicative space for the study. The most important was to reinforce the point from the use of AR in conflict resolution and ensure that the DAR process started with each sub-group of participants - users and state agents - given time to work within their own groups. This was designed to enable them reach a common understanding of the issues from the perspective of that group, before the process moved into dialogue with the other group. Each group also had some prior discussion of the key issues raised by the other group. This allowed each group to enter the dialogue phase with a more collective and self-assured view of their own identity, and also with their eyes opened to the perceptions of the other.

\section{Participation and Ethics}

As Reason observes, a defining feature of a quality approach to action research is 'building democratic, participative, pluralist communities of inquiry' (Reason, 2006, p.193) 
drawn from the people affected by the issue. In addition to the earlier discussion about "situating" (Shotter, 2010) the issue of citizen/state trust within a mixed group of citizens and state agents, there were a number of other operational and ethical choices to be made in designing an AR process from this perspective. These are summarised by Reason as addressing power relations to ensure all have a voice, providing time and space for effective deliberation, challenging denial and the danger of 'consensus collusion' (a group banding together to protect its position).

Another factor for Reason is how to scale participation beyond the initial investigation to similar but broader social and political processes. In the context of this study, these issues crystallised around the issue of power, and ensuring that all had a voice, in the face of the intrinsic asymmetry in the citizen/state power relationship and the potential power of the researcher in relation to the exercise. The study needed to create a process that would enable a challenging but constructive dialogue between users that could be replicated across different studies and which would reduce the risk of 'consensus collusion'.

Gaventa and Cornwell echo this study's Foucauldian perspective on power in arguing that in the context of social research the issue requires a broad understanding of how it manifests itself (2006). The design of the DAR was in the context of trying to anticipate the "multiplicity of force relations" (Foucault, 1988, p.92) intrinsic to the citizen/state relationship and that might constrain the ability of either set of participants to engage in the discourse and, equally crucial, be able to imagine other ways of being. Applying this conceptualisation of power led to practical design choices intended to empower all participants to think and contribute freely. Allowing service users and staff to meet separately prior to collective dialogue was important. A second principle was that the participating staff group comprised only agents whose roles included regular contact with users. This excluded managers with no user contact. Both users and staff commented that this was important in liberating discussion, because it kept the focus on the user experience and change, with fewer vested interests in defending the status quo. A third principle was that the discussions should aim to achieve consensus among all participants. It was important for the researcher/facilitator to set that expectation, nurture debate and actively seek and give space for dissent. Figure 3.2 illustrates the position of the researcher in facilitating this form of DAR. 
Figure 3.2 The position of the researcher as facilitator in the process

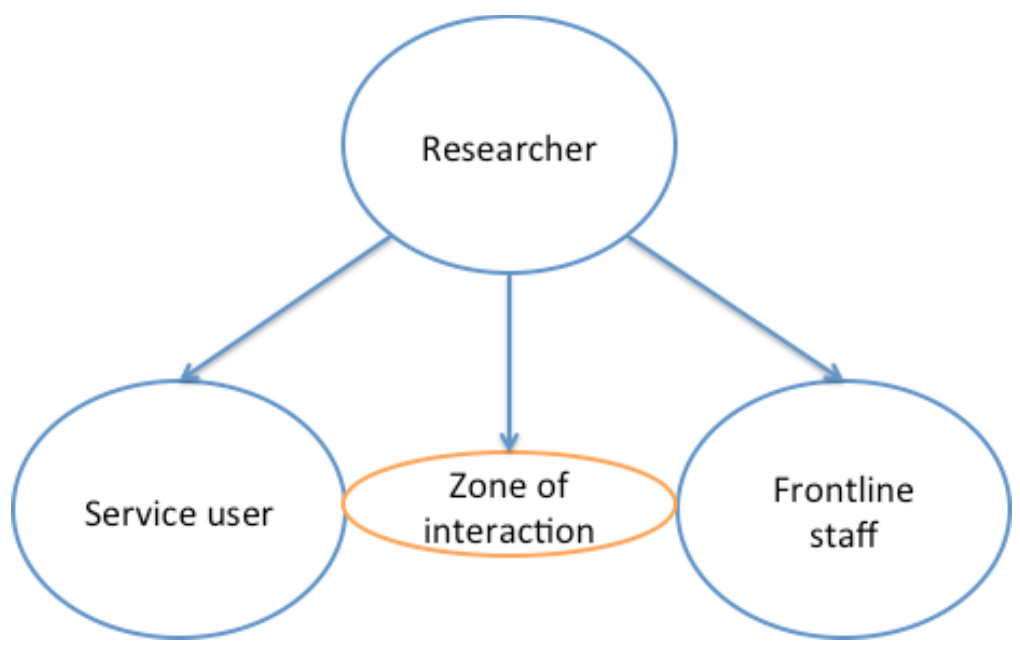

One way of doing this was for the researcher/facilitator to make extensive use of a flipchart during all the group discussions, and to pause at all key points to check the group were content with and accepted the summary of the main points being made. The slide in Figure 3.3 below was used at the beginning of each AR session as the way of explaining this approach and setting expectations. 


\section{Workshop protocol}

- The role of the facilitators is to set the questions and to help make sure everyone gets to speak. The direction the discussion takes is entirely for the group.

- We want to hear the full range of your reactions, however 'important' or apparently 'trivial'. This is an under-researched area and there is no agreement on what factors currently impact on trust and co-operation.

- We welcome strong views, and just ask that they are presented in a way that is not aggressive to others.

- We are audio and videoing the proceedings. For ease of transcription please try to give your name when speaking and avoid talking at the same time as other people. The video recording will be destroyed once the discussions have been transcribed. Your contribution will be anonymised, all participants will be identified by a unique code.

- The facilitators will record all main points on a flipchart for agreement by the group at the end of the workshop.

If you have any questions or worries please do not hesitate to give Rob a ring on 07767 400335

The ethical considerations for the process focussed on the safe and effective participation of volunteers. Securing informed consent from the participants to the research process and the recording of their discussions was a significant issue. This was secured on the basis of complete anonymity in the transcribing and reporting of the discussions. This was a condition of receiving approval from the University's research ethics committee (Appendix 2), as was written agreement from the senior manager of the Housing Benefit service. Also, before the study each participant was given a short summary of the purpose, structure and code of practice for the exercise, along with a consent form for signature. Finally the user participants were reimbursed all out of pocket expenses and offered $£ 10$ for each session they attended.

The ethical approach within the study also acknowledged the additional risks and demands posed by this particular form of DAR compared to other qualitative methods. The deliberate focus on the dynamic between citizen and state agent posed the risk of 
conflict or domination. It was also important to acknowledge that this form of DAR is demanding of participants, both in practice - in attending a number of sessions - and in terms of their emotional engagement. The groups were not just being asked their view but also to go the extra mile in proposing solutions. It is for this reason that Mary Brydon-Miller (2006, p.191) argues that AR should adopt what she calls a "covenantal" ethics - a proactive commitment to act in the best interests of the participants - as opposed to what she calls "contractual" ethics, or simply sticking to the letter of what has been agreed. Thus, the ultimate test of the ethical integrity of the process was the emotional and physical welfare of the participants, and their sense that their contribution was being acknowledged as a useful investment in the future of the service. This placed an additional demand on the process of facilitation to anticipate and resolve discomfort, partly by offering a form of mentoring outside of the formal meetings, and partly by intervening with strategies to defuse conflict in the sessions - such as by formalising moments of disagreement and inviting the whole group to contribute to the resolution of the issue.

\section{Knowledge}

The next step was to design the process to tap into the subjective and intersubjective knowledge required by the research questions. Reason (2006) articulates the design choices around this as how to surface tacit knowledge, the need for attentiveness to language and how to support the group in developing new theories and understandings, particularly through an appropriate cycle of deliberation and action.

In keeping with the earlier description of the key principles for the process the main objective was to let the participants speak for themselves, both because they are the active constructors of the evidence, and because it was in the free flow of their stories and mutual reactions that tacit as well as conscious insights could be found. From the point of view of psychology Frosh deepens the understanding of what it means for the researched to be the researcher:

"What is central here is the ambiguity in the notion of the subject: it is both a centre of agency and action (a language user for example) and the subject of (or subjected to) forces operating from elsewhere whether that be the 'crown', the state, gender race and class, or the unconscious" (Frosh, 2003, p.1549). 
This view of the subject as researcher underpins the practical advice from Clarke (2009). He suggests a number of principles that, following Holloway and Jefferson (2000), should govern the facilitation of psycho-social evidence - such as using open ended questions, and avoiding 'why' questions that might invite a clichéd response.

However it was for the researcher to distil the findings from the research. The risk in this process is that the interpretation is framed and distorted by the conscious and unconscious concerns of the researcher. Hoggett and Clarke explore this topic in their survey of psychosocial methods "Researching Beneath the Surface" (2009). Their observation is that risk can be lowered by structured reflexivity. The researcher must acknowledge and record their own feelings and thoughts, and then consider whether these have illegitimately permeated their study. Hoggett describes an associated skill of the psychosocial researcher as maintaining an attitude of openness to the process and data. In his article 'Working psycho-socially and dialogically in research' he advises the researcher "to sustain what Bion, following Keats, called 'negative capability', that is the capacity for being in uncertainties, mysteries, doubts, without any irritable reaching after fact and reason" (Hoggett et al., 2010, p. 185).

The key means for encouraging a structured reflexivity within this study was the prior articulation of the coding process and structure within the evaluation framework described later in 2.3.2. This was a systematic attempt to articulate transparently the issues on the mind of the researcher in the search for both tacit as well as conscious evidence of the deeper relational dynamics that underpinned the formal recommendations of the group. Moreover as described later in this chapter a parallel inductive process of coding further stimulated this reflexivity.

\section{Emergent developmental form}

In many ways, the final set of choices offered by Reason in pursuit of $A R$ as an emergent practice echoes the earlier advice from Hoggett. Reason emphasises the importance of viewing the research process as continuous. Insight leads to challenge and further insight in a constant process of iteration: 
"Because action research starts with everyday experience and is concerned with the development of living, situational knowledge, in many ways, the process of enquiry is as important as specific outcomes" (Reason, 2006, p.197).

Such considerations lay at the heart of the deliberative process, with the structured approach to the cycle of analysis and action designed to promote new insight by encouraging the collective exploration of the implications of key themes. Moreover the overall research approach was designed to be iterative. The second DAR case study was used to test and refine the findings from the first. Repeatability also meant the DAR method, including the structure for the evaluation, was designed to be both available to other researchers working in different services, and useful in building up a growing comparative knowledge base of results.

\subsubsection{The choice of case studies and participants}

A key decision was the choice of public services in which to conduct the DAR. The range of potential services for investigation was wide. The segmentation of public services previously described in table 1.2 illustrates the main relational dynamics for consideration. These distinguish between services that are universal or rationed, coercive or voluntary, delivered remotely or face to face, largely transactional or more relational and finally whether there is some frontline autonomy as against a prescribed process of production. A second aspect to the decision was the prevailing service situation and citizen relationship. This posed questions such as whether to target services that presented as high or low trust, and the associated question of whether a service was regarded as high performing or experiencing operational difficulties. Other operational questions were whether to select a publically managed entity or alternatively an outsourced service, and whether it was significant that a service was locally managed or part of a nationally organised provision. A final consideration was the unit of management to target - whether to focus on a specialised sub-activity within a service or look at a more holistic management entity.

A number of key criteria helped to navigate these options in selecting the two case studies: 
- The services should have a significant element of citizen interaction and contribution (in reality this did not preclude many options, including transactional services) and (just as important) be likely to generate citizen views on the relationship since this was the raw material required to answer the research question.

- It was important that the case studies offered insight into a range of trust relationships, comparing findings from situations of lower trust and higher trust.

- The two service qualities regarded as having most immediate importance to the initial case studies were to compare differences between universal and rationed services, and to explore the importance of a coercive or regulatory component in a service. By the same token the decision was taken to exclude largely digital or telephone services from the initial studies because the focus was the nature of the core relationship itself rather than the medium through which it was enacted.

- An important operational criteria was to ensure the active support of management for both objectives and process of the research - including a willingness to include as wide a range of user views as was practical and to exclude themselves from the actual DAR process if their role did not contain significant user contact (as described in the section on participation and ethics above, this was an important design principle intended to maintain focus on the user experience rather than institutional priorities, and also to encourage frontline staff to speak without inhibition). The second operational criteria was that the unit of investigation should be sufficiently broad to enable a range of views of related aspects of the service (for example including disappointed users) whilst being sufficiently discrete that users and frontline staff would be able to talk with authority and understanding about the totality of the service and the value it achieved.

The two case studies selected conformed to these criteria in providing contrasting service dynamics and contexts. The first study was of a busy urban housing benefit (HB) service. This service can be viewed as both welcome (dispensation of benefits) and regulatory (refusal to offer benefits or their withdrawal). It also contained both transactional and 
relational aspects and benefitted from user cooperation in providing accurate personal information. The overriding service concern was to find ways of streamlining the service in order to cope with the impending introduction of Universal Credit. The unit of investigation was taken to be the whole HB service for the city, in order to capture views of the overall process as well as specialised aspects of the service, and to help to ensure a heterogeneous sample of service users from across a range of social and ethnic backgrounds and service experiences. Moreover the specific HB study selected offered senior management highly supportive of the project. It also offered a rich and diverse operational context. It served a city with approximately 450,000 residents, categorised by the census of 2011 as $78 \%$ "White' British", 16\% "Black or Minority Ethnic" (BAME) and $6 \%$ "White non-British". The census recorded residents following at least 45 different religions and speaking 91 main languages. The city also contained significant areas of deprivation, with a Council study from 2015 estimating that $17 \%$ of residents suffered income deprivation, and $16 \%$ of residents lived in some of the most deprived areas of England $^{12}$. The total number of HB claimants during the period of the case study was approximately 42,000 .

The key principle guiding the selection of user participants was to ensure a wide range of views on the service from a group as representative as possible of the wider population. The approach to recruitment was necessarily pragmatic, given the limits to the number of participants dictated by the DAR method and that participation was voluntary. The main

12 Defined as amongst the most deprived 10\% of LSOAs (Lower Layer Super Output Areas) identified by the 2015 DCLG statistical analysis on "English Indices of Deprivation. (Department of Communities and Local Government, 2015) 
safeguard in ensuring a diverse group was to encourage the service in using multiple methods to publicise the initiative and seek volunteers. In the event the makeup of the participant group for the HB study reflected the broad dimensions of this demographic mix. Users were recruited via an automated phone message, by posters in the service access points and in conversation with frontline staff. Eight users participated in the study, of which three were women and five male. Three of the eight were drawn from BAME communities. They also represented a mix of service experience, including several who were able to talk about the experience of being refused benefit. Nine frontline staff participated in the study, of which three were women and two drawn from BAME communities. The staff group also contained a good range of experience of the service, including both the initial assessment and the more detailed appraisal of claims. A junior member of the housing policy team also worked alongside the researcher, supporting the production of material for the workshops, helping both to interpret the evidence and implement agreed actions. However the researcher facilitated all the group discussions.

The second case study was a group general practice in the same city. This was an example of a more universal service, and one that was highly relational. The national trends for trust in professions (Ipsos Mori, 2016) suggested that it was likely to provide evidence of a higher trust relationship, and therefore the qualities that give rise to such trust. The particular practice that volunteered for the study (and formed the unit of analysis) was regarded anecdotally as high performing, however the management group were concerned that this reputation would be put under threat unless they could find ways of managing demand more effectively. The practice was based in a locality that shared many of the same broad demographic characteristics of the overall city described above. The statistical profile of the relevant electoral ward indicated an age profile that was slightly higher on average (in the main due to fewer families with young children). It also had pockets of significant deprivation, with $12 \%$ suffering from income deprivation, although marginally lower than the city wide average. The numbers from BAME communities were also a little lower than the citywide average but all the main indicators for health (e.g. numbers with chronic long term conditions or mortality) were in line with the city average. The practice itself had grown significantly over the previous years and with seven full time doctors was midsized compared to local comparators. 
As with the HB case study the approach to recruiting patient participants was to use multiple means of recruitment to try and ensure a spread of views on the service, and a group broadly representative of the wider population served by the practice. This resulted in seven patient participants in the study. Two were recruited from the surgery's existing patient reference group, two from adverts put up in the surgery waiting room and the remainder from running a stall at one of the surgery's flu vaccination days. All but one of these participants were female and one patient was drawn from the BAME community. Two had long-term conditions that meant regular contact with the surgery, whilst the others had more intermittent requirements. As with the HB study the recruitment process was successful in attracting a spread of opinion on the service and included a number of critical perspectives. Nine staff participants were drawn from reception, administration, nursing, operations, and including a longstanding member of the GP group. All but two were female and two were from BAME communities. The patient champion employed by the surgery acted as the support to the facilitator and attended all meetings. .

Thus taken together the case studies fulfilled the criteria described above in providing insight into citizen trust in contrasting service contexts. These included differences in availability (universal or rationed), whether welcome or coerced, different degrees of frontline autonomy and different starting points in respect to the level of citizen trust. These were the main variables prioritised in the planning for this study, and given the intensive nature of the DAR process this was all that could be the pragmatically achieved. However in section 7.4 there is a further discussion of options for further case studies, such as within the services within the policing and judicial services, or services that are delivered remotely or by automatic systems. The analysis and method developed by this thesis is intended to be relevant to all, and it is hoped that others will find the approach useful across a range of public services.

\subsubsection{Applying the method with a housing benefit service in the first case study}

The graphic in Figure 3.4 illustrates the study process for the initial HB case study as it took participants through three phases of diagnosis, analysis and option development. Each phase was structured around a number of formal workshops, and it was important that the groups completed each phase before proceeding to the next. The process was 
completed over about a month, which balanced the investment of time of the participants with maintaining momentum as the group deepened their understanding of the issues.

Figure 3.4 The stages in the DAR process

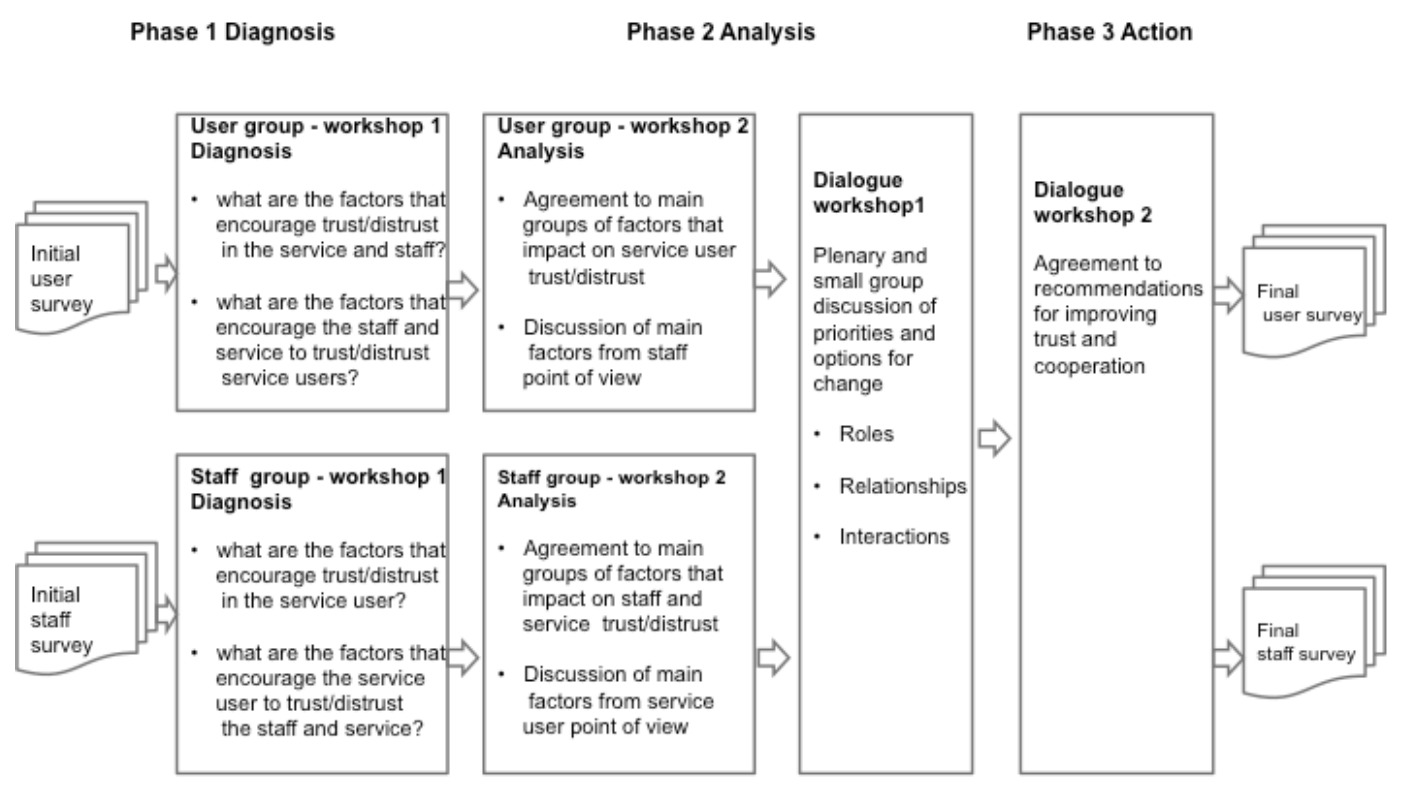

The diagnostic phase was informed by each participant completing an online survey of his or her views on the current service relationship prior to the first workshop. This asked for responses to a series of open questions on their perception of the strengths and weaknesses of the current relationship and their initial views on the key issues to address. This was used to open the analysis phase; the results for each group (user and staff) were anonymised and aggregated to form the basis for the initial discussion within each group. Subsequent workshop sessions of about two hours were video and audio recorded and subsequently transcribed. In addition, the researcher and housing policy officer captured key points on a flip chart and played back key points of agreement or disagreement within the groups. The formal output of the process was a short list of recommendations for improvement agreed by the group, with a brief analysis of the issues and discussions that led to them. This report was shared and agreed with participants before presentation to senior management. 


\subsection{The evaluation framework for data analysis}

This section describes the approach to the theory driven aspect of coding and evaluating the data gathered in the course of the DAR (there is a description of a complimentary process of inductive coding in the next section). In doing so it fulfils the second requirement for repeatability and transparency - presenting the "body of ideas" (Checkland and Holwell, 1998, p.18) that underpins the research method and findings. This body of ideas has been translated into an evaluation framework for coding and analysis.

The section starts (3.2.1) with a brief reprise of the framework structure and the key inputs from the review of existing research. Subsequent sections develop the more detailed underpinning structure of the evaluation framework under the headings of connectivity (3.2.2), agency (3.2.3) and interactivity (3.2.4). The final section (3.2.5) describes the process of coding the fieldwork data.

\subsubsection{The evaluation framework was built on the relational model}

The context for the evaluation framework is the relational model described in Chapter 1 , as further amplified by the analysis of issues from current research in the previous chapter. The intent in constructing the framework is to highlight the dynamics of the citizen/state relationship with most potential pertinence to the citizen perception of trustworthiness. The framework is constructed to be generic, offering a way of analysing the data that is comprehensive of, and sensitive to, all the main possible explanations and theories of trust and applicable in different contexts. It takes the form of a set of descriptive categories intended to act as a map of the relational terrain. In itself it is not intended to offer solutions or priorities, but rather offer the means for the identification of the factors of importance within the data. The key inputs are significant academic contributions around the dynamic dimensions of the relational model ('connectivity', 'agency' and 'interactivity') and the conclusions of the analysis of empirical issues for state trustworthiness from the previous chapter, organised under the same headings. For completeness this table is reproduced here as table 3.2 . 
Table 3.2 Summary of factors for evaluation framework from review of existing research

Factors related to
'Connectivity'

The perception of how the parties relate to each other in a citizen/state interaction
Factors related to 'Agency'

The perception of the roles and competence of each party in the execution of a citizen/state interaction

Competence
Motivation
Incentives
Fairness
Equity
Legitimacy
Personal contact
Role
Commitment
Service quality
Empowerment
Authority
Resources
Predictability
Consistency
Efficiency
Access
Responsibility
Intention
Continuity of relations

Factors relating to
'Interactivity'

The perception of the coordination and governance of what happens in a citizen/state interaction

Policy outcomes
Valency
System drivers
Process trust
Reciprocity
Consent
Entitlement
Power, and its abuse
Coordination/control
(Inter) dependency
Influence
Accountability
Redress
Fulfilment
Betrayal and revenge
Response to mistakes
Proximity

Policy outcomes

System drivers

Process trust

Reciprocity

Consent

Entitlement

Power, and its abuse Coordination/control (Inter) dependency Influence Accountability

Betrayal and revenge

Proximity

The task was to build on these inputs to organise this material into a structure that was more systematically comprehensive, generic, repeatable and integrated the related academic thinking. The important methodological point is that the evaluation categories are designed to operate at a level above any one theory or form of trust.

\subsection{2 'Connectivity'}

The 'connectivity' category of the framework concerns how citizens and state relate to each other - addressing the factors that inform the quality of the emotional and affective engagement within an interaction. These are grouped within three sub-headings following a logical deconstruction of the category. The starting point is the mutual identity that the 
participants to a citizen/state interaction understand for themselves and confer on the other, followed by the nature of their mutual affect and finally their communication with each other. The definition, scope and key concepts informing these three headings are summarised below.

\section{Connectivity and 'identity'}

The first issue posed by the conceptualisation of connectivity is the nature or 'identity' of the entities between which the connection is taking place. Identity lies at the heart of the academic discourse on the politics of recognition. Insights from this literature helped to inform the lines of inquiry that the issue posed for the study. Most key contributors to this school, such as Taylor (1989; 1991), Honneth (2007), Fraser (1989) and Tully (1994) focus on the relationship of citizen to citizen. However, many of the key concepts also hold relevance for the mutual recognition between citizen and state

In applying these the evaluation framework follows Thompson's (2006) summary of the politics of recognition in using the Honneth (1996) formulation of three separate but complimentary dimensions to recognition - love, respect and esteem. Love and respect are most relevant to the issue of identity, esteem more pertinent to affect. These concepts are captured in the framework as an awareness of the inter-subjective nature of identity and any evidence of the participants' perception that their identity is being misrepresented, negated or objectified, or that they are not regarded as "acting autonomously on the basis of rational insight" (Honneth, 1996, p.114). A practical concern is the significance to citizens of feeling that their needs and strengths are understood in the round.

\section{Connectivity and 'affect'}

The second category within connectivity is 'affect', the nature of the feelings and emotions in the relationship between citizen and state. Affect is a more individual aspect to any relationship, formed by the specificity of the mutual regard of each participant to an interaction. It is related to Honneth's conception of esteem in going beyond the universalism of equity and respect to explore a specific feeling towards another derived from their individual attributes and achievements (2007). Therefore the framework probes such issues as the importance of the citizen's sense of entitlement to a service and the 
impact of discourses of difference - such as 'strivers and shirkers' - that might be felt to diminish the esteem towards some groups of citizens. A second strand of analysis concerns the contribution made by emotion to what has been called the psychoanalytic rationality by which social phenomenon are understood (Clarke, Hoggett and Thompson, 2006). The evidence discussed in the previous chapter suggested that investigating feelings like fear, anger, alienation, compassion, friendliness, empathy and pity, would be important to this study.

\section{Connectivity and 'communicative competence'}

The final component of connectivity is communication, the effectiveness of the two-way exchange of information, knowledge and meaning. The Habermassian concept of 'communicative rationality' (1987) and the associated attributes of 'communicative competence' offer a way of categorising the components relevant to the study. These are summarised by Thomas Webler (2000) as:

- Cognitive competence - giving other people something to understand, or speaking something true.

- Speech competence - saying something understandably.

- Pragmatic competence - saying something in such a way that the intentions are recognized and appreciated for what they are.

- Role competence - coming to an understanding with another person, or using words that both actors can agree.

These competencies pose questions not just about the surface of the communication process, the language and words used, but also about the effectiveness of the process what is understood, agreed and done as a consequence. This emphasis on the quality of the communication also suggests another competency for the evaluation, that of 'active listening'. The coding of references within this subheading focussed on participant perception of these, and related issues such as language, honesty, dialogue, and understanding. 
Table 3.3 summarises how the connectivity category was conceived and applied in the evaluation framework. The issues drawn forward from the discussion of existing research in the previous chapter are grouped within the three sub-headings of 'identity', 'affect' and 'communicative intelligence'.

Table 3.3 Evaluation factors relating to 'connectivity'

\begin{tabular}{|c|c|c|}
\hline 'Identity' & 'Affect' & $\begin{array}{l}\text { 'Communicative } \\
\text { competence' }\end{array}$ \\
\hline $\begin{array}{l}\text { Respect } \\
\text { Discrimination } \\
\text { Domination } \\
\text { Subjects/objects } \\
\text { Personalisation } \\
\text { Diversity } \\
\text { Kinship } \\
\text { Culture } \\
\text { Integrity }\end{array}$ & $\begin{array}{l}\text { Empathy } \\
\text { Compassion } \\
\text { Anger } \\
\text { Friendliness } \\
\text { Dislike } \\
\text { Disapproval } \\
\text { Benevolence } \\
\text { Courtesy }\end{array}$ & $\begin{array}{l}\text { Honesty } \\
\text { Language } \\
\text { Understanding } \\
\text { Information } \\
\text { Dialogue } \\
\text { Listening and learning } \\
\text { Explaining } \\
\text { Transparency }\end{array}$ \\
\hline
\end{tabular}

\subsection{3 'Agency'}

The second dynamic dimension of the relational model is the mutual 'agency' that participants perceive themselves and the other to bring to an interaction. If 'connectivity' captures issues to do with how the participants relate to each other, then the category of agency is intended to capture issues of how they understand their operational engagement with each other.

The investigation of this area tests for the importance of such issues as service quality and performance as drivers of citizen trust. It also tests the converse consideration for citizens; whether their awareness of their own autonomy and contribution (or lack of it) is of significance to their sense of trust. The sub-headings for this aspect of the evaluation framework follow a logical thread from the 'motivation to act', the 'opportunity to act' and the 'capacity to act'. 
The 'motivation' sub-heading concerns the impulse to act; the motives of citizens engaging with the service and the motives of staff responding. This includes testing for models of behaviour like the aging but still dominant paradigm of the rational utilityseeking individual, motivated to maximise, or at least satisfice, their own return from interactions between themselves and with the state (Blackburn, 1998). This thinking is apparent in public policy that emphasises material, and often negative, incentives such as the withdrawal of benefits or services.

Modern scholarship challenges this paradigm. For example, behavioural economists emphasise the importance of habit, emotion and intuition in governing day-to-day behaviour. Such thinking can help design the citizen/state relationship, as demonstrated by the Behavioural Unit referred to earlier and other policy think tanks (Dolan et al., 2009). Social movement theory (Young, 2002) suggests that some motivation is intrinsic, better understood as being at one remove from self-interest and to do with broader social goals and shared values. Also, some radical post-structuralists question personal autonomy in the face of systems of domination and the internalisation of wider systems of thought. References were tagged to this sub-heading if they cast light on participant perceptions on the goals and integrity of a service, their own motivations in using or delivering the service and their response to rules governing the exchange.

\section{Agency and 'opportunity to act'}

The second element of agency is termed 'opportunity to act'. This seeks to understand the importance or otherwise to the perception of state trustworthiness of how the participants conceive their mutual contribution and remit. It looks at issues related to the scope of action that can be taken by either party in respect of the other. The underlying question is whether both parties consider their mutual roles to be conducive to a complimentary, dynamic and co-operative interaction. Alternatively roles may be regarded as dysfunctional, lacking balance and mutuality.

The new institutional school of organisational analysis (Fisher, 2010; Weerakkody, 2009; Lowndes, 1997) is helpful in understanding the mix of conscious and unconscious signals 
and structures that create and solidify the rules and norms that structure individual contributions. This category of analysis also asks whether citizens are seen as an asset to be effectively deployed and maximised in the delivery of collective outcomes, or are better understood as a passive bystander to the production of the service, and asked for little feedback on consumption. A related consideration for the evaluation of the data was the perception of the importance of the empowerment of state agents to respond with integrity to the needs of citizens.

\section{Agency and 'capacity to act'}

The final element of agency is the 'capacity' that parties perceive themselves to bring to the transaction. This is conceived as a mix of attributes such as the skills, knowledge, resources and personal confidence. Viewing capacity in this broad way provides a link to sociological conceptions of personal and social capital, such as that of Bourdieu (1996). Swartz (1997) characterises Bourdieu's view of the social world as one of constant struggle, with individuals adopting strategies to advance what they see as their 'interests' (widely defined to capture a broad idea of maximising 'symbolic' as well as economic 'profit'). This involves deploying various types of 'capital' (analogous to financial capital, but comprising economic, cultural, social, symbolic and statist resources) as commodities within the 'social relations of power'. Accordingly, possession (or lack) of these types of capital in relation to others helps explain the pattern of relations and action within social formations. Relevant factors for the evaluation framework to probe were how these components of capability, and particularly knowledge and expertise, were distributed between the participants, and how this affected their trust. The converse consideration was to look for evidence that systemic or individual inefficiency or incompetence might affect trust.

\section{Summary of the evaluation framework for 'agency'}

Table 3.4 summarises how the agency category was applied in the evaluation. The key concepts from the discussion above, and summary of research findings from the previous chapter are grouped within the three sub-headings of 'motivation', 'opportunity' and 'capacity', to act. 
Table 3.4 Evaluation factors relating to 'agency'

\begin{tabular}{|l|l|l|}
\hline 'Motivation to act' & 'Opportunity to act' & \\
\hline $\begin{array}{l}\text { Engagement } \\
\text { Ownership }\end{array}$ & Roles & \\
Fairness & Rules and norms for action & Competence \\
Equity & Responsibility & Efficiency \\
Incentives & Fragmentation & Expertise \\
Predictability & Authority & Resources \\
Corruption & Access & Information \\
Probity & Engagement & Service quality \\
Intentions & Commitment & Empowerment \\
& Consistency & \\
& Independence & \\
& & \\
& & \\
\hline
\end{tabular}

\subsection{4 'Interactivity'}

The final aspect of the evaluation framework explores the reciprocal dynamics of a citizen/state interaction; how positions taken by each party affect the other, and what events during the interaction influenced trust in the relationship. The focus of this element is primarily on the issues to do with the coordination and governance of the interaction, looking at the role of trust as a mechanism for the structuring of social interactions. Thus, two important considerations here are the power relations between the parties and the governance of the reciprocity between them, including issues to do with expectations and mutual accountability that might influence behaviour.

The sub-headings adopted to underpin and explore interactivity in more detail follow the distinction between 'outcomes' and 'process' derived from the discussion of public policy models in 2.1, along with a third dimension aimed at analysing the 'structure' of the interaction. The rationale for 'structure' is partly to disentangle the myriad issues that tend to be subsumed by commentators within the idea of 'process', and partly a reflection of the relational emphasis of the study. This leads to the consideration of how the interaction is framed, as well as how it is conducted and the outcomes it produces. The definition, 
scope and key concepts informing each of these three sub-headings are summarised below.

\section{The 'structure' of the interaction}

Analysing the structure of the interaction probes the nature of the formal and informal rules governing the co-ordination and decision-making within the interaction. It embraces questions around how participants perceive the rationale for the transaction, how risk and reward within the encounter are distributed, and the nature of the mechanisms by which the transaction governed.

Key concepts underpinning this aspect of the evaluation framework include the issue of 'legitimacy', exploring the importance of the participant perspective on the appropriateness of the goals of the interaction, and the expectations of each in achieving these, and how this related to a sense of entitlement to services. A related consideration for this category is the nature and effect of the characterisation of the citizen role - for example looking at evidence for the different citizen discourses such as that of the empowered or consumer citizen. A third consideration is the perception of the relationship between the individual and the collective - for example whether participants would accept a decision as appropriate and legitimate even if not necessarily in accordance with their personal interests (Fukuyama, 1995). Reflecting these issues the data was coded for references to the perception of the service offer and decisions, the importance of equity and the nature and significance of mutual expectations.

\section{The 'process' of the interaction}

The 'process' of the interaction probes how well the parties work together in enacting their role and how these dynamics can be improved. The scope includes the formal and informal, conscious and unconscious, dynamics of the exchange between citizen and state agent. The central question for the evaluation is whether participants are variously adopting co-operative, conflictual, or passive strategies for working together, and how this affects trust. For example this includes looking at instances of users wanting to influence decisions and the means for achieving this. It also means looking at how the state agents encourage compliance with processes, and in turn how the user receives these. Any 
evidence for the dynamics of reciprocity are also of interest - how the attitude or behaviour of one party impacts that of the other and vice versa.

In pursuing these themes specific topics coded to this sub-heading included anything to do with consent or dissent, including instances of complaint and how these were dealt with and resolved. Other key topics coded were perceptions of the importance of probity in the process, and the significance of any element of personal contact in the service process.

\section{The 'outcomes' of the interaction}

'Outcomes' require analysis at two levels, assessing the importance of the fulfilment of expectations at both the macro level of policy and the micro level of each individual interaction. Both are relevant to the role of trust as a co-ordinating mechanism, looking at the importance of what was actually achieved in an interaction. The twin nature of these questions goes to the heart of dual nature of state trustworthiness exposed at the conclusion of chapter 1 , that the state must reconcile trustworthiness to the collective in faithfully fulfilling the policy goals that have been set by the 'authorising public', with trustworthiness to the individual in her experience of the public service or state activity.

These themes would be manifest in coding for references that concern the perception of mutual accountability between users and frontline staff including how commitments were monitored and enforced. An important related set of questions related to the perception of the importance of service quality, and the relevance of the perception of the consequences of success or failure on both sets of participants. A specific issue was to examine whether the system of redress was seen as significant to trust and trustworthiness.

\section{Summary of the evaluation framework for 'interactivity'}

Table 3.5 summarises this formulation of the interactivity category, grouping the issues identified previously within the sub-headings of 'structure', 'process' and 'outcome' of the interaction. 
Table 3.5 Evaluation factors relating to 'interactivity'

\begin{tabular}{|l|l|l|}
\hline 'Structure' & 'Process' & 'Outcomes' \\
\hline Legitimacy & & \\
Dependency & Coordination & Valency \\
Systerdependency & Relational dynamics & Accountability \\
Entitlement & Patterns of reciprocity & Commitments \\
Mutual expectations & Cooperation/conflict & Monitoring \\
& Corruption/Probity & Redress \\
& Personal contact & Fulfilment \\
& Proximity & Service quality \\
& Consent/ control & Betrayal and revenge \\
& Power, and its abuse & Response to mistakes \\
& Influence & \\
& Proximity & \\
& Continuity of relations & \\
& & \\
\hline
\end{tabular}




\subsection{Theory driven and emergent approaches to data analysis}

The final preparatory step before the fieldwork was to anticipate the main aspects of the evaluation of the data. In the context of adopting the DAR process and evaluation framework described in previous sections, there were four main sets of data to interrogate for meaning and insight. Their nature, potential utility, and how they were evaluated is summarised below. The actual findings derived from each are the subject of the next chapter.

The first body of evidence is the formal report of the DAR process itself, produced out of the discussions and containing all the recommendations agreed by the participants. These recommendations evolved through the process of DAR. The opening sessions of the analysis phase arrived at a long list of issues from each group in response to the question "what factors would encourage you to trust the other?". Once the long list of issues had been formed and agreed, they were subsequently grouped and discussed under the three broad headings of the relational model (using the more accessible language of 'relational issues' for connectivity, 'role issues' for agency, and 'what happens' for interactivity). The final report was compiled by the researcher but was circulated to all participants for checking prior to being submitted to senior management.

The recommendations within the report were agreed in the final dialogic workshop. These were summarised within three broad themes calling firstly for "a more direct and respectful relationship", secondly for "a more joined up service" and thirdly for "more straightforward and honest interactions". As the direct testimony of the DAR participants, this report is a data set of fundamental importance. The recommendations are reproduced in full in the subsequent chapter and form the spine for the interpretation of the evidence.

The second data set was the result of applying the theory driven categories of the evaluation framework to the coding of the transcript material using the Nvivo data management tool. The entirety of over ten hours of transcript text was examined for contributions relevant to the main categories and sub-headings as described above. Each reference was also tagged for whether the speaker was a user or staff member (enabling the comparison of different viewpoints) and whether the contribution concerned the source 
talking about themselves, the 'other' group, or the process of interaction between them. This led to over a 1,000 individual references providing a body of transcript evidence within each of the nine sub-categories, separated between users and staff. This enabled a process of reflection on the key messages and the different 'voices' of the two groups within those headings. These are summarised in the next section.

The third data set, derived from an inductive process of coding for 'emergent' issues, proved a powerful and useful addition to the analysis. This involved tagging any relevant text with the specific nature of the topic to which it was referring. This was done relatively fast and free style, and responded to the immediate issue whether of major strategic significance or more tactical concerns. This process was done twice, once in parallel with the theory driven coding and then separately without reference to the theory driven headings. This helped to build up a second list of the issues that recurred throughout the discussions. There were over 65 such topics, labelled 'trust elements', and these were also compiled according to whether they were from staff or users. Reflecting on these references in the context of the theory driven framework provided a helpful amplification and challenge to the preconceived categories described above.

The final data set is my own reflections and feelings arising from the DAR process and during the subsequent evaluation. These are an important component, but are contributed with caution and discipline. They are most evident in the role of facilitator in summing up and organising the material from the group, and the judgements made within the evaluation process. These include the summary analysis of the significance and meaning of each of the 'trust elements', and in the final judgements made at the conclusion of each category of evaluation in distilling the key findings. The latter judgements were made after deep immersion in the research data, and to maintain the integrity of the contribution they are linked to the process and contents of the evaluation. Every attempt is made to ground them in the evidence; the endeavour is to ensure they are both transparent and properly reflexive.

The evidence and findings presented in the next chapter are a synthesis of all four data sets. These are analysed within the broad headings of the relational model, with each data set contributing an important dimension to the eventual conclusions. Each main 
section starts with the formal recommendations, showing due respect to the direct testimony of the participants. The theory driven and emergent coding is then used to test and amplify the significance of these. Both coding processes proved vital. In particular the emergent coding process produced insight at a level of granularity that was useful in clarifying, testing and refining the evidence from the theory driven approach. The output is a complimentary synthesis of both approaches with neither predominating. 


\section{Key themes from the initial fieldwork}

The previous chapters described the research questions, the theoretical context for investigating them, and the specific approach to a process of DAR as the research method. This chapter moves from theory to practice in presenting the findings from the initial fieldwork for the study conducted with an urban housing benefit service. In synthesising and distilling the evidence from the various data sets, a number of core themes on the factors citizens associate with a trustworthy state emerge. These take the study beyond the "performance model" of trust in emphasising relational issues such as respect and consent as well as competence in the delivery of the service.

The first section (4.1) describes the conduct of the research and summarises the evidence it produced. The subsequent three sections describe the key findings within each of the three main areas of the evaluation framework - 'connectivity' (4.2), 'agency' (4.3) and 'interactivity' (4.4). Each of these more detailed sections follows a similar structure to report findings. They start by describing the recommendations from the DAR process. They then use each of the sub-headings of the evaluation framework to provide a summary of the findings from the theory driven coding process along with a sample of relevant quotations. These are labelled according to the workshop from which they were taken. These are respectively staff or user workshops 1 and 2 (referring to the two initial workshops conducted separately with each group for the analysis phase), and dialogue workshops 1 and 2 for the two subsequent involving both groups together. Each subsection then discusses the main emergent trust elements relevant to that sub-category, before concluding with a table that summarises the main themes for the characteristic of the trustworthy state to be derived from the analysis of that topic. Finally, section 4.5 distils the main recurring factors that emerged for the qualities of the trustworthy state, which were then addressed in the second case study. 


\subsection{The types of data generated by the case study}

This section describes the conduct of the first case study (4.1.1), and the various types of data it produced (4.1.2). This provides the context for the more detailed description of the findings in the subsequent sections of the chapter.

\subsubsection{Overview of process and results}

The DAR workshops brought together eight service users and nine frontline staff for two hours, once a week for four weeks. Each participant completed an initial online survey and then met with others from their group (users and staff meeting separately) for two workshop sessions. Then the two groups met together for two workshop sessions to discuss how to improve their mutual relationship.

A personal observation is that the participants engaged well. Both groups immediately related to the topic of trust and its significance to the service and its users. Moreover, attendance was good; there was never more than one absentee from each group at each for their views on the current relationship and its strengths and weaknesses. The issues reported were taken forward to the analysis phase for discussion. The survey also asked for a number of quantitative judgments to provide context. These results are summarised in Figure 4.1 (which is taken from the formal report of the DAR). These are included to provide some indication of the participant feedback on the exercise. The survey scores concerning the substance of the relationship improved over the course of the case study. Participants also valued the actual process of the research; service users scoring the usefulness of the debate at $6.35 / 7$ and staff at $6 / 7$. 
Figure 4.1 The quantitative scores for mutual trust before and after the process

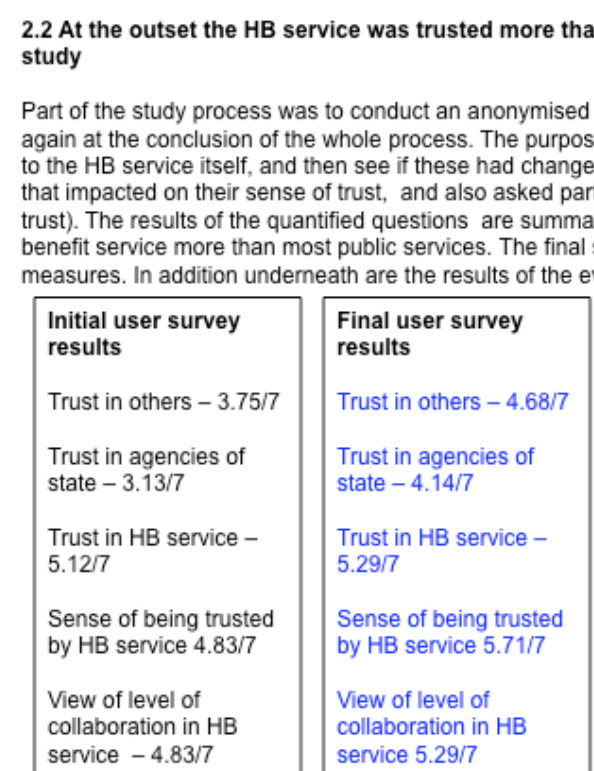

On a scale between $1-7$ (where 1 means wholly unproductive and 7 means very

productive) how useful would you say the study

process and dialogue has been?

Average service user response $6.53 / 7$

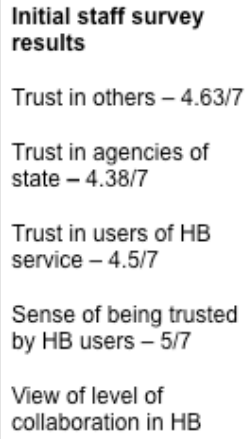

On a scale between $1-7$ (where 1 means wholly unproductive and 7 means very productive) how useful would you say the study process and dialogue has been?

Average service staff response $6 / 7$

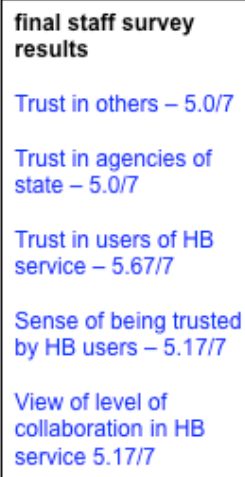

The process achieved its primary aim of generating a dialogue between a group of service users and frontline staff that the participants reported as productive. Other positive learning points included feedback that the two groups meeting separately first was useful in stimulating the subsequent dialogue. This helped to clarify the main issues, and it also allowed some of the initial user emotion to be understood and recognised before meeting staff. The passion remained but the final scores suggest it was constructively channelled into the debate. Involving a member of the service as a second facilitator was also useful. It meant that there was an 'owner' of the recommendations, who was able to take forward the changes that were agreed in the course of the exercise.

However there were also learning points for the future: 
- The process relied heavily on the facilitator to capture and shape points so that they were both clear and shared by the group.

- Four meetings over a month was a major investment of time for staff and users, with several requests to streamline the process.

- A striking number of the eventual recommendations were relatively easy to implement. But some would involve major system change outside the control of the service management who commissioned the study. Both types of recommendations were legitimate and important but differentiating between them helped manage everyone's expectations.

These learning points were built into the second phase of diagnostic testing.

The process produced a multitude of issues. The survey asked a number of open questions on participant views of the strengths and weaknesses of the current relationship, and the factors that contributed to these. The diagnostic phase worked through all these issues, and any others raised in the course of the discussions. Once they had been agreed and prioritised by each set of participants, they were then grouped within related families of issues for the analysis and action phases of the discussions. It was at this stage that the broad headings of the relational model were introduced as the means for this grouping. They were translated into language more accessible to the participants. The objective was to test whether they were useful in helping participants see common threads in the issues they had raised. The dimensions were variously described as:

- The 'role' of the participants in service delivery - the 'agency' dimension of the model.

- The 'relationship' of the participants in service delivery - the 'connectivity' dimension of the model.

- 'What happens' between the participants in service delivery - the 'interactivity' dimension of the model. 
This mapping proved relatively easy and provided a useful way of grouping related issues in the minds of the participants. For example in the first of the plenary sessions the participants were put into three smaller mixed groups of users and staff aligned with the three headings set out above. Each of these worked on the specific issues relating to that heading and produced relevant proposals. Figure 4.2 (also reproduced from the final report) illustrates how the issues were grouped for this session. The descriptions of the findings in the subsequent sections of this chapter follow this structure.

\section{Figure 4.2 The high-level mapping of case study issues within the headings derived from the relational model}

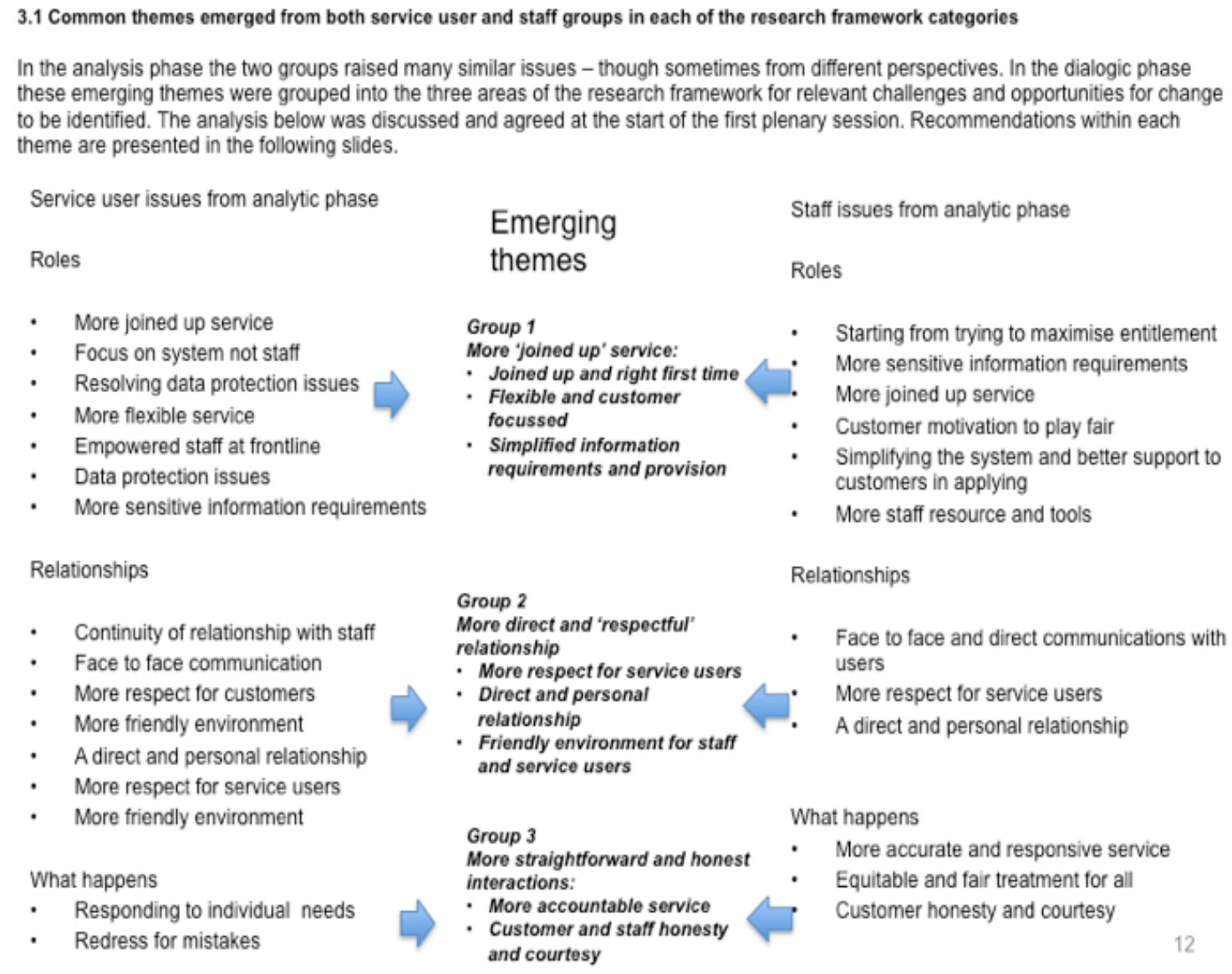

One indicator of the traction the process achieved was in a key discussion of the reciprocal relationship towards the end of the final dialogue session. The shared conclusion was that users could make a significant additional contribution to the service 
through a more energised role in voluntarily providing accurate and timely information on their circumstances as they changed. The corollary for the housing benefit service was that it would need to be trusted to be proactive in helping users to identify and receive their full entitlement to benefit. Figure 4.3 summarises this conclusion as presented in the formal report, using the categories of role, relationship and what happens.

\section{Figure 4.3 An improved service relationship as agreed by the participants}

2.1 Framing the service objective as seeking to maximise the take up of legitimate entitlement would encourage service user co-
operation

At the conclusion of the study there was broad agreement amongst the participants that the optimum relationship was one in which the role of the benefits service was framed as the proactive effort to ensure that all eligible claimants received the maximum entitlement (with the corollary of zero payments to those who were not eligible). This meant a corresponding duty on the customer to take on the role of the 'active citizen' - in this case pro-actively to provide full, accurate and timely information on their circumstances. This transaction would need to be conducted in a professional manner, as in any other service industry, with mutual respect between the parties. The recommendations in this report look at the challenges to, and ideas for, creating this systemic relationship.

The graphic below illustrates this proposition illustrating how the interaction between an 'engaged' customer and 'responsive service leads to better service outcomes. The graphic uses the headings from the relational research framework for this study to summarise the key factors participants felt would encourage this sort of mutual trust and cooperation.

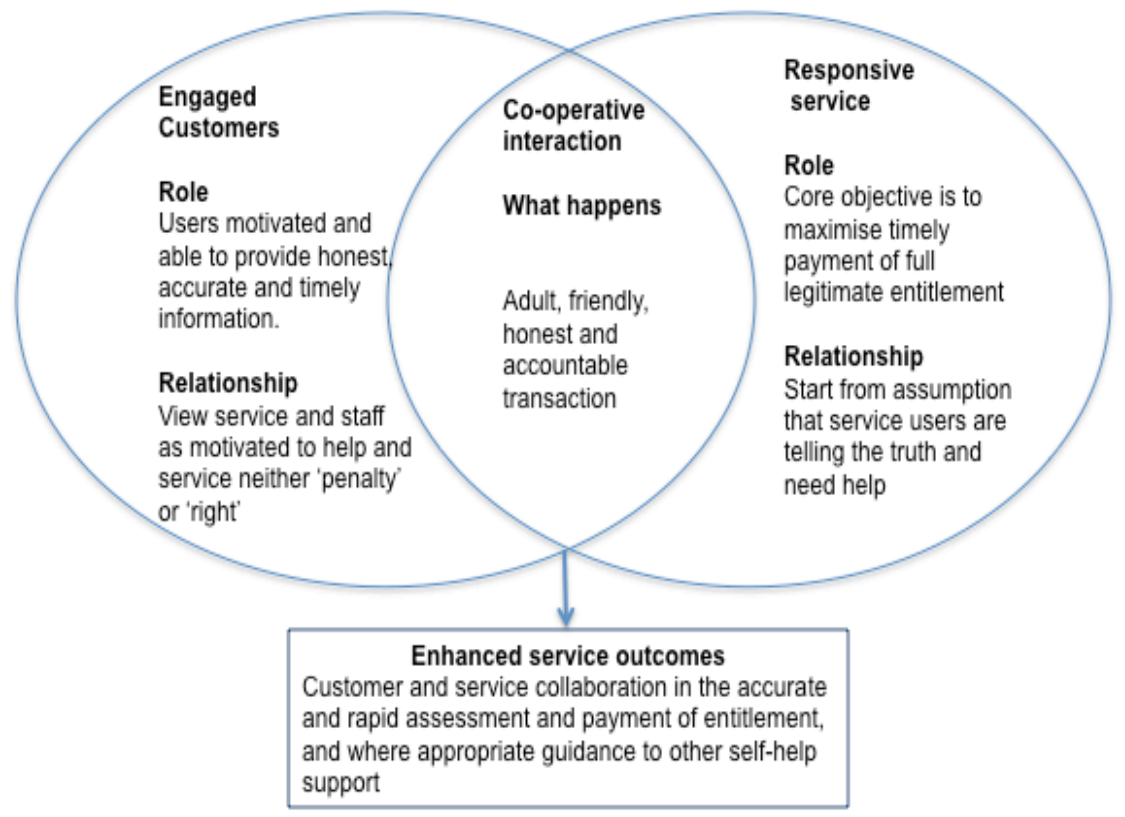

The subsequent sections of this chapter develop this overall finding. The consensus on improving the relationship was also an interesting example of the concept of co-creation of public value as the starting point of this study. Both users and staff saw the service as a transaction between citizen and service agents, and that the transaction would be better if 
users played a more effective role as both producers (providing accurate information) and consumers (satisfied they have been offered their proper and full entitlement).

\subsubsection{The study produced considerable data}

As described in the previous chapter the exercise produced a variety of data, all of which contributes to the evaluation within this chapter. The first output was a set of recommendations agreed by both groups. These were developed in the course of the workshops, and were formally agreed by the full group in the final dialogic session. These were subsequently written up in a short PowerPoint report for the senior management of the service. These were summarised within three broad themes calling for "a more direct and respectful relationship", "a more joined up service" and thirdly "more straightforward and honest interactions". That report was circulated to all participants for agreement prior to submission.

The second output from the study was transcripts of all the separate and dialogic group discussions. That produced over ten hours of transcript evidence. As previously discussed the data was evaluated in two ways. In the first, the theory driven coding of material within the headings of the relational model was used and produced over a thousand separate references. Table 4.1 summarises the number of references at the top level of the framework and whether the source was staff or user, illustrating the distribution of references between the main categories.

Table 4.1 Total number of references coded to the top-level headings of the evaluation framework

\begin{tabular}{|l|l|l|l|}
\hline & $\begin{array}{l}\text { Coding to } \\
\text { 'connectivity' }\end{array}$ & Coding to 'agency' & $\begin{array}{l}\text { 'Coding to } \\
\text { interactivity' }\end{array}$ \\
\hline Staff & 151 & 149 & 260 \\
\hline Users & 156 & 122 & 288 \\
\hline
\end{tabular}

It was not difficult to allocate between categories, although contributions were often coded to more than one category. 
The second approach to the coding was inductive and is described as 'emergent' in the analysis that follows. This led to a separate long list of 'trust elements' - the individual issues that were raised by the discourse as relevant to the user perception of state trustworthiness. There were approximately 65 such headings, from major structural issues such as 'legitimacy' to more immediate and visceral points such as 'jobsworth' behaviour. The coded references for each element were separately evaluated for evidence and then allocated to the most relevant category within the evaluation framework. Once the material had been coded, all the individual references - both theory driven and emergent - were separated to distinguish staff and users comments. The evaluation of these emergent factors was invaluable in refining and supplementing the theory driven evidence.

The findings at the conclusion of each section are derived from all these data sets supplemented by my own judgements and observations from the exercise. As one way of maintaining the integrity of those judgements they were derived from being embedded within the process of evaluation and the evidence. For example the evaluation itself was done in an immersive and iterative manner over a couple of months. The results of were recorded at length at the time, and discussed with the supervision team.

All these data sets contribute to the analysis and judgements in the next sections of this chapter. In these I describe the research findings derived from this process under the three headings of 'connectivity', 'agency' and 'interactivity'. Each section starts with a description of the formal recommendations arising from the DAR process. The deeper dynamics behind these recommendations are then analysed through the outcomes of the coding process - both theory driven and emergent - applied at the level of the evaluation framework sub-categories. Each section concludes with a table distilling key themes for the nature of the trustworthy state for that sub-category to be addressed in the second case study.

\subsection{Findings for 'connectivity'}

This section addresses the category of 'connectivity' from the evaluation framework, investigating how users and staff engaged with each other in terms of identity and emotion in the course of the service delivery. It opens by describing the overall recommendations of the DAR process (4.2.1), and then considers the evidence from the 
process of coding for recognition (4.2.2), affect (4.2.3), and communicative competence (4.2.4).

\subsubsection{The formal DAR recommendations on the theme of 'connectivity'}

Topics relevant to 'connectivity' were grouped together, using the more accessible language of 'relationships'. Users and frontline staff identified and worked on several common issues that both saw as central to trust and cooperation in this domain. They identified a 'direct and respectful' relationship between them as a key precondition for mutual trust, and made recommendations for three areas of change needed to achieve this sort of relationship. They concerned 'more respect for users', a 'more direct and personal' relationship and a 'more friendly environment' for staff and service users. Figure 4,4 provides the summary of these recommendations as recorded in the final report of the DAR. 


\subsection{Recommendations for seeking to create a more direct and 'respectful' relationship between service users and staff \\ Challenges to trust \\ More respect for service users \\ - The system is perceived to create an underlying sense of disrespect for/irritation with the customer, creating unnecessary suspicion \\ - It can seem that the assumption is that someone will not be telling the truth, or has done something wrong \\ - Claiming benefit can feel like being in an 'open prison' because of loss of personal control \\ Opportunities for better collaboration \\ - Start from assumption that people are telling the truth and more use of 'local knowledge' to target defrauders \\ - Better explanations for how decisions have been reached \\ - The service should better to reflect the social and ethnic mix of its customer, and have better customer insight and understanding of local issues \\ Potential service benefits from these opportunities \\ - Positive expectations on the customer to provide timely and accurate information should encourage compliance and reduce the rework caused by false or wrong claims \\ A more direct and personal relationship \\ - The online form and telephone system are unhelpful \\ - Face to face or personal communication is an important element of the service for both customers and staff \\ - Maintaining contact with someone you know helps to build trust \\ - Review online and phone channels with objective of improving utility and usability for customers as well as service \\ - Back up use of online systems with clarity on how customer can get personal support and advice when needed. \\ - Endeavour to provide continuity of relationships wherever possible. \\ - Continuity of relationships should lead to a more accurate and personalised service \\ - Reducing staff churn would reduce recruitment and training costs.}

More friendly environment for staff and service users

- The working environment, and reception of customers, feels unfriendly and alienating.
- Encourage closer team working and better professional and social integration of front and back office

- A 'happier' environment will encourage customer co-operation and staff satisfaction.

Below I briefly describe the rationale for these recommendations.

\section{More respect for service users}

Much of the initial user discussion was about the perception that housing benefit claimants were held 'in contempt' by the service. Users felt that the intrinsic nature of the HB service was for 'socially inferior' claimants, unable to look after themselves. They also felt that the 
service was predicated on the assumption that they were lying, and that many of the steps and checks in the application process were intrusive and designed to catch them out.

Interestingly staff participants predicted this reaction. They readily sympathised with the reasons for this impression, though they tended to blame the system rather than their own role. One powerfully felt consequence of this was a sense that the user had little traction or voice, leading to a metaphor that took hold of the system being akin to an 'open prison'.

This shared analysis led to recommendations that started to define some of the underlying aspects of a respectful transaction. The key principles were that the service should be shaped around the assumption that people are telling the truth and that decisions should be explained to the satisfaction of users. There was also a strong feeling that more effort should be placed on trying to understand the user situation, including reflecting the social and ethnic mix of service users in the recruitment of frontline staff.

\section{A more direct and personal relationship}

Both sets of participants articulated the value of having direct relationships between a user and a staff member who was felt to be accountable and responsible for the transaction, and be a continuous and known point of contact with the service. This reflected considerable frustration with more remote forms of communication such as online and automated telephone systems. However there was also recognition that such automated channels of communication were an inevitable aspect of a modern service. Consequently, the recommendations were for a more relational perspective in their use, so that all channels of communication were designed to be overseen by a single overall point of contact for the user.

\section{More friendly environment for staff and service users}

There were a number of issues around the 'emotional environment' within which the service took place. A recurring theme was that users perceived the offices and customer access points of the service as 'cold' and unfriendly, and relations within the staff group were felt to be at times hostile and dysfunctional. The staff group validated this view, though with less importance placed on it. The agreed recommendation was to make the 
working environment more sympathetic, and the need for more collaborative relations between frontline and back office was a point made by both groups.

These recommendations offer a window into some of the relational aspects of a more trustworthy state. The process of coding the evidence within the sub-themes of connectivity - recognition, affect and communicative intelligence - added colour and nuance to these findings, particularly in differentiating the voices of staff and users. I describe these findings below.

\subsubsection{Connectivity and 'recognition'}

As described previously the sub- category of 'recognition' was adopted to capture all references to 'identity', both that each party perceives in the other, and the perception of the identity that the other confers in return. 'Recognition' was particularly important to users. In analysing the findings this section follows a common template in first considering the outputs of the theory driven coding process (along with relevant quotes) and then a tabular analysis of the relevant 'trust elements' derived from the emergent coding process. It concludes with a summary of the main findings to be taken forward to the next stage of the diagnostic development.

\section{Overview of findings}

Identity emerged as one of the most troubled issues in the evaluation. The topic was addressed by both users and staff in numerous contexts; including both the general relationship and specific dimensions such as the awareness of special needs, the impact of racism and the importance of compassion. However analysing the diverse threads of the discourse indicated an underlying distinct and quite hard-edged definition of respect important to a trusting citizen/state relationship.

\section{Users}

All users felt, although to different degrees, that their identity was compromised in the eyes of the service. In their first workshop, participants spoke of being treated with 'contempt' by the service, a view generally shared. The anger expressed became 
moderated during discussions with the staff group, but it remained an important factor throughout.

User workshop 1

U1: But the thing is I just feel that they speak to you as if you're an abject moron, as if you have a low IQ and obviously they believe truly that everyone that lives in Social Housing is inferior. I actually believe that that is this Council's attitude.

\section{User workshop 2}

U8: Yeah, and confidentiality as well, the way some staff speak to you at the desk, like asking you what you want very loudly, whereas there are tens of people standing behind me. You should go in and come out without anyone know what you are there for.

Obviously people would know you are there for Benefit, but not to know exactly what you are there for.

U1: I agree with that, why don't they have separate rooms?

U8: It's like, "What are you here for?" - "Housing Benefit." "Housing Benefit" they go very loud.

\section{Staff}

The staff view was more reactive and to some extent more instrumental. References to the topic were therefore fewer in general. For staff, on the whole the issue came into focus only when raised by users in the joint workshops. However, once prompted, the frontline staff perspective was immediately sympathetic, in many ways anticipating and empathising with the user view though with less emotional intensity. There was also ambivalence in the staff view of the users, illustrated by a running debate on the extent that they could be trusted to be honest. 


\section{Staff workshop 1}

S6: I think the nature of the job and I've been in the job little less than two years and you do come in with these great ideas that are going to change the world, and within a short space of time you do, then realise the reality of the situation, and you do start looking at claims and as [S9] was saying I guess you do start to approach it from the point of view of is this an honest claim? It's probably one of the first questions that you actually ask yourself. Because you see so many examples of blatant fraud or lies or abuse. And it's trying to drill down through that and get to the genuine claims. And you do come across some really genuine people who are really on their last legs as it were. And it's being able to try and help them get up and get back on, whether they've lost a job or lost a family, wife, etc whatever. And try from an Assessor's point of view, ok this a real genuine case, I can see that, let's try and get this guy back up and running again. But it's balancing act.

\section{Staff workshop 2}

S5: Is that kind of naturally you are mistrusting of the customer or is it that there's some kind of political pressure, or kind of status quo that leads you to believe that people are less trustworthy than they actually are. Because for the most part, like, and I think you said this as well, $95 \%$ of the time the people that you are dealing with are genuinely in need of help. And there's only a very small percentage of people that are kind of trying to dupe the system. But we seem to be kind of drawn to that $5 \%$ of kind of people that we think might be yeah - untrustworthy.

S9: I'm going to disagree with the $5 \%$, it's more like $40 \%$.

S5: No way.

S9: Yes way.

S5: Wow what are you basing that on?

S9: Based on a lot of experience.

The trust components that emerged around recognition are summarised in table 4.2. The first column defines the issue and the next two summarise the different views of users and 
staff. The final column captures the essence of the finding within the topic relevant to the user perspective of trust.

Table 4.2 Trust elements relevant to 'recognition'

\begin{tabular}{|c|c|c|c|}
\hline $\begin{array}{l}\text { Trust element and } \\
\text { description }\end{array}$ & User perspectives & Staff perspectives & $\begin{array}{l}\text { Finding relevant to } \\
\text { sub-category }\end{array}$ \\
\hline $\begin{array}{l}\text { Accessibility } \\
\text { References to } \\
\text { attempts to } \\
\text { overcome systemic } \\
\text { barriers to user } \\
\text { access }\end{array}$ & $\begin{array}{l}\text { Insufficient attention } \\
\text { to the needs of } \\
\text { people with } \\
\text { disabilities, and } \\
\text { mental health } \\
\text { problems }\end{array}$ & $\begin{array}{l}\text { Limited discussion, } \\
\text { mainly focussed on } \\
\text { special needs and } \\
\text { capabilities to } \\
\text { complete form }\end{array}$ & $\begin{array}{l}\text { An important } \\
\text { component of } \\
\text { recognition is a } \\
\text { proactive } \\
\text { awareness of the } \\
\text { barriers to } \\
\text { participation }\end{array}$ \\
\hline $\begin{array}{l}\text { Confidentiality } \\
\text { References to } \\
\text { integrity of personal } \\
\text { information }\end{array}$ & $\begin{array}{l}\text { Lack of confidentiality } \\
\text { in interviews, and } \\
\text { intrusive nature of } \\
\text { information required, } \\
\text { seen as major } \\
\text { problem in own right, } \\
\text { symbolising lack of } \\
\text { respect }\end{array}$ & $\begin{array}{l}\text { Debate about the } \\
\text { sensitivity of some of } \\
\text { the information } \\
\text { required }\end{array}$ & $\begin{array}{l}\text { Confidentiality of } \\
\text { personal data } \\
\text { sensitive in itself } \\
\text { and also seen as } \\
\text { deeply symbolic of } \\
\text { the underlying } \\
\text { structure of the } \\
\text { relationship }\end{array}$ \\
\hline $\begin{array}{l}\text { Respect } \\
\text { References to user } \\
\text { identity and whether } \\
\text { regarded as } \\
\text { autonomous } \\
\text { subjects }\end{array}$ & $\begin{array}{l}\text { A key theme - initial } \\
\text { user perspective was } \\
\text { that they were } \\
\text { treated with } \\
\text { 'contempt' } \\
\text { Metaphor of service } \\
\text { as 'open prison' with } \\
\text { little control for users }\end{array}$ & $\begin{array}{l}\text { Staff awareness that } \\
\text { this was likely to be } \\
\text { the user view, but } \\
\text { less engagement } \\
\text { with issue and blame } \\
\text { attributed to 'system' }\end{array}$ & $\begin{array}{l}\text { A vital aspect of } \\
\text { trust - validation of } \\
\text { relationship } \\
\text { between two } \\
\text { subjects not } \\
\text { subject/object }\end{array}$ \\
\hline $\begin{array}{l}\text { Understanding the } \\
\text { customer } \\
\text { References to ability } \\
\text { of service to properly } \\
\text { identify and } \\
\text { understand entirety } \\
\text { of user needs }\end{array}$ & $\begin{array}{l}\text { Major issue - } \\
\text { powerful demand for } \\
\text { user's personal } \\
\text { situation to be } \\
\text { understood in the } \\
\text { round }\end{array}$ & $\begin{array}{l}\text { Aspiration to help } \\
\text { more, more holistic } \\
\text { information required } \\
\text { at start of process }\end{array}$ & $\begin{array}{l}\text { Trust requires that } \\
\text { the other } \\
\text { understands your } \\
\text { needs }\end{array}$ \\
\hline $\begin{array}{l}\text { Victimisation } \\
\text { References to fear of } \\
\text { inappropriate use of } \\
\text { power by service }\end{array}$ & $\begin{array}{l}\text { Emerged several } \\
\text { times as a perceived } \\
\text { threat, mainly around } \\
\text { challenging the } \\
\text { system rather than } \\
\text { social issues such as }\end{array}$ & Little mention & $\begin{array}{l}\text { Users worried that } \\
\text { speaking out seen } \\
\text { as trouble- } \\
\text { making; leading to } \\
\text { lower priority }\end{array}$ \\
\hline
\end{tabular}




\begin{tabular}{|c|c|c|c|}
\hline & racism & & \\
\hline $\begin{array}{l}\text { Whole person } \\
\text { References to } \\
\text { inadequate or } \\
\text { fragmented view of } \\
\text { user }\end{array}$ & $\begin{array}{l}\text { Sense that user seen } \\
\text { only as a set of } \\
\text { 'needs' - and even } \\
\text { then often partial }\end{array}$ & $\begin{array}{l}\text { Considerable desire } \\
\text { for a more rounded } \\
\text { service, for example } \\
\text { joining up information } \\
\text { on all benefits }\end{array}$ & $\begin{array}{l}\text { A wider service, } \\
\text { and broader } \\
\text { customer } \\
\text { understanding, } \\
\text { seen as key to } \\
\text { getting service } \\
\text { right first time by } \\
\text { both users and } \\
\text { staff }\end{array}$ \\
\hline $\begin{array}{l}\text { Entitlement } \\
\text { References that } \\
\text { capture the user } \\
\text { perception of the } \\
\text { basis for their } \\
\text { eligibility for the } \\
\text { service }\end{array}$ & $\begin{array}{l}\text { Strong theme of } \\
\text { users justifying their } \\
\text { claims as a right } \\
\text { Much discourse } \\
\text { about having paid } \\
\text { taxes and broader } \\
\text { contributions to state }\end{array}$ & $\begin{array}{l}\text { Staff protective of } \\
\text { public money and } \\
\text { suspicious of } \\
\text { entitlement thinking } \\
\text { amongst users }\end{array}$ & $\begin{array}{l}\text { Is service a gift or } \\
\text { a right? Basis of } \\
\text { entitlement is } \\
\text { important to form } \\
\text { of trust, and } \\
\text { indicates more } \\
\text { social perspective } \\
\text { from user }\end{array}$ \\
\hline
\end{tabular}

The range of emergent factors to do with the need to understand citizens in the round confirmed and enlarged the results from the theory that recognition and identity contribute strongly to a trusting citizen/state relationship. They were also suggestive that this recognition took on a specific form for the citizen/state relationship. Analysing these findings in the context of Axel Honneth's (1996) three-way differentiation of aspects of recognition discussed previously, respect was the most important aspiration.

However there was a strong sense that this form of respect also contains an element of 'esteem'. For users, the argument for respect went beyond a generalised view of human worth to include something closer to 'entitlement', as described in the trust elements. As an analogy it felt that the users perspective on the core relationship between them and the state had many of the qualities associated with membership of a social institution or club. Users felt they had rights as a result of having paid their taxes and following the rules. They considered themselves as active participants rather than a 'need' to be resolved. Trust required the sense that they were seen by the state as having a persona in the relationship. Table 4.3 summarises this emerging theme, and the ensuing characteristics, for inclusion within the trustworthiness diagnostic. 
Table 4.3 Key findings for 'recognition' and trustworthiness

\begin{tabular}{|l|l|l|l|}
\hline $\begin{array}{l}\text { Evaluation } \\
\text { category }\end{array}$ & Definition & Emerging themes & Characteristics \\
\hline Recognition & $\begin{array}{l}\text { The identity each party } \\
\text { perceives in the other, } \\
\text { and the perception of } \\
\text { the identity that the } \\
\text { other confers in return } \\
\text { and citizens } \\
\text { predicated on } \\
\text { 'membership model' } \\
\text { of citizenship }\end{array}$ & $\begin{array}{l}\text { Respect for users } \\
\text { language for describing } \\
\text { the identity of users }\end{array}$ \\
& $\begin{array}{l}\text { An holistic view of the } \\
\text { user }\end{array}$ \\
\hline $\begin{array}{l}\text { Services designed around } \\
\text { individual need }\end{array}$ \\
$\begin{array}{l}\text { Address structural } \\
\text { barriers to mutual } \\
\text { engagement such as } \\
\text { racism, sexism, physical } \\
\text { and mental disability }\end{array}$ \\
\hline
\end{tabular}

\subsubsection{Connectivity and 'affect'}

The second sub-category within the connectivity theme was the role of affect in the relationship, coding for any references to the emotions that each party brings to the engagement. This too offered several specific issues for both groups, though once again they were more significant for users.

\section{Overview of findings}

'Affect' and emotion emerged from the analysis as both present and important within the relationship, though again in quite a specific form. There was significant overlap with the 
issues posed by identity, including user's perception of contempt implying considerations of both recognition and affect. In fact this link suggested the important observation that the key user requirement for state trustworthiness in this context was not to be disliked. Also significant, but less powerful, both staff and users felt that emotions - particularly user emotions - were difficult territory that both parties found hard to accommodate, whilst acknowledging their presence and importance.

\section{Users}

Users identified many instances of what was regarded as 'rudeness' in the conduct of the service, both in the way the process and system worked and also the personal behaviour of frontline staff. This damaged relationships through the irritation of the moment, and also because it reinforced users' impression being held in contempt and being unimportant to the service.

\section{Dialogue workshop 1}

U1: What I'm trying to say to you is having been on the other end of it I know what it's like when someone is screaming at you telling you to F-off and f-ing this and that. But at the same time you know I think you have a terrible attitude, why do you write letters to people that are so rude? I mean for one they explain absolutely precisely nothing and secondly you get these letters saying you are in arrears, and you know full well that you're not ....

\section{User workshop 2}

U8: About a friendlier environment, like the way the staff talk to you is like being screened for drugs or something. Sometimes you feel so uncomfortable having to go in. It's just there's no smiles on the face, we need a smile. 


\section{Staff}

Conversely, staff made very little reference to whether they felt liked by users. Staff discussion on their feelings for users conveyed a more socially distanced attitude, mainly concerned with functional issues such as whether users were accurate or truthful. However there was a definite if subdued awareness of the potency of users' negative emotions, and the challenges that posed. There was also a lingering differentiation between deserving and undeserving clients.

\section{Dialogue workshop 2}

S3:... one of the things that started to resonate within me was this idea that people who are customers are so used to say that we can be very faceless, very sometimes faceless monoliths that they to encounter. These issues of where we start to - the impression that we start blaming each other. And I was thinking about that and thinking why, what makes people like me that go into the Council and work for them, with all the best intentions suddenly become this - kind of give this impression that we don't care.

\section{Staff workshop 2}

S2: The case I'm thinking of in particular was a lady on the phone, it was a twenty minute conversation and this lady was literally sobbing down the phone. I felt really bad because she was on a bus and it must be horrible. And basically we'd refused a backdate request because they'd had a previous claim. And the fundamental issue that this lady was trying to convey across was the fact that she needed to make a claim. She'd go and she'd start the claim and she had stress issues, and she'd get about four pages in and then it was just too much for her so she'd hide it. And then the rent would build up and the problem would get worse. There was a Council Tax summons involved in it. And what she was trying to say to me is 'I'm disabled, I have issues, this is too complex,' and we were still saying 'no we're not going to backdate it actually, you should have made this claim earlier. S7: But did she communicate that in writing that she had? 
S2: No, no.

S7: Well she hadn't, so how would the assessor know?

The emergent trust elements that mapped to this theme confirms the general picture that affect was important but in quite specific ways, in the main directed against negative affect rather than advocating positive relations. As before, table 4.4 captures the different voices of users and staff, with the final column showing the significance of the issue from the perspective of the user.

Table 4.4 Trust elements relevant to 'affect'

\begin{tabular}{|c|c|c|c|}
\hline $\begin{array}{l}\text { Trust element } \\
\text { and description }\end{array}$ & User perspectives & Staff perspectives & $\begin{array}{l}\text { Finding relevant } \\
\text { to sub-category }\end{array}$ \\
\hline $\begin{array}{l}\text { Compassion } \\
\text { References to the } \\
\text { extent of 'caring' in } \\
\text { the service }\end{array}$ & $\begin{array}{l}\text { Absence of } \\
\text { compassion in } \\
\text { system, particularly } \\
\text { lack of whole } \\
\text { customer } \\
\text { understanding and } \\
\text { perception of } \\
\text { inflexibility (such as } \\
\text { arbitrary suspension } \\
\text { of payments) }\end{array}$ & $\begin{array}{l}\text { Fewer references, but } \\
\text { genuine compassion } \\
\text { for 'deserving cases' }\end{array}$ & $\begin{array}{l}\text { Mutual aspiration } \\
\text { for a system that } \\
\text { starts with the } \\
\text { needs of the } \\
\text { individual and with } \\
\text { more flexibility to } \\
\text { respond }\end{array}$ \\
\hline $\begin{array}{l}\text { Empathy } \\
\text { References that } \\
\text { indicate } \\
\text { importance of } \\
\text { deep } \\
\text { understanding of } \\
\text { the individual }\end{array}$ & $\begin{array}{l}\text { Lack of empathy in } \\
\text { the service } \\
\text { Some user empathy } \\
\text { for the challenges } \\
\text { staff face }\end{array}$ & $\begin{array}{l}\text { Staff recognition that } \\
\text { service structure could } \\
\text { force suspension of } \\
\text { empathy in interests of } \\
\text { work process }\end{array}$ & $\begin{array}{l}\text { Empathy important, } \\
\text { but in a concrete } \\
\text { sense of looking for } \\
\text { understanding } \\
\text { rather than emotive } \\
\text { connection }\end{array}$ \\
\hline $\begin{array}{l}\text { Friendliness } \\
\text { References } \\
\text { relevant to } \\
\text { relational } \\
\text { 'atmosphere' }\end{array}$ & $\begin{array}{l}\text { Recurring theme was } \\
\text { the unfriendliness of } \\
\text { the environment, and } \\
\text { that staff seemed } \\
\text { cold and hostile to } \\
\text { each other }\end{array}$ & $\begin{array}{l}\text { Some awareness of } \\
\text { depersonalising } \\
\text { aspects of service, } \\
\text { and engagement with } \\
\text { user's observation } \\
\text { about staff hostility to } \\
\text { each other } \\
\text { Emotional quality of } \\
\text { the interaction less } \\
\text { valued }\end{array}$ & $\begin{array}{l}\text { Trust damaged by } \\
\text { overly formal } \\
\text { relationships with } \\
\text { user, along with } \\
\text { symbolism of drab } \\
\text { environment }\end{array}$ \\
\hline
\end{tabular}




\begin{tabular}{|c|c|c|c|}
\hline $\begin{array}{l}\text { Indifference } \\
\text { References that } \\
\text { indicate } \\
\text { differences in } \\
\text { perception of the } \\
\text { importance of the } \\
\text { service to user or } \\
\text { staff }\end{array}$ & $\begin{array}{l}\text { Perception of the } \\
\text { asymmetric } \\
\text { importance of each } \\
\text { transaction; life- } \\
\text { changing } \\
\text { consequences for } \\
\text { users contrasted with } \\
\text { service inflexibility }\end{array}$ & $\begin{array}{l}\text { Some awareness of } \\
\text { the depersonalising } \\
\text { aspects of the service }\end{array}$ & $\begin{array}{l}\text { Making each } \\
\text { transaction feel } \\
\text { important; vital to } \\
\text { users with no power }\end{array}$ \\
\hline $\begin{array}{l}\text { Courtesy } \\
\text { References to } \\
\text { manners and } \\
\text { behaviour in the } \\
\text { service }\end{array}$ & $\begin{array}{l}\text { Valued - 'rude' } \\
\text { letters particularly } \\
\text { disliked - but few } \\
\text { complaints about } \\
\text { face-to-face } \\
\text { encounters }\end{array}$ & $\begin{array}{l}\text { Valued - particular } \\
\text { dislike of pushy or } \\
\text { aggressive users }\end{array}$ & $\begin{array}{l}\text { Basic standards of } \\
\text { good manners } \\
\text { should be applied }\end{array}$ \\
\hline $\begin{array}{l}\text { Attitude to the } \\
\text { other } \\
\text { References that } \\
\text { indicate the view } \\
\text { of one group } \\
\text { towards the other }\end{array}$ & $\begin{array}{l}\text { Diverse and } \\
\text { fragmented } \\
\text { Some staff singled } \\
\text { out for praise but in } \\
\text { context of general } \\
\text { suspicion }\end{array}$ & $\begin{array}{l}\text { A sense of } \\
\text { responsibility for } \\
\text { customer balanced } \\
\text { with responsibility for } \\
\text { system } \\
\text { Worried about losing } \\
\text { humanity }\end{array}$ & $\begin{array}{l}\text { Users quick to } \\
\text { differentiate 'well } \\
\text { intentioned' staff } \\
\text { from rest }\end{array}$ \\
\hline
\end{tabular}

In different ways both user and staff contributions indicated the importance of a sort of practical empathy in the relationship. The user requirement related to trust is not to be liked, or for emotions to sway decision-making. Rather their aspiration is for sympathetic understanding - the situation and their needs being understood from their point of view. From this perspective, rudeness symbolises not just the lack of respect discussed above, but also the alienation of the service from them as individuals. Table 4.5 crystallises this theme, and the ensuing characteristics, for taking forward within the trustworthiness diagnostic. 
Table 4.5 Key findings for 'affect' and trustworthiness

\begin{tabular}{|l|l|l|l|}
\hline $\begin{array}{l}\text { Evaluation } \\
\text { category }\end{array}$ & Definition & $\begin{array}{l}\text { Emerging } \\
\text { themes }\end{array}$ & Characteristics \\
\hline $\begin{array}{l}\text { Affect } \\
\text { brings to the engagement, } \\
\text { including the warmth of the } \\
\text { regard of each party for other, } \\
\text { and the perception of how } \\
\text { regarded by the other }\end{array}$ & $\begin{array}{l}\text { The importance } \\
\text { of practical } \\
\text { relationship }\end{array}$ & $\begin{array}{l}\text { Users formally and } \\
\text { informally reassured } \\
\text { that their individual } \\
\text { needs are important } \\
\text { and understood }\end{array}$ \\
\hline
\end{tabular}

\subsubsection{Connectivity and 'communicative competence'}

The final sub-category within the connectivity theme was the quality of communication between user and service. The analysis within this heading addressed how successfully each party conveyed accurate, full, timely and persuasive information to the other. In the event effective communication was of great mutual interest, permeating discussions of staff and users throughout. 


\section{Overview of findings}

Both groups continuously identified communication problems. The cumulative impression is of fragmented and partial dialogue, with much misunderstanding and need for repetition. The sense of not being fully informed emerges as a major source of distrust. In many ways this symbolised several broader issues in the relationship, with both parties viscerally aware of the gulf, but also frustrated and unable to cut through bureaucratic systems to create genuine communication.

\section{Users}

Users highlighted the tone, language, confusing nature of written communication and the strong sense that they were not being listened to; exemplified in the perception that information once provided was not being recorded or used. A very sensitive example, arousing much passion and seen as symbolic of the relationship, was letters suspending benefits sent out after the event and without explanation. There was also underlying resentment at the seemingly patronising tone of much communication.

\section{User workshop 1}

U2: Well yes. I mean first of all perhaps if you write to people, you know, and explain why their benefits have changed and why they've gone arrears. Perhaps they'd like to explain why they've gone into arrears, not some letter that is immediately threatening when you open it. 'If you don't adhere to this, you know if you don't pay this within so and so we will take legal proceedings against you' - I find that very offensive.

\section{User workshop 2}

R: What would encourage you to trust?

U1: Well I don't think I can specifically say trust or distrust because the thing is if you phone them up with a particular query i.e. one of those awful letters, the ones in arrears, 
and there will be this if you don't do blablabla. And you'll phone them up and ask, 'Why have I had this letter in the post?' And to be honest with you they can't answer you, they can't reply. And then they'll say, 'Well actually I'm sorry,' and they'll give you some sort of gobbledy gook which you don't really understand. And I think it's deliberate. In fact I know this because I was trained to do that, so it does happen. But there's all the transferring to someone else and explaining your problem again, and they say, 'Well why were you transferred here?' And they then profess to not knowing anything about it. I found sometimes you just go around in circles....

\section{Staff}

Most staff discussion was about the difficulty of ensuring that the information provided by users was honest and accurate. However staff were also very conscious that much of the communication from the service was negative in tone, compounding the problem of getting accurate information first time. They were also conscious of internal communication problems between sections and the frustrations that caused for users.

\section{Staff workshop 2}

S3: I don't know where this point fits and I think it might fit somewhere in this section. One of the things I was thinking about was certain generic standard letters that we have, that we write to people that generate confusion. One letter that immediately springs to mind is the Council Tax Reduction letter that we send out to people. It's a generic Council Tax Reduction letter that's sent out and that generates lots of calls back in. We were saying 'this is the amount of Benefit that we are paying you.' And people saw that as a bill, they thought they were being invoiced.

\section{Staff workshop 2}

S5: Because the maximum entitlement is kind of like it's based on figures. So you can't help but offer maximum entitlement so long as you are presented with the right documentation to then do a calculation on that basis. 
S4: Sorry to interrupt but you need to ask the correct information to find out. It's about getting the right information. It's not just using the figures on the documentation, but it's working out if they're in attendance or if they're a carer that kind of thing. Asking those kinds of questions, to see if they get a premium, all those kinds of things which is obviously quite technical. It's taking that information so we can translate it properly, and to do both and maximise it and get it right.

Dialogue workshop 2 (in response to question about impact of dialogue process)

S4: ...I guess the one thing already I think differently when I'm listening to somebody on the phone. Although I have worked in a customer service environment before, when I'm on the phone now l'm really conscious, I'm thinking about the people in the room when I'm talking to the person on the phone. So yeah I'm a different story. Although I don't feel I was ever rude to anybody I just think I've got a different mind-set.

The trust components that contributed most directly to this theme along with the number of references is summarised in table 4.6. They all relate to the importance of mutual understanding and how meaning can become lost or opaque. They also point to the instinctive sense of suspicion and alienation that accompanies a lack of understanding or misunderstanding.

Table 4.6 Trust elements relevant to 'communicative competence'

\begin{tabular}{|c|c|c|c|}
\hline $\begin{array}{l}\text { Trust element and } \\
\text { description }\end{array}$ & User perspectives & $\begin{array}{l}\text { Staff } \\
\text { perspectives }\end{array}$ & Fit with category \\
\hline $\begin{array}{l}\text { Dialogue } \\
\text { References that } \\
\text { indicate the } \\
\text { presence or } \\
\text { absence of two way } \\
\text { communication }\end{array}$ & $\begin{array}{l}\text { The ability to talk to } \\
\text { someone who can } \\
\text { respond - aspiration } \\
\text { for proactive advice } \\
\text { before problems } \\
\text { occur }\end{array}$ & $\begin{array}{l}\text { Difficulties } \\
\text { imposed by call } \\
\text { times and service } \\
\text { targets } \\
\text { Major problems } \\
\text { with internal } \\
\text { comms }\end{array}$ & $\begin{array}{l}\text { Importance of being } \\
\text { able to ask questions } \\
\text { and get answers }\end{array}$ \\
\hline $\begin{array}{l}\text { Honesty } \\
\text { References to the }\end{array}$ & $\begin{array}{l}\text { Users feel they are } \\
\text { assumed to be lying; } \\
\text { the system can force }\end{array}$ & $\begin{array}{l}\text { Difficult to know if } \\
\text { user information is } \\
\text { true }\end{array}$ & $\begin{array}{l}\text { Users sensitive to } \\
\text { assumptions of } \\
\text { dishonesty, particularly }\end{array}$ \\
\hline
\end{tabular}




\begin{tabular}{|c|c|c|c|}
\hline $\begin{array}{l}\text { integrity of } \\
\text { information and } \\
\text { decisions }\end{array}$ & $\begin{array}{l}\text { you to lie because of } \\
\text { complexity and } \\
\text { 'traps' }\end{array}$ & & as starting position \\
\hline $\begin{array}{l}\text { Language } \\
\text { References to the } \\
\text { vocabulary and } \\
\text { style of } \\
\text { communication }\end{array}$ & $\begin{array}{l}\text { Complexity and } \\
\text { difficulty of technical } \\
\text { language }\end{array}$ & $\begin{array}{l}\text { Complexity and } \\
\text { difficulty of } \\
\text { technical language }\end{array}$ & $\begin{array}{l}\text { Simple and clear } \\
\text { language vital to } \\
\text { mutual understanding }\end{array}$ \\
\hline $\begin{array}{l}\text { Listening } \\
\text { References to } \\
\text { whether } \\
\text { participants felt } \\
\text { heard }\end{array}$ & $\begin{array}{l}\text { Suspicion that } \\
\text { information provided } \\
\text { is not recorded }\end{array}$ & $\begin{array}{l}\text { Users can be } \\
\text { selective in what } \\
\text { they take on board }\end{array}$ & $\begin{array}{l}\text { Need for } \\
\text { acknowledgement of } \\
\text { what is communicated, } \\
\text { otherwise messages } \\
\text { lost }\end{array}$ \\
\hline $\begin{array}{l}\text { Transparency } \\
\text { References } \\
\text { indicating how easy } \\
\text { and accessible is } \\
\text { service information }\end{array}$ & $\begin{array}{l}\text { Lack of explanations } \\
\text { for decisions } \\
\text { Fascination with } \\
\text { hidden internal } \\
\text { processes - } \\
\text { particularly the } \\
\text { impact of internal } \\
\text { call time standards }\end{array}$ & $\begin{array}{l}\text { Awareness of } \\
\text { opacity of comms } \\
\text { to users }\end{array}$ & $\begin{array}{l}\text { Understanding where } \\
\text { the other party is } \\
\text { coming from is central } \\
\text { to the decision to trust }\end{array}$ \\
\hline $\begin{array}{l}\text { Arbitrary decisions } \\
\text { References to } \\
\text { difficulties in } \\
\text { establishing the } \\
\text { rationale for } \\
\text { decisions }\end{array}$ & $\begin{array}{l}\text { Unexplained or } \\
\text { unexpected } \\
\text { decisions resented, } \\
\text { particularly where a } \\
\text { matter of } \\
\text { interpretation of } \\
\text { rules }\end{array}$ & $\begin{array}{l}\text { Awareness of } \\
\text { arbitrariness } \\
\text { (especially in case } \\
\text { of DWP), but } \\
\text { tendency to blame } \\
\text { user and less } \\
\text { conscious of } \\
\text { impact }\end{array}$ & $\begin{array}{l}\text { Decisions should have } \\
\text { explanations and prior } \\
\text { notice }\end{array}$ \\
\hline
\end{tabular}

Effective two-way communication emerges from both the theory driven and emergent evaluation as a key enabler of trusting relations, for both staff and users. Both groups acknowledged the damage done by the communication gap - derived as much from system factors and complexity as from individual misunderstanding. Staff and users believed the barrier to effective communications was systems and processes that were impervious to change even when desired by both. The key gaps were perceived to be in establishing the full information from the user needed to establish their full entitlement, 
and the lack of explanation from staff for decisions. Distrust thrived in this information vacuum. Table 4.7 summaries this finding for taking forward within the trustworthiness diagnostic.

Table 4.7 Key findings for 'communicative competence' and trustworthiness

\begin{tabular}{|c|c|c|c|}
\hline $\begin{array}{l}\text { Evaluation } \\
\text { category }\end{array}$ & Definition & Emerging themes & Characteristics \\
\hline $\begin{array}{l}\text { Communicative } \\
\text { competence }\end{array}$ & $\begin{array}{l}\text { The sense that each party } \\
\text { is able to convey } \\
\text { accurate, full, timely, and } \\
\text { persuasive information to } \\
\text { the other, and that this } \\
\text { information is received } \\
\text { and understood }\end{array}$ & $\begin{array}{l}\text { User needs to } \\
\text { understand what is } \\
\text { going on and feel } \\
\text { that they, and their } \\
\text { needs, are } \\
\text { understood }\end{array}$ & $\begin{array}{l}\text { Written explanation } \\
\text { of all major } \\
\text { decisions referring } \\
\text { to criteria used } \\
\text { Clear language, } \\
\text { designed for } \\
\text { understanding } \\
\text { Openness of } \\
\text { service and user } \\
\text { information and } \\
\text { records } \\
\text { Expectation of } \\
\text { honesty and } \\
\text { accuracy from both } \\
\text { parties }\end{array}$ \\
\hline
\end{tabular}




\subsection{Findings for 'agency'}

The second dimension of the framework concerned 'agency', conceived as the capacity of each party to act in conjunction with the other. This was described to the group as any issues that concerned the 'roles' that each was expected to play.

This section starts with a brief description of the formal outputs of the DAR process (4.3.1), and then investigates the detailed evidence from the coding of references within the evaluation framework sub categories of 'motivation to act' (4.3.2), 'opportunity to act' (4.3.3) and 'capacity to act' (4.3.4).

\subsubsection{The formal DAR recommendations on 'agency'}

Both groups had strong views on the roles they perceived as expected from themselves, and the other group. However in discussion a consensus emerged on a shared recommendation for what was summarised as 'a more joined up service'. This reflected a common frustration at service fragmentation. Processes were distributed across several participants, which disempowered users and staff. Participants' response was that trust would be generated if users and staff were empowered to get the transaction "right first time". This would be a big shift for both. The user must be motivated and able to offer the appropriate information, and the frontline staff empowered with all the information, systems and authority needed to resolve the application or issue.

This broad proposition was developed in the three areas of recommendations summarised in figure 4.5. As before I explore each area before summarising the outcomes from the data coding. 
Figure 4.5 Summary of DAR recommendations on the 'roles' of the participants

\subsection{Recommendations for Improving service user and staff roles to enable a more 'joined up' service}

Challenges to trust

Service more 'joined up' and right first time

- Fragmentation of service amongst different sections can lead to user/staff confusion, bottlenecks and errors

- Multiple requests for similar information are confusing and cause delays

- Getting it right first time means investing resources in early stages of transaction, and helping the customer to provide all the right information at the first time of interaction

More flexible and customer focused service

- Lack of understanding of full customer circumstances may impact on entitlement, and reduce ability to offer other support

- Standardised call times can lead to failure to deal with each customer on their merits

- A more customer focused service would be as flexible as possible in supporting people to improve their situation without losing benefit

\author{
Opportunities for better collaboration Potential service benefits from \\ these opportunities \\ - Continuity of contact (same team, - Continuity of contact should \\ information recorded, someone encourage more accurate \\ responsible) for all aspects of a claim, assessment (and re- \\ using colleagues as necessary \\ - Investigate whether stratifying the \\ process around hard/easy cases would \\ improve first time resolution \\ claims. More rounded jobs \\ should increase staff satisfaction \\ and retention
}

\footnotetext{
- Seek more rounded understanding of - Understanding and responding customer situation and needs, with better staff training in mental health issues

- Be able to offer proactive and accessible advice on benefits, and what is possible without impacting payments - Being able to guide users to

- Conduct study of whether use of more flexible call time targets and measuring quality/resolution might reduce rework overall

- Better staff training and retention
}

Simplifying information requirements and provision

- Complexity and personal nature of information requirements can lead to customer suspicion and error.

- Service information and letters can be hard to understand, leading to frustration with 'gobbledegook'
- Review information requirements, and how these are communicated, to make - Customer information right first easier for customer and frontline staff to time would reduce rework and understand and provide

- Investigate ability to join up and share customer information

\author{
to holistic and individual needs \\ of customers would reduce \\ wasted effort where \\ standardised response \\ ineffective \\ other sources of support may \\ help reduce demand for $\mathrm{HB}$
}

\section{Services more joined up and right first time}

Fragmented services obstruct trust, because they prevent an effective and direct relationship with someone with whom you 'can do business'. This is exemplified by user frustration at being asked for similar information at different times by different people. In the same way many staff mentioned their inability to respond to users because different parts of the process were owned in different places in the organisation. Ideally, a single staff member should be responsible for the entirety of each user transaction, including accountability for the final decision, and for explaining and negotiating this with the user. 
Both groups also felt that the service was unduly standardised, in the range of factors considered and the time allocated to each case irrespective of its complexity. Both groups wanted a more personalised service, and more proactive additional advice and support on related benefits.

\section{Simplifying information requirements and provision}

The discussion about roles also confirmed the evidence already discussed on 'communication'. The way poor communications created barriers to co-operation came in for considerable scrutiny. Users particularly complained about opaque language, a complaint readily recognised by staff, especially the lack of clarity in explaining what was required from users and what they could expect from staff. Getting different information systems to share user data was also seen as useful.

In the next sections I discuss the results of the more detailed coding of the transcript evidence to the categories of 'motivation to act, 'opportunity to act' and 'capacity to act'. It is interesting to note that while the references for connectivity arose more from users, the converse was true of agency. Agency seemed more relevant to staff. The structure of the sections follows the same approach as previously, firstly discussing the theory driven findings, illustrated with relevant quotations, and then using the emergent trust elements to test and amplify the key messages.

\subsubsection{Agency and the 'motivation to act'}

The first sub-theme of agency was 'motivation', defined as the will to act, for self and in collaboration with the other, in pursuit of the interaction. The category explored the factors that might contribute to psychological engagement in the relationship, and to identify barriers to it. Both groups made many comments on the topic, though more so in the staff group. 


\section{Overview of findings}

The perception of the motivation of the other was a particularly sensitive topic for both groups. The user discourse returned to the question of the 'real agenda' for the service in a number of contexts, both in terms of formal goals and in underlying incentives for staff. For their part staff suspicion of users 'gaming' the system was also a consistent theme.

\section{Users}

Users started from a position of vague but palpable suspicion. This was directed mainly at what they saw as the 'system'. The dominant view around the table was that the real but implicit service driver was to minimise payments to claimants. This perception was allied to sensitivity to having to claim in the context of the discourse around 'strivers and scroungers'. The response was a corresponding emphasis on fairness, and entitlement based on having paid tax. However users took a much more nuanced view of the frontline staff themselves, discussing the difference between helpful staff and those viewed with suspicion. They also wanted to understand how internal targets influenced behaviour.

\section{User workshop 2}

U8: The point is really, the whole thing is that they want to actually cut all benefits and not pay out anything.

User workshop 2

U1: Can I just point out that a lot of people claim Benefits have paid taxes in the past to pay for things like this when they need it. And I do think it comes back to this thing where they shouldn't assume that everyone sponges off the State. I mean I've worked hard and paid Income Tax and God know what else. And therefore if you do have to claim something through no fault of your own then I do think that they should be made aware of that fact. I mean I do know that having worked in the Benefit system that there is a percentage of people that are basically spongers, and you can always back it with who 
they are. But the majority of people who do come to claim Benefits are doing it because they have no real choice but to. And I think that's really important, don't you?

\section{Staff}

If anything there was even deeper ambiguity among the staff. On the positive side there was a deep discourse conducted with passion and frustration about how they would prefer to offer a much better quality of service, with a strong view that a one stop benefit service covering all state aid was the best way to help people. But there was also deep suspicion of claimants gaming the system to gain unfair additional support.

\section{Staff workshop 2}

S6: I think there's also a shift in peoples' perceptions of what Benefits are now, in terms of it's their right to receive these Benefits. Whereas before it was something which people probably another generation looked upon as being a helping hand. Whereas we know that some people make a career out of claiming Benefits, whereas that would have never happened twenty years ago.

\section{Staff workshop 1}

S2: The thing that I would like to change, ideally like to change about the way we operate is l'd like to, if you like, reverse the current mentality where I feel that our processes drive our targets, and our targets then drive the behaviours of the people trying to work within those targets, and the customers that are exposed to those behaviours, if that makes sense. So what I would like to see is almost a kind of bottom up mentality in that what we actually need to do is to start with what the customers actually need...

The emergent coding of 'trust elements' relevant to this theme exposed a number of underpinning issues summarised in table 4.8. The two that most recurred confirmed and strengthened the findings from the theory driven coding. These were references to the 
perceived hidden goals of the service and considerable emphasis on the importance of equity in service decisions.

Table 4. 8 Trust elements relevant to 'motivation to act'

\begin{tabular}{|c|c|c|c|}
\hline $\begin{array}{l}\text { Trust element } \\
\text { and description }\end{array}$ & User perspectives & Staff perspectives & Fit with category \\
\hline $\begin{array}{l}\text { Goals and } \\
\text { agenda } \\
\text { References to the } \\
\text { perceptions of } \\
\text { the underlying } \\
\text { goals of the } \\
\text { service }\end{array}$ & $\begin{array}{l}\text { Sense that service is } \\
\text { not on the side of } \\
\text { the user } \\
\text { Strong sense of } \\
\text { 'fairness' informing } \\
\text { perception of } \\
\text { entitlement }\end{array}$ & $\begin{array}{l}\text { Awareness of tension } \\
\text { between process } \\
\text { requirements and the } \\
\text { outcomes for some } \\
\text { applicants, for example } \\
\text { impact of call times etc } \\
\text { Evidence of } \\
\text { differentiation between } \\
\text { 'deserving' and } \\
\text { 'undeserving' customers }\end{array}$ & $\begin{array}{l}\text { Understanding the } \\
\text { drivers and } \\
\text { motives for action } \\
\text { is key to trusting } \\
\text { the other. } \\
\text { Suspicion and } \\
\text { mistrust emerges } \\
\text { from ambiguity }\end{array}$ \\
\hline $\begin{array}{l}\text { Ownership } \\
\text { References that } \\
\text { allude to the } \\
\text { sense of } \\
\text { responsibility of } \\
\text { the participants }\end{array}$ & $\begin{array}{l}\text { Low ownership of } \\
\text { service process and } \\
\text { need to collaborate, } \\
\text { mitigated by } \\
\text { acceptance of } \\
\text { difficulties for front- } \\
\text { line staff }\end{array}$ & $\begin{array}{l}\text { Desire to be managed } \\
\text { and measured on } \\
\text { outcomes rather than } \\
\text { speed of process }\end{array}$ & $\begin{array}{l}\text { Ownership of role } \\
\text { and sense of } \\
\text { responsibility is } \\
\text { strongly influenced } \\
\text { by perception of } \\
\text { what is required to } \\
\text { achieve targets }\end{array}$ \\
\hline $\begin{array}{l}\text { Fairness and } \\
\text { Equity } \\
\text { References to } \\
\text { whether } \\
\text { decisions are } \\
\text { perceived to be } \\
\text { appropriate, } \\
\text { credible and } \\
\text { justified }\end{array}$ & $\begin{array}{l}\text { Equity of huge } \\
\text { importance } \\
\text { Very sensitive to } \\
\text { partial treatment or } \\
\text { decisions and what } \\
\text { looks like unfair } \\
\text { outcomes even if } \\
\text { within process }\end{array}$ & $\begin{array}{l}\text { Fairness mainly seen as } \\
\text { operating the rules } \\
\text { Staff lament lack of user } \\
\text { understanding of rules }\end{array}$ & $\begin{array}{l}\text { Transactions being } \\
\text { seen to be carried } \\
\text { out objectively and } \\
\text { fairly is vital to trust }\end{array}$ \\
\hline $\begin{array}{l}\text { Service rules } \\
\text { References to the } \\
\text { core regulations } \\
\text { in respect of } \\
\text { decisions over } \\
\text { benefit levels }\end{array}$ & $\begin{array}{l}\text { Surprisingly little } \\
\text { complaint about the } \\
\text { level of benefits } \\
\text { Intense frustration at } \\
\text { the complexity of } \\
\text { system and } \\
\text { apparent }\end{array}$ & $\begin{array}{l}\text { Acute awareness of how } \\
\text { complexity and } \\
\text { intrusiveness of system } \\
\text { impacts the user } \\
\text { relationship }\end{array}$ & $\begin{array}{l}\text { Users accept rules } \\
\text { if rational and } \\
\text { explained; hostile } \\
\text { otherwise }\end{array}$ \\
\hline
\end{tabular}




\begin{tabular}{|c|c|c|c|}
\hline & $\begin{array}{l}\text { arbitrariness of } \\
\text { regulations }\end{array}$ & & \\
\hline $\begin{array}{l}\text { Service targets } \\
\text { References that } \\
\text { concern the } \\
\text { overall incentives } \\
\text { within the service } \\
\text { and the priorities } \\
\text { these imply }\end{array}$ & $\begin{array}{l}\text { Internal incentives } \\
\text { and drivers hidden, } \\
\text { and a source of } \\
\text { great fascination } \\
\text { Eager to understand } \\
\text { the impact on } \\
\text { service - e.g. } \\
\text { average call times }\end{array}$ & $\begin{array}{l}\text { Major complaint is that } \\
\text { most targets are about } \\
\text { efficiency and process, } \\
\text { not outcomes } \\
\text { Strong sense that targets } \\
\text { create perverse } \\
\text { inefficiencies (e.g. an } \\
\text { incentive to put people } \\
\text { back in the queue rather } \\
\text { than resolve issues) }\end{array}$ & $\begin{array}{l}\text { Another key area } \\
\text { of misalignment in } \\
\text { context of trust in } \\
\text { eyes of both staff } \\
\text { and users } \\
\text { Impact is to } \\
\text { incentivise staff to } \\
\text { put people back in } \\
\text { process rather } \\
\text { than resolve }\end{array}$ \\
\hline
\end{tabular}

This analysis confirmed the importance to trust of the perception of the motivation of the other. In the coding process issues of equity and the perception of fairness came to the fore. The central issue was whether the offer to the individual was appropriate in the context of what was offered to others. Interestingly both groups feared that the other group was in some way 'gaming' the system to gain an unjustified 'advantage'. This focus on equity resonated with several associated themes discussed elsewhere including issues of consent and legitimacy. Table 4.9 summarises the analysis.

Table 4.9 Key findings for the 'motivation to act' and trustworthiness

\begin{tabular}{|c|c|c|c|}
\hline $\begin{array}{l}\text { Evaluation } \\
\text { category }\end{array}$ & Definition & Emerging themes & Characteristics \\
\hline $\begin{array}{l}\text { Motivation } \\
\text { to act }\end{array}$ & $\begin{array}{l}\text { The will to act, for } \\
\text { self and in } \\
\text { collaboration with } \\
\text { the other }\end{array}$ & $\begin{array}{l}\text { Importance to trust of } \\
\text { understanding the } \\
\text { motives that drive the } \\
\text { other party } \\
\text { Key for users is } \\
\text { transparency of goals } \\
\text { for the service and }\end{array}$ & $\begin{array}{l}\text { Clear service mission } \\
\text { (maximise entitlement or } \\
\text { minimise payments?) } \\
\text { Transparent rules, } \\
\text { processes and targets } \\
\text { driving behaviour }\end{array}$ \\
\hline
\end{tabular}




\begin{tabular}{|l|l|l|}
\hline & fairness of provision & $\begin{array}{l}\text { Gain agreement of users to } \\
\text { major decisions (and } \\
\text { acknowledging and } \\
\text { resolving disagreement) }\end{array}$ \\
\hline
\end{tabular}

\subsubsection{Agency and 'opportunity to act'}

The second sub-theme within 'agency' explored how the parties felt about their 'opportunity to act' in the course of an interaction - the scope and importance of the role required of them. This was a topic found relevant by users and staff equally.

\section{Overview of findings}

Both users and frontline felt their role to be inadequate and disempowering in transacting with the other. A prerequisite for trusting relationships was an empowered user dealing with an empowered frontline agent. The theory driven coding provided numerous examples of mutual frustration at the fragmentation of frontline line authority because it prevented the immediate resolution of the issue at hand, reducing the user sense of agency in turn.

\section{Users}

The user role was perceived ambiguously. Discussions often described users as passive and reactive, simply responding to requests or demands from staff. On the other hand both staff and users recognised that users had the key role of integrating HB with other relevant state services, like other benefits or welfare provision. Users understood and sympathised that staff were often similarly disempowered. 
User workshop 2

U5: ... but it seems the Benefits department weren't chatting to the rents, and the rents weren't chatting to the Council Tax, and they still left my account open in [address] where we used to live, because I'm saying I'm in rented. Whereas at [address], you know, there's no point. As soon as I get the letter saying this, I just walk out the front door, walk around to [service point] and pick up a number and sit down and wait and get it sorted.

\section{User workshop 1}

U1: Well I think really its true yes. I think the front line staff should have a lot more support from their superiors. I get the feeling that they don't.

U4: Absolutely they do not.

U1: That's the impression that I have. And I mean I just feel so sorry for those people working there.

U4: And they get blamed for a lot of things that has nothing to do with them.

\section{Staff}

Staff were also acutely aware of the fragmentation of the service, for themselves and users. Staff consistently wanted to provide a more empowered service at the first point of contact, to provide a comprehensive response to the user, integrating and co-ordinating information across the system to make sense of it for each individual. The inability of staff to explain DWP letters suspending payments was a particularly sensitive example.

\section{Dialogue workshop 2}

S2: But what you do get going back to what [S10] was saying if you don't get it right the first time, you get wrong, or if you get it half right, and it's like one man and his dog trying to herd sheep into this kind of thing at the other end of the field, the pen, and we can't quite see where we're going and the people at the CSP are trying to do their bit and the 
back office are trying to do their bit. And it just seems to me that if we had the time and the staff to say people, what is it that you need, tell me about it, tell me about yourself, tell me about this complaint, tell me that situation - right, now I understand, I've understood that, I've sorted that, now I can anticipate what my colleagues in the back office will need, what information is required, if I have the time to work the Department of Work and Pensions to link it with what's actually happened. If I had the time to do that to start you get the impression that we care a little bit more. I'd enjoy my job, because everyone I've spoken to I've been able to - not joke and laugh and not take it seriously, but just that human interaction I suppose.

\section{Staff workshop 2}

S3: When you think of the complexity sometimes, the very nature of the complexity there is a certain proportion of our customers that when faced with something complex will just automatically switch off. Sometimes they ignore the requests. Sometimes the interaction over the telephone we spend as much time as we are able to trying to simplify what to us seems really simple. We deal with people who have made mortgage applications and other applications, sometimes there is an element of our customers that generally if there are more than three things we are asking for the same letter, that to them is really complex. Sometimes it's just driving around the fear of what is complex. It's interesting that we've identified that, it would be interested to see if they saw it as being complex. Because a lot of what we do we think is quite simple, self-employed notwithstanding. But a lot of the conversation we have we're kind of thinking this is really simple, but they're finding it really complex.

Several emergent trust elements related to this category of the analysis. The most numerous references were to the perceived fragmentation of the service, consistent with the theme running throughout this section of the analysis. There were many associated references to the complexity of the system and the difficulties this created. Table 4.10 summarises the heading and references relevant to the sub-theme. 
Table 4.10 Trust elements relevant to 'opportunity to act'

\begin{tabular}{|c|c|c|c|}
\hline $\begin{array}{l}\text { Trust element } \\
\text { and description }\end{array}$ & User perspectives & Staff perspectives & Fit with category \\
\hline $\begin{array}{l}\text { Fragmentation } \\
\text { References to } \\
\text { ways in which } \\
\text { disparate } \\
\text { responsibility and } \\
\text { processes } \\
\text { intrude on } \\
\text { relationship }\end{array}$ & $\begin{array}{l}\text { Frustration at } \\
\text { fragmentation of all } \\
\text { benefit services, } \\
\text { especially HB - } \\
\text { particularly around } \\
\text { multiple requests for } \\
\text { info and multiple } \\
\text { letters }\end{array}$ & $\begin{array}{l}\text { Frustration at } \\
\text { fragmentation of all } \\
\text { benefit services, } \\
\text { especially HB - } \\
\text { particularly around } \\
\text { multiple requests for } \\
\text { info and multiple letters }\end{array}$ & $\begin{array}{l}\text { Trust requires a } \\
\text { holistic view of } \\
\text { service with key } \\
\text { players } \\
\text { empowered to join } \\
\text { up pieces in } \\
\text { collaboration with } \\
\text { the other }\end{array}$ \\
\hline $\begin{array}{l}\text { Joined up Govt } \\
\text { References that } \\
\text { spoke of the need } \\
\text { for a more } \\
\text { coherent and } \\
\text { integrated service }\end{array}$ & $\begin{array}{l}\text { Aspiration for joined } \\
\text { up benefits service }\end{array}$ & $\begin{array}{l}\text { Aspiration for joined up } \\
\text { benefits service }\end{array}$ & $\begin{array}{l}\text { Trust requires a } \\
\text { holistic view of } \\
\text { service with key } \\
\text { players } \\
\text { empowered to join } \\
\text { up pieces in } \\
\text { collaboration with } \\
\text { the other }\end{array}$ \\
\hline $\begin{array}{l}\text { Queuing } \\
\text { References that } \\
\text { indicate impact of } \\
\text { waiting for the } \\
\text { service }\end{array}$ & $\begin{array}{l}\text { Getting through to } \\
\text { the service is } \\
\text { frustrating whether } \\
\text { on phone or } \\
\text { physically }\end{array}$ & $\begin{array}{l}\text { Conscious of } \\
\text { frustration of users }\end{array}$ & $\begin{array}{l}\text { Queuing users } \\
\text { without } \\
\text { explanation or } \\
\text { apology seen as } \\
\text { symbolic of } \\
\text { asymmetric power } \\
\text { relationship }\end{array}$ \\
\hline $\begin{array}{l}\text { Understanding of } \\
\text { the service internal } \\
\text { processes } \\
\text { References that } \\
\text { illustrate the } \\
\text { perceptions of how } \\
\text { internal processes } \\
\text { and procedures } \\
\text { might shape roles } \\
\text { and behaviours }\end{array}$ & $\begin{array}{l}\text { Desire for better } \\
\text { understanding of } \\
\text { service background } \\
\text { as well as precise } \\
\text { internal service } \\
\text { targets }\end{array}$ & $\begin{array}{l}\text { Many references to the } \\
\text { users' lack of } \\
\text { understanding of } \\
\text { purpose and workings } \\
\text { of service }\end{array}$ & $\begin{array}{l}\text { Both parties' } \\
\text { aspiration for } \\
\text { better user } \\
\text { understanding and } \\
\text { sympathy for the } \\
\text { internal targets } \\
\text { and mechanics of } \\
\text { delivery }\end{array}$ \\
\hline $\begin{array}{l}\text { System complexity } \\
\text { References that }\end{array}$ & $\begin{array}{l}\text { A major issue for } \\
\text { structure of } \\
\text { interaction- }\end{array}$ & $\begin{array}{l}\text { System complexity a } \\
\text { major theme - } \\
\text { particularly in terms of }\end{array}$ & $\begin{array}{l}\text { Both parties share } \\
\text { mutual view of } \\
\text { system as over- }\end{array}$ \\
\hline
\end{tabular}




\begin{tabular}{|l|l|l|l|}
\hline $\begin{array}{l}\text { relate to where } \\
\text { undue demands of } \\
\text { system complicate } \\
\text { relationship }\end{array}$ & $\begin{array}{l}\text { complexity of rules } \\
\text { and process gets in } \\
\text { the way of user } \\
\text { empowerment and } \\
\text { cooperation }\end{array}$ & $\begin{array}{l}\text { information asked for } \\
\text { User fascination with } \\
\text { internal incentives as } \\
\text { way of understanding } \\
\text { what going on }\end{array}$ & $\begin{array}{l}\text { engineered and } \\
\text { getting in the way } \\
\text { of cooperation }\end{array}$ \\
& & & \\
\hline
\end{tabular}

This analysis confirmed the importance to users' trust of the capacity of the state agent to fulfil the transaction fully and successfully. This identifies a key link between trust and power, but this is less about inequality in the relations and more to do with the capacity of each party to fulfil their role effectively in the eyes of the other. The finding here is that cooperation and mutual trust thrives where an empowered user transacts with an empowered provider. Obstacles to this were perceived to be the diffusion of responsibility across multiple state functions and the disempowerment of the frontline agent dealing with the user issue. Table 4.11 below summarises this finding.

Table 4.11 Key findings for the 'opportunity to act' and trustworthiness

\begin{tabular}{|l|l|l|l|}
\hline $\begin{array}{l}\text { Evaluation } \\
\text { category }\end{array}$ & Definition & Emerging themes & Characteristics \\
\hline $\begin{array}{l}\text { Opportunity } \\
\text { to act }\end{array}$ & $\begin{array}{l}\text { The scope and } \\
\text { importance of the } \\
\text { role that each } \\
\text { party plays in the } \\
\text { transaction }\end{array}$ & $\begin{array}{l}\text { The need to empower } \\
\text { frontline service delivery } \\
\text { agents, giving them } \\
\text { responsibility (in the eyes } \\
\text { of users) for the success } \\
\text { of the relationship }\end{array}$ & $\begin{array}{l}\text { All users should have a } \\
\text { single named point of } \\
\text { contact responsible for } \\
\text { their experience of the } \\
\text { service }\end{array}$ \\
\hline
\end{tabular}




\begin{tabular}{|l|l|l|}
\hline & & $\begin{array}{l}\text { behalf of user } \\
\text { (caseworker system) }\end{array}$ \\
& & $\begin{array}{l}\text { Simplify service } \\
\text { processes and reduce } \\
\text { fragmentation }\end{array}$ \\
& & \\
\hline
\end{tabular}

\subsubsection{Agency and 'capacity to act'}

The final sub-theme within the 'agency' category was 'capacity to act'. Coding material to this heading explored whether both parties felt they had the appropriate resources and skills needed to fulfil their role. Users and staff both made many references to their own perceived capabilities, and the capabilities of the other.

\section{Overview of findings}

Staff and users both had reservations about the capabilities of the other to fulfil their role in the transaction. However both groups also understood that the complexity of the service, and lack of resources and time, made this difficult. Both groups agreed on the need to improve this by further empowering frontline case workers to resolve as many issues as possible first time round. For example, frontline staff should be able to work through each initial claim with the applicant, investing more time up front explaining the service and the information required, and if possible calculating their entitlement immediately.

\section{Users}

Users differentiated between staff they felt had appropriate skills and experience, and others they felt had more limited understanding. They were critical of high staff turnover and suspicious of the training for new staff. They also perceived that frontline staff had little support from managers. Users prized empathy and understanding, with less discussion of the technical process of assessment. Users' perception of their own skills was coloured by frequent references to the over-complex system and its obscure 
requirements. They felt patronised by a system perceived to be much more difficult and complex than it need be, and they felt insufficiently supported for their part in the transaction.

\section{User workshop 1}

U3:....People who are on $£ 40,000$ a year, $£ 25-30,000$ a year don't comprehend that somebody who is on $£ 4,200$ a year, $£ 80$ a week disability, whatever it is, the idea that on a Friday morning before that cheque arrives that you still have money to jump in a taxi, come down town and sort - 'Can you come down the office and sort something out?'. No you can't. And why do you feel lethargic? It's because you've got up, or that person has gotten up and all they've had is a plate of Weetabix, they haven't had fruit and vegetables and the next day they'll get up and have Weetabix and they might have toast for tea. And all of that wears people down.

\section{Dialogue workshop 1}

U2: And one other point was in terms of the system is so complex that basically it becomes a problem for the first time user. If it has been simplified with respect to focusing on in terms of the user values, it will enhance the performance levels. It could also enhance focus, it could also give value to in terms of the first time issue. So the basic system with trying to interact all the things, we found that the most important thing was the system needs simplification. If the system is simplified it will eventually give rise to enhanced service levels.

\section{Dialogue workshop 2}

U4: How long have you been working here?

S9: I've been in [Town] for seven years.

U4: And how about you? 
S7: A number of years.

U4: You see for me that sounds like doctors, my old doctor retired and I had to find a new doctor and every doctor I saw in there were like children that just finished medical school or something. I know they have all the latest up-dates but they have no other skills that I need. So I would personally move to find the right doctor, because l'm quite happy with somebody who has been in their job for a few years, they have some practical sense as well as some medical sense. And there is a big difference between practical sense and the sense of whatever of your situation that you're working as an assessor. So he has this practical sense, he knows exactly what he's doing but that's his job and he has to look things as well in a practical way...

\section{Staff}

Staff also recognised that the system was dauntingly complex in places, and that this made it difficult for the user. Examples were the difficulties in maintaining accurate records for the fluctuating incomes of the self employed, the difficult language of some of the standard letters, and the "clunkiness" of online systems seemingly designed with neither user nor staff in mind.

\section{Staff workshop 1}

S4: Where we're talking about distrust we're not just talking about the claimant being dishonest, it's the fact of their lack of knowledge and confidence in providing us with information. Now I think we'll be a bit disingenuous to ourselves on the benefit side here. We have counter intuitive mechanisms to build that trust, we don't review claims, we don't look at claims as often as we'd like. So touching on what [S9] says we've go into the (47.54 inaudible) mentality, because we know full well that if we would pry further back, we're going to find discrepancies on peoples' claims. So I think to make clear, it's not just [S5] s concern, l'm not saying they're necessarily dishonest, we're just distrustful in the competence of the claimant to provide us with up-to-date information. 
Dialogue workshop 1

S2: More awareness of the system is needed by the customers, because we have this thing where customers are coming in and they don't even know whether they're not entitled or if they're entitled or what they have to do. And straight away if they got some kind of information, an overview given to the customer before they start, this idea that the customer can come and find out things before they change their claim and their circumstances. So more awareness of how the system operates is needed by the customer as well as by the staff in the system.

The emergent coding confirms the importance of competence to trust, and conversely that suspicion of each other's capabilities effects cooperation. Many of the issues identified also corroborate the finding that the complexity of the system - this time in the context of the skills required by both groups to navigate it - was perceived as a key cause of mutual disempowerment. Table 4.12 summarises these.

Table 4.12 Trust elements and the 'capacity to act'

\begin{tabular}{|c|c|c|c|}
\hline $\begin{array}{l}\text { Trust element } \\
\text { and description }\end{array}$ & User perspectives & Staff perspectives & Fit with category \\
\hline $\begin{array}{l}\text { Accuracy } \\
\text { References } \\
\text { concerning the } \\
\text { precision and } \\
\text { integrity of the } \\
\text { process and } \\
\text { decisions }\end{array}$ & $\begin{array}{l}\text { Key to equity of } \\
\text { service } \\
\text { Concern that } \\
\text { 'objective' } \\
\text { assessments } \\
\text { conceal value } \\
\text { judgements }\end{array}$ & $\begin{array}{l}\text { Key to equity of service } \\
\text { Concern that system } \\
\text { encourages users to be } \\
\text { inaccurate }\end{array}$ & $\begin{array}{l}\text { Both parties see } \\
\text { accuracy as key } \\
\text { test of competence }\end{array}$ \\
\hline $\begin{array}{l}\text { Staff competence } \\
\text { References that } \\
\text { allude to the skills } \\
\text { of staff to enact } \\
\text { their role }\end{array}$ & $\begin{array}{l}\text { The key staff } \\
\text { competences } \\
\text { desired were } \\
\text { listening and } \\
\text { recording } \\
\text { information } \\
\text { accurately }\end{array}$ & $\begin{array}{l}\text { The key staff } \\
\text { competencies were } \\
\text { asking the right } \\
\text { questions and } \\
\text { recording information } \\
\text { accurately } \\
\text { User competence } \\
\text { questioned in } \\
\text { maintaining accurate } \\
\text { information }\end{array}$ & $\begin{array}{l}\text { Competence a key } \\
\text { theme, seen as a } \\
\text { prerequisite for trust } \\
\text { and one that both } \\
\text { parties returned to } \\
\text { constantly }\end{array}$ \\
\hline
\end{tabular}




\begin{tabular}{|c|c|c|c|}
\hline $\begin{array}{l}\text { Customer lack of } \\
\text { skill } \\
\text { References to } \\
\text { specific user } \\
\text { capability } \\
\text { problems }\end{array}$ & $\begin{array}{l}\text { A sensitive area - } \\
\text { regarded largely as } \\
\text { a fault of an overly } \\
\text { complex system }\end{array}$ & $\begin{array}{l}\text { An important area - } \\
\text { regarded largely as a } \\
\text { fault of an overly } \\
\text { complex system }\end{array}$ & $\begin{array}{l}\text { A major area for } \\
\text { improvement - } \\
\text { particularly in } \\
\text { constructing helpful } \\
\text { systems }\end{array}$ \\
\hline $\begin{array}{l}\text { Customer } \\
\text { understanding of } \\
\text { service process } \\
\text { References that } \\
\text { talk to the } \\
\text { importance of user } \\
\text { understanding }\end{array}$ & $\begin{array}{l}\text { Keen interest in } \\
\text { understanding more } \\
\text { about the } \\
\text { technicalities of how } \\
\text { the service delivered }\end{array}$ & $\begin{array}{l}\text { Consensus that more } \\
\text { effort up front to explain } \\
\text { the service rules and } \\
\text { how it works would } \\
\text { help everyone }\end{array}$ & $\begin{array}{l}\text { The user getting } \\
\text { transparency of the } \\
\text { production process } \\
\text { was one of the } \\
\text { main gains from the } \\
\text { research according } \\
\text { to participants }\end{array}$ \\
\hline $\begin{array}{l}\text { Information } \\
\text { References to the } \\
\text { role and } \\
\text { importance of } \\
\text { information to the } \\
\text { relationship }\end{array}$ & $\begin{array}{l}\text { Complexity of } \\
\text { information } \\
\text { requirement is a } \\
\text { problem, along with } \\
\text { knowing who keeps } \\
\text { records and of what } \\
\text { Wish for more } \\
\text { holistic information } \\
\text { on benefits } \\
\text { generally }\end{array}$ & $\begin{array}{l}\text { Complexity of } \\
\text { information } \\
\text { requirement is a } \\
\text { problem, along with } \\
\text { suspicion of user ability } \\
\text { to provide }\end{array}$ & $\begin{array}{l}\text { The nature of the } \\
\text { relevant } \\
\text { information, and } \\
\text { how this is provided } \\
\text { and kept, } \\
\text { particularly } \\
\text { contentious }\end{array}$ \\
\hline $\begin{array}{l}\text { Resources } \\
\text { References to the } \\
\text { impact of } \\
\text { availability of all } \\
\text { resources on the } \\
\text { service }\end{array}$ & $\begin{array}{l}\text { Interest and concern } \\
\text { at time limits in } \\
\text { service process }\end{array}$ & $\begin{array}{l}\text { Focus on how limits to } \\
\text { resourcing (numbers of } \\
\text { cases per staff as well } \\
\text { as time limits per } \\
\text { transaction) prevents } \\
\text { building of both user } \\
\text { and staff capabilities }\end{array}$ & $\begin{array}{l}\text { Key constraint on } \\
\text { the service, but } \\
\text { many instances of } \\
\text { waste and abuse } \\
\text { meant that it was } \\
\text { less respected as } \\
\text { reason for service } \\
\text { problems than } \\
\text { might be the case }\end{array}$ \\
\hline $\begin{array}{l}\text { Training } \\
\text { References to the } \\
\text { need for additional } \\
\text { skill development } \\
\text { for staff and users }\end{array}$ & $\begin{array}{l}\text { Perception that little } \\
\text { provided }\end{array}$ & $\begin{array}{l}\text { Perception that training } \\
\text { kept to a minimum, and } \\
\text { mainly around technical } \\
\text { issues rather than } \\
\text { overall user experience }\end{array}$ & $\begin{array}{l}\text { Both user and staff } \\
\text { training an } \\
\text { important topic }\end{array}$ \\
\hline $\begin{array}{l}\text { Waste and } \\
\text { inefficiency }\end{array}$ & $\begin{array}{l}\text { Users identified } \\
\text { waste as evidence }\end{array}$ & $\begin{array}{l}\text { Staff very aware that } \\
\text { incentives drove them }\end{array}$ & $\begin{array}{l}\text { Waste seen as } \\
\text { symptomatic of }\end{array}$ \\
\hline
\end{tabular}




\begin{tabular}{|l|l|l|l|}
\hline $\begin{array}{l}\text { References to the } \\
\text { perception of } \\
\text { flawed or } \\
\text { redundant } \\
\text { processes }\end{array}$ & $\begin{array}{l}\text { for a wider lack of } \\
\text { competence that } \\
\text { undermined } \\
\text { underlying trust }\end{array}$ & $\begin{array}{l}\text { to short term actions } \\
\text { (putting people back in } \\
\text { the system) that would } \\
\text { lead to longer term } \\
\text { costs }\end{array}$ & $\begin{array}{l}\text { dysfunctional } \\
\text { elements of } \\
\text { relationship }\end{array}$ \\
\hline Common sense & $\begin{array}{l}\text { Main complaint was } \\
\text { around flawed or } \\
\text { duplicated } \\
\text { processes, creating } \\
\text { distrust of process } \\
\text { References to } \\
\text { characteristics of } \\
\text { the service held to } \\
\text { be manifestly } \\
\text { illogical }\end{array}$ & $\begin{array}{l}\text { Main complaint was } \\
\text { around fragmented } \\
\text { internal processes and } \\
\text { in users } \\
\text { misunderstanding of } \\
\text { instructions }\end{array}$ & $\begin{array}{l}\text { Distrust arises } \\
\text { where aspects of } \\
\text { the rules or process } \\
\text { are manifestly } \\
\text { inappropriate }\end{array}$ \\
\hline $\begin{array}{l}\text { System problems } \\
\begin{array}{l}\text { References that } \\
\text { relate to where } \\
\text { system } \\
\text { incompetence } \\
\text { complicates } \\
\text { relationship }\end{array}\end{array}$ & $\begin{array}{l}\text { Problems are } \\
\text { identified mainly } \\
\text { with waste and } \\
\text { asymmetric nature } \\
\text { of system rules }- \\
\text { e.g. multiple } \\
\text { requests for same } \\
\text { information and } \\
\text { clawing back of } \\
\text { money without } \\
\text { notice }\end{array}$ & $\begin{array}{l}\text { Staff awareness of } \\
\text { problems matched by } \\
\text { impotence to rectify } \\
\text { system }\end{array}$ & $\begin{array}{l}\text { A big issue for staff } \\
\text { in particular, } \\
\text { fragmentation and } \\
\text { lack of usability } \\
\text { blamed for poor } \\
\text { service }\end{array}$ \\
\hline
\end{tabular}

The perception of competence, of self and the other, emerges from this study as an important and basic component of trust and trustworthiness in the state. For users, competency concerns both the system and the individual. Users sought more than just an instrumental capacity to resolve the immediate issue, although important. Users also sought a more holistic intelligence and perspective in how the design and working of the system itself. Obvious wastage or inefficiency was a source of distrust because seen as symbolic of a deeper incompetence and lack of care within the entirety of the service, not just the area immediately affected. Table 4.13 captures this finding. 
Table 4.13 Key findings for the 'capacity to act' and trustworthiness

\begin{tabular}{|c|c|c|c|}
\hline $\begin{array}{l}\text { Evaluation } \\
\text { category }\end{array}$ & Definition & Emerging themes & Characteristics \\
\hline $\begin{array}{l}\text { Capacity to } \\
\text { act }\end{array}$ & $\begin{array}{l}\text { The availability of the } \\
\text { appropriate resources } \\
\text { and skills needed by } \\
\text { each party to fulfil } \\
\text { their role in the } \\
\text { transaction }\end{array}$ & $\begin{array}{l}\text { Providing both staff and } \\
\text { users with the tools and } \\
\text { skills to do the job - } \\
\text { systems designed and } \\
\text { simplified around the } \\
\text { frontline transaction } \\
\text { A key objective was to } \\
\text { provide the information, } \\
\text { knowledge and systems } \\
\text { such that frontline staff } \\
\text { could resolve issues } \\
\text { immediately and directly } \\
\text { with the user }\end{array}$ & $\begin{array}{l}\text { Mutually accessible } \\
\text { best practice } \\
\text { guidance available to } \\
\text { both staff and users } \\
\text { Align information and } \\
\text { knowledge systems } \\
\text { with needs of } \\
\text { frontline } \\
\text { Test of system } \\
\text { competency is to } \\
\text { achieve 'first time' } \\
\text { resolution of issues } \\
\text { User and staff } \\
\text { training }\end{array}$ \\
\hline
\end{tabular}

\subsection{Findings for 'interactivity'}

The third dimension of the evaluation framework concerned the exploration of the process of 'interaction' in the course of the service delivery. The focus was on issues of reciprocity, power, and mutual influence in understanding the relational dynamics at play within the immediate moment of a service interaction, and how the behaviour of each party affected the other. This category was described to participants as understanding 'what happens', or how the relationship plays out in practice. The expectation was that this category would 
overlap with connectivity and agency. It would amplify and corroborate the priorities for action within those headings as they were reflected in the conduct of an interaction, as well as offering new insights on what makes for the governance of a trustworthy interaction.

As before, I start by describing the formal outcomes of the action research process (4.4.1), and then describe the coding evidence within the sub-categories of the 'structure of interaction' (4.4.2), the 'process of interaction' (4.4.3), and the 'outcomes of the interaction' (4.4.4).

\subsubsection{The DAR recommendations on the theme of 'interactivity'}

There was a strong emotional response from users to questions of control, or the lack of it, in how the service was delivered and how this impacted on trust. Discussion directly addressed some of the underlying user issues already surfaced about opaque decision making, the difficulty of getting answers to questions, and users feeling they could not influence the service. Staff difficulties in responding to users effectively also emerged. There was a shared frustration that 'the system' undermined the participants' ability to collaborate.

Discussion led to the theme of encouraging 'straightforward and honest' interactions'. This was discussed in terms of the transparency of the 'system' and also in personal relationships of mutual courtesy and honesty. The relevant page from the formal report is reproduced in figure 4.6 . 
Figure 4.6 The formal recommendations in respect of 'what happens'

\subsection{Recommendations for creating the conditions for more straightforward and honest interactions in practice between service users and staff}

Challenges

More accountable service

- Lack of customer or frontline staff transparency and control over status of cases can be frustrating.

- Little redress for service errors feels unfair

- Lack of customer leverage over service, including delays, can lead to suspicion and lack of $\mathrm{co}$ operation

Customer and staff courtesy and honesty

- It can feel like the system is set up to make customers lie because of complexity

- Lack of customer understanding of rules can lead to defensive behavior - fear of losing out

- Timely provision of accurate user information is key to the effective working of the service

- Some customers can feel they have a right to 'play the system'
Opportunities for better collaboration

- Enable frontline to set timescales and SLAs for all key transactions with the customer, and monitor delivery

- Consider meaningful redress for customers subject to errors or delays

- Seek better co-ordination with DWP, and other relevant depts. and external agencies
Potential benefits for service and customer

- Customer and frontline staff 'in control' of transaction should lead to less frustration and time occupied with complaints
- Offer more support to customers in providing the right information (including better training for frontline staff)
- Create a friendlier and more private environment for discussing customer information
- Make more visible the expectations on people to provide accurate information and consider ways of strengthening user incentives to be honest.

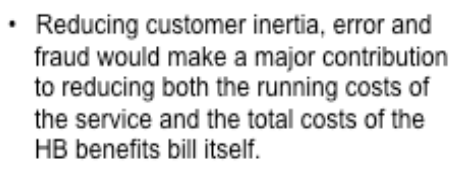
fraud would make a major contribution to reducing both the running costs of the service and the total costs of the $\mathrm{HB}$ benefits bill itself.

\section{More accountable service}

Users felt they had little control or purchase over the process or the outcome of their claim. They felt passive participants in the service despite potentially life changing consequences for them. The staff validated this. They also felt little authority or ability to track transactions on behalf of the customer, or deal with some of the other crucial agencies such as the DWP. This shared frustration led to common agreement that there should be a clearer statement of the service process and standards so that both sides would share common expectations of each other. Fair redress in the event of service failure was also considered important. 
A key area of discussion was that mutual trust also placed an obligation on users to provide honest and timely information; all accepted this. However some users felt it fair to be "economical" with the truth if the system itself was set up to penalise claimants "unfairly". The conclusion of the discussion was general acceptance that reframing the service positively - with the overt objective of ensuring the maximum user take-up of all legitimate entitlements - would encourage greater user honesty.

The sections below discuss the results of the coding of the data to the sub-categories of the evaluation framework covering the 'structure', 'process' and 'outcomes' of the interaction. Topics investigated included perceptions of the intrinsic nature of the relationship implied by the service, topics and metaphors for how the interaction was governed and worked, and insights into the strategies employed by each group for influencing the other.

The next three sections follow the same approach, as previously, firstly discussing the theory driven findings, illustrated with relevant quotations, and then using the emergent trust elements to test and amplify the key messages.

\subsubsection{The 'structure' of the interaction}

The first category within interactivity relates to the perception of the conscious and unconscious 'structuring' of the interaction, potentially illuminating the way the role of each party relates to the other. A particular focus was to maintain awareness to references to power and reciprocity during the transaction. The number of references recorded was roughly equal between users and staff.

\section{Overview of findings}

No single simple 'paradigm' of the underlying relationship as perceived by both sets of participants emerged. However, several recurring themes spoke of a transactional and at times dysfunctional relationship. One theme was an underlying sense of the role of the user being largely passive, unless called upon for specific information specified by the 
service. The asymmetric power relationship between users and staff compounded this passivity. The image of the service as an 'open prison', with users as the inmates fundamentally trapped though given the occasional 'day pass' gained traction with both groups as a harsh but understandable metaphor for the service. However also woven into this critical discourse was a theme of consumerism, for example in users feeling entitled to certain standards of behaviour and service and comparing their experience with other financial service such as banking or insurance.

This complex picture combines competing elements of user domination and agency. One reflection is that it felt like a relationship in transition. It manifestly contains some of the elements of a traditional bureaucracy, but an unrelieved caricature of an instrumental indifference does not feel entirely accurate. However, the sharp edges of the bureaucratic paradigm are softened as much by the cultural lack of deference from the user group also recognised by the staff group - as by the efforts of the service to adopt a more holistic approach. One final observation of note was the very limited reference to democracy as a factor in creating trust in the service or its management.

\section{Users}

Users clearly felt that they were not the important players in the interaction. Their comments indicated they felt their presence was more a set of "needs" to be dealt with rather than an individual with whom to engage. They wanted a more sympathetic service, offering advice not merely a purely transactional function. In the context of power and reciprocity the discourse pointed to an underlying sense of being in a relationship structured by dependence rather than interdependence - a perception given powerful articulation by the metaphor of the open prison.

Dialogue workshop 1 (staff member reporting on small group discussion with both users and staff)

S2: And there was a feeling that sometimes you go in to Customer Service Points or ring us up and it's almost kind of like '(sigh) What do you want? What are you here for?' And there was a brilliant comment that [U8] did make was that sometimes being on benefits is like being in an open prison. It kind of makes us the gaolers if you like. But we were 
saying it's not as bad as being locked up with the serial killer, but it's that kind of fact that it feels like I'm in prison, I'm stuck in the system and how does that feel to the people who use it and how do we come across even if it is an open prison, are we coming across as gaolers?

\section{Dialogue workshop 1}

U3: One of the points is there was a thing again about the flexibility about when people make life changing decisions about whether they take on a job, whether they move to a different address, having that ability to be a little bit more flexible when people come to us and say rather than this has happened and now l've fallen into this trap, come to us and say well if I move here, what's the likely impact? If I take this job, what's the likely impact? If I move my partner in with their children or whatever, what's the likely impact? And I'll make that decision based upon what's going to happen to me, rather than l've done it and now l've fallen into this trap and l've been suspended.

\section{Staff}

Staff were often focussed on their own role in the transaction, with less time in the sessions spent discussing the nature of the user. They reflected some elements of a 'consumerist' model for the transaction, but the predominant sense was of users as passive recipients of unilateral decisions arrived at by the service. This is eloquently illustrated by staff worries that they were driven by the system to a relationship that was primarily about managing process and demand rather than serving the individual.

\section{Dialogue workshop 2}

S3: And I'll be honest with you, I know I can do a better job if I had the time to do it. And I know that sometimes I shouldn't do it, but sometimes I'm thinking you come in in the morning and you get the email saying 'your average target, you've achieved 457 seconds, you need to work on your call time.' When I deal with that seven seconds that can make such a fundamental difference to peoples' lives. And I'm starting to feel a loss of sense of 
who I am since I started doing this job. And I think that's something you've kind of reflected.

\section{Dialogue workshop 2}

U6: Would you like to be the boss?

S9: When I am looking at the job I do it is that I am the boss. I make the decisions that affects people's lives. It's a very responsible job. You have to take account not just of revelations but their circumstances. So in a sense I am the boss.

U6: It is a responsibility and you're directly affecting somebody's life.

Below is the summary analysis of the trust elements most relevant to this theme. They offer an interesting mix of issues that relate both to perceptions of the overall structure and context of the interaction, and in addition how the structure is perceived to work in practice. The references to issues such as 'gaming the system' and 'legitimacy' offer a window into the complex but real nature of the reciprocity between users and the service.

Table 4.14 Trust elements that relate to the 'structure of the interaction'

\begin{tabular}{|l|l|l|l|}
\hline $\begin{array}{l}\text { Trust element and } \\
\text { description }\end{array}$ & User perspectives & Staff perspectives & Fit with category \\
\hline $\begin{array}{l}\text { Legitimacy } \\
\text { References that } \\
\text { behaving } \\
\text { inappropriately }\end{array}$ & $\begin{array}{l}\text { Appropriateness of } \\
\text { process largely } \\
\text { unchallenged, but } \\
\text { validity of decisions } \\
\text { problematic }\end{array}$ & $\begin{array}{l}\text { Appropriateness of } \\
\text { questions or process } \\
\text { largely unchallenged } \\
\text { Lie detector seen as } \\
\text { illegitimate }\end{array}$ & $\begin{array}{l}\text { Importance of } \\
\text { validity of service } \\
\text { function and } \\
\text { decision making in } \\
\text { eyes of users } \\
\text { illegitimate }\end{array}$ \\
$\begin{array}{l}\text { Politics } \\
\begin{array}{l}\text { References that point } \\
\text { to role of political } \\
\text { discourse in } \\
\text { relationship }\end{array}\end{array}$ & $\begin{array}{l}\text { Main reference is to } \\
\text { national politics and } \\
\text { discourse of } \\
\text { 'scroungers' }\end{array}$ & $\begin{array}{l}\text { Politics generally } \\
\text { seen as unhelpful in } \\
\text { leading to short-term } \\
\text { and arbitrary } \\
\text { changes in priorities }\end{array}$ & $\begin{array}{l}\text { The impact of } \\
\text { political discourse } \\
\text { is significant but } \\
\text { cultural }\end{array}$ \\
\hline Customised Service & Individual needs & Staff desire to offer & Importance of a \\
\hline
\end{tabular}




\begin{tabular}{|l|l|l|l|}
\hline $\begin{array}{l}\text { References to } \\
\text { importance of } \\
\text { acknowledgement of } \\
\text { user individuality }\end{array}$ & $\begin{array}{l}\text { being understood in } \\
\text { the round comes up } \\
\text { repeatedly as a test } \\
\text { of whether the } \\
\text { service 'cares' }\end{array}$ & $\begin{array}{l}\text { an individualised } \\
\text { service is genuine - } \\
\text { tempered by } \\
\text { awareness of } \\
\text { limitations imposed } \\
\text { by system }\end{array}$ & $\begin{array}{l}\text { service that } \\
\text { responds to the } \\
\text { individual } \\
\text { requirements of } \\
\text { each individual } \\
\text { user; essential to } \\
\text { getting it right first } \\
\text { time }\end{array}$ \\
\hline $\begin{array}{l}\text { Feferences to the } \\
\text { importance of } \\
\text { adaptability in the } \\
\text { service }\end{array}$ & $\begin{array}{l}\text { Main concern is with } \\
\text { flexibility in } \\
\text { interpreting rules } \\
\text { and short term } \\
\text { decisions on } \\
\text { benefits }\end{array}$ & $\begin{array}{l}\text { Aspiration to deal } \\
\text { with greater range of } \\
\text { benefits - and } \\
\text { provide more } \\
\text { comprehensive } \\
\text { service but not really } \\
\text { more flexibility }\end{array}$ & $\begin{array}{l}\text { Key issue is } \\
\text { discretion to fix } \\
\text { unintended } \\
\text { consequences } \\
\text { within service } \\
\text { rules }\end{array}$ \\
\hline $\begin{array}{l}\text { Gaming the system } \\
\begin{array}{l}\text { References to } \\
\text { strategies for } \\
\text { manipulating } \\
\text { outcomes in favour of } \\
\text { a particular result }\end{array}\end{array}$ & $\begin{array}{l}\text { A sense of } \\
\text { legitimacy in gaming } \\
\text { the system where it } \\
\text { was perceived to be } \\
\text { designed to trick, or } \\
\text { in the interests of a } \\
\text { 'proper' result }\end{array}$ & $\begin{array}{l}\text { A sense that a large } \\
\text { number of users } \\
\text { blurred the } \\
\text { boundaries where } \\
\text { their self interest } \\
\text { was at stake }\end{array}$ & $\begin{array}{l}\text { Both parties seem } \\
\text { to expect a certain } \\
\text { amount of low } \\
\text { level gaming - but } \\
\text { not deliberate } \\
\text { fraud }\end{array}$ \\
\hline
\end{tabular}

Two conclusions emerge from this analysis. The first supports the importance of respect, courtesy, and empathy already discussed in the connectivity section. The second confirms the theoretical discussion in Chapter 2 that there can be a deep and complex relationship between power and trust, and that a useful way to think about the working of power in this respect is through the concepts of dependence and interdependence. The image of the service as an open prison speaks to the importance to users of feeling they have some traction in the interaction.

The recommendation from the DAR that addresses this specific problem was the suggestion for a formal statement of the expectations that each party could have of the other in the conduct of the service. If sufficiently specific, this would empower users to understand the structure of the service and give a concrete basis on which to argue their case. This is indicative of a more active form of trust rooted in a concrete understanding of mutual obligations. Table 4.15 summarises the point. 
Table 4.15 Key findings for the 'structure of the interaction' and trustworthiness

\begin{tabular}{|l|l|l|l|}
\hline $\begin{array}{l}\text { Evaluation } \\
\text { category }\end{array}$ & Definition & Emerging themes & Characteristics \\
\hline $\begin{array}{l}\text { of } \\
\text { interaction }\end{array}$ & $\begin{array}{l}\text { The perception of the } \\
\text { unconscious and } \\
\text { structuring' of the } \\
\text { interaction, illuminating } \\
\text { the way the role of } \\
\text { each party relates to } \\
\text { that of the other }\end{array}$ & $\begin{array}{l}\text { Interactions built around a } \\
\text { meaningful statement of } \\
\text { reciprocal rights and duties, } \\
\text { creating a structure of } \\
\text { interdependence and } \\
\text { reciprocity notwithstanding } \\
\text { asymmetric power } \\
\text { relationships }\end{array}$ & $\begin{array}{l}\text { Published } \\
\text { standards for } \\
\text { service processes } \\
\text { and criteria for } \\
\text { decisions }\end{array}$ \\
\hline
\end{tabular}

\subsubsection{The 'process' of interaction}

The second dimension of the interactivity category was the 'process' of interaction. This explores what factors, if any, were important to citizen trust in the way each party engages with, and seeks to influence, the other.

\section{Overview of findings}

The dynamics of the reciprocal interaction, and particularly the perceived incentives and penalties designed to encourage compliance, provoked considerable discussion. The 
evaluation revealed a mixed terrain with areas of comparative mutual understanding and sympathy contrasting with different and dynamic strategies for dealing with and influencing the other. Most, but not all, strategies adopted by users were reactive, seeking to influence through negative pressure. Perhaps this reflects the asymmetric power relations. The staff perspective was on creating the conditions for compliance with an emphasis on pre-empting and neutralising conflict.

\section{Users}

Users were aware of, and sensitive about, their comparative impotence in influencing the interaction, which they saw as defined by the service. In discussion there was a quality of a shared secret knowledge in the way the group swapped anecdotes about informal strategies for trying to hold their own in the face of asymmetric power. These included selective engagement (e.g. waiting for a frontline agent known to be sympathetic), passive resistance (e.g. ignoring requests for information), sabotage (e.g. 'legitimate lying' when the system was perceived to be designed to entrap) and even outright 'revenge' (using the complaints systems and appealing to MPs were seen this way). Users also demonstrated a fascination with understanding how the system influences the behaviour of staff - looking for explanations for what they perceived as curious actions in term of management targets and system rules.

\section{Dialogue workshop 2}

U8: I'm already with what everybody said. I have a question for those working there what happens when you reach 450 seconds when you're on the phone to the person?

S4: It's an average. Some calls might take one minute, some might take thirty, so it's an average. We don't actually think oh my God we've got to end this call at 450 seconds.

U8: Are you still continuing?

S4: You're conscious of the time, l'll still continue and then maybe you're hopefully going to get some quick calls which you do. And the next call may be 'can you tell me when I'm going to get my next payment, thank you very much, bye bye.'

U8: So if someone is being pleasant?

S4: It's an average of the number of calls you take and the time in total. You're conscious 
of the time but I don't think personally, right, you've got thirty seconds, it's not like that, that's not the reality of it.

\section{User workshop 1}

U4: I never hit one. I just literally get up and say, 'I can't speak to you,' it's not going to work and I just take another ticket and get somebody, and then I go and find one of them, show them my ticket and that way I get what I'm looking for because seriously when they annoy me, I just say 'I can't deal with you'. I want to slap them mind you but I can't, so I get up and take another ticket and get somebody else to take care of me.

\section{Staff}

For staff, the discussion was about how to persuade users to observe the basics of the process without argument. They emphasised pre-empting or avoiding conflict and noncompliance, rather than active co-operation. Their imperative was to complete their part of the process in a timely manner rather than worry about overall outcomes. From their point of view, this seemed entirely rational both to avoid conflict and also because of the risk of becoming too engaged in any one case.

\section{Staff workshop 1}

S6: What we do very cleverly at the moment, we kind of silo things don't we? Say if you have a problem we'll deal with this little bit about your problem in this much time, in this fashion. And if that problem doesn't fit in with that kind of square hole, if you're a round peg, we kind of try and bash you in as much as we can into that shape. But then we always then have to pass you off to somewhere else ... do we then send you back to the Customer Service Point, do we send you back to the Call Centre? Do we try and make you provide documents because that's easier for us to process? It's all about process, and I think what we really need to start doing is thinking about actually if we can just handle 
that enquiry in the first place in the right way, we'll build trust because I think trust is resilient, so trust - you can develop the trust that you've got.

Dialogue workshop 1

S2: We then started talking about customer honesty and courtesy, again a lot to talk about, unfriendly in the CSC and CSP. Talking about staff blaming each other and its interesting because the whole process of this is about trust, we're talking about trust and we're trying to give the impression of trust to people who use the service. If we don't come across as though we trust ourselves, how can we come across as being trustworthy ourselves? Because if we're going 'yeah but it's not my fault? I didn't suspend your claim.' If we're pointing the finger when somebody comes to us you fail on trust before you've even started.

The emergent coding of the transcript material confirms the almost visceral nature of the issue of mutual influence, with both users and staff expending much emotional energy on anticipating and attempting to shape the actions of the other. The coding as trust elements of issues such as 'directness', 'authenticity' and 'jobsworth' all point to the importance to trust of a straightforward interaction in which both parties feel the other is responding to them not the system. Table 4.16 lists the trust elements that were most directly relevant to the topic.

Table 4.16 Trust elements relevant to the 'process of the interaction'

\begin{tabular}{|l|l|l|l|}
\hline $\begin{array}{l}\text { Trust element and } \\
\text { description }\end{array}$ & User perspectives & Staff perspectives & Fit with category \\
\hline Directness & $\begin{array}{l}\text { An instinct running } \\
\text { through the discourse } \\
\text { for when the user is } \\
\text { being "fobbed off" } \\
\text { either consciously or } \\
\text { by fragmented } \\
\text { system }\end{array}$ & $\begin{array}{l}\text { Staff complain of } \\
\text { users who use } \\
\text { illegitimate meat the } \\
\text { importance of being } \\
\text { 'straight' }\end{array}$ & $\begin{array}{l}\text { Distrust arising } \\
\text { prioritise claims } \\
\text { from a sense of } \\
\text { being patronised } \\
\text { or manipulated }\end{array}$ \\
\hline
\end{tabular}




\begin{tabular}{|c|c|c|c|}
\hline $\begin{array}{l}\text { Jobsworth } \\
\text { References that talk } \\
\text { about hiding behind } \\
\text { process to evade } \\
\text { responsibility }\end{array}$ & $\begin{array}{l}\text { Frustration comes } \\
\text { from sense of not } \\
\text { being able to } \\
\text { challenge even if } \\
\text { complaint is sensible, } \\
\text { illustrative of true } \\
\text { impotence }\end{array}$ & $\begin{array}{l}\text { Staff group } \\
\text { recognised pattern, } \\
\text { but less significant } \\
\text { and considerable } \\
\text { respect for 'rules' }\end{array}$ & $\begin{array}{l}\text { Belief that staff } \\
\text { hide behind } \\
\text { system a major } \\
\text { challenge to trust }\end{array}$ \\
\hline $\begin{array}{l}\text { Joint working } \\
\text { References that } \\
\text { indicate the } \\
\text { importance of a } \\
\text { collaborative } \\
\text { relationship }\end{array}$ & $\begin{array}{l}\text { Clear differentiation } \\
\text { between helpful and } \\
\text { unhelpful agents }\end{array}$ & $\begin{array}{l}\text { Clear differentiation } \\
\text { between co-operative } \\
\text { and uncooperative } \\
\text { customers }\end{array}$ & $\begin{array}{l}\text { Co-operative } \\
\text { attitude important } \\
\text { to trustworthiness }\end{array}$ \\
\hline $\begin{array}{l}\text { Responsiveness } \\
\text { References that } \\
\text { indicate the } \\
\text { importance of } \\
\text { demonstrably taking } \\
\text { notice of the other }\end{array}$ & $\begin{array}{l}\text { Of major importance, } \\
\text { examples of } \\
\text { frustration are } \\
\text { interview notes not } \\
\text { written up and failure } \\
\text { to act promptly }\end{array}$ & $\begin{array}{l}\text { Aspiration to provide } \\
\text { more timely service, } \\
\text { but system to blame } \\
\text { for difficulties }\end{array}$ & $\begin{array}{l}\text { Importance of a } \\
\text { sense that the } \\
\text { other has listened } \\
\text { and } \\
\text { acknowledged an } \\
\text { issue }\end{array}$ \\
\hline $\begin{array}{l}\text { Conflict } \\
\text { References that } \\
\text { indicate the } \\
\text { presence of conflict }\end{array}$ & $\begin{array}{l}\text { A wider range of } \\
\text { conflict situations, } \\
\text { from low level } \\
\text { irritations through to } \\
\text { actual arguments } \\
\text { over decisions }\end{array}$ & $\begin{array}{l}\text { Highlighted } \\
\text { occasions of physical } \\
\text { and emotional } \\
\text { aggression from } \\
\text { users }\end{array}$ & $\begin{array}{l}\text { Argument and } \\
\text { dissent part of the } \\
\text { intrinsic emotional } \\
\text { tableau for the } \\
\text { service } \\
\text { System not good } \\
\text { at coping }\end{array}$ \\
\hline $\begin{array}{l}\text { Authenticity } \\
\text { References that } \\
\text { indicate the } \\
\text { importance placed } \\
\text { on consistency and } \\
\text { naturalness of } \\
\text { behaviour }\end{array}$ & $\begin{array}{l}\text { Ambiguous - frontline } \\
\text { staff seen as } \\
\text { authentic but } \\
\text { constrained by } \\
\text { system? } \\
\text { Fascination with how } \\
\text { the system works and } \\
\text { impact on staff } \\
\text { behaviour }\end{array}$ & $\begin{array}{l}\text { Self-image of } \\
\text { authenticity but } \\
\text { lurking understanding } \\
\text { of impact of system } \\
\text { on their individuality }\end{array}$ & $\begin{array}{l}\text { Importance of a } \\
\text { relationship that } \\
\text { works naturally } \\
\text { without hidden } \\
\text { agendas }\end{array}$ \\
\hline $\begin{array}{l}\text { Continuity of } \\
\text { relationship } \\
\text { References that } \\
\text { indicate the }\end{array}$ & $\begin{array}{l}\text { Continuity of a } \\
\text { relationship important } \\
\text { to assessing whether } \\
\text { there is a } \\
\text { corresponding sense }\end{array}$ & $\begin{array}{l}\text { Continuity seen as } \\
\text { desirable, particularly } \\
\text { in completing } \\
\text { individual } \\
\text { transactions }\end{array}$ & $\begin{array}{l}\text { Of great } \\
\text { significance } \\
\text { particularly to } \\
\text { users, as much } \\
\text { about }\end{array}$ \\
\hline
\end{tabular}




\begin{tabular}{|l|l|l|l|}
\hline $\begin{array}{l}\text { importance of } \\
\text { maintaining an on- } \\
\text { going link between } \\
\text { user and staff } \\
\text { member }\end{array}$ & $\begin{array}{l}\text { of responsibility within } \\
\text { service provider }\end{array}$ & $\begin{array}{l}\text { However also worry } \\
\text { about getting too } \\
\text { involved with } \\
\text { individual cases }\end{array}$ & $\begin{array}{l}\text { responsibility as } \\
\text { user being known }\end{array}$ \\
\hline Personal relationship & $\begin{array}{l}\text { Users valued the } \\
\text { personal dimension, } \\
\text { but less because of } \\
\text { affect and more } \\
\text { because it gives point } \\
\text { of accountability }\end{array}$ & $\begin{array}{l}\text { Staff saw the } \\
\text { personal relationship } \\
\text { as important but } \\
\text { mainly in context of } \\
\text { someone being } \\
\text { empowered to } \\
\text { indicate the } \\
\text { importance of havieve first time } \\
\text { a relationship with a } \\
\text { named and known } \\
\text { individual }\end{array}$ & $\begin{array}{l}\text { Similar to } \\
\text { continuity - } \\
\text { having a single } \\
\text { named person } \\
\text { responsible for } \\
\text { resansaction }\end{array}$ \\
\hline $\begin{array}{l}\text { Power and control } \\
\begin{array}{l}\text { References that } \\
\text { directly allude to the } \\
\text { power relationship } \\
\text { between user and } \\
\text { staff }\end{array}\end{array}$ & $\begin{array}{l}\text { A considerable sense } \\
\text { of impotence, but } \\
\text { balanced by } \\
\text { surprisingly dynamic } \\
\text { discourse about } \\
\text { holding the service to } \\
\text { account }\end{array}$ & $\begin{array}{l}\text { An underlying } \\
\text { understanding of the } \\
\text { asymmetry of the } \\
\text { relationship and the } \\
\text { perverse dynamics } \\
\text { this can produce }\end{array}$ & $\begin{array}{l}\text { An asymmetric } \\
\text { relationship, but } \\
\text { users conscious } \\
\text { of the strategies } \\
\text { that give them } \\
\text { some purchase }\end{array}$ \\
\hline
\end{tabular}

Several observations emerge from this. One is the importance of reciprocity to the participants. The behaviour of the other and how to influence it concerned both groups, although with different emphases. Staff wanted to avoid conflict and follow due process. Users wanted something more dynamic and substantial, though in a practical way. They spotted aspects of the process that appeared dysfunctional, and quickly interpreted these as implying that co-operation with the user was a low priority. The importance of continuity of relationships was also emphasised. Finally it is interesting that whilst the concept of consent was not overtly articulated by either party as a mechanism for managing cooperation, the aspiration that dissent should be acknowledged and taken seriously recurred many times and in many different ways.

These findings are captured in table 4.17. 
Table 4.17 Key findings for the 'process of interaction' and trustworthiness

\begin{tabular}{|l|l|l|l|}
\hline $\begin{array}{l}\text { Evaluation } \\
\text { category }\end{array}$ & Definition & Emerging themes & Characteristics \\
\hline $\begin{array}{l}\text { Process of } \\
\text { interaction }\end{array}$ & $\begin{array}{l}\text { The way each party } \\
\text { engages with each other, } \\
\text { including strategies for } \\
\text { influencing the other in } \\
\text { the co-production of the } \\
\text { service }\end{array}$ & $\begin{array}{l}\text { Design of the } \\
\text { to maximise } \\
\text { collaboration }\end{array}$ & $\begin{array}{l}\text { Continuity of } \\
\text { relationships and } \\
\text { communication in the } \\
\text { process of service } \\
\text { production }\end{array}$ \\
& $\begin{array}{l}\text { Consent, or more } \\
\text { specifically dissent, } \\
\text { acknowledged and } \\
\text { resolved }\end{array}$ & $\begin{array}{l}\text { Anticipation of key } \\
\text { points of potential } \\
\text { conflict }\end{array}$ \\
\hline
\end{tabular}

\subsubsection{The 'outcomes 'of the interaction}

The third and final dimension of interactivity was to examine what factors connected with the 'outcomes' of an interaction affected citizens' views of trustworthiness. This included what each party perceived as the outcome, and the importance of the other party properly fulfilling their role in completing tasks properly.

\section{Overview of findings}

Fulfilment - what each party actually does in the delivery of the service, and how far they meet the expectations of the other - was also a subject of considerable debate.

Perhaps inevitably, most of the discussion focussed on examples of perceived failure in delivery. And there was a shared if tacit understanding that actions spoke louder than words, and revealed the reality of the relationship behind the rhetoric. 


\section{Users}

For users, whether the service was actually delivered went to the heart of what they perceived as their asymmetric relationships. This showed clearly in several contributions where the significance of the eventual benefit payment to the user was often emotionally articulated in terms of life chances and survival. By contrast, the scale and monolithic nature of the service, and the difficulty of assessing whether it had acted properly and to high standards, made that seem that process was more important than a correct outcome.

Users also emphasised the importance of predictability of payment. Retrospective clawbacks due to changes of circumstance were particularly resented. Another irritation was the perceived unfairness of the system of redress. Users complained of the punishing impact of delays in payment if they made a mistake; whereas if the system or staff made a mistake, there appeared to be no corresponding redress or consequences, unless major and formal steps are taken to complain - and that was seen as a risky because of the perceived threat of victimisation.

\section{User workshop 1}

U3: Oh it's their home, it's not just one meal or a car, and it's somebody's entire life you know in this one application and if it fails they can lose their home, their family. It's really traumatic for the applicant. If the person delivering the service messes up once they'll get a written warning, they still get their wages. If they mess up twice, three times they're out. But there doesn't seem to be that 'my job depends on a happy customer' that you get in a restaurant, even a takeaway you know, spending $£ 4.99$ on a pizza sometimes.

\section{Dialogue workshop 2}

U4: And the other thing about handling if they're doing well, monitoring, you can either get a thing on the phone that says 'blablabla, did you like the service, blablabla? They could send those out a couple of times a year to their claimants to see if they like it. First of all I 
invite you all to go on the complaint site and if you complain about anything it's sorted like this (clicks fingers).

\section{Staff}

Staff recognised the importance of predictability and timeliness of payments to users, but much of their discussion concerned the need for accuracy, both preventing overpayments and ensuring applicants got their full entitlement. They were frustrated if users did not volunteer full information about changes in domestic circumstances. Staff also recognised that putting complex cases back into the pipeline for someone else to deal with often led to inefficiency, fragmentation, and delay.

\section{Dialogue workshop 1}

S10: I think it was about getting more time. I think this goes down to the whole thing about the Customer Service Points, Customer Service Centre, you're controlled by a time limit and how much time you have to see the customer. And from the back office, sometimes you're not giving that customer at the customer facing point enough time to get that information or listen to their questions. So you solve their queries and then they're ringing back or coming back. Or we're having to write to them again and ask for the same information because the person on the frontline didn't have the time to check our document imaging system to make sure the person has got the information and written a statement for them to answer the questions. So then we're just getting the person in again and spending another 420 seconds to answer their query. So that's really frustrating for the back office, for the customer, and for the person who is seeing that customer.

S2: Yes, the more we rush things the more things we can get wrong.

S10: And in fact if we answered that query first time, the right time, and all the information needed, then maybe that person didn't come back, which means there's less time in the office for that person, because there's more people coming into the office every day and getting not a good enough service and not getting an answer, so we're just getting duplicate people coming three times rather than one time, if that makes sense. 
S3: We were talking about the most straightforward and honest interaction, and bearing in mind that we've got this lovely open quality, that we have an ideal wish list for what we wanted. And one of the things that cropped up we were talking about the fact that very often people call us, they have their Benefits suspended, so payments have stopped, the money has dried up and what we wanted was 'I've provided my information, now when can I have my money?'. And we were talking about in this ideal world what we wanted was some sort of timescale, some sort of agreement, rather than being able to say 'we don't know, we're not able to tell you now, we don't know how many people are in the process'. What we wanted was an ideal situation where we can say, 'your claim will always be paid by $X$ amount of time'. And there was a little bit of a debate about what that time was going to be, because some people thought fourteen days, some people were going five minutes. So the ideal thing is that when people contact us, when customers contact us whether it's by phone or they go into the Customer Service Point, whatever, we can say 'do you know what, you've changed, the money has dried up, but we can guarantee that it's going to be back into your pocket by ..

The emergent coding to this dimension referenced all comments concerned with what was actually done by the other or the self, including comments where the issue was the completion, or not, of some action or task that was specifically promised or expected. The recurring picture is of the perception of the asymmetry of the importance of the service and following through of commitments for users compared to staff. The other areas of concern included the nature of feedback in the system and the quality of the service outcomes. Table 4.19 summarises these points.

\subsection{Trust elements relevant to the 'outcomes of the interaction'}

\begin{tabular}{|l|l|l|l|}
\hline $\begin{array}{l}\text { Trust component } \\
\text { and description }\end{array}$ & User perspectives & Staff perspectives & Fit with category \\
\hline Action & $\begin{array}{l}\text { What happens in } \\
\text { reality is seen as key } \\
\text { to service attitude, } \\
\text { one of the main } \\
\text { ways it is judged }\end{array}$ & $\begin{array}{l}\text { Action is frequently } \\
\text { widely distributed } \\
\text { across the service, no } \\
\text { one person } \\
\text { responsible }\end{array}$ & $\begin{array}{l}\text { What happens as a } \\
\text { result of a } \\
\text { user/staff } \\
\text { imteraction and } \\
\text { importance of } \\
\text { getting things doner process or } \\
\text { decisions followed }\end{array}$ \\
\hline
\end{tabular}




\begin{tabular}{|c|c|c|c|}
\hline & & & $\begin{array}{l}\text { up is key to } \\
\text { credibility }\end{array}$ \\
\hline $\begin{array}{l}\text { Feedback } \\
\text { References to the } \\
\text { importance of } \\
\text { getting and giving } \\
\text { feedback on } \\
\text { progress }\end{array}$ & $\begin{array}{l}\text { Feedback as well as } \\
\text { action vital in case of } \\
\text { difficulties - few } \\
\text { other ways of } \\
\text { knowing if user had } \\
\text { any impact }\end{array}$ & $\begin{array}{l}\text { Feedback and } \\
\text { committing to action } \\
\text { difficult when implies } \\
\text { actions by others }\end{array}$ & $\begin{array}{l}\text { When there is a } \\
\text { problem then } \\
\text { feedback as well } \\
\text { as action is } \\
\text { important to } \\
\text { maintaining the } \\
\text { relationship }\end{array}$ \\
\hline $\begin{array}{l}\text { Fulfilment } \\
\text { References to the } \\
\text { importance of } \\
\text { people doing what } \\
\text { they say they will } \\
\text { do }\end{array}$ & $\begin{array}{l}\text { The service doing } \\
\text { what it says it will do } \\
\text { at the right time is } \\
\text { key indicator of } \\
\text { competence and } \\
\text { attitude }\end{array}$ & $\begin{array}{l}\text { Of less importance to } \\
\text { any individual staff } \\
\text { member- no one } \\
\text { person seems } \\
\text { responsible or gains } \\
\text { from fulfilment }\end{array}$ & $\begin{array}{l}\text { Doing what you } \\
\text { say you will do is of } \\
\text { asymmetric } \\
\text { importance to user } \\
\text { and to staff }\end{array}$ \\
\hline $\begin{array}{l}\text { Quality of service } \\
\text { References that } \\
\text { indicate what } \\
\text { factors are } \\
\text { important to the } \\
\text { quality of the } \\
\text { service }\end{array}$ & $\begin{array}{l}\text { Relationship as } \\
\text { important to users' } \\
\text { sense of quality as } \\
\text { the technical } \\
\text { aspects of service }\end{array}$ & $\begin{array}{l}\text { Quality of service } \\
\text { important to staff, } \\
\text { however largely } \\
\text { defined in technical } \\
\text { terms of accuracy and } \\
\text { timeliness of payments } \\
\text { rather than } \\
\text { relationship }\end{array}$ & $\begin{array}{l}\text { Different definitions } \\
\text { of service quality } \\
\text { No common } \\
\text { statement of what's } \\
\text { expected }\end{array}$ \\
\hline $\begin{array}{l}\text { Service outcomes } \\
\text { References that } \\
\text { offer insight into the } \\
\text { importance of the } \\
\text { service for the } \\
\text { user's quality of life }\end{array}$ & $\begin{array}{l}\text { Of vital importance, } \\
\text { often discussed in } \\
\text { context of life } \\
\text { chances and wider } \\
\text { social capital }\end{array}$ & $\begin{array}{l}\text { Outcomes less } \\
\text { discussed, most staff } \\
\text { at one remove from } \\
\text { the impact of the } \\
\text { service - only deal } \\
\text { with applications and } \\
\text { problems }\end{array}$ & $\begin{array}{l}\text { Objective of right } \\
\text { money in the right } \\
\text { account at the right } \\
\text { time }\end{array}$ \\
\hline $\begin{array}{l}\text { Accountability } \\
\text { References that } \\
\text { indicate importance } \\
\text { of being able to } \\
\text { challenge the } \\
\text { service for } \\
\text { perceived failures }\end{array}$ & $\begin{array}{l}\text { Little sense of any } \\
\text { direct responsibility } \\
\text { from the service to } \\
\text { users for monitoring } \\
\text { and reporting on the } \\
\text { service, even when } \\
\text { things go wrong }\end{array}$ & $\begin{array}{l}\text { Complexity of multiple } \\
\text { accountabilities to } \\
\text { politicians, managers } \\
\text { and staff } \\
\text { Also complex internal } \\
\text { production chains and } \\
\text { handoffs }\end{array}$ & $\begin{array}{l}\text { Clarify who is } \\
\text { responsible (and to } \\
\text { whom) for key } \\
\text { aspects of the } \\
\text { service }\end{array}$ \\
\hline $\begin{array}{l}\text { Redress } \\
\text { References to the }\end{array}$ & $\begin{array}{l}\text { Little sense of any } \\
\text { formal redress } \\
\text { available - }\end{array}$ & $\begin{array}{l}\text { See importance of } \\
\text { making good service } \\
\text { errors, but little sense }\end{array}$ & $\begin{array}{l}\text { Importance to trust } \\
\text { of appropriate } \\
\text { compensation for }\end{array}$ \\
\hline
\end{tabular}




\begin{tabular}{|l|l|l|l|}
\hline $\begin{array}{l}\text { importance of } \\
\text { making good error }\end{array}$ & $\begin{array}{l}\text { perception that } \\
\text { users get } \\
\text { disproportionate } \\
\text { penalties for errors } \\
\text { compared to service }\end{array}$ & $\begin{array}{l}\text { of urgency - seen as } \\
\text { technical issue rather } \\
\text { than compromising } \\
\text { relationship }\end{array}$ & failure \\
\hline $\begin{array}{l}\text { References that } \\
\text { identify lack of } \\
\text { consequences } \\
\text { having impact in } \\
\text { shaping behaviour }\end{array}$ & $\begin{array}{l}\text { State functions and } \\
\text { bureaucracy too big } \\
\text { to challenge, and } \\
\text { management too } \\
\text { distant }\end{array}$ & $\begin{array}{l}\text { No great sense that } \\
\text { problems with } \\
\text { decisions or processes } \\
\text { will be challenged in } \\
\text { the future }\end{array}$ & $\begin{array}{l}\text { Importance to } \\
\text { trustworthiness of } \\
\text { consequences for } \\
\text { failure or error } \\
\text { consequences }\end{array}$ \\
\hline
\end{tabular}

The main theme from this area of investigation was users' perception of the comparative unimportance of their individual case and need to the service 'machine'. When things worked well this was less important, but the asymmetry became more perceptible and more frustrating in the event of a service error or user dissent. The perception that there was one law for the user - with immediate consequences for an error - and another for the state with no corresponding penalties was particularly corrosive of trust.

The asymmetry of power cannot be easily changed, but the traction of the individual in the face of the asymmetry can. One mechanism for achieving interdependence in assessing the outcomes of a trust transaction is mutual transparency and reporting - both parties being monitored and assessed for whether they have properly completed what was expected of them in the eyes of the other. Users felt this was already the case for them, and their comments indicated they wanted to replicate a corresponding regime in their relationship with the staff. There was confirmation that admitting error and making good would restore trust. Table 4.20 summarises these findings. 
Table 4.20 Key findings for the 'outcomes of the interaction' and trustworthiness

\begin{tabular}{|c|c|c|c|}
\hline Theme & Definition & Emerging principles & Potential mechanisms \\
\hline $\begin{array}{l}\text { Outcomes } \\
\text { of } \\
\text { interaction }\end{array}$ & $\begin{array}{l}\text { What the parties } \\
\text { perceive as the } \\
\text { outcomes of the } \\
\text { interaction, and how } \\
\text { these affect the } \\
\text { relationship with the } \\
\text { other }\end{array}$ & $\begin{array}{l}\text { The performance of both } \\
\text { parties measured and } \\
\text { recorded against } \\
\text { expectations and open to } \\
\text { question by the other } \\
\text { party } \\
\text { Redress should be given } \\
\text { without cavil if justified } \\
\text { and should be } \\
\text { commensurate with the } \\
\text { fault }\end{array}$ & $\begin{array}{l}\text { Transparency of } \\
\text { information on } \\
\text { performance } \\
\text { All measures capable } \\
\text { of individual } \\
\text { verification } \\
\text { Mutual feedback } \\
\text { Mutual 'surveillance' } \\
\text { Symmetric' incentives } \\
\text { (rewards and } \\
\text { punishments) on both } \\
\text { parties to co-operate } \\
\text { and to deliver }\end{array}$ \\
\hline
\end{tabular}

\subsection{Emerging themes for the trustworthy state}

It is important to be cautious about the findings in this chapter. It was but one study in a specific service context, and moreover testing an innovative relational DAR process and evaluation framework. Nevertheless there were also reasons for taking the results forward to the next stage. The process of DAR itself was a substantial exercise provoking considerable and passionate debate. The voices of staff and users could be differentiated in this process, often offering a different perspective on the same topic; but the fact that the key recommendations were often shared between staff and users offers reassurance that the study probed issues of genuine significance to the relationship. Finally the 
evaluation process, and in particular the parallel analysis of the emergent coding categories with the theory driven framework, provided a reasonably substantial evidence base for this phase of the study. The conclusions at the end of each of the sub-sections have been moulded by the interaction of each set of evidence with the other.

However, before addressing the main substantive themes suggested by these conclusions, it is necessary to appraise both limitations and value of this evidence base, and the lessons learnt from the process of data evaluation. Given that the evidence has been analysed and presented within the preconceived categories of the evaluation framework, there are two main questions to address. Firstly, are there any relevant outlier results that the framework inadvertently excluded? Secondly, did the data that fell within the boundaries of the framework have to be unduly manipulated to fit the sub-categories? A useful approach to assessing these challenges is to consider the integrity of the mapping of the 'trust elements' to the categories of the evaluation framework. These 'trust elements' were derived inductively to represent a full list of the 'raw' issues addressed in the evaluation. Thus the challenge concerns whether any of the issues identified through this inductive process could not be credibly attributed to an evaluation category.

Taking the overall scope of the evaluation framework first, the vast majority of the trust elements could be mapped relatively easily within the three broad headings of 'connectivity', 'agency' and 'interactivity'. In the first pass through the data there were only five 'trust elements' that resisted easy classification, and all for the reason that they were insufficiently precise (the five elements were coded as 'experience', 'history and culture', 'distrust', 'responsibility' and 'management'). It was necessary to revisit these references in order to clarify the actual issues concerned in order to place them properly within the framework. In one sense this is evidence for the value of the framework in imposing a high-level structure on the data that helped target greater precision whilst also being comprehensive. That most trust elements fell within the three broad categories was reassuring as the structure of the framework, embracing both subjective and intersubjective experience and 'connectivity' in addition to 'agency', was designed to be sufficiently abstract to be collectively comprehensive of the main relational dynamics pertinent to the research question. 
Having said this, the process of data evaluation had considerable practical impact on the definition and structure of the sub-categories within the framework. The process of mapping trust elements to the sub-categories of the main headings was dynamic in shaping and refining their nature. The sub-categories of 'connectivity' ('recognition', 'affect' and 'communicative intelligence') were relatively uncomplicated as discrete and accessible headings, as were the 'opportunity to act' and 'capability to act' sub-categories of the agency dimension. The sub-category covering 'motivation to act' was more problematic, because its boundaries were harder to define. Locating it within the 'agency' theme captured issues pertinent to 'motivation' (or lack of it) derived from material factors such as goal alignment or positive and negative incentives in the system. However a recurring theme within the data was the importance of relational factors, such as staff politeness or helpfulness coded to the connectivity theme, in creating a sense of reciprocal obligation. As presented here, the results capture both hard and soft dimensions of 'motivation', but across these different categories.

Also of significance was the impact of the data evaluation in driving adaptations to the evaluation structure within the category of 'interactivity'. This was initially conceived as a single all-encompassing heading intended to capture the reciprocal and intersubjective aspects within the data. However it became evident in the first phase of the evaluation that this offered insufficient granularity, and this forced a revision to the structure to embrace the three categories of the 'structure', 'process' and 'outcomes' of the interaction. This also prompted revisiting the analysis of the contemporary literature described in chapter 2. A second related issue posed by the analysis was how this intersubjective 'zone of interaction' related back to the subjective categories of 'connectivity' and 'agency'. The problem here was less about definitions than overlapping boundaries. To some extent this was both expected and required. The 'zone of interaction' was defined as the space where subjectivities engage, so of necessity issues of connectivity and agency recurred. This was important in making connections between the findings. For example, to return to the example of 'motivation', this was also present in the coordination and governance mechanisms investigated within the 'interactivity' category - most evident in the formal and informal strategies used to influence the other. This helped broaden the understanding of the issue, but also serves as a warning on the complexities of analysing 
causality within the framework, not least in the dynamic between the subjective and intersubjective citizen experience of the relationship.

Notwithstanding these complexities reflecting on this process of data evaluation, and the substantive findings described within each of the final sub-categories, gives rise to a number of important themes of potential significance in addressing the research question. The first observation is abstract and implicit, but nonetheless important. In all the discussions both users and staff started from the assumption that they were in a relationship, and the question of their interaction was an important one that had immediate consequences for the quality and outputs of the service. The implicit frame for the study of the public value relational model (and related trust model) was not just an analytic concept, but also resonated with how users and staff saw the world in actuality.

Secondly the findings are suggestive of a number of themes that potentially describe some quite specific qualities to the form of trust, and trustworthiness, applied by citizens in their dealings with a state activity. Describing these within the frame of a trust transaction helps develop the outline of this picture:

- The citizen as trustor looks for a level and type of respect born out of a sense of membership or 'equitable entitlement'. They also wish to see a 'practical empathy' in the state's understanding of their needs and capabilities.

- To be a credible trustee in the eyes of the citizen, the most important quality for the state is to demonstrate it is prepared to take ownership and responsibility for an equitable and effective service, not just observe process. A commitment to delivery was also important, partly in terms of technical competence but as significant was demonstrating follow through to commitments.

- Finally in terms of the trust interaction itself the citizen's desire was for sufficient authority and weight that their voice could be heard, particularly when they were in conflict. The aspiration was not to be asked to consent, but for dissent to be recognised and resolved. 
If these broad themes are repeated in other areas of the citizen/state relationship they represent a major challenge to the 'performance model' of trust described in chapter 2. Relational factors loom just as large as technical competence, and even in respect of the latter whilst valued it was cast in the context of responsibility rather than expertise. The learning from this case study is that a focus on delivery is necessary, but not sufficient, for trust to thrive.

These findings are also suggestive of some of the potentially radical implications for the organisation of the state of seeking greater trustworthiness. The recommendations for action included some profound challenges. Some concerned the very nature of the service itself such as in reorienting and rebranding it to the objective of the provision of advice to maximise benefit take up. Some were structural, such as the empowerment of the frontline with new systems and single point of responsibility for each individual case. Some were a challenge to power relations, for example the recommendation for a duty to explain. And finally some were cultural, about the language and empathy in the relationship.

However, whilst suggestive these findings did not in themselves provide a simple way of presenting the key issues and tests. This was the next step in the study process, described in the next chapter, where the themes that emerged from this case study were integrated with the theoretical insights into the nature of trust to form a diagnostic around six 'heuristic tests of state trustworthiness. 


\section{The diagnostic tests of a trustworthy state}

This chapter brings together the theory and practice addressed thus far in a first iteration of a diagnostic structure to assess state trustworthiness. Inputs include the key themes from the case study in chapter 4 (summarised at the end of each sub-section for 'connectivity', 'agency' and 'interactivity'), and the trust typology in chapter 2. Analysing the empirical results in the context of the typology exposes differences in trust norms in use by citizen and state. This helps distil the key issues for citizens when assessing state trustworthiness.

The first section (5.1) addresses the rationale for, and structure of, the diagnostic. The next section (5.2) describes the derivation and contents of each proposed test of state trustworthiness and the final section (5.3) considers the objectives for using this structure to stimulate public sector change. This diagnostic was subsequently tested in a second case study, described in Chapter 6.

\subsection{The rationale and structure of the diagnostic}

The housing benefit case study identifies important themes for citizens' perceptions of the trustworthy state, highlighting the importance of issues of respect for citizens, a voice in the relationship and the state taking responsibility for service delivery. These themes resonate with many important issues for the citizen/state relationship raised in other relevant research in chapter 2 , and the different forms of trust identified by the trust typology. The next step is to synthesise this into a comprehensive diagnostic to help citizens assess the trustworthiness of a state activity. This section discusses the rationale and design principles for that diagnostic.

A diagnostic tool, defined as series of tests designed to interrogate the trust relationship between citizen and state, is appropriate here because it reflects the knowledge being generated. It helps assess whether those characteristics are present or not in any interaction. Also it embodies the objective of the study set out in chapter 1 - an output that can help improve the citizen/state relationship, accessible for wider use and replication as well as offering theoretical insight. It could help citizens and services alike to assess and improve trustworthiness. When repeated, it would build a library of results to inform further 
theory development. Finally, a diagnostic offers a useful intellectual challenge. To be effective, diagnostics must address all potentially relevant issues while avoiding overlap between the component tests.

The main design principle is that the diagnostic should be in the voice of the citizen, following the study's view that the arbiter of state trustworthiness is the citizen's subjective judgement. This means articulating the tests of trustworthiness within the common sense 'heuristic' (Scholz and Pinney, 1998) questions people commonly use when judging issues too complex for full cognitive and emotional interrogation, such as the citizen/state relationship. The diagnostic must capture the issues in a way explicable and useful to citizens rather than through the lens of academic evaluation frameworks.

The diagnostic therefore integrates the insights from the evaluation and the trust typology into questions structured within the three basic components of the citizen/state trust transaction (as described earlier as the trust version of the relational model) - with the citizen as trustor (1) expecting the state as trustee (2) to achieve some mutual purpose through the coordination and governance of the actual interaction (3). This maintains an intellectual thread to the nature of trust and dimensions of the typology. It also builds on the case study; this conceptualisation of the situation resonates with how citizens themselves view the relationship, and it maps to the public value relational model. That model provides an intellectual frame for the study, and an accessible narrative for citizens.

Mapping the empirical findings from chapter 4 to the trust typology, it is clear that citizens and the state are not at opposite ends of the continuums. The findings are more nuanced, although they demonstrate that citizens operate to a different norm of trust than the state. To summarise briefly, for the social/instrumental continuum users are further towards the social end of the continuum than the state (for example seeing a social basis for the relationship and demanding respect), while still prizing a strong instrumental element of competence. On the active/passive continuum, users want a more active form of trust, evident in their wish for the state to take more responsibility. The third continuum of (inter)dependent trust also shows divergence, with users wanting more traction on the interplay between themselves and the service. The diagnostic is underpinned by the 
fieldwork findings and by the conceptual implications of this calibration of the results.

Figure 5.1 illustrates this analysis and positioning.

Figure 5.1 Positioning state and citizen on the dimensions of the trust typology
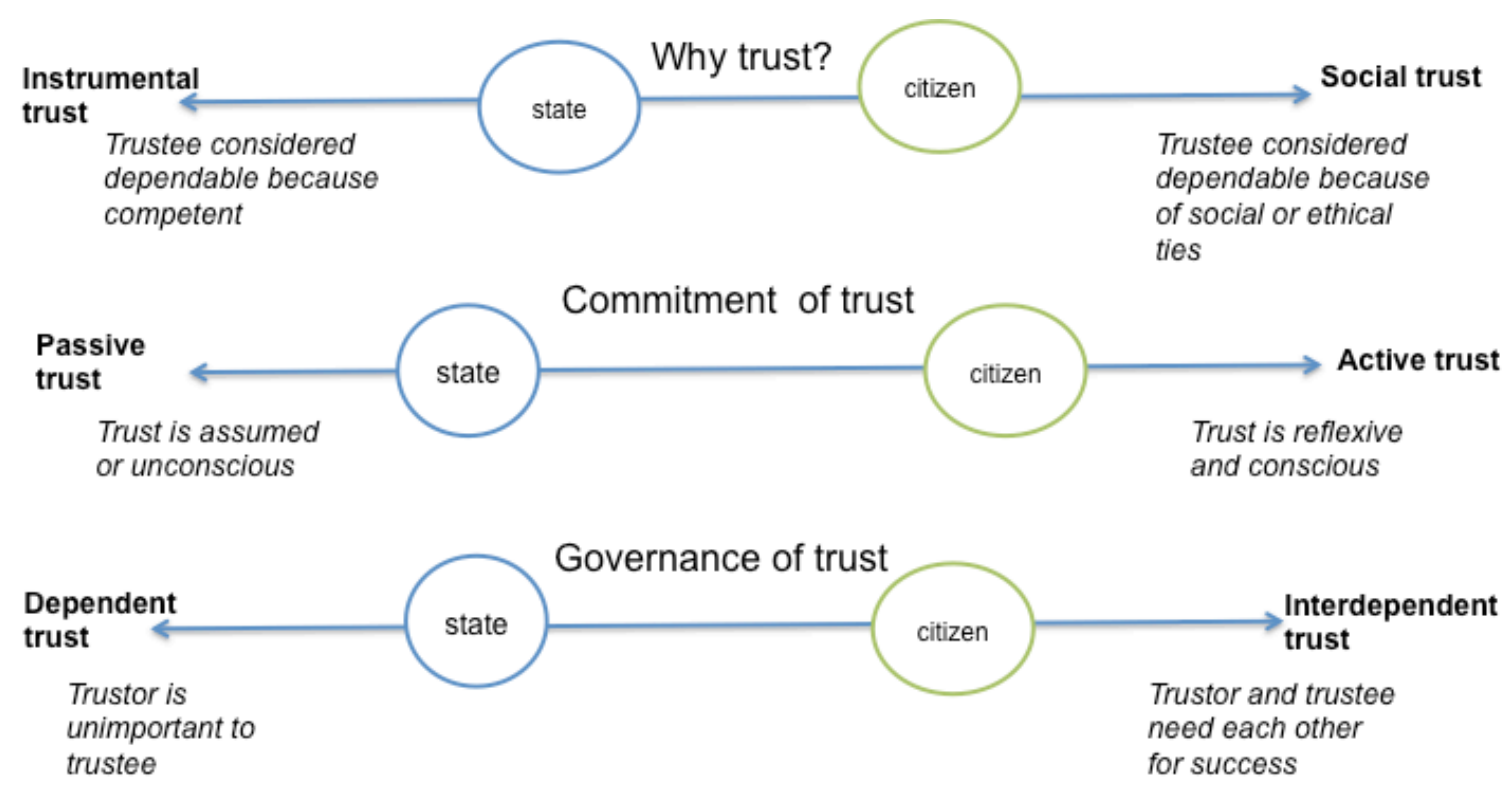

Integrating these considerations suggests a diagnostic crystallised around six tests capturing how citizens consciously and unconsciously assess state trustworthiness. The structure of these tests is analytic as they describe the main issues in citizens' minds when making this assessment. Each test leads to subsidiary diagnostic questions applicable to any public service. The precise issues will likely vary by service, but this process offers a streamlined and challenging framework for asking the right questions in the right areas. The diagnostic was tested in a second case study, described in chapter 6 . I summarise below the six tests of state trustworthiness resulting from this analysis. The next section describes each test in more detail, including the evidence base from which they are derived.

1. The identity test - 'Am I respected and what is my role?' 
This concerns the implicit and explicit identity citizens perceive as conferred in the process of interaction with the state. It touches on the defining nature of the relationship itself, and whether citizens feel perceived as active participants, treated with respect.

2. The consent test - 'what is the (real) deal, and is it fair?'

This concerns the nature and equity of the deal on offer, and how the interests of the individual are perceived to be balanced against the interests of the collective. It addresses the legitimacy of state functions and citizen's perceived 'entitlement' to services.

3. The responsibility test - 'is there someone with whom I can do business?'

This concerns the nature and capability of the public sector counterparty to the citizen, and their ability to expedite the issue at hand. It reflects the importance to citizens of a consistent and known point of contact who can be held responsible for delivery of the service or activity within a meaningful interaction.

4. The relationship test - 'Am I being treated with empathy, and do I understand what is going on?'

This concerns the quality of the emotional and communicative 'connectivity' the citizen feels when interacting with the state. It addresses issues of empathy and compassion, as well as the clarity, accessibility and comprehensiveness of information exchanged.

5. The competence test - 'Is the service efficient and do people do what they say?'

This concerns the perceived capability of the service to act effectively and efficiently. It addresses the quality of delivery, whether staff do what they say they will do, and whether the process of production looks sensible to the user.

6. The accountability test - 'Is my trust being vindicated, and if not can I make sure things are put right?' 
This concerns the governance of the interaction. It relates to issues of power and interdependence and addresses how citizens can assess whether things have turned out as they expected, and their faith in the mechanisms for resolving distrust if things go wrong.

Figure 5.2 illustrates these six tests and maps them to the trust version of the relational model. The first three tests frame the model by asking questions of the core engagement between the parties (respectively the identity and responsibility test), and the agreement between them (the consent test) to achieve the service purpose (public value). The relationship, competence, and accountability tests were conceived as describing the key aspects of the reciprocal interplay within the zone of interaction.

Figure 5.2 The tests of trustworthiness mapped to the trust version of the relational model

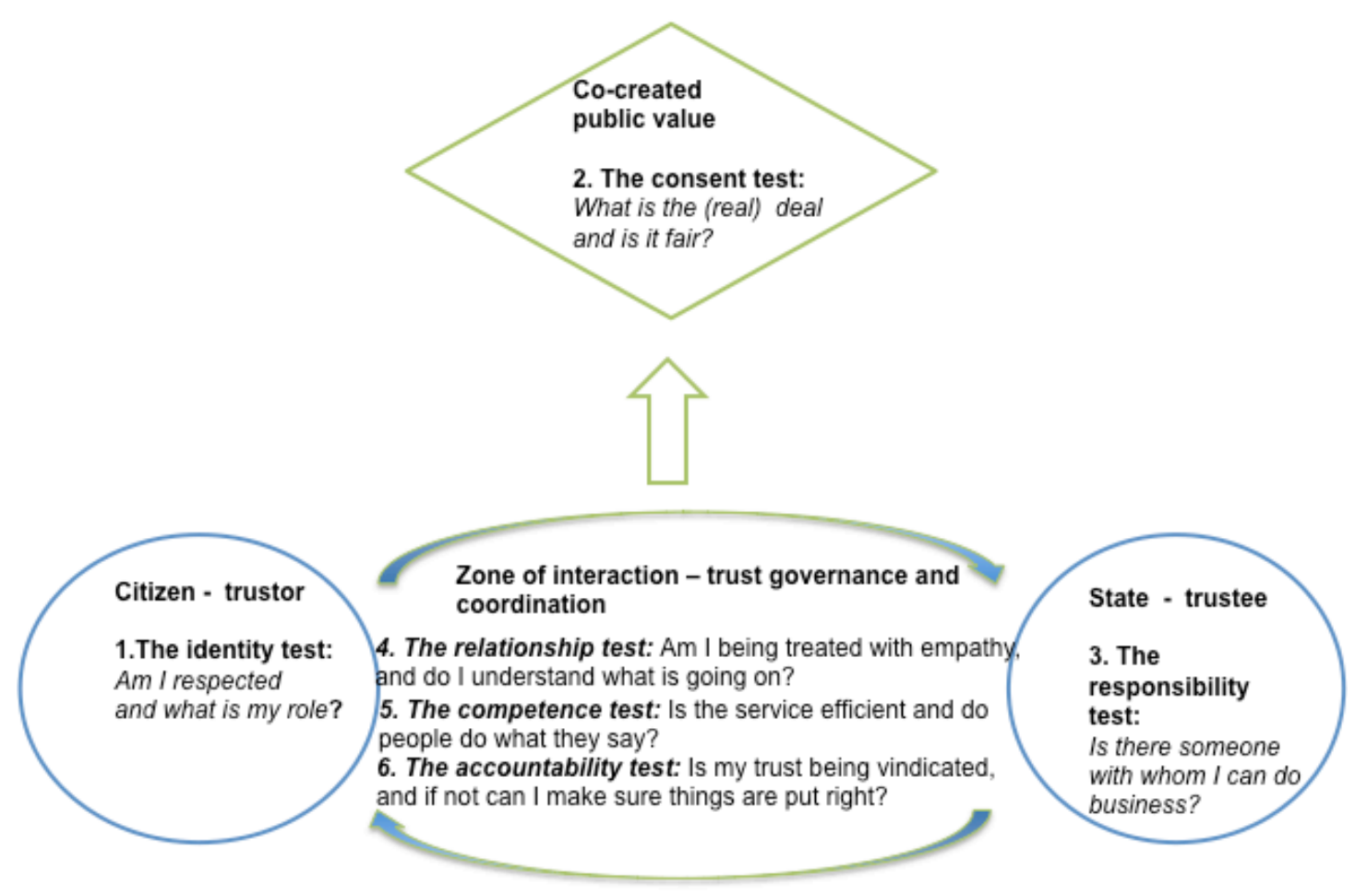


There is a final point implicit in constructing the diagnostic in this way that should also be noted and tested. In the housing benefit study both users and staff agreed that trust would be best served by a 'direct and meaningful' relationship between users and a frontline agent responsible for the service. Focussing the use of the diagnostic on the frontline embodies that assumption. The implication is that trustworthiness is enhanced by direct accountability between public service and citizens at the point, and moment, of the interaction. Barriers to the frontline agent being able to respond in this way will militate against citizen trust. I discuss this and other organisational implications in the concluding chapter.

\subsection{The development of the diagnostic tests}

Each test described in this section starts with a summary of the input evidence from the case study in the context of the relevant dimensions of the trust typology. Each is then integrated into a single diagnostic table summarising the overall test, a synthesis of the key issues it addresses, and some diagnostic questions for use with users and staff of a service to tease out their views. As a final test of coherence and comprehensiveness the tables also record some potential areas for action to improve this aspect of the relationship arising from the research. These implications are considered in the final chapter.

\subsubsection{The identity test - 'Am I respected, and what is my role?'}

Identity goes to the core of the social/instrumental dimension of the trust typology. This is described as a continuum concerning the core rationale for a trust relationship, and the basis on which people decide whether trustees are trustworthy. Social trust is largely based on bonds of emotion and shared identity, whereas instrumental trust is based more on calculating the capabilities and self-interest of the other. The fieldwork supports the hypothesis that citizens take a more social view of citizen/state relationship than the state (although they still have a strong instrumental strand). This more social tendency is evident, for example, in the strong emotional reactions when users perceive a lack of respect for them personally. This corresponds with pleas to be considered and treated 
holistically, as individuals with varying needs and capacities. It also chimes with the view that state agents should treat users as contributors to the community that gave rise to, and paid for, the state. This was the main finding from the fieldwork in respect of the subcategory of 'recognition'.

The implications are significant. Emphasising respect helps reduce the perception that the citizen is an 'object' of the interaction rather than a participant with feelings and agency. At a more operational level this test underlines the importance of the micro dynamics of each interaction, for example the language and emotional environment of its delivery, and efforts to personalise services to individual needs. The issue of identity is intertwined with the role each party believes they are taking on within an interaction. This also concerns whether users perceive themselves to be full players in the transaction, encouraged to engage reciprocally with the service. This resonates with the different conceptualisations of the role of the citizen including consumer, stakeholder, or co-worker models. The case study supports the view that citizens see their role as going beyond passive consumption, for example acknowledging their role in providing accurate information, and offered many passionate observations on how their feedback could be used to improve the service.

This suggests that the perception of state trustworthiness would be enhanced by structuring the roles of the parties to allow both to participate appropriately, and understand the value each brings. This was the message of the analysis on the 'structure of the interaction' category of the evaluation framework; it concluded that interactions should be "built around a meaningful statement of reciprocal rights and duties, creating a structure of interdependence and reciprocity notwithstanding asymmetric power relationships". Table 5.1 places these findings into a single diagnostic structure for a test of identity. 
Table 5.1 Trust diagnostic 1. The identity test - 'Am I respected and what is my role?'

\begin{tabular}{|c|c|c|c|}
\hline $\begin{array}{l}\text { The test of } \\
\text { trustworthiness }\end{array}$ & $\begin{array}{l}\text { Potential factors } \\
\text { and issues }\end{array}$ & $\begin{array}{l}\text { Diagnostic } \\
\text { questions }\end{array}$ & $\begin{array}{l}\text { Potential action } \\
\text { areas }\end{array}$ \\
\hline $\begin{array}{l}\text { Citizens' conscious } \\
\text { and unconscious } \\
\text { understanding of } \\
\text { how they are } \\
\text { perceived by the } \\
\text { public service and } \\
\text { their role in the } \\
\text { transaction } \\
\text { State } \\
\text { trustworthiness is } \\
\text { enhanced if } \\
\text { citizens believe } \\
\text { themselves } \\
\text { considered with } \\
\text { respect as a full } \\
\text { participant in the } \\
\text { service } \\
\text { Trustworthiness is } \\
\text { diminished by a } \\
\text { perception of a lack } \\
\text { of respect or a } \\
\text { sense of } \\
\text { marginalisation in } \\
\text { the service process }\end{array}$ & $\begin{array}{l}\text { The structure of the } \\
\text { engagement and } \\
\text { roles of citizen and } \\
\text { state. Are citizens } \\
\text { trusted partners? } \\
\text { The language and } \\
\text { symbols used to } \\
\text { define the } \\
\text { relationship } \\
\text { Operational } \\
\text { procedures and } \\
\text { processes, such as } \\
\text { those related to } \\
\text { confidentiality and } \\
\text { ownership of } \\
\text { personal } \\
\text { information that } \\
\text { relate to respect } \\
\text { and role }\end{array}$ & $\begin{array}{l}\text { To what extent do } \\
\text { you have any } \\
\text { concerns about the } \\
\text { respect this service } \\
\text { shows towards you } \\
\text { and others? } \\
\text { To what extent do } \\
\text { you feel trusted by } \\
\text { this service? }\end{array}$ & $\begin{array}{l}\text { Recognition of } \\
\text { users' own } \\
\text { definition of identity } \\
\text { Ensure user } \\
\text { defined service } \\
\text { standards and } \\
\text { tests of quality are } \\
\text { understood } \\
\text { Involve users in } \\
\text { assessing courtesy } \\
\text { and confidentiality } \\
\text { in all } \\
\text { communications } \\
\text { and action on } \\
\text { language and } \\
\text { terminology used } \\
\text { with citizens } \\
\text { Develop } \\
\text { transparent and } \\
\text { accessible } \\
\text { description of the } \\
\text { citizen relationship, } \\
\text { and articulate } \\
\text { expectations of }\end{array}$ \\
\hline
\end{tabular}




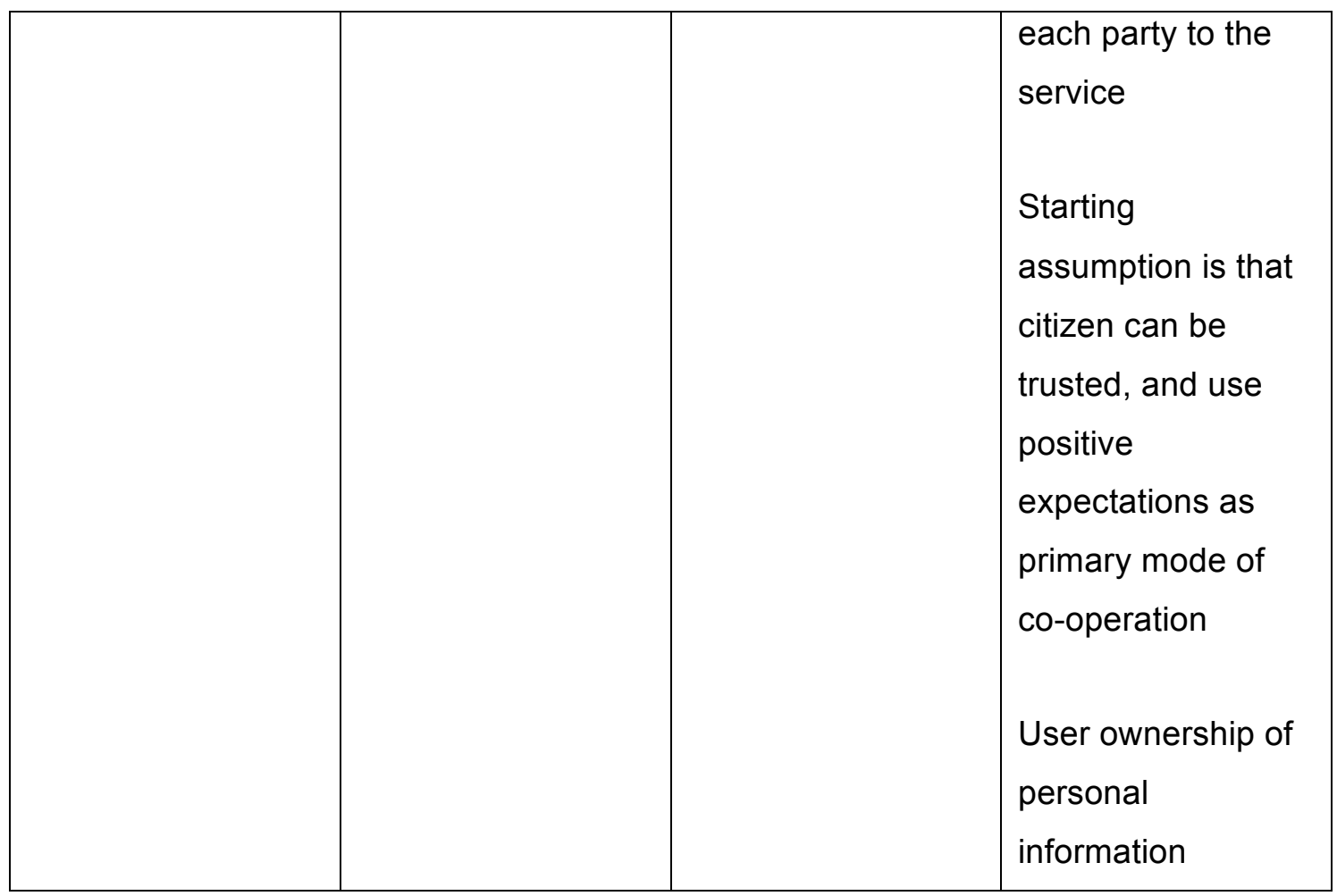

\subsubsection{The consent test - 'what is the (real) deal, and is it fair?'}

This test focuses on the nature of the 'deal' from the citizen perspective, and how far they feel it reflects their concerns and issues. It explores whether citizens perceive the service 'offer' to be equitable and appropriate in the context of the provision to others.

The analysis of encapsulated interests within the social/instrumental dimension of trust is particularly germane to this test. It allows an analysis of the fieldwork evidence in the context of understanding the importance of the perception of the (real) goals of a state activity. For example, is it perceived to work for its users, or is it best understood as driven by maintaining its own institutional wellbeing? The housing benefit study provides a powerful example of the importance and damage done by the perception of hidden agendas. Users were sensitive to any hint of what they regarded as real but hidden drivers, such as the possible ambition to minimise payments. The internal management targets influencing frontline behaviour also fascinated them. The finding recorded for the 
motivation sub category of the framework noted the importance to users of service motives, transparency of goals and fairness of provision.

The evidence is that trustworthiness is closely bound to demonstrating in concrete terms the criteria that inform service decisions. The more services and decisions are seen as fair and impartial, the greater the level of trust. This echoes much academic work on legitimacy and equity. The empirical finding is that users do not expect services to fulfil their wants without regard to the needs of others. However, they are sensitive to conflicts of interest, and want re-assurance that their interests are considered fairly overall.

This analysis also shows the significance of the earlier theoretical discussion of the importance of 'consent' in the relationship between trust and power. This suggested that acts of trust hinge on trustors voluntarily consenting to the trust transaction, and those different forms of trust would define consent in different ways. For example, passive trust implied a taken-for-granted and assumed consent, while active trust involved a conscious and reflexive agreement. The case study provided a small but eloquent cameo of the importance of this dynamic. Both users and staff observed that key steps in the process, such as the demand for sensitive personal data and the issuing of decisions on eligibility, were done automatically with acceptance and compliance simply assumed. Users resented this assumed consent, both in their critiques and the repeated vivid imagery of the 'open prison'. An example was changes to benefit levels applied automatically and retrospectively because of unexplained 'changes of circumstance'; exposing the illusion of autonomy and a reality closer to compulsion. This was a key finding from the DAR evaluation of factors in the 'process of the interaction'. The findings argued that the production process should encourage voluntary, consenting collaboration with, or more specifically dissent, acknowledged and resolved.

This view of the importance of resolving dissent is significant, not just to trustworthiness itself but also because it underpins other tests of trustworthiness. The evidence is that citizens do not expect a veto on decisions. But they expect an avenue of appeal or mediation to be able to understand and resolve their perspective on contentious issues. This theme recurs below in the context of redress and liberating distrust. Table 5.2 integrates and synthesises this thinking into a single diagnostic structure. 
Table 5.2 Trust diagnostic 2. The consent test - 'What is the (real) deal, and is it fair?'

\begin{tabular}{|c|c|c|c|}
\hline $\begin{array}{l}\text { The test of } \\
\text { trustworthiness }\end{array}$ & Factors and issues & $\begin{array}{l}\text { Diagnostic } \\
\text { questions }\end{array}$ & $\begin{array}{l}\text { Potential action } \\
\text { areas }\end{array}$ \\
\hline $\begin{array}{l}\text { Citizens' sense of } \\
\text { whether they are } \\
\text { being treated fairly, } \\
\text { and whether their } \\
\text { consent is } \\
\text { important } \\
\text { Trustworthiness is } \\
\text { manifest in } \\
\text { demonstrably } \\
\text { equitable decision- } \\
\text { making that fairly } \\
\text { balances needs of } \\
\text { individual against } \\
\text { public policy, } \\
\text { proving this is so } \\
\text { by opening up the } \\
\text { possibility of } \\
\text { dissent } \\
\text { the objectives of } \\
\text { the service are not } \\
\text { wistrust arises if } \\
\text { titizens believe } \\
\text { they are not being } \\
\text { tred in the same } \\
\text { tos others, if } \\
\text { to }\end{array}$ & $\begin{array}{l}\text { The stated and } \\
\text { unstated goals of } \\
\text { the service, and } \\
\text { management } \\
\text { pressures on staff } \\
\text { The status of the } \\
\text { public good in } \\
\text { respect of the } \\
\text { citizen - e.g. } \\
\text { entitlement or gift } \\
\text { Transparency to } \\
\text { citizen of service } \\
\text { offer and targets } \\
\text { Mechanisms by } \\
\text { which consent or } \\
\text { dissent are } \\
\text { registered and } \\
\text { acted on }\end{array}$ & $\begin{array}{l}\text { To what extent do } \\
\text { you think this } \\
\text { service does } \\
\text { everything it can to } \\
\text { be fair in the way it } \\
\text { treats you and } \\
\text { others? } \\
\text { To what extent do } \\
\text { you feel you have a } \\
\text { voice in agreeing } \\
\text { the nature of the } \\
\text { service you } \\
\text { receive? }\end{array}$ & $\begin{array}{l}\text { Statement of } \\
\text { service goals and } \\
\text { values, including } \\
\text { criteria for access } \\
\text { (who has a 'right' to } \\
\text { the service) } \\
\text { Transparency of } \\
\text { service information } \\
\text { and results, } \\
\text { including on } \\
\text { management } \\
\text { targets and } \\
\text { incentives } \\
\text { Formalise } \\
\text { individual } \\
\text { statements of } \\
\text { service 'offers' or } \\
\text { 'packages' and } \\
\text { demonstrate } \\
\text { degree to which } \\
\text { service is } \\
\text { 'personalised' } \\
\text { Formalise } \\
\text { processes of }\end{array}$ \\
\hline
\end{tabular}




\begin{tabular}{|l|l|l|}
\hline $\begin{array}{l}\text { seen as legitimate, } \\
\text { or if they think that } \\
\text { decisions are } \\
\text { influenced by the } \\
\text { organisational } \\
\text { convenience of the } \\
\text { service }\end{array}$ & $\begin{array}{l}\text { and shirkers' } \\
\text { organisational and } \\
\text { professional } \\
\text { incentives and } \\
\text { conflicts of interest } \\
\text { on staff }\end{array}$ & $\begin{array}{l}\begin{array}{l}\text { agreeing and } \\
\text { recording consent, } \\
\text { and mechanisms } \\
\text { for resolving } \\
\text { dissent }\end{array} \\
\text { Accept a 'duty to } \\
\text { explain' decisions }\end{array}$ \\
\hline
\end{tabular}

\subsubsection{The responsibility test - 'Is there someone with whom I can do business?'}

The theoretical literature and the fieldwork evaluation both show the importance to users of putting a name to front line staff. This fits with the evidence around recognition summarised earlier. Citizens want to be acknowledged as individuals, and engage with a known individual they can hold responsible for their experience of the service.

The DAR evidences the damaging caricature of 'faceless bureaucracy' and its continuing presence within the relationship. Both empirical and theoretical considerations emphasise that trustworthiness is partly a judgement on whether the agents with whom citizens interact are seen as credible partners in the transaction. The DAR evidence confirms this, even when aspects of the engagement are automated or done remotely. Users still want assurance that someone behind the scenes is responsible for the integrity of the processes, systems and decisions.

It is important to name a service partner, but also to assess their ability and commitment to responding - to "do business", as one participant put it. Users and staff shared similar views on the challenges to the state this might entail. Both expressed frustration at fragmented service processes, and the inefficiency and diluted responsibility that followed. Both recommended greater empowerment of frontline staff. They felt that trust was maximised by direct engagement with someone who could actually respond directly to issues. This was the conclusion of the 'opportunity to act' category of the evaluation; the need for empowered frontline agents, with responsibility in users' eyes for successful transactions. 
This finding is potentially relevant across the public sector and has considerable ramifications for how services are structured and commissioned. It means reversing the paradigm of an under-skilled and under-paid frontline directing traffic to back office 'experts'. Instead, state trustworthiness benefits from frontline staff with whom users can directly engage to resolve issues, rather than multiple and confusing points of contact that citizens themselves must integrate. Table 5.3 integrates and synthesises these findings into a single diagnostic structure.

Table 5.3 Trust diagnostic 3. The responsibility test - 'Is there someone with whom I can do business?'

\begin{tabular}{|c|c|c|c|}
\hline $\begin{array}{l}\text { The test of } \\
\text { trustworthiness }\end{array}$ & $\begin{array}{l}\text { Factors and } \\
\text { issues }\end{array}$ & $\begin{array}{l}\text { Diagnostic } \\
\text { question }\end{array}$ & $\begin{array}{l}\text { Potential action } \\
\text { areas }\end{array}$ \\
\hline $\begin{array}{l}\text { Ctizens' sense that } \\
\text { they have a } \\
\text { meaningful point of } \\
\text { contact within the } \\
\text { service with which } \\
\text { to have a } \\
\text { relationship in the } \\
\text { first place } \\
\text { Trustworthiness is } \\
\text { derived from the } \\
\text { sense that there } \\
\text { someone to take } \\
\text { responsibility and } \\
\text { accountability for } \\
\text { the integrity of the } \\
\text { relationship } \\
\text { Corresponding } \\
\text { sources of distrust }\end{array}$ & $\begin{array}{l}\text { How the } \\
\text { responsibility for a } \\
\text { transaction is } \\
\text { structured within } \\
\text { the delivery agent } \\
\text { or across multiple } \\
\text { agents } \\
\text { The continuity of } \\
\text { the relationship } \\
\text { between the } \\
\text { service agent and } \\
\text { citizens } \\
\text { The relationship of } \\
\text { the frontline agent } \\
\text { with any back } \\
\text { office casework, or } \\
\text { service processing }\end{array}$ & $\begin{array}{l}\text { To what extent do } \\
\text { you feel that there } \\
\text { is someone within } \\
\text { the service who is } \\
\text { taking } \\
\text { responsibility for } \\
\text { your service, and } \\
\text { to whom you could } \\
\text { turn if there are } \\
\text { problems? }\end{array}$ & $\begin{array}{l}\text { Map citizen } \\
\text { 'experience' of } \\
\text { service to ensure } \\
\text { point of } \\
\text { responsibility for } \\
\text { each stage } \\
\text { Integrate } \\
\text { fragmented } \\
\text { production } \\
\text { processes within } \\
\text { authority of single } \\
\text { 'case manager' } \\
\text { Analyse and } \\
\text { enhance case } \\
\text { manager and } \\
\text { frontline authority } \\
\text { and capabilities to } \\
\text { enable resolution }\end{array}$ \\
\hline
\end{tabular}




\begin{tabular}{|l|l|l|}
\hline $\begin{array}{l}\text { are the } \\
\text { fragmentation or } \\
\text { worse dissipation } \\
\text { of responsibility } \\
\text { across different } \\
\text { people or agencies }\end{array}$ & functions & $\begin{array}{l}\text { of citizen issue 'first } \\
\text { time' }\end{array}$ \\
. & & $\begin{array}{l}\text { Information and } \\
\text { knowledge } \\
\text { systems designed } \\
\text { around citizens and } \\
\text { frontline agent }\end{array}$ \\
& & \\
\hline
\end{tabular}

\subsubsection{The relationship test - 'Am I being treated with empathy, and do I understand what is going on?'}

Another corollary of citizens' more social view of trust, as defined by the social/instrumental dimension of the trust typology, is that they look for a more rounded and emotionally satisfying relationship than typical of purely instrumental or task focussed transactions. In the fieldwork, users and staff repeatedly called for the service to have a fuller understanding of users' needs. They agreed on the alienating effect of communications in inaccessible language, ineffectively explaining situations or decisions. In theoretical terms the aspiration for more rounded and compassionate relationships is also echoed in the active/passive dimension of the trust typology. A more rounded interest in citizens would reflect a more active form of trust from the state, where citizens perceive a genuinely 'reflexive' sense of commitment to the interaction.

As with the identity test, citizens wish to retain some instrumentality. The relationship sought is not an extreme of the social continuum, but a balance with a task focus. This shows in the findings on the 'affect' element of the research framework. One conclusion was the importance of avoiding dislike rather than being actively liked. Another was for an empathy described as 'practical' rather than emotionally unconditional. Several contributors described this as having 'someone on your side'. 
Another aspect of relational trustworthiness lies in the language, tone, media of the communications with citizens and the willingness for dialogue. The DAR results emphasised this in both formal recommendations and the analysis of the transcript data within the 'communicative competence' category of the evaluation framework. Users need to understand what is going on and feel that they, and their needs, are understood. Users and staff were clearly irritated by over-complex, opaque language. For this reason, the recommendations go beyond obvious points around clarity of language and appropriateness of the medium of communication. Users wanted greater openness in the round, including a duty to explain and ensure understanding, particularity for contested decisions or behaviour. Table 5.4 integrates and synthesises these findings into a single diagnostic structure.

Table 5.4 Trust diagnostic 4. The relationship test - 'Am I being treated with empathy, and do I understand what is going on?'

\begin{tabular}{|c|c|c|c|}
\hline $\begin{array}{l}\text { The test of } \\
\text { trustworthiness }\end{array}$ & $\begin{array}{l}\text { Factors and } \\
\text { issues }\end{array}$ & $\begin{array}{l}\text { Diagnostic } \\
\text { questions }\end{array}$ & $\begin{array}{l}\text { Potential action } \\
\text { areas }\end{array}$ \\
\hline $\begin{array}{l}\text { Citizens' sense that } \\
\text { their needs and } \\
\text { capabilities and } \\
\text { properly understood } \\
\text { and that they } \\
\text { understand the } \\
\text { basis for the service } \\
\text { provision }\end{array}$ & $\begin{array}{l}\text { The 'friendliness' of } \\
\text { the service towards } \\
\text { its users, and the } \\
\text { way that staff treat } \\
\text { each other } \\
\text { The importance of a } \\
\text { practical empathy } \\
\text { and compassion in } \\
\text { the relationship with } \\
\text { citizens } \\
\text { The range of } \\
\text { individual factors } \\
\text { that each service } \\
\text { takes into account }\end{array}$ & $\begin{array}{l}\text { To what extent do } \\
\text { you feel that you } \\
\text { properly understand } \\
\text { the way the service } \\
\text { is working with } \\
\text { you? }\end{array}$ & $\begin{array}{l}\text { Review and } \\
\text { enhance } \\
\text { information systems } \\
\text { that collect data on } \\
\text { citizen needs } \\
\text { Formalise needs } \\
\text { assessment in } \\
\text { communication with } \\
\text { citizen } \\
\text { Create } \\
\text { organisational } \\
\text { capacity to collect } \\
\text { and understand } \\
\text { citizens' needs at }\end{array}$ \\
\hline
\end{tabular}




\begin{tabular}{|c|c|c|}
\hline $\begin{array}{l}\text { orofessional way } \\
\text { and that there is } \\
\text { effective two way } \\
\text { communication } \\
\text { Distrust arises from } \\
\text { he sense of being } \\
\text { disliked, or ignored } \\
\text { as unimportant to } \\
\text { sense that is } \\
\text { compounded by } \\
\text { opaque } \\
\text { communications }\end{array}$ & $\begin{array}{l}\text { in their relationship } \\
\text { with citizens } \\
\text { The accessibility } \\
\text { and tone of } \\
\text { communications }\end{array}$ & $\begin{array}{l}\text { an individual and } \\
\text { collective level } \\
\text { Demonstrate } \\
\text { understanding of } \\
\text { citizen needs by } \\
\text { publishing analysis } \\
\text { of trends and } \\
\text { success in dealing } \\
\text { with problems } \\
\text { A duty of candour } \\
\text { Ensure that } \\
\text { physical } \\
\text { environment is } \\
\text { welcoming and } \\
\text { appropriate } \\
\text { Ability to signpost to } \\
\text { other related } \\
\text { services or user } \\
\text { groups }\end{array}$ \\
\hline
\end{tabular}

\subsubsection{The competence test -'Is the service efficient and do people do what they say?'}

Previously it was argued that competency lies at the heart of the traditional 'performance model' perspective on the nature of state trustworthiness, and that competency is what a bureaucracy thinks it should be judged on. This draws more from the instrumental aspect of the social/instrumental continuum of trust types because it bases trust on a calculation of the likelihood of the counterparty complying with the requirement, rather than the nature of the social obligation to comply. 
The fieldwork confirms this is also important to citizens, although as already reported they also value some aspects of a social type of trust. The findings suggest that the citizen perspective is not just a simple calculation of technical expertise; it is also toward the active end of the active/passive continuum of the trust typology. Citizens assess and prize the state agents' capabilities, but also look for commitment to successful delivery, demonstrated by a sense that statements and undertakings should be reflexive and authentic.

The summary findings of the capacity to act component of the evaluation framework support these observations. This category of the evaluation identifies the importance of perceived skills of the state agent, and also the state's willingness to support and enhance the skills of citizens to participate. A test of the state is whether systems and processes for both frontline agent and user are designed sensibly and practically. This reflects contemporary good practice. Most private sector companies invest in user self-service, for example operational computer systems designed around the user with inbuilt explanations of process and language in order to simplify and support good practice.

Assessing state competency to manage the interaction also means addressing user questions on efficiency. The DAR stimulated many examples of how perceived incompetent service delivery compromises trust. This is a feature of the evidence on the 'opportunity to act' dimension of the relational framework, which highlights the importance of state agents having authority to fulfil a citizen/state interaction. The second aspect of this finding is that delivery processes should be streamlined and sensible. Users and frontline staff were scathing about processes that manifestly led to rework or additional effort, taken as evidence of general managerial incompetence, and by users as indicating lack of care. Table 5.5 integrates and synthesises these findings. 
Table 5.5 Trust diagnostic 5. The competence test - 'Is the service efficient and do people do what they say?'

\begin{tabular}{|c|c|c|c|}
\hline $\begin{array}{l}\text { The test of } \\
\text { trustworthiness }\end{array}$ & $\begin{array}{l}\text { Factors and } \\
\text { issues }\end{array}$ & $\begin{array}{l}\text { Diagnostic } \\
\text { questions }\end{array}$ & $\begin{array}{l}\text { Potential action } \\
\text { areas }\end{array}$ \\
\hline $\begin{array}{l}\text { Citizens' } \\
\text { perception that the } \\
\text { service can } \\
\text { manage its affairs } \\
\text { and functions } \\
\text { professionally } \\
\text { Trust comes from } \\
\text { the perception that } \\
\text { systems and } \\
\text { processes are } \\
\text { efficient and } \\
\text { accurate, and that } \\
\text { there is a culture in } \\
\text { which people do } \\
\text { what they promise } \\
\text { Evidence of } \\
\text { individual or } \\
\text { systemic } \\
\text { incompetence } \\
\text { leads to immediate } \\
\text { source } \\
\text { worries are } \\
\text { service offers that } \\
\text { do not match }\end{array}$ & $\begin{array}{l}\text { The service } \\
\text { delivery model and } \\
\text { whether need } \\
\text { assessment is } \\
\text { aligned with } \\
\text { service delivery } \\
\text { The perception of } \\
\text { the efficiency of the } \\
\text { production } \\
\text { process, and the } \\
\text { extent of rework } \\
\text { required } \\
\text { Monitoring and } \\
\text { accounting for } \\
\text { results }\end{array}$ & $\begin{array}{l}\text { To what extent do } \\
\text { you have any } \\
\text { concerns about the } \\
\text { quality of the } \\
\text { service or the way } \\
\text { it is delivered? } \\
\text { To what extent do } \\
\text { you think the } \\
\text { service could be } \\
\text { delivered in a more } \\
\text { efficient way? }\end{array}$ & $\begin{array}{l}\text { Clarity of standards } \\
\text { Transparency of } \\
\text { information on } \\
\text { performance } \\
\text { Provide feedback } \\
\text { to both parties on } \\
\text { value of their } \\
\text { contribution } \\
\text { Systems to assist } \\
\text { 'case manager' } \\
\text { and citizen in } \\
\text { monitoring delivery } \\
\text { to agreed } \\
\text { standards and } \\
\text { timetable including } \\
\text { provision for both } \\
\text { citizen and case } \\
\text { manager to sign off } \\
\text { completion of a } \\
\text { service transaction } \\
\text { Capability building } \\
\text { with staff and } \\
\text { citizens }\end{array}$ \\
\hline
\end{tabular}




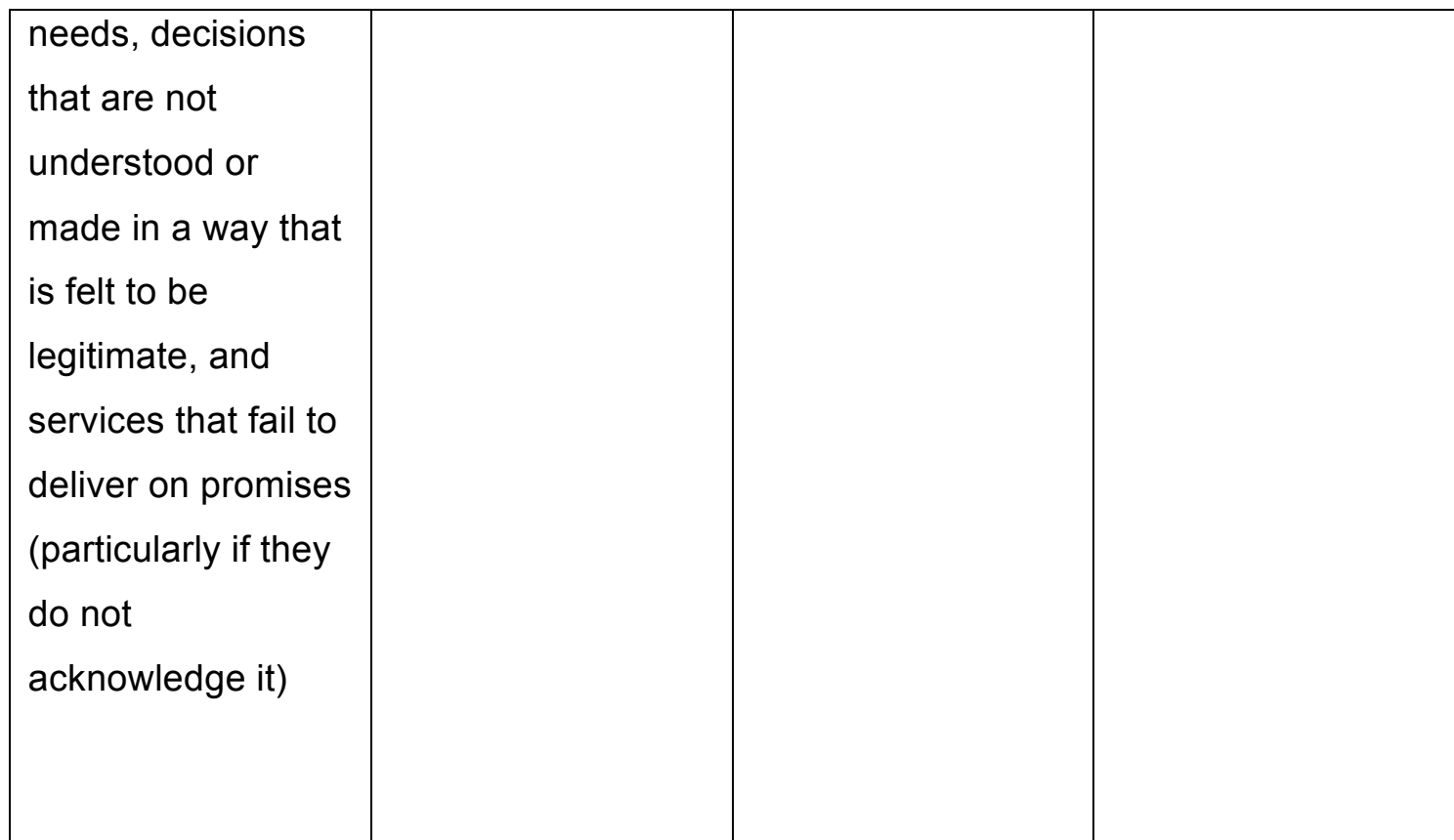

\subsubsection{The accountability test - 'Is my trust being vindicated, and if not can I make sure things are put right?'}

Chapter 2 holds a discussion of the link between trust and power. It concludes that they work together in different ways in different trust relationships. For the citizen/state relationship, the main issue is the degree of dependence or interdependence in the trust transaction. The hypothesis is that the state will tend to gravitate towards relationships of dependence, while citizens perceive some interdependence as necessary to trustworthiness.

The findings for the 'outcomes of the interaction' element of the evaluation supports this hypothesis. They capture users' frustration at their inability to challenge unsatisfactory service, such as unexplained delays or benefit reductions. Users wanted a louder voice in the quality of what was done, with their feedback counting for more, both in individual cases and more generally. There was an interesting discussion making performance information available to users, and a desire for more transparency over targets. The second and more emotive issue contrasted poor user redress for a service failure, with apparently punitive consequences for comparatively minor user infractions. 
The accountability test builds from these findings, and from the analysis of trust based mechanisms of mutual governance. These considerations suggest several measures needed to reassure citizens that the state could be made systemically trustworthy. One is transparency of information so citizens can judge whether their expectations have been properly fulfilled. This transparency should embrace whether each individual case has been resolved appropriately, and the general results achieved. Moreover users want to know the internal dynamics of the service, including how rules and regulations are interpreted, and the extent of local discretion.

A small but revealing discussion on mutual monitoring of performance arose during the case study. One user talked about recording her own interview. Citizens are increasingly able to devise and implement their own measures of monitoring and reporting, as the relatives of vulnerable clients placing cameras in care homes shows. The technology has arrived, and the state would be wise to accept both the inevitability and usefulness of such mutual 'surveillance' in demonstrating trustworthiness. Resolving distrust is also the perspective to apply to redress. The user frustration was less to do with actual failure and more about the systems' apparent inability to acknowledge mistakes. To address this, users and staff recommended that user redress and penalties should be demonstrably proportionate to the damage done.

Finally, Chapter 2 argues that the effective governance of trust relationships necessarily requires capacity to surface distrust, and also to provide mechanisms by which it can be resolved such as complaints and appeals procedures. In addition in the public sector an important instrument for public reassurance is an informal or formal regulatory capacity above any particular function. Maintaining citizen trust brings the perceived role and independence of such functions into focus, as impartial umpires of the system and as user advocates in the event of broken relations. The lesson from the research and the literature is that people will believe in such trust systems only if they think they are genuinely objective and impersonal, immune to manipulation by any of the parties to citizen/state trust transaction. Some of the organisational and political consequences of enhancing the states' capacity to acknowledge and resolve distrust is discussed more fully chapter 7 . Table 5.6 integrates and synthesises these findings into a single diagnostic. 
Table 5.6 Trust diagnostic 6. The accountability test - 'Is my trust being vindicated, and if not can I make sure things are put right?'

\begin{tabular}{|c|c|c|c|}
\hline $\begin{array}{l}\text { The test of } \\
\text { trustworthiness }\end{array}$ & $\begin{array}{l}\text { Factors and } \\
\text { issues }\end{array}$ & $\begin{array}{l}\text { Diagnostic } \\
\text { questions }\end{array}$ & $\begin{array}{l}\text { Potential action } \\
\text { areas }\end{array}$ \\
\hline $\begin{array}{l}\text { Citizens' sense that } \\
\text { they have sufficient } \\
\text { traction on an } \\
\text { interaction to } \\
\text { understand } \\
\text { whether it has } \\
\text { been correctly } \\
\text { delivered, and that } \\
\text { their voice will be } \\
\text { heard if they are } \\
\text { unhappy } \\
\text { Trustworthiness is } \\
\text { enhanced by a } \\
\text { sense that both } \\
\text { parties are able to } \\
\text { independently } \\
\text { assess whether } \\
\text { distrust has been } \\
\text { successfully } \\
\text { resolved } \\
\text { Distrust is } \\
\text { associated with a } \\
\text { lack of }\end{array}$ & $\begin{array}{l}\text { Formal and } \\
\text { informal } \\
\text { mechanisms for } \\
\text { registering } \\
\text { agreement, } \\
\text { consent, and } \\
\text { satisfaction } \\
\text { Transparency of } \\
\text { information and } \\
\text { explanations } \\
\text { Mechanisms for } \\
\text { withdrawing } \\
\text { consent and } \\
\text { resolving distrust, } \\
\text { including } \\
\text { independent } \\
\text { regulation } \\
\text { Proportionality and } \\
\text { equity in the } \\
\text { incentives and } \\
\text { forms of redress } \\
\text { applied to both }\end{array}$ & $\begin{array}{l}\text { To what extent do } \\
\text { you feel your } \\
\text { satisfaction with } \\
\text { the service is } \\
\text { important? } \\
\text { To what extent do } \\
\text { you feel confident } \\
\text { that this service } \\
\text { would put things } \\
\text { right if they made a } \\
\text { mistake? }\end{array}$ & $\begin{array}{l}\text { Find mechanisms } \\
\text { for registering } \\
\text { consent and for } \\
\text { surfacing and } \\
\text { resolving latent or } \\
\text { overt discontent } \\
\text { Engage citizen in } \\
\text { performance } \\
\text { management, and } \\
\text { feedback } \\
\text { Encouragement of } \\
\text { mutual surveillance } \\
\text { Create senior and } \\
\text { credible } \\
\text { organisational } \\
\text { capacity for citizen } \\
\text { advocacy in the } \\
\text { event of } \\
\text { dissatisfaction, and } \\
\text { management } \\
\text { responsibly for } \\
\text { maintaining }\end{array}$ \\
\hline
\end{tabular}




\begin{tabular}{|l|l|l|}
\hline $\begin{array}{l}\text { transparency or } \\
\text { sanctions that are } \\
\text { inequitable or } \\
\text { ineffective }\end{array}$ & state and citizen & $\begin{array}{l}\text { integrity of citizen } \\
\text { relationship }\end{array}$ \\
& & $\begin{array}{l}\text { Ensure that } \\
\text { individual citizen } \\
\text { can assess all } \\
\text { service targets }\end{array}$ \\
& & \\
\hline
\end{tabular}

\subsection{The diagnostic and change}

Developing a diagnostic structure is intended to create a tool to enhance citizen/state relationships. Having described the diagnostic structure and provenance, it is important to reflect on that objective and particularly how it might affect service relationships. This is the test for assessing its success or failure in the second case study.

By its nature the diagnostic travels the terrain between the potential identification of profound structural issues on the one hand, and the micro-dynamics of the relationship on the other. Both types of issue loomed large in the fieldwork. The evidence is that they are often linked. In a striking conversation from the housing benefit fieldwork, a user illustrated disrespect for users from the lack of confidential interview rooms. By these apparently minor symbols, users interpret the bigger picture. The strategic relationship will not be improved if the tactical picture remains unaltered, and vice versa. The diagnostic is intended to stimulate both small scale and transformatory change, in a way that links both.

Finally, the evidence so far suggests that some change prompted by the diagnostic will be comparatively easy and cheap to implement. A user charter in the housing benefit service, for example, would take staff time to develop but entail few other costs or risks (unless the charter was undeliverable). By contrast, an empowered frontline equipped with the systems to achieve first time resolution would require major change. This poses an additional issue for trust - how to manage expectations arising from the diagnostic if the public body is not committed or resourced or empowered to achieve trustworthiness. This is discussed further in the light of the findings described in the next chapter. 


\section{Testing the diagnostic with a GP surgery}

The first iteration of the trust diagnostic was described in the previous chapter. Its coherence and effectiveness was then tested in a second case study in partnership with an urban GP surgery. This chapter describes the process and results of that study, and the learning for the diagnostic that led to a final iteration of the diagnostic structure and questions.

The first section (6.1) describes how the tests were applied within a more focussed form of DAR. The second section (6.2) summarises the findings for each test, and its utility in uncovering the right issues. The final section (6.3) builds on the experience to propose amendments to the diagnostic structure.

\subsection{Testing the tests}

The final stage of the research was to test the diagnostic structure and process by using it in practice. A universal public service like a GP surgery was a different context to housing benefit, and was particularly interesting because surveys (Ipsos Mori, 2016) consistently identify GPs as the most trusted public sector workers. The research followed the same process and protocols, except with fewer workshops because using the diagnostic tests as a targeted set of questions enabled some streamlining. Three workshops were sufficient; one each with patients and staff separately, described as diagnostic, and a third workshop together, described as dialogue. The researcher, supported by the surgery patient champion, facilitated the workshops. The ethical considerations and requirements, including the need for management approval and participants' informed consent, were the same as for the housing benefit study.

As before, the process had two stages. Firstly, users and staff groups completed a short survey and then met separately in order to agree a list of the issues from that group's perspective. Secondly, the two groups met together to share and discuss these issues with the aim of achieving a shared view of relational problems and potential solutions. This process is illustrated below. 


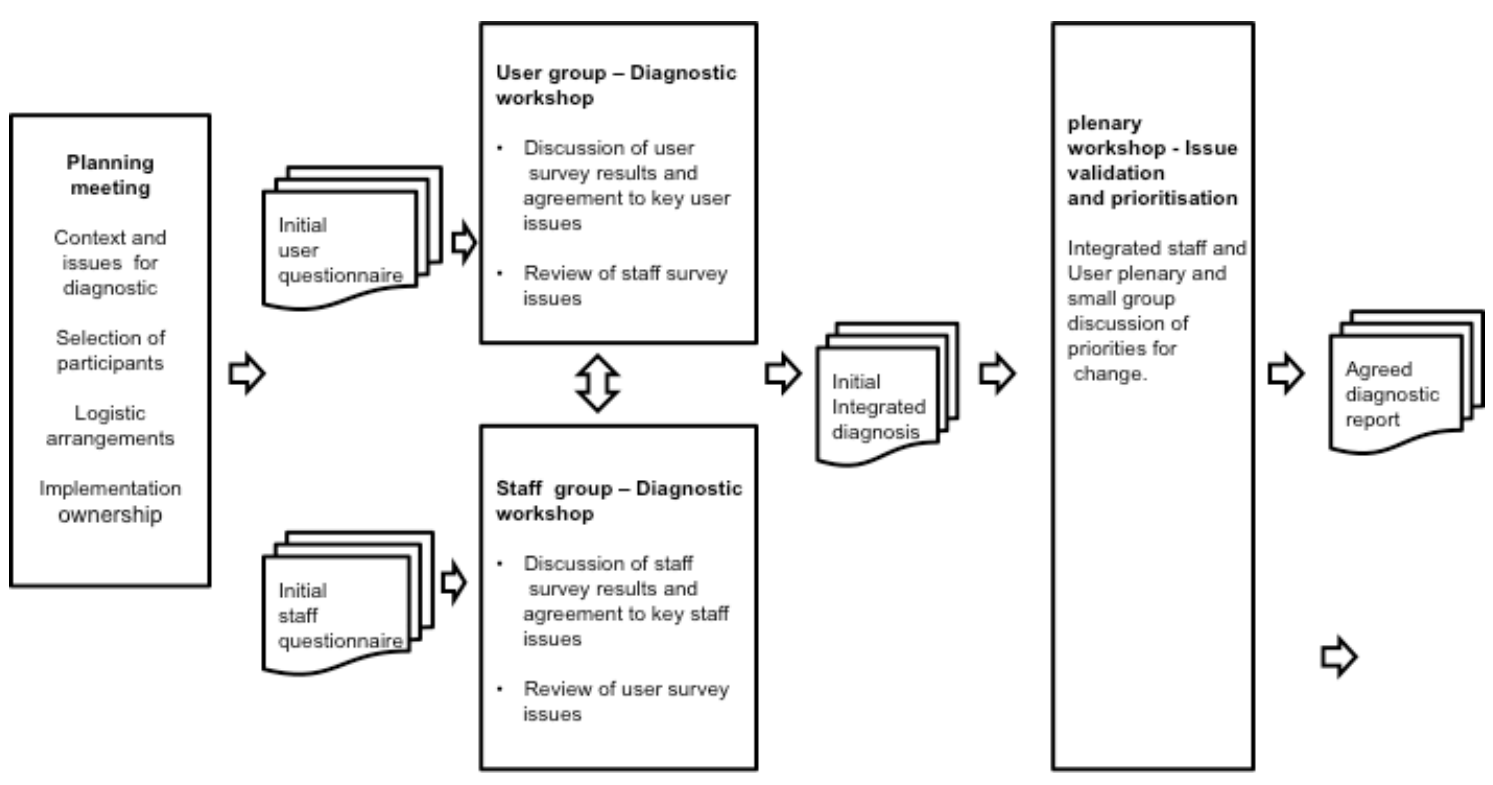

The exercise lasted five weeks. Participants were given two weeks to complete the online survey, and the results were analysed in the third week. The individual workshops with patients and staff were held in the fourth week and the final workshop in the fifth. The written survey started to expose the main issues for both patients and staff. It was both quantitative and qualitative. Many questions required a score ${ }^{13}$ before asking participants their reasons for that judgement. In order to focus more clearly on the citizen experience of trust, staff were asked not about their own trust in the patient, but to anticipate the

${ }^{13}$ As for the Housing Benefit service, participants gave a score between 1 and 7 , which were then averaged with other members of their group (patient or staff). The table shows that average. 
scores and issues they thought patients would provide. This risked excluding discussion of staff distrust in patients, and how that might trigger patient distrust. However in the event this issue arose naturally in the discussions from both staff and patients.

The survey's design tested the validity and relevance of the six tests of trust. It started with open questions about views on the current levels of mutual trust between patients and staff and the current "spirit of cooperation". These were followed by questions that targeted aspects of the diagnostic tests. These questions were described as "relational", and were linked to the diagnostic tests as summarised in table 6.1. The survey concluded with a final open question on what practical changes the participant would make, as a way of testing whether the relational questions had opened up any new thinking about cooperation not captured already.

Table 6.1 Mapping of relational survey question topics to the six tests of trust

\begin{tabular}{|l|l|}
\hline Trust test & $\begin{array}{l}\text { Survey questions tested the extent to which patients } \\
\text { feel... }\end{array}$ \\
\hline Identity & $\ldots$ they are valued \\
\hline Consent & $\ldots$ they have a voice and are treated fairly \\
\hline Responsibility (of state agent) & $\ldots$ there is someone to turn to \\
\hline Relationship & $\ldots$..understood and informed \\
\hline Competence & $\ldots$ satisfied with way service delivered \\
\hline Accountability & $\ldots$..the surgery would put mistakes right \\
\hline
\end{tabular}

A long list of all issues raised by both patients and staff was prepared, without reference to the diagnostic structure. Figure 6.2 summarises the results and was used to brief participants. It shows the quantitative scores for each group, and summarises the main 
qualitative comments offered by group members, under the heading 'top issues'. Positive comments about the current relationship were ticked and potential areas for improvement indicated by a question mark.

Figure 6.2 Summary of the initial survey results

\section{Summary of survey responses}

\begin{tabular}{|c|c|c|c|c|c|c|c|}
\hline Pationt recnonses & & & & & Staff & ponse & \\
\hline $\begin{array}{l}\text { Trust and cooperation } \\
\text { questions }\end{array}$ & $\begin{array}{l}\text { Scores - } \\
\text { out of } 7\end{array}$ & & Top issues & $\begin{array}{l}\text { Trust and cooperation } \\
\text { questions }\end{array}$ & Score & but of 7 & 7 Top issues \\
\hline Can most people be trusted? & 5.22 & $\checkmark$ & $\begin{array}{l}\text { Value of } \\
\text { courtesy and } \\
\text { respect }\end{array}$ & Can most people be trusted? & 4.88 & $\checkmark$ & $\begin{array}{l}\text { Value of friendly } \\
\text { staff and using }\end{array}$ \\
\hline Can the state be trusted? & 4.67 & $\checkmark$ & Professional & Can the state be trusted? & 4.75 & & first names \\
\hline Spint of cooperation? & 5.89 & & $\begin{array}{l}\text { and caring } \\
\text { service }\end{array}$ & Spirit of cooperation? & 5.38 & $\checkmark$ & Focus on patient \\
\hline Trust in staff & 6.00 & & & Trust in patients & 5.50 & & \\
\hline Trusted by staff & 5.89 & $?$ & $\begin{array}{l}\text { Appointments } \\
\text { system }\end{array}$ & Trusted by patients & 5.88 & $?$ & $\begin{array}{l}\text { Consistency of } \\
\text { messages } \\
\text { Coping with }\end{array}$ \\
\hline Relational questions & & $?$ & $\begin{array}{l}\text { consistent } \\
\text { Internal }\end{array}$ & Relational questions & & $?$ & $\begin{array}{l}\text { 'special cases' } \\
\text { Supporting patient }\end{array}$ \\
\hline Valued? & 6.0 & $?$ & $\begin{array}{l}\text { communication } \\
\text { More help from } \\
\text { reception }\end{array}$ & Valued? & 4.88 & & $\begin{array}{l}\text { self help } \\
\text { Empowering } \\
\text { reception }\end{array}$ \\
\hline Fairness? & 6.13 & $?$ & $\begin{array}{l}\text { Continuity of } \\
\text { care and see }\end{array}$ & Faimess? & 4.25 & $?$ & $\begin{array}{l}\text { Reception } \\
\text { Booking system }\end{array}$ \\
\hline Voice? & 6.00 & $?$ & $\begin{array}{l}\text { own doctor } \\
\text { Face to face }\end{array}$ & Voice? & 4.25 & ? & $\begin{array}{l}\text { Impact of media on } \\
\text { perception of } \\
\text { service }\end{array}$ \\
\hline Someone to turn to? & 6,25 & $?$ & $\begin{array}{l}\text { when needed } \\
\text { Sufficient time } \\
\text { with Doctor }\end{array}$ & Someone to turn to? & 5.38 & $?$ & $\begin{array}{l}\text { Managing } \\
\text { expectations }\end{array}$ \\
\hline Individual understanding? & 5.86 & $?$ & Urgent cases & Individual understanding? & 4.63 & ? & $\begin{array}{l}\text { Continuity of } \\
\text { relations/named }\end{array}$ \\
\hline Informed? & 6.25 & ? & $\begin{array}{l}\text { Follow Doctors } \\
\text { advice } \\
\text { Easier Access }\end{array}$ & Informed? & 5.25 & $?$ & $\begin{array}{l}\text { doctor } \\
\text { Customising the }\end{array}$ \\
\hline Satisfaction with delivery? & 6.38 & & & Satisfaction with delivery? & 4.88 & & needed \\
\hline & & & & & & $?$ & Easier access \\
\hline Putting things right? & 6.0 & & & Putting things right? & 5.75 & & \\
\hline
\end{tabular}

As with the Housing Benefit study, the quantitative scores need to be treated cautiously. They helped take the temperature of the relationship and provided a useful point of departure, helping agenda setting and encouraging participant thought and discussion. But they are not statistically valid in themselves. However it is indicative that both the scores and qualitative comments were considerably more positive than the Housing Benefit study. This fits with the view of GPs as the most trusted public servants. The 
challenge for the case study was whether this trust could be improved, and also whether the diagnostic itself could help explain such high levels of trust.

The agenda for the initial patient and staff workshops was derived from mapping the long list of survey comments to the relevant trust test. Each group worked through the issues identified by their own, and the other, group, and agreed the key issues for discussion in the final joint workshop. It became clear that there were several common issues, although each group had different perspectives. For patients, most issues were about difficulties accessing the service (navigating the appointments system and reception, and getting their preferred doctor). The staff also raised access, but in their case how to manage demand by sign-posting alternative provision and enabling greater patient self-help.

The final dialogue session reviewed all the main issues from both groups within each of the relevant trust tests, along with a summary of the reasons for inclusion and any practical suggestions for improvement. Six patient and six staff representatives attended the final meeting. All participants had attended the previous separate group sessions except for one patient (who had completed the survey). There was an engaged dialogue, with participation from both patients and staff, resulting in a number of significant recommendations for change.

\subsection{The diagnostic findings}

This section discusses the issues and recommendations that emerged from the DAR within each of the six trust tests. The six sub-sections describing each test $(6.2 .1-6.2 .6)$ follow a common structure. Each starts with a summary of the intended scope of the test (taken from Chapter 5), followed by a brief description of the main discussion points. Where relevant this is illustrated by quotations from the DAR (labelled patient or staff diagnostic workshop for the initial separate session and dialogue workshop for the combined meeting). Each sub-section then summarises the agreed conclusions of the dialogue in a table (taken from final report of formal process). The first two columns in each of the tables record the patient and staff perspectives. The third column summarises agreements from the dialogue. The final column lists actions arising. The final part of each sub-section reflects on how well the test itself exposed the quality of the relationship, and whether the diagnostic structure worked from the participants' perspective. This led to a 
further tightening of the alignment of the diagnostic structure with the core nature of a citizen/state trust transaction, proposed in the final section of this chapter.

\subsubsection{The identity test - 'Am I respected and what is my role?'}

This concerns the implicit and explicit identity citizens perceive as conferred in the process of interaction with the state. It touches on the defining nature of the relationship itself, and whether citizens feel perceived as active participants, treated with respect.

The survey results and discussions found that patients felt respected. The patients' score for the sense of being valued averaged 6/7. Staff were more wary, predicting the score patients would provide at $4.88 / 7$. The main issues raised by patients and staff were around the patient's role and authority in accessing the service. Patients saw reception staff as a barrier to seeing the doctor, and were sensitive around confidentiality and disabled access. For staff, the biggest issue was how to encourage patient self-help to reduce service demand. Staff also worried that negative press coverage would undermine patient confidence.

In the final discussion, staff and patients coalesced around the role of the reception function. There was an animated discussion about empowering receptionists to become 'health system navigators'; triaging patients in order to signpost the right resource. Patients welcomed faster access to the right service, but emphasised the need for sufficient receptionist training and medical oversight of the process. It also provoked an interesting discussion on whether the patient should have easy access to their own records to check their accuracy. Who defines and owns how the citizen is recorded in a state system touches interestingly on the issue of identity. The exchange between staff ( $S$, in all the transcripts below) and patients ( $P$, in all the transcripts below) on this issue showed a lingering institutional worry about such user empowerment, even within the comparatively benign environment of a well-regarded GP surgery. 
P1: It would be quite good if we could have access to our own records.

P3: You can though.

S5: You can.

P5: You can but they tell that they have to... yeah.

P2: You have a right.

P3: So we request it but I mean easily, like online, I could just login...

S5: Ah you can, on what, yeah. ....

P3: But that information hasn't been communicated because I didn't know that.

S5: It has but very, very smalley because otherwise you can have 8,000 patients wanting their...

P4: Was there a trial done, wasn't one of the PP, Patient Participation Groups did a trial, didn't they about that?

S5: But you can, it is around but I say we've deliberately kept it small because we could potentially... And every doctor, if someone wants to request their records, the doctor has to authorise it, so it's not just quick. Because there's some information that perhaps isn't appropriate in some patients' cases that it could do more harm than good, so.......

The outcomes of this part of the discussion were recorded in table 6.2, summarising both the agreed actions and the mutual concerns.

Table 6.2 Outcomes of the identity test

\begin{tabular}{|c|c|c|c|}
\hline Patient perspective & Staff perspective & $\begin{array}{l}\text { Key points of } \\
\text { agreement }\end{array}$ & Actions \\
\hline $\begin{array}{l}\text { Welcome quicker and } \\
\text { more direct routes to } \\
\text { appropriate (and self } \\
\text { directed care) } \\
\text { Corollary is effective } \\
\text { coordination of patient }\end{array}$ & $\begin{array}{l}\text { Main concern is to } \\
\text { how to help } \\
\text { reception staff to } \\
\text { evaluate need and } \\
\text { refer to right } \\
\text { solution }\end{array}$ & $\begin{array}{l}\text { Key issue is to help } \\
\text { reception staff } \\
\text { provide fuller service } \\
\text { in a way trusted by } \\
\text { patients } \\
\text { A key to facilitating }\end{array}$ & $\begin{array}{l}\text { Form a small task } \\
\text { force to design } \\
\text { and implement a } \\
\text { new role for } \\
\text { reception staff, } \\
\text { enabling them to } \\
\text { give more advice }\end{array}$ \\
\hline
\end{tabular}




\begin{tabular}{|c|c|c|c|}
\hline $\begin{array}{l}\text { information and } \\
\text { patient access to own } \\
\text { information } \\
\text { Also, confidence in } \\
\text { signposting process } \\
\text { enhanced by medical } \\
\text { oversight and more } \\
\text { surgery acceptance of } \\
\text { patient wish for } \\
\text { alternative } \\
\text { provision/private care }\end{array}$ & $\begin{array}{l}\text { What should be the } \\
\text { 'first question' for } \\
\text { the receptionist to } \\
\text { ask - this sets the } \\
\text { scene for and the } \\
\text { role of the } \\
\text { reception. Question } \\
\text { is how to empower } \\
\text { reception to provide } \\
\text { health navigation } \\
\text { advice trusted by } \\
\text { patients? }\end{array}$ & $\begin{array}{l}\text { patient self care is to } \\
\text { empower the } \\
\text { reception function to } \\
\text { perform 'resource } \\
\text { triage', guiding } \\
\text { patients to best } \\
\text { source of help. } \\
\text { Requires creating role } \\
\text { of 'treatment } \\
\text { coordinator' } \\
\text { It is important to get } \\
\text { receptionist training, } \\
\text { authority (e.g. asking } \\
\text { on behalf of doctors), } \\
\text { and 'first question' } \\
\text { right so that patients } \\
\text { trust non-medical } \\
\text { judgment } \\
\text { surgery } \\
\text { communications } \\
\text { (including idea for } \\
\text { surgery face book } \\
\text { page) should } \\
\text { publicise most } \\
\text { common 'pathways'. } \\
\text { The physio direct pilot } \\
\text { was considered a } \\
\text { good model, partly } \\
\text { because the patient } \\
\text { path established } \\
\text { wice provider }\end{array}$ & $\begin{array}{l}\text { to patients. This } \\
\text { proposal would be } \\
\text { discussed with the } \\
\text { patient reference } \\
\text { group }\end{array}$ \\
\hline
\end{tabular}




\begin{tabular}{|l|l|l|}
\hline & $\begin{array}{l}\text { and therefore the } \\
\text { patient need rapidly } \\
\text { acknowledged and } \\
\text { acted upon }\end{array}$ & \\
\hline
\end{tabular}

The issue of identity, embracing both respect and roles, led to a useful and animated discussion. In the housing benefit study, the issue of respect dominated. For this study, the debate was more balanced between the two topics, with almost equal attention on the practical issues of the mutual roles of patient and staff as well as the nature of the service's respect for the patient. The issue of respect was particularly nuanced because it mainly emerged through a comparison between the relationship with doctors and receptionists. There was little complaint about doctors; in fact there were a number of explicit statements of how this sense of respect created the current high trust relationship. By contrast, patients perceived a less respectful culture amongst receptionists. The specific issues raised were very different from the housing benefit study, and the evidence in part derived from positive rather than negative comments, but these results support the view that both aspects of the Identity test - role and respect - are important to the perception of state trustworthiness.

\subsubsection{The consent test - 'What is the (real) deal and is it fair?'}

This concerns the nature and equity of the deal on offer, and how the interests of the individual are perceived to be balanced against the interests of the collective. It addresses the legitimacy of state functions and citizen's perceived 'entitlement' to services.

The initial survey indicated an interesting tension between patients and staff on the consent test. The two relevant survey questions questioned patients on the fairness of decisions taken by the practice and the extent to which they felt they had a voice. Once again patients' scores were very positive (averaging 6.13/7 and 6/7 respectively). Staff anticipated less satisfaction among patients, predicting average scores of $4.25 / 7$ for both questions. 
The issues raised by both groups provided some explanation. Staff were particularly sensitive to their role in equitably rationing services. There was a pointed discussion about how some patients gamed the system (primarily by exaggerating the urgency of a problem to get faster service) and about how to challenge this. By contrast patients were comparatively sanguine about both queue jumping (pointing out that this might demonstrate need, or difficulty in navigating the system) and the way the practice differentiated urgent and non-urgent cases. The main issues for patients were the perception that some processes such as repeat prescriptions were not clear or consistent, and the aspiration for the surgery to become advocates, making patients' voice heard elsewhere in the NHS.

The dialogic process arrived at a practical proposal. The patients suggested a simple 'charter' setting out the key elements of the service on offer from the practice, and how patients should co-operate. In an interesting example of cooperation, a patient framed the proposal as helping the staff manage patient expectations. This was agreed by both groups, and included in the brief for the task group to develop.

\section{Dialogue workshop}

P2: I was just, just saying that, you know, the emphasis always seems to be on the, the, the patients, what they should expect from...

P6: Mhm.

P2: You know, the doctor surgery. And I'm thinking that, you know, you need to turn it the other way; what does doctor surgery expect from you? And that you could have just, sort of, I don't know, four points on each side and say, you know, this is what we, I don't know, this is what we expect of you and this is what we expect of you, so from all sides.

[...This was discussed and the conclusion was enthusiastic staff approval...]

S1: I think it might be something that might be useful to put on the, on the new patient pack, to actually have an, almost an agreement in there that this person...

S7: Yeah. 
S1: So that they read it, they tick it and they say, I will, you know, do this and I will do this and in, and in response, we will do this, this, this and this....

The outcomes of this aspect of the dialogue are summarised in table 6.3.

Table 6.3 The outcomes of the consent test

\begin{tabular}{|c|c|c|c|}
\hline Patient perspective & Staff perspective & $\begin{array}{l}\text { Key points of } \\
\text { agreement }\end{array}$ & Actions \\
\hline $\begin{array}{l}\text { Suggest clear } \\
\text { statement of what } \\
\text { service standards } \\
\text { can be expected } \\
\text { from surgery and } \\
\text { what expected from } \\
\text { patients } \\
\text { Understand priority } \\
\text { of high need. } \\
\text { Patients 'gaming } \\
\text { system' may still be } \\
\text { in real need of help } \\
\text { Some patients would } \\
\text { value more help with } \\
\text { complex forms and } \\
\text { finding the right } \\
\text { advice }\end{array}$ & $\begin{array}{l}\text { Expectations of the } \\
\text { service have risen } \\
\text { over the years } \\
\text { Health bodies give } \\
\text { contradictory } \\
\text { messages about } \\
\text { visiting GPs } \\
\text { Need to explain and } \\
\text { educate patients on } \\
\text { what expectations } \\
\text { are legitimate and } \\
\text { what alternatives are } \\
\text { available } \\
\text { Want to respond to } \\
\text { 'special cases' but } \\
\text { inconsistency causes } \\
\text { increased demand } \\
\text { and distrust from } \\
\text { others } \\
\text { Need for consistency }\end{array}$ & $\begin{array}{l}\text { Need for common } \\
\text { understanding of } \\
\text { legitimate } \\
\text { expectations of each } \\
\text { party } \\
\text { Surgery and patient } \\
\text { reference group will } \\
\text { develop a service } \\
\text { agreement } \\
\text { articulating the } \\
\text { mutual expectations } \\
\text { of surgery and } \\
\text { patients } \\
\text { Amongst other issues } \\
\text { this would address } \\
\text { how routine and } \\
\text { urgent cases are } \\
\text { prioritised, the } \\
\text { timeliness of surgery } \\
\text { activities, and } \\
\text { common processes } \\
\text { such as repeat }\end{array}$ & $\begin{array}{l}\text { Refer to task force } \\
\text { working with } \\
\text { patient reference } \\
\text { group }\end{array}$ \\
\hline
\end{tabular}




\begin{tabular}{|l|l|l|l|}
\hline & $\begin{array}{l}\text { in approach from all } \\
\text { sections of surgery. } \\
\text { including doctors }\end{array}$ & $\begin{array}{l}\text { prescriptions } \\
\text { It would also set out } \\
\text { clearly the } \\
\text { procedures patients } \\
\text { Advocacy role with } \\
\text { secondary care adds } \\
\text { to demands on } \\
\text { services }\end{array}$ & $\begin{array}{l}\text { were expected to } \\
\text { follow to ensure } \\
\text { equity in the system }\end{array}$ \\
\hline
\end{tabular}

Several conclusions can be drawn about the utility of this test. Discussing equity and voice provoked an important and lively discussion. This confirmed that in the public sector how the individual service offer fits equitably within broader collective provision is a key consideration for trust for users and providers. However the discussion also suggests some refinements to the questioning within this theme. Firstly, it is interesting that this debate arrived at the proposition for a service charter, just as with the housing benefit study. This prompts an additional supporting question around the perceived clarity and transparency of the service offered, which can be seen as a precondition for discussing consent. The second point also echoes the housing benefit study; the patient issue was not consent per se, but how to register dissent. The main issue issues were getting access to a doctor, and also the surgery's role in helping the patient register concerns within the NHS. I return to this in the final chapter.

\subsubsection{The responsibility test - 'Is there someone with whom I can do business?'}

This concerns the nature and capability of the public sector counterparty to the citizen, and their ability to expedite the issue at hand. It reflects the importance to citizens of a consistent and known point of contact who can be held responsible for delivery of the service or activity within a meaningful interaction.

The survey question exploring whether patients felt there was someone to whom they could turn for help gained the most positive response of any (6.25/7). Staff also predicted a positive response, anticipating a score of 5.25/7. Both parties saw this as a strength in the relationship. However, for patients, this test provoked discussion of areas where the 
system seemed to fragment responsibility. At a personal level they emphasised the importance of continuity in seeing the same GP, especially for continuing treatment of the same condition. More systemically, they accepted the need for greater delegation, and that the days of the family doctor consistently available had past. However they saw the corresponding need for the practice to pool information on each patient, and for a single point of responsibility to take a holistic overview. This aspiration was not confined to the GP surgery; it also embraced the role of GPs in championing patients' interests elsewhere within the NHS.

The staff group were sensitive to the issue. The need to join up service delivery was evident in practical attempts to integrate internal systems. One staff member explained the thinking to the patients in the final dialogic workshop.

\section{Dialogue workshop}

S1 ....So what we try to do is, so you hear me talking about that veneer of trust, what we try and do is pass some of that trust on to somebody else. So we have, in some cases, we have what we call shared care, so we have a nurse who is able to do the long term condition and reviews but the blessing was given by the doctor for the patient to go to the nurse for that review, and the doctor isn't letting go. What they're saying is, "the nurse will do your review; if she picks anything up, then it will be relayed back to me and I will make a decision about what needs to be done".

Staff were also aware of the problem of system fragmentation. They shared patients' frustration at the lack of coordination with related secondary or community health services, such as mental health services and hospital appointments. The GP practice was often seen as the gatekeeper, but in fact had little authority. This shared perspective was recorded in the final recommendation from the combined discussion, summarised in table 6.4 . 
Table 6.4 The outcomes of the responsibility test

\begin{tabular}{|c|c|c|c|}
\hline Patient perspective & Staff perspective & $\begin{array}{l}\text { Key points of } \\
\text { agreement }\end{array}$ & Actions \\
\hline $\begin{array}{l}\text { Importance of seeing } \\
\text { same doctor, } \\
\text { particularly for } \\
\text { ongoing cases } \\
\text { Personal relationship } \\
\text { important to trust; } \\
\text { doctors regarded as } \\
\text { friends } \\
\text { Sometimes } \\
\text { messages not } \\
\text { communicated } \\
\text { across sections (e.g. } \\
\text { doctors' discretion on } \\
\text { repeat prescriptions?) } \\
\text { If seeing someone } \\
\text { other than own } \\
\text { doctor, patients want } \\
\text { information to be } \\
\text { pooled }\end{array}$ & $\begin{array}{l}\text { Doctors also } \\
\text { welcome continuity } \\
\text { of relationships with } \\
\text { patients, however } \\
\text { can be a bottleneck } \\
\text { in the system } \\
\text { Sometimes patients } \\
\text { present different } \\
\text { issues to reception } \\
\text { and doctors } \\
\text { Need for consistent } \\
\text { messages, actions, } \\
\text { and information } \\
\text { feedback across all } \\
\text { sections of surgery } \\
\text { and partners }\end{array}$ & $\begin{array}{l}\text { Key issue is } \\
\text { continuity of care } \\
\text { The surgery tries to } \\
\text { allow patient to see } \\
\text { preferred doctor } \\
\text { (particularly for } \\
\text { ongoing conditions); } \\
\text { however high } \\
\text { demand requires } \\
\text { some delegation } \\
\text { from doctor to others } \\
\text { including other } \\
\text { health professionals } \\
\text { Implication is that all } \\
\text { information should } \\
\text { be reported to single } \\
\text { named doctor for } \\
\text { overall oversight } \\
\text { Patients can refer } \\
\text { problems to doctor } \\
\text { via phone } \\
\text { to register with most } \\
\text { appropriate doctor in } \\
\text { the first instance }\end{array}$ & $\begin{array}{l}\text { Practice charter } \\
\text { should commit to } \\
\text { trying to achieve } \\
\text { continuity of doctor } \\
\text { for same condition, } \\
\text { and explain how } \\
\text { patient information } \\
\text { is collated if } \\
\text { derived from } \\
\text { multiple sources }\end{array}$ \\
\hline
\end{tabular}


Continuity of care within the practice was significant to patients and staff. The practice's efforts to maintain as much continuity as possible were a principal explanation given by both groups for the positive mutual relationship. Perhaps this is one reason that GPs are consistently the most trusted professionals. Patients were frustrated by the systemic inability of the rest of the NHS to replicate that sense of responsibility.

The empowerment (or not) of the frontline worker to respond effectively to citizens emerged strongly in this study, and that for housing benefit. The comparative power of doctors within the system may strengthen trust. The role of reception staff in the relationship test is discussed next. It also links to the issue of competence, to which I return in the final section.

\subsubsection{The relationship test - 'Am I being treated with empathy, and do I understand what is going on?'}

This concerns the quality of the emotional and communicative 'connectivity' the citizen feels when interacting with the state. It addresses issues of empathy and compassion, as well as the clarity, accessibility and comprehensiveness of information exchanged.

Patients were again considerably more positive than staff anticipated. Patients scored 5.86/7 on how well they felt the surgery understood their needs; staff predicted 4.67/7. Patients rated the quality of information provided by the surgery at $6.25 / 7$; staff predicted $5.25 / 7$. Once again, the two groups articulated a similar set of issues. Both picked up on the theme from the identity test around the perceived difference in the relationship between patients and doctors, and patients and receptionists (but this time in the context of empathy rather than roles). Patients felt a strong relationship with doctors, raising only the issue of rigid ten-minute appointments. But patients felt a colder, less helpful attitude from receptionists, as the following exchange illustrates. 
P2: For me with receptionists, the big thing is empathy. That's the big thing, not the, what do you want now? [Unclear 01:59:30]. And you're much less likely to open up to somebody who asks, "what are your symptoms? Can I help in another thing...?" If you, if you get empathy. the patient's more likely to open up to you anyway.

S7: Some, some of that is also, sort of, communication skills, isn't it? P2: Yes, exactly. Yeah.

S7: They may be feeling the empathy but if they're not showing you...

P2: Yeah. Yeah. You know, l've experienced both ends and depending on the receptionist and sometimes you're thinking what am I going to get today? Am I going to get the sigh.....

S7: That's the consistency then as well, isn't it?

In their initial diagnosis workshop, staff anticipated this perception. In the course of the discussion an idea emerged for changing the reception layout to encourage patients and staff to interact more informally, as crystallised in the following exchange.

\section{Staff diagnosis workshop}

S8; I just... You're just completely set up from the patients... You don't [unclear].

S7: [Unclear].

S8: You can't... I just find it odd. They [patients] come in and they book in, and they've got to sit in the waiting room. Now, until they go in and see the doctor, that's your waiting room. You'll keep an eye on the patients. If you need to speak to a patient, you have to go all the way out, or if they need to come and ask a question, they need to come all the way in. And so more often than not, I find that if they need to know anything, they won't ask anything. If nothing, they'll ask on the way out. Then they just don't bother.

S7: So if we knock down that wall between reception...

S8: I just think it makes people look more approachable if they're sat in the same room. S5: Yeah, if they're sitting there and think oh, I've just got this question, oh, there's no one at the desk at the minute. I'll just go and ask.

S8: Because everyone's opinion of this surgery that I asked before I started working here 
was... Fantastic surgery. What's reception like? Oh, I don't know, I don't have any idea.

Do they have reception?

S7: That's really interesting.

The proposal to help empower receptionists in support of patients was welcomed enthusiastically by everyone. The discussion and recommendations are summarised in table 6.5.

Table 6.5 The outcomes of the relationship test

\begin{tabular}{|c|c|c|c|}
\hline Patient perspective & Staff perspective & $\begin{array}{l}\text { Key points of } \\
\text { agreement }\end{array}$ & Actions \\
\hline $\begin{array}{l}\text { Make it easier to ask } \\
\text { questions, however } \\
\text { small or } \\
\text { embarrassing } \\
\text { Suggested } \\
\text { preparation sheets } \\
\text { for patients to fill in if } \\
\text { multiple needs } \\
\text { Attitude of reception } \\
\text { is more important } \\
\text { than knowledge; } \\
\text { more valued in } \\
\text { sympathy, smiling, } \\
\text { eye to eye contact, } \\
\text { and listening } \\
\text { Sometimes a face to } \\
\text { face meeting is } \\
\text { essential, or perhaps }\end{array}$ & $\begin{array}{l}\text { Make reception } \\
\text { more accessible to } \\
\text { people in waiting } \\
\text { room to encourage } \\
\text { interaction and } \\
\text { questions } \\
\text { More flexibility in } \\
\text { process, such as } \\
\text { saying will phone } \\
\text { back later with } \\
\text { information (but } \\
\text { must follow through) }\end{array}$ & $\begin{array}{l}\text { Make reception } \\
\text { service more } \\
\text { accessible and open } \\
\text { Friendlier waiting } \\
\text { area encourages } \\
\text { patients to ask } \\
\text { questions, and } \\
\text { allows deeper and } \\
\text { more empathetic } \\
\text { relationships; } \\
\text { practical issues } \\
\text { around } \\
\text { confidentiality could } \\
\text { be overcome }\end{array}$ & $\begin{array}{l}\text { Proposal for } \\
\text { restructuring } \\
\text { reception area, } \\
\text { including knocking } \\
\text { down adjoining wall } \\
\text { with patient waiting } \\
\text { area, to be put to } \\
\text { the practice } \\
\text { management group }\end{array}$ \\
\hline
\end{tabular}


Both groups engaged with the discussion, and the proposal for the reception area was warmly welcomed as significant both culturally and practically. These results support the housing benefit study finding that for citizens the way relationship is constructed is as important as what is done. It also confirms that to citizens many important factors are evident in the micro dynamics of the interaction, including language, the use of space, and the emotional culture of the different staff groups.

However a practical learning point for the test is that for participants, conflating the two aspects of the relationship test (the understanding and empathy felt by the patient for their situation, and their understanding of the information being provided as a result of that understanding) was not entirely successful. It was revealing that the relationship discussion returned to similar territory to the identity test. On reflection this makes sense, as the group was making a natural link between respect and empathy; empathy emerges as a precondition for respect. In addition, as discussed below there was considerable overlap in the discussions between this category and the competence test around the surgery's communication with patients. Both these considerations contributed to the proposed restructuring of the tests discussed in the final section of this chapter.

\subsubsection{The competence test - 'Is the service efficient, and do people do what they say?'}

This concerns the perceived capability of the service to act effectively and efficiently. It addresses the quality of delivery, whether staff do what they say they will do, and whether the process of production looks sensible to the user.

Satisfaction with service delivery followed a similar pattern. Very positive results came from patients (6.38/7), but staff anticipated worse (4.88/7). Reasons for staff apprehension were dominated by the appointment system, and patients' frustration at the difficulty of getting access. Patients' discontent arose from having to ring when new slots for appointments were released at 8.30 each day. This could be personally inconvenient, but 
also raised concerns about the surgery's systemic competence, as the exchange below makes clear.

\section{Patient diagnosis workshop}

P5: The point I want to make is the 8:30 - you can't make an appointment unless you phone on the day. Now I can understand that for say, you suddenly become ill, but if you've got something you want to see the doctor about and you know sort of next week, you've still got to wait to make a phone on the day at 8:30 and everybody's phoning at $8: 30$ and it gets a little bit sort of.... And I wish we could still sort of say, right in a week's time doctor says they want to see you, make an appointment, so and so. But it seems everything's starting, you've got to phone at 8:30 and I don't know whether anybody else finds that as well. You know.... can understand that for emergency [unclear].

P1: I never even bother because you never get through, so I....

P5: Well I find if I phone...

P1: I always just queue. [Laughing].

P5: If you phone at $8: 25$ it becomes $8: 30$ because my $8: 25$ is their $8: 30$. [Laughing]. So, with different clocks, different times.

P2: I can't remember the last time I phoned because I never get through.

P5: Oh I do quite [unclear], it was...

P1: I always just come.

Clearly several patients had given up telephoning entirely and queued at the surgery. One patient poignantly asked for a shelter when the line extended outdoors.

Patient diagnosis workshop

P4: Kind of related to that is... Okay we've kind of accepted we have to queue and that, so can we please have a shelter. [Laughing]. Absolutely drenched, in the winter it's freezing.

P6: Yeah, so I can ...

P4: And there used to be a shelter, the plastic one there and they've taken it away. P6: Oh yes. That's right, you can see that. 
P4: And so you're just standing in the pouring rain, you see some people in wheelchairs getting absolutely drenched.

Staff showed an awareness of patients' frustration, but also a defensiveness, perhaps born out of impotence at finding any better solution. The report of the patients' views provoked the following exchange:

\section{Staff diagnostic workshop}

S2: I think our appointment system is quite good.

S4:Yeah, I think so as well.

S2: I mean, I don't know about anybody else, whether anybody else tried to get appointments at their own GP, you can never get an appointment.

S4: It takes months.

S2: Yeah. Like here, you know, I don't think the people really have to wait.

S5: The main thing they were saying was they couldn't physically get on the phone at $8: 30$.

Discussing this in preparation for the dialogic session noticeably heightened the urgency with which staff addressed the issue, and led to what felt like a much more grounded and honest discussion of the issue in the combined session.

\section{Dialogue workshop}

P4: Would you say that all those that come needed to come?

S7: No, and I think that goes back to our previous one about honesty and trust really, is that, quite understandably, patients say, the only way I can get to see a doctor is by saying it's urgent for today, so that's what l'm going to do. And you can't blame them really, but it means they usually see the wrong doctor for the wrong problem at the wrong time and they get an exhausted doctor when they could have seen, you know, [unclear].

P4: So it's about education.

S7: Yeah, yeah.

P3: Is there a priority for children or, or anything like that? 
S7: No, there isn't a priority currently, no.

P3: No.

S7: No. Because all ages will have the same sort of...

P3: Yeah, yeah. I didn't know there was...

S7: issues of being acutely ill. I mean, effectively, we don't really turn people away... P4: No.

S7: But we... And that's where the big, I think for me, that's the big trust thing of trying to match expectation against capacity....

The outcome was better mutual understanding of the rationale for the current system and some practical measures to ameliorate the worst aspects, for example more use of the online system and confirmation of the value of reception guiding patients to other resources where appropriate. The appointment system dominated the agenda within this test. However there was also a productive discussion about helping patients follow a doctor's advice by making sure that notes or printouts were provided of all important instructions made during consultations. These agreements are summarised by table 6.6.

Table 6.6 The outcomes of the competence test

\begin{tabular}{|c|c|c|c|}
\hline Patient perspective & Staff perspective & $\begin{array}{l}\text { Key points of } \\
\text { agreement }\end{array}$ & Actions \\
\hline $\begin{array}{l}\text { Booking system: } \\
8.30 \text { bottle } \\
\text { neck/getting through } \\
\text { on phone. Easier to } \\
\text { queue in person (but } \\
\text { no shelter),not } \\
\text { online, inability to } \\
\text { make appointments } \\
\text { at other times } \\
\text { means cannot plan } \\
\text { ahead (e.g. when Dr } \\
\text { says see me again }\end{array}$ & $\begin{array}{l}\text { Booking system: } \\
8.30 \text { bottleneck } \\
\text { More receptionists } \\
\text { would just mean } \\
\text { appointments filled } \\
\text { quicker } \\
\text { Online system is } \\
\text { working }\end{array}$ & $\begin{array}{l}\text { The key issues are } \\
\text { the appointments } \\
\text { system and how to } \\
\text { help patients follow } \\
\text { doctors' advice } \\
\text { Booking system: } \\
50 \% \text { of } \\
\text { appointments } \\
\text { released ahead, } \\
50 \% \text { on the day. } \\
\text { That policy still }\end{array}$ & $\begin{array}{l}\text { Outside shelter to be } \\
\text { recommended to } \\
\text { practice } \\
\text { management group } \\
\text { Doctors to have } \\
\text { notepads to help }\end{array}$ \\
\hline
\end{tabular}




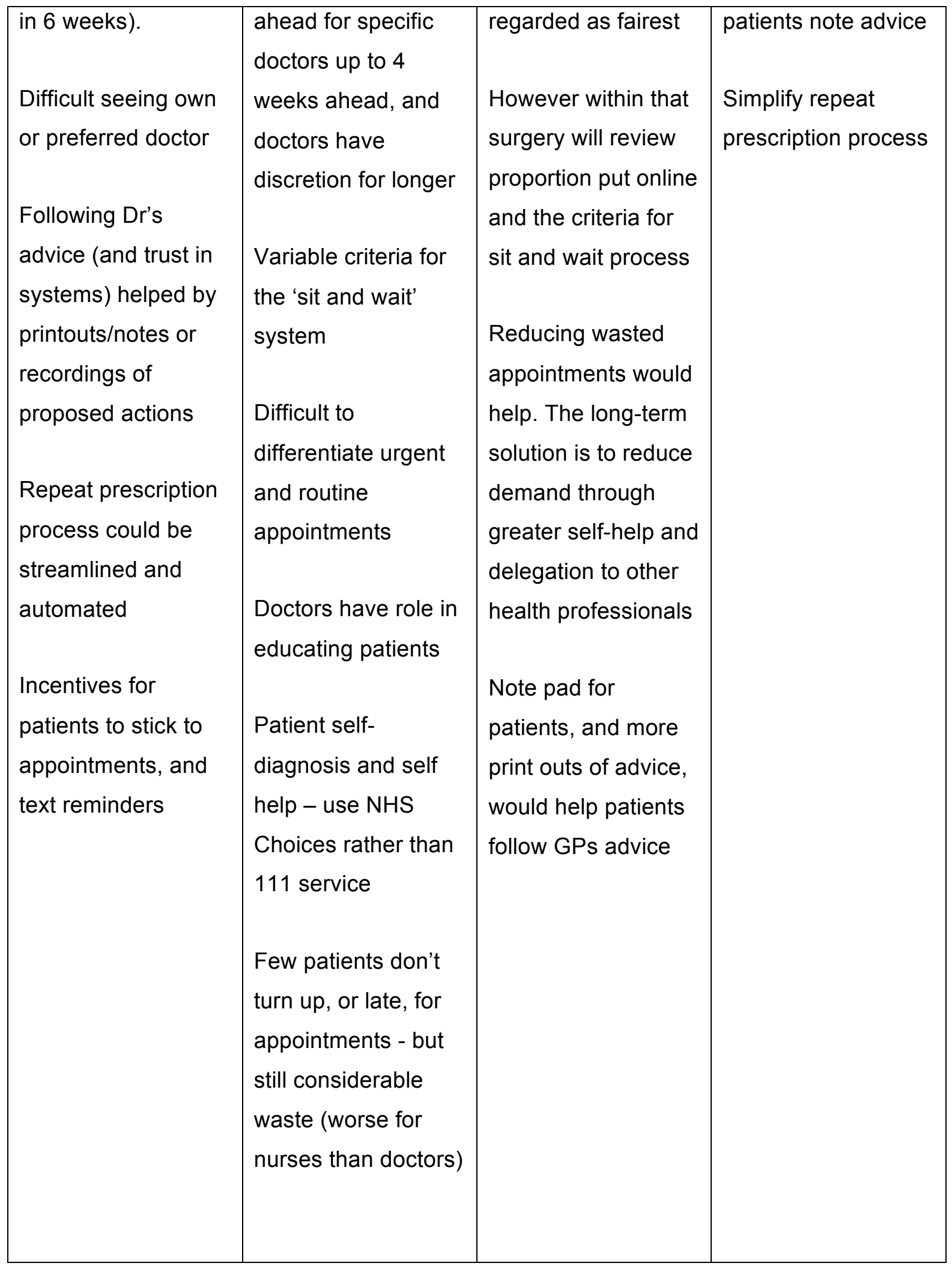


The passionate debate around the appointment system illustrates the importance of competence to citizens, in both systems as well as individuals. However the gap between the strong emotions in discussion compared to the very positive initial score is also interesting. It demonstrates the importance of deliberative debate in exposing issues beneath the surface of the quantitative survey. The debate gathered momentum during the dialogue. Surfacing the issues in the early stages of the DAR seemed to give the patient group increasing confidence to articulate previously tacit concerns. This also seemed an interesting example of the holistic nature of the overall relationship of trust, as patients' belief in the personal competence of doctors seemed to make patients more forgiving - at least in the initial scores - when frustrated by this aspect of the system.

A further reflection is that patients and staff seem to apply a relatively nuanced and sophisticated approach to competence, understanding that the capability of a public service is made up of a combination of personal skills, system procedures, and frontline empowerment. It was also interesting that in practice this test was closely associated with two others - the responsibility test (part of responsibility is to ensure adequate ability to deliver) and the accountability test (how to monitor and report on competence in the delivery of a service). This contributed to the restructure of the tests described in the final section.

\subsubsection{The accountability test - 'Is my trust being vindicated, and if not can I make sure that things are put right?'}

This concerns the governance of the interaction. It relates to issues of power and interdependence and addresses how citizens can assess whether things have turned out as they expected, and their faith in the mechanisms for resolving distrust if things go wrong.

This test was less controversial. In response to the survey question about whether mistakes would be put right, patients scored an average 6/7, while staff averaged 5.75/7). There seemed a shared sense that the surgery's culture was to prioritise patient complaints and wherever possible resolve them as they arose, as one staff member explained to the researcher $(R)$. 
S1: .....it's always been our philosophy that we don't want to make mountains out of molehills, get people in front of us...

R: Yeah.

S1: We'll talk to them, that's fine. You know, I have to do a report every year about complaint letters that we've had...

R: Yeah.

S1: And I'm struggling to find stuff.

S8: Yeah.

S1: Which is a good way to be.

Patients reflected a similar sense that the surgery was concerned to understand and rectify errors or resolve complaints. For patients, it was important that the surgery followed through on commitments; this was seen as strength of the surgery. Indeed one of the main issues for the patient group was the need to encourage patients to be more assertive in voicing concerns rather than criticise the staff for not being receptive, as illustrated below.

Patient dialogue workshop

P4: But again I think it is down to us because sometimes here, you know, when that chatting, which your doctor da, da, da, ooh so and so, so and so. Did you tell him? Did you speak? Did you, you know and they said: oh no. And I think, you know it's up to us if you think something's not right to say. You know I don't think, because otherwise how will they, how will they know?

This shared view was reported in table 6.7. 
Table 6.7 The outcomes of the accountability test

\begin{tabular}{|l|l|l|l|}
\hline Patient perspective & Staff perspective & $\begin{array}{l}\text { Key points of } \\
\text { agreement }\end{array}$ & Actions \\
\hline $\begin{array}{l}\text { Important for staff to } \\
\text { follow through on } \\
\text { commitments }\end{array}$ & $\begin{array}{l}\text { Culture is to resolve } \\
\text { issues at the time, } \\
\text { always accept } \\
\text { mistakes, and put } \\
\text { right if communicated }\end{array}$ & $\begin{array}{l}\text { Surgery committed } \\
\text { to enhancing current } \\
\text { culture of } \\
\text { accountability and } \\
\text { trying to resolve } \\
\text { issues as they arise }\end{array}$ & $\begin{array}{l}\text { Review } \\
\text { accessibility of } \\
\text { complaints process } \\
\text { added to the brief } \\
\text { of task group } \\
\text { working with } \\
\text { patient reference } \\
\text { group }\end{array}$ \\
& & $\begin{array}{l}\text { All staff expected to } \\
\text { follow through on } \\
\text { actions }\end{array}$ & \\
\hline
\end{tabular}

The lack of contention within this test appeared to reflect the strong relationship between surgery and patients, rather than the test being unimportant. Reviewing the transcripts, it was also apparent that the key issue for patients was less the question of redress in the event of service failure (which was such a large part of the Housing Benefit study) than the ability to challenge if promised actions such as calling back were not fulfilled. In this sense the discussion overlapped most with the consent test, and the importance of clarity over what expectations of each other were legitimate.

\subsection{A refined diagnostic structure}

The findings in this chapter, and those from the housing benefit case study, need careful interpretation. They are only two public services, and the themes and tests they have identified are at best emergent. However there is much that resonates with the wider evidence in Chapter 2, and there were many common themes in the two case studies. This section reflects on the learning, both positive and developmental, to be derived from the study - and building on this makes proposals for restructuring the diagnostic. This restructure is mainly a reconfiguration of the tests used so far, bringing together 
commonalities and aligning more closely to the three part model of the citizen/state trust transaction. Some additional underpinning questions are also proposed.

The framework and process proved helpful in exploring the relationship between patients and staff at the surgery. Each test generated an engaged debate between patients and staff and these discussions gave rise to practical steps to enhance trust and cooperation. The grounded nature of many of the suggestions also supports the broader proposition that enhancing trust and cooperation between citizen and state could produce practical mechanisms for improving service outcomes. There was also considerable positive feedback on the benefits of the dialogic process as a way of constructively exploring issues and solutions. Finally there were significant commonalities between the findings of the two case studies, such as the importance of respect and empathy, the need to understand mutual expectations and the aspiration for a sense of responsibility as well as competence from the state.

However, before exploring these substantive findings, the prior question is to test the integrity of the data, especially as it was generated by the use of a targeted diagnostic. As with the use of the evaluation framework described in chapter 4 , this poses the twin risks of excluding issues that fall outside the tests posed to the participants, or misunderstanding the significance of issues by aligning them with inappropriate headings. The mitigation for the first of these risks was to use the initial participant survey to ask open questions probing the issues the minds of participants, prior to focussing on questions mapped to the diagnostic tests. Table 6.2 summarises all the substantive issues raised before they were allocated to the relevant test. As with the mapping of trust elements to the evaluation framework described in chapter 4 , the main difficulty in allocating issues to specific tests was if they were described in general terms. For example, one of the issues raised by the staff group was the aspiration for greater 'customisation of the service'. In discussion this was seen as impacting on a number of the tests, including the identity test (to understand individual need), the consent test (to articulate better the individual service 'offer') and the competence test (the ability to provide a more individualised service). Once unpacked to this level of granularity there were no issues that could not be assigned to a relevant test. This was a reassuring test of theory in that the structure of the diagnostic, derived from the relational model and the 
relational framework, was intended to be comprehensive of the main relational dynamics at play in a citizen/state interaction.

However reflecting on the internal coherence of the diagnostic in mapping the data to the tests prompted more challenging questions. There were a number of significant learning points for the structure of the diagnostic, in part to make it more intuitive for participants, and in part to tighten the intellectual rigour of the analysis. In practice, the discussion flowed across a number of tests at the same time, as noted in the individual sections above. Combining some of the related tests would also help align them more clearly with the three parts of the trust model described previously, reinforcing the original design intent in using the structure as the architecture for the tests. Reflecting on these observations, and also bearing in mind the value of simplifying the diagnostic to its essential elements, led to a final revised structure for wider use as the final output of this study. This revised approach more clearly differentiates the analytic and normative aspects of the diagnostic. This is helpful theoretically and also practically, as it creates more flexibility to add other normative tests within the same structure, should these emerge in other service contexts.

Thus the final proposed approach strengthens the orientation of the diagnostic tests within the analytic structure offered by the trust version of the public value relational model. This aligns the top-level diagnostic themes according to whether they are targeting issues to do with:

- How the citizen as trustor perceives the recognition of their identity and need by the state (aligning with the respect theme described below)

- The degree of confidence of the citizen in the arrangements for the coordination and governance of the relationship (aligning with the consent theme described below)

- How the citizen judges the attributes of the state as trustee, in delivering to citizen expectations (aligning with the responsibility theme described below). 
The actual diagnostic tests that align to this analytic structure - represent the normative aspirations of citizens for the specific qualities of the trustworthy state as revealed by the fieldwork for this study. The result is a three-fold structure as an umbrella for the tests. In this revised approach the three top-level headings are more accurately understood as themes, which then embrace a number of more specific tests. The first of these themes integrates what was previously the identity test along with the empathy component of the relationship test. This is now called the respect theme to acknowledge the dominant normative aspiration in this area. The second theme retains the concept of consent as its defining characteristic, but also integrates the elements of what was previously the accountability test. The third theme is a revised version of the responsibility test that encompasses elements of competence.

Underpinning each of these themes are the specific tests developed for the case study described above, and incorporating additional emerging factors. These tests are still described as generic, and are intended as comprehensive of all the issues encountered in the case study. However should other issues emerge in other usage of the diagnostic more tests can be added. Aligning the tests more clearly within three high level and easy to explain themes, which are themselves linked to the three essential elements of a citizen/state trust transaction, offers a coherent intellectual framework, and one tested in the course of the study. It also better reflects the rhythm and tenor of the discussions in the dialogic sessions described above. Finally describing the tests in this way gives a clearer line of sight back to the trust typology, offering reassurance that these tests fit with theory as well as practice.

This is important as the evidence here supports the observation that the citizen aspiration is for a different norm of trust in their interaction with the state than that on offer. The form adopted by citizens is nuanced, but it combines a more social element along with instrumental trust. It also seeks a more active trust, particularly in terms of a sense of responsibility from the state, and more collaborative governance.

Figure 6.3 illustrates the logic of the proposal and is followed by a fuller listing of the underpinning tests of trustworthiness within this simplified structure. 
Figure 6.3 The three sets of tests of trustworthiness

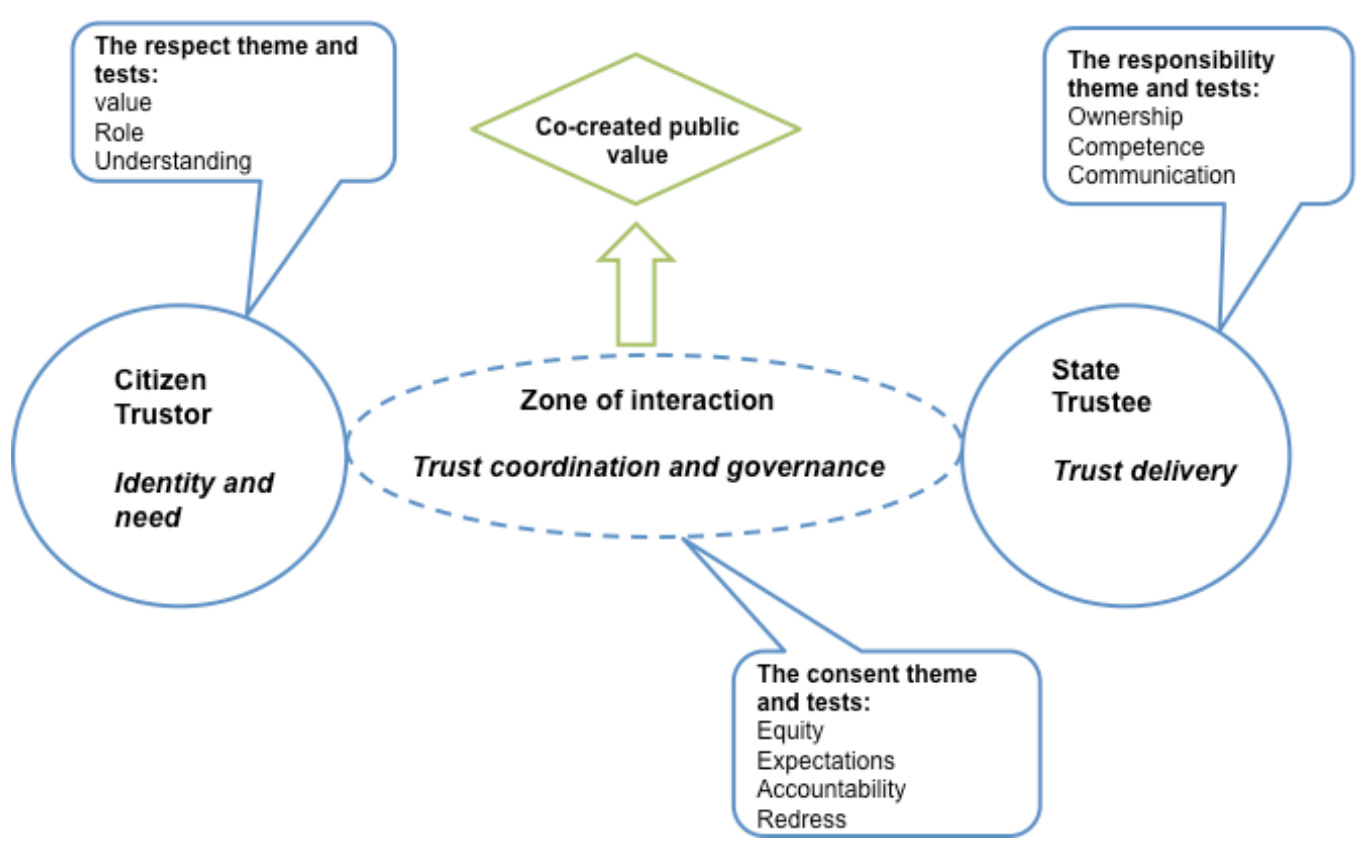

Below is a summary definition of each theme, with each underpinning test.

The respect theme and tests concern the implicit and explicit identity citizens perceive as conferred on them while interacting with the state. It assesses how far citizens feel they are treated with respect as a genuine 'presence' in a citizen/state interaction. It is evidenced by the citizen perception of whether they are valued and understood as individuals, and whether they feel they have a meaningful role. These tests are most focused on where citizens consider the trust relationship sits on the instrumental/social axis of the trust typology. They also reflect a corresponding implication from the passive/active continuum, reflecting citizens' important role in service delivery. It has three distinct diagnostic sub-components:

- Do you feel valued by the service? (previously in the identity test) 
- Do you feel you play a full part in the service? (previously in the identity test)

- Does the service fully understand your needs and capabilities? (previously in the relationship test).

The consent theme and tests concern the governance of the interaction, and whether citizens feel they have sufficient traction on its nature and success. It is evidenced by whether citizens feel the service on offer is fair and appropriate, whether they have agreed to it (mainly through recognition of dissent), whether there is transparency in assessing whether it has been achieved in practice or not, and finally whether they believe the public body will rectify errors. These tests correspond most closely to the dependency/interdependency aspect of the trust typology, and concentrates on the options for the governance mechanism offered by trust. It is also supported by several diagnostic subcomponents:

- Do you think the service is treating you fairly? (previously in the consent test)

- Do you know what to expect from the service, and what it expects from you? (new test to reflect recurring point from case studies)

- Do you feel you have a voice in assessing the quality and delivery of the service? (previously in the accountability test)

- Do you believe that the service would admit to mistakes and put things right if they went wrong? (previously in the accountability test).

The responsibility test completes the diagnostic by assessing the degree to which citizens feels confident in the capability and commitment of the state to deliver on the relationship and perceived obligations. It is evidenced by the perception whether the state is organised to take ownership of an issue, whether citizens feel they have adequate and transparent communication with the state, and their sense of the competence or otherwise of staff and systems. These tests focus primarily on the citizen's perception of whether the state is operating to an active or passive form of trust, although it also resonates with the 
implication of a more social form of trust as citizens expect the state to have a sense of ownership of the issue. It is also underpinned by several diagnostic components:

- Do you understand who in the service is responsible for ensuring your satisfaction with the service? (previously in the responsibility test)

- Do you have confidence that the service will deliver to your satisfaction? (previously in the competence test)

- Do you believe that the service is organised in a sensible and efficient manner? (previously in the competence test)

- Do you believe that the service is transparent and effective on communicating what is going on? (previously in the relationship test).

There is a final implication of this revised structure. Simplifying the tests in this way should makes it easier to embed them in the systemic governance of the relationship, as as well as a one off diagnostic, by making it easier to get immediate feedback at the level of the themes at least. The other implication is to prioritise the identification and resolution of dissent. This is discussed further in the next chapter. 


\section{Critical evaluation and future lines of inquiry}

This chapter concludes the thesis by evaluating how far the study achieved its objectives, through considering the main theoretical and empirical challenges to the results.

In chapter 1 the research questions explored by this study were described as twofold. The first was to understand the tests in the mind of citizens when assessing the state's trustworthiness, and whether these are different in kind to the norm of trust and trustworthiness in use within the agencies of the state. The second question followed; once identified, can these tests help structure the citizen/state relationship to encourage a more co-operative interaction? The ambition was to explore whether trust, as a mechanism of governance for the relationship, could supplement voice and choice in helping to create a relational paradigm of cooperation rather than compliance. The scope of the questions and ambition were illustrated with a 'trust version' of the public value relational model, incorporating the three-part definition of trust described earlier, and reproduced below in figure 7.1. The study was designed to explore what would enable the citizen as trustor (1) to trust the state as trustee (2) in the pursuit of the trust transaction within the zone of interaction (3).

Figure 7.1 The research question and trust version of the public value relational model

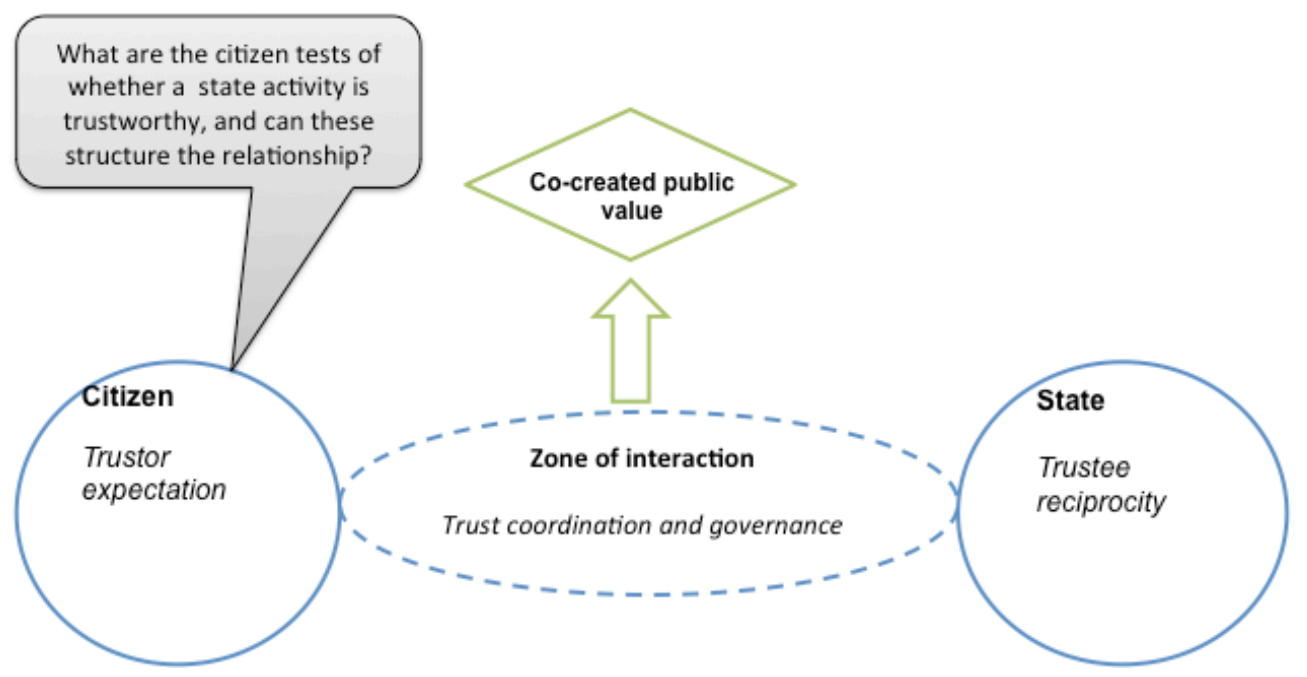


The answers to these questions developed in the course of the study are emergent, but suggest that there is merit in the approach. Both the research method and findings help to illuminate significant aspects of the direction of travel. The study argues that the three fold diagnostic structure and supporting tests summarise the empirical evidence on the factors that citizens associate with state trustworthiness. Specifically, highlighting the importance of the relational qualities of 'respect' and 'consent' as well as 'responsibility' represents a major step beyond the traditional 'performance' model of trust within the public sector. Moreover they are open to practical implementation as part of structuring the citizen/state relationship. The diagnostic and its tests can be used as a one off tool to assess the health of a relationship or more ambitiously to generate information needed to redesign the delivery of a public service. It is even possible to conceive of the tests being embedded in the day-to-day process of service delivery - for example by institutionalising the need to acknowledge and resolve citizen dissent.

This chapter seeks to assess the credibility and value of this conclusion by critiquing each of the key steps, theoretical and methodological, from which it has been derived. It starts (7.1) by reviewing the overarching approach to the study. The following sections then discuss the four specific contributions of the study required to address the research questions, as summarised at the start of Chapter 1 . These were

- Analytic - The research questions rest on a relational perspective in conceptualising and investigating the way citizens and state interact, and the importance and problem of citizen/state cooperation. Section 7.2 challenges the validity of this conceptualisation.

- Propositional - the key theoretical contribution to addressing the research questions was in exploring the core nature and action of trust as a mechanism for the coordination of social interactions, and its potential to improve the citizen/state relationship. Section 7.3 tests the robustness of this view of trust.

- Methodological - the method for addressing the research questions was to develop a repeatable way of tapping deliberative and relational knowledge of 
citizens and frontline staff. Section 7.4 addresses the integrity of this process and the data it produced.

- Practical - synthesising a diagnostic for use by citizens and public services to improve their mutual trust and cooperation. Section 7.5 critiques whether the diagnostic is effective in structuring the citizen/state relationship as claimed above.

The chapter concludes (7.6) with an overall assessment of what has been achieved and implications for state reform and further research.

Each section summarises the objectives for that component of the study and the main points of value and innovation developed during the study. It then addresses the key challenges to each contribution, and reviews any mitigating considerations. Each section concludes with an overall assessment of the contribution, and lines of inquiry required for further progress.

\subsection{Critiquing the iterative research process}

This section discusses the overarching research process, and the risks involved in starting from a proposition for change.

Chapter 1 positioned the approach in the spirit of critical inquiry, in pursuing a research question intended to yield answers that would have concrete application in improving the citizen/state relationship. The point of departure was to conceptualise the theory and practice that might embody this change, developing the proposition that a form of trust could improve citizen/state cooperation. This was then tested and developed in iterative cycles of empirical fieldwork. The approach is illustrated at figure 7.2, reproduced from chapter 1. 
Figure 7.2 Illustration of iterative study process

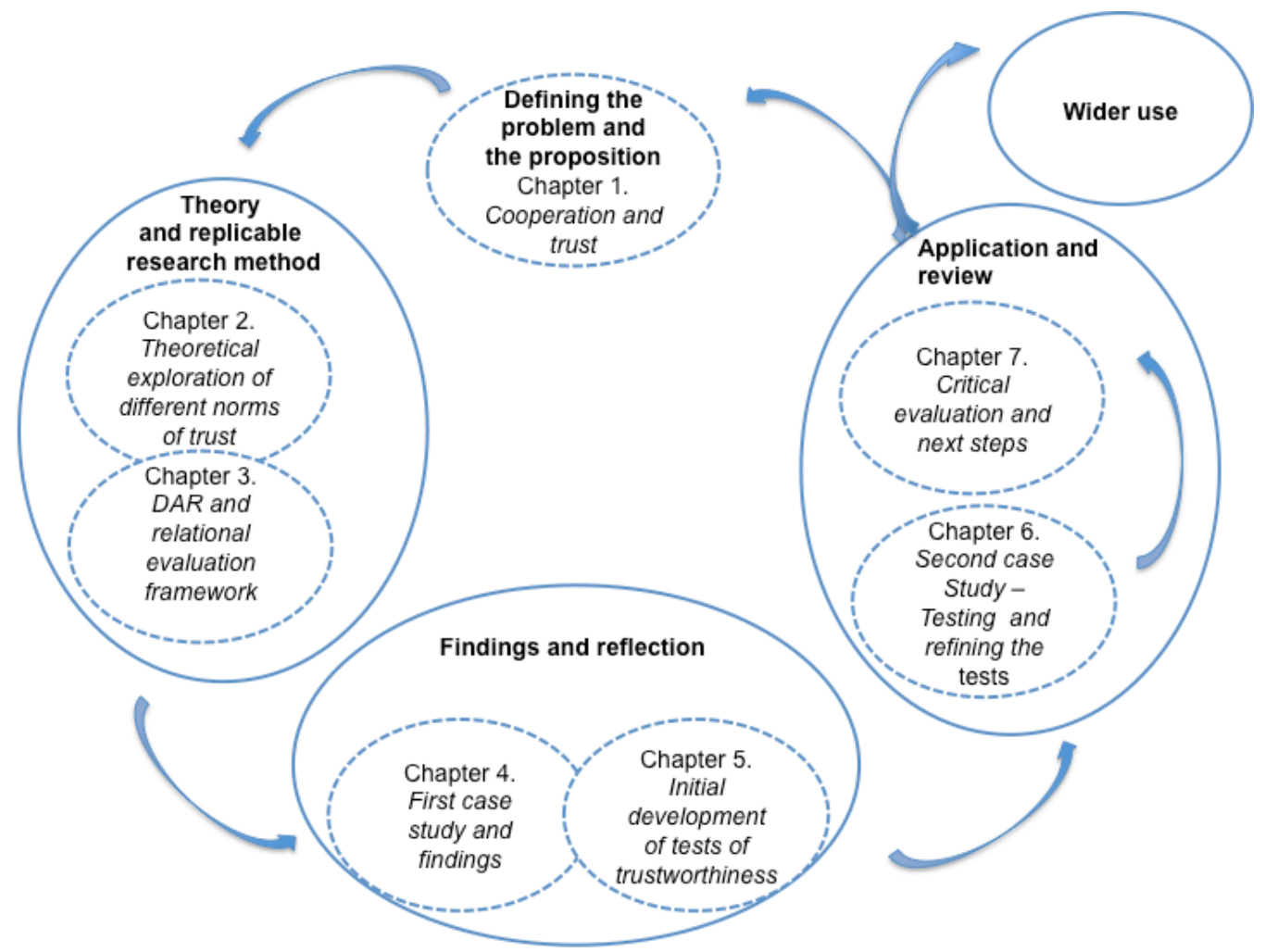

This approach aimed to maximise the prospects of achieving a definitive outcome, to prove or disprove this proposition. Being proposition driven was intended to help accelerate thinking and target insight. The corollary was to design an iterative approach to the fieldwork that would develop knowledge in the context of the theory, but also challenge the thinking - potentially to destruction. This chapter questions each main step in the process, and the validity and efficacy of the final outputs. This section frames that evaluation by considering the dangers posed by the approach. Two developments particularly accelerated progress whilst maintaining a line of sight from objectives to outputs. Firstly the evaluation framework ('connectivity', 'agency' and 'interactivity') provided a hinge between theory and practice, supporting the interrogation of the fieldwork data in the context of a prior attempt to anticipate what might be significant. Secondly the iterative approach to learning and testing helped, as the second case study tested the outputs from the first. 
This also created dangers. Evaluating the fieldwork data within the preconceived categories of the evaluation framework in the first study, and the categories of the tests of trust in the second, may have skewed results. The framework and tests helped identify insight, but may have excluded other issues rendered invisible by not being anticipated. The theoretical mitigation of this risk was that the dimensions of the framework were conceived to be generic, comprehensive and inclusive, identifying broad themes so that nothing of importance was excluded. Also, they were tested empirically by developing the framework with issues derived from other research and by the parallel process of 'freeform' coding of the data for emergent issues. In addition the second case study was constructed to enable challenge to the findings from the first dialogic action research (DAR). Section 7.4 assesses the credibility of the empirical findings in more depth.

Extrapolating the main diagnostic tests from just two case studies may also have skewed results. The housing benefit case study combined welfare (payment of benefit) with regulation (eligibility for payment), and represented an environment of lower trust than the second case study of the universal service provided by a GP surgery. The contrast represents two significant types of citizen/state relationships. But the obvious risk remains that different relational contexts, such as a coercive service like prisons, would produce different results. This risk was partially managed by the measures described above, but the broader mitigation is that the study anticipates, and requires, the use of the diagnostic with other public services to determine its usefulness and value across the wider public sector. Section 7.5 discusses the integrity and efficacy of the final formulation of the diagnostic and section 7.6 outlines possible future lines of inquiry.

A final methodological challenge to the overarching approach is whether an alternative study process might have also satisfied the research questions whilst carrying less risk. For example an entirely empirical study might avoid these dangers. This could involve several DAR case studies, in different service areas, using the method developed here, but evaluating the data without any prior structure, along the lines of the emergent coding process. This would reduce the risk of the evaluation framework being insufficiently comprehensive and provide an interesting comparison with the results of this study. However it would pose risks of its own. For example without a backbone of critical theory the results might be skewed to current assumptions about the nature of citizen/state trust. 
On balance the critical and iterative approach adopted proved robust in the context of the research question but is open to further validation.

\subsection{Critiquing the value of the relational model}

The first substantive contribution of the study was to develop a model of the citizen/state relationship from the citizen's perspective. The rationale was that any study of citizen/state trust had to be grounded in a realistic perspective of the nature of the relationship from the perspective of the citizen as the potential trustor. In this section I consider the value of this conceptualisation, and challenges whether it is irrelevant or misguided.

The relational model was conceived as a corrective to traditional 'provider' oriented depictions of citizens as passive consumers of public services. Starting from a narrow view of citizens' contributions to the mutual relationship would inevitably limit conceptions of the means for improving it. In this sense the intention was analytic, to create a more realistic understanding of the reciprocal interplay between citizen and state. The result was the public value relational model reproduced in figure 7.3. This described the range and elements of the relationships in scope and identified the primary 'relational dynamics' for investigation (connectivity, agency and interactivity). This provided the basis for the argument that current relational mechanisms of voice, choice, exit and silence underpin a paradigm of compliance rather than cooperation.

Figure 7.3 The public value relational model

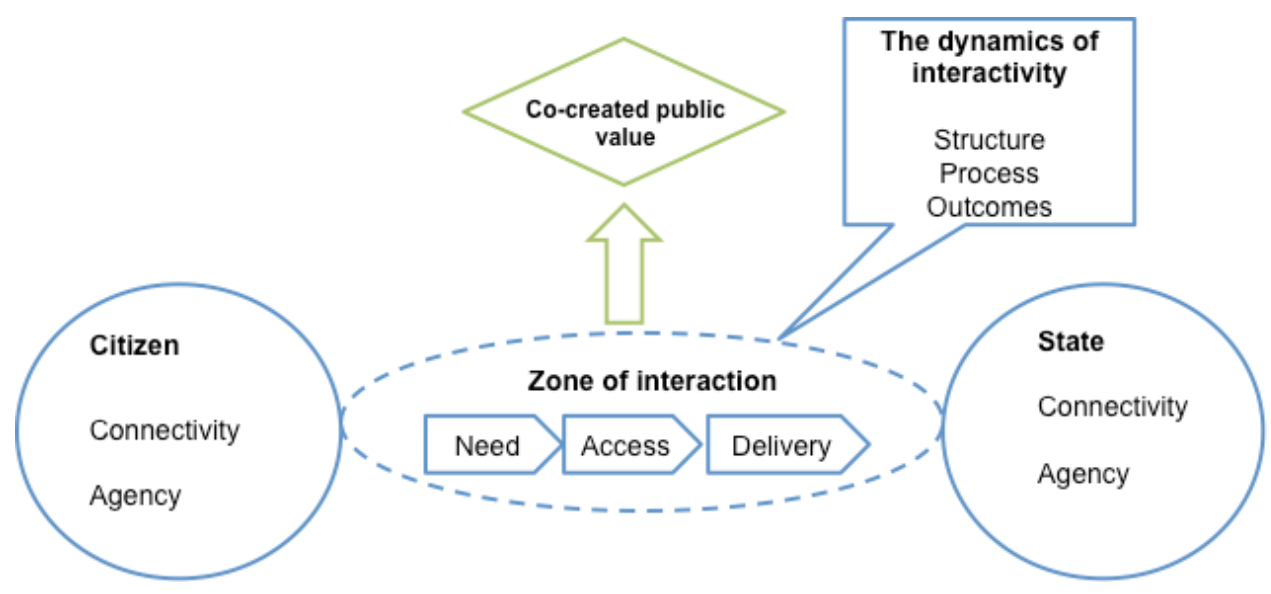


Initially the model was intended to describe discursively the scope and thrust of the analysis. However during the study it assumed increasing methodological importance, and practical value, in challenging current approaches to service design and policy development. From the perspective of method it directed the focus of the research onto the intersubjective relational dynamics within the 'zone of interaction' (Stolorow and Atwood, 2002), and the subjective attitudes and capabilities that contributed to these (Leonard, 1997; Bakan, 1966). The model and framework also underpinned the development of the trust typology, and in a 'trust version' provided the architecture for the final diagnostic.

This deployment of the model indicates the potential innovative value of the conceptualisation beyond the specific scope of this study. It provides an analytic basis, and example, for how genuinely to put the 'citizen experience' at the heart of public sector reform. Its value in this respect is in part derived from a more realistic evaluation of the full contribution citizens make to the relationship, as well as the methodological insights summarised above. The result challenges conceptions of public service reform that see citizens as stakeholders to change, rather than its drivers (Cabinet Office, 2006). The model provides the intellectual framework for arguing that reform should start with the 'citizen experience', and the processes of public value co-creation, as a pre-eminent consideration in driving institutional change.

This is a lot of weight for the conceptualisation to carry, and it has been contested. The idea that the preponderance of public value created by the state is co-created with citizens is frequently challenged, often in the context of public services that are predominantly 'transactional' or those services where the citizen ostensibly has little agency, such as regulatory services. For example critics challenge whether it is useful to think of the prison service and its relationship with inmates in this way, or automated transactions such as paying parking fines.

There are two aspects to this critique. The first is that the citizen contribution - or requirement for cooperation - is so minimal to production and consumption that it is irrelevant to professional service delivery, and therefore in service modernisation. There is a seductive common sense to this argument. It certainly describes the prevailing paradigm 
for public policy development. To take the citizen contribution to production first, budgets for public services rarely account for the costs or benefits of the activity of citizens necessary to the service, partly because they are enforced and externalised. In terms of citizens and consumption, it is equally rare for a public service to be rewarded on successful outcomes. Public services are largely constructed and funded on the basis of providing a service process, rather than on the success of the service. Whatever the citizen contribution to service production or consumption is, today there are only weak practical incentives for this to be a major consideration in service management.

The second, related, critique is the difficulty of quantifying the benefits of enhanced cooperation. One way of countering the argument above would be evidence for the step change in service effectiveness from better citizen/state relationships. However the evidence base for this is under-developed. The literature discussed in the study references anecdotal evidence for the advantages of better cooperation, but hard quantified studies are more elusive. There is evidence that suggests the potential prize is considerable (Scholz and Pinney, 1998). Commentators point to examples of operational efficiency leading to running cost reductions (e.g. improvements in the housing benefit process from reducing rework) and in the outcomes of programme benefits (e.g. better targeting of housing benefit on need, and reductions in benefit fraud). However the picture is currently fragmentary (Boyle and Harris, 2009; Coats and Passmore, 2008; Parker, 2008; Duffy, Downing and Skinner, 2003).

The debate about the citizen contribution to the relationship with the state is an important challenge to the premise for the study. If the need for cooperation is insignificant, the argument for trust is reduced. The issue is answered in several ways. Grounding the argument in the analytic framework of public value provided a recognised and solid foundation for developing the model. The argument was further strengthened by incorporating modern scholarship around 'service logic' (Grönroos, 2011; Normann, 1991), providing a compelling perspective on user value derived from service consumption from outside the public sector. Finally the two case studies themselves gave multiple examples of the intrinsic nature of the reciprocal interplay of citizens and state in production and consumption. 
This mix of evidence provides a robust but partial rationale for the model as the premise on which to base the research questions. From the perspective of this study the benefits of greater cooperation should be a priority for future research. The public sector is only likely to move beyond well intentioned but ineffective rhetoric on putting citizens at the heart of government when there is a more concrete understanding of the potential value of the citizen contribution.

\subsection{Critiquing the proposition to enhance citizen trust}

An important part of the theory development required to address the research questions was to shape the proposition that trust offers the potential for a relational coordination mechanism that can work alongside voice, choice and silence in holding the state to account, and promoting more cooperative citizen/state interactions. In assessing the credibility of the proposition I firstly consider challenges to the objective itself; that the aspiration is either futile, or the wrong concept to apply to the state. Secondly I consider challenges to the integrity of the trust typology used to differentiate forms of trust.

The proposition became firmer while peeling away the layers of trust. The initial intent was that trust would be a productive point of departure for the study because it was a relational phenomenon linked to social co-operation. It also tapped existing relational research energised by contemporary concerns about a crisis of public trust. However in investigating the function of trust the perspective within this study moved from seeing it as a broadly homogeneous and benign emotion underpinning positive relationships, to a harder edged view of trust as a contingent and potentially potent mechanism for the governance of reciprocal relationships, even ones based on an asymmetry of power such as those between citizen and state. It is difficult, perhaps impossible, to force people to trust.

The observation that trust can take on plural forms is increasingly present in some of the contemporary literature (Simpson, 2012; Jones, 1999), but the consequences have not been fully developed. The innovative contribution of this study was the development of a typology of forms of trust; grounding the principle of pluralism in operational terms that can be studied and evaluated. This provided the basis for a tougher articulation of the observation that the reason for falling trust in the state was due to different norms of trust 
used by each party, potentially explained by the state clinging to the bureaucratic legacy of assumed trust while citizens operate to a more critical agenda (Christensen and Per Lægreid, 2005; Duffy, Downing and Skinner, 2003; Fotaki, 2014; O'Neill, 2002; Park and National Centre for Social Research (Great Britain), 2008; Taylor-Gooby, 2008). This insight liberated the study to consider trust from the citizen perspective. The analysis was summed up by the graphic in chapter 2 and reproduced as figure 7.4.

Figure 7.4 Citizen and state may be operating to different norms of trust

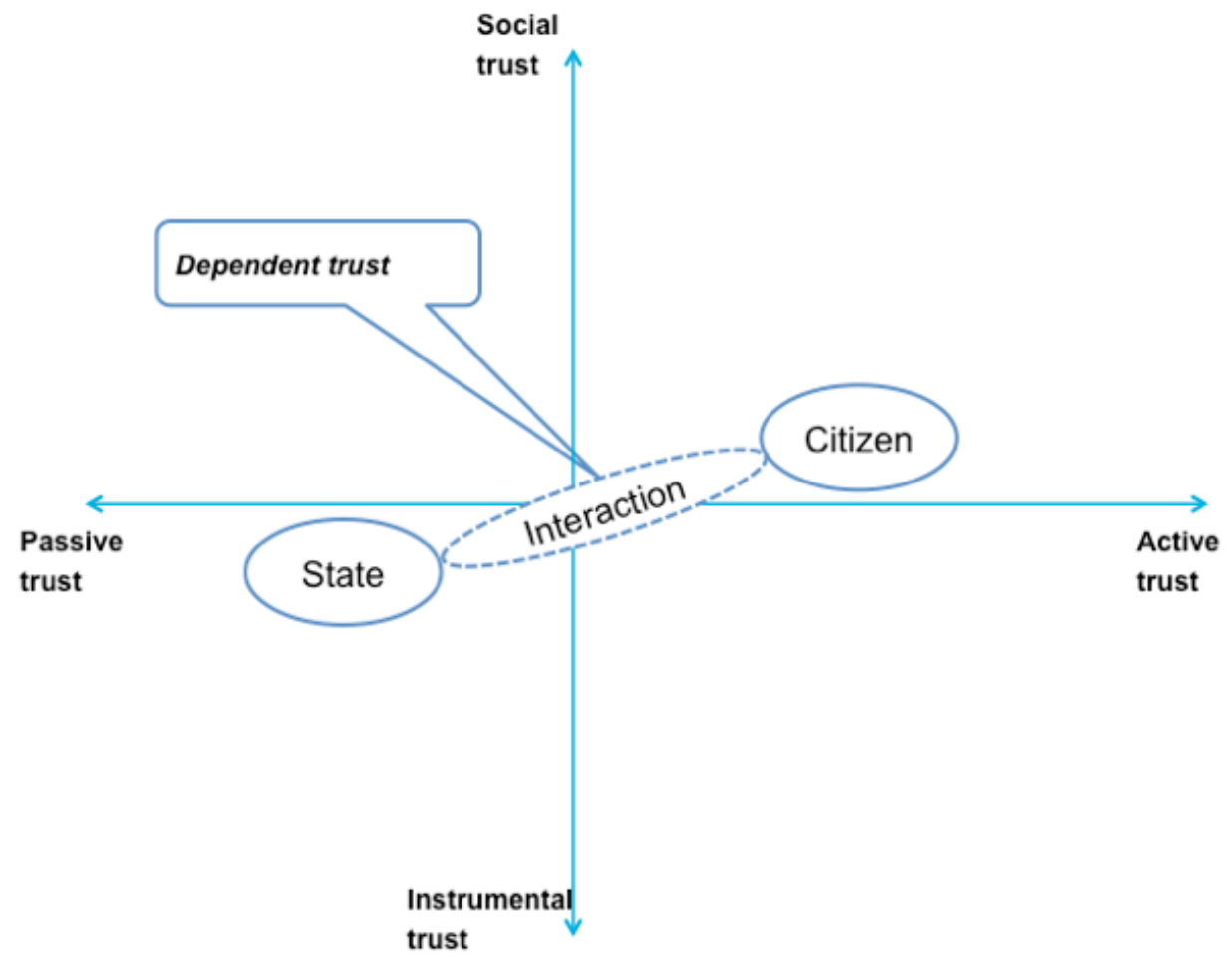

The value of this theoretical frame for the study was to enforce consideration of a research method adequate to analysing different norms of trust. Another potentially valuable aspect of the typology was that it worked with the grain of the relational model, with connectivity translated to the social/instrumental dimension and agency to the 
active/passive. Dependency and interdependency provided a basis for the analysis of the control function of trust in the reciprocal dynamics of the zone of interaction.

This proposition for the potential role of trust also attracted considerable and interesting ${ }^{14}$ contestation when discussed at conferences and seminars. These critiques fall into three broad families. One response is outright rejection; the idea of trust in the state is implausible, ineffectual and potentially damaging to the interests of citizens. This is often associated with the neo liberal suspicion that the state is impervious to such strategies and therefore citizens should be always on their guard in any interaction (Hardin, 2002). This critique dismisses even the theoretical possibility of giving trust enough teeth sufficient to affect the goals and competence of the largely opaque and powerful institutions of state. Other more sympathetic responses have shared this scepticism though more pragmatically; trust in the state would be a laudable objective but the scale and complexity of the task is too great, and the return too poor, to make this a priority (Cook, Hardin and Levi, 2005).

These are pertinent and powerful challenges that echo the pessimism of the political philosophies reviewed earlier in the thesis. The theory of change articulated in the first chapter accepted that the current trust relationship was flawed. The question for the study was whether this pessimism could be challenged in practice. In this sense these

\footnotetext{
${ }^{14}$ A personal reflection is the surprising level of emotion with which people engage with the topic of trust in the state, whether for or against it.
} 
challenges help pose the criteria by which the efficacy of the diagnostic should be judged. This is addressed in section 7.5.

A second and even more fundamental challenge to the proposition is that trust is the wrong concept to apply to the state, because the state should not aspire to it. This critique stems from the view that the role of the state is inherently conflictual. A core role is to resolve different interests, between groups, classes, and between the collective and the individual. According to this account trust could imply the state being unduly benign in trying to appease all interests. Respect for the authority of the state, balanced by accountability, is the answer rather than trust.

This is also an important challenge that adds a further dimension to the assessment of the research findings. It rests on the assumption that trust and competing interests cannot easily co-exist. The implication is that individuals and groups will trust the state more if its decisions and actions favour them against others. This was a key question when evaluating the research data. However the evidence from the case studies showed that the citizen aspiration was primarily for equity - trustworthiness was associated as much with the fairness of decisions as individual self-interest. So one response to this challenge is that it underestimates the citizen understanding that there are two aspects to state trustworthiness, in equitably balancing the interests of the collective with those of the individual.

There is another broader response. In different ways both the challenges to trust described thus far derive from the view of trust as a benign but passive relational archetype, ineffective in the context of the state. As a result they share the premise that the current paradigm of the citizen/state trust relationship - towards the passive, instrumental and dependent ends of the typography dimensions - is immutable. For this study, the trust typology is the means to challenge this assumption. The data found many instances of a different norm of trust in use by citizens and the state agents, not least in the more relational and 'tough' areas of respect and consent. The key test in response to both challenges is whether the citizen perspective on trust is any better at enforcing a more cooperative relationship with the state than the current norm. This chapter returns to this theme in section 7.5 in considering whether the tests of trustworthiness developed in 
this study can effect real change in the citizen/state relationship, in the face of both asymmetric power and conflict.

A third challenge to the approach to trust in this study is the view that seeks explanations for trust in the state in factors outside the control of the state; for example from dispositional and demographic factors, or from larger issues such as the growth of inequality in late capitalism (Uslaner and Brown, 2005). It is true that reported levels of trust in more economically equal societies such as Scandinavia are higher than elsewhere, though they reflect the same trend downwards over recent decades.

This critique questions the wisdom of placing the trustworthiness of the state at the heart of the study. However logic and evidence for it are weak. Those surveys that have tested for causality in these terms conclude that the prior experience of the trust relationship is of overwhelming importance compared to external factors (Van de Walle and Bouckaert, 2007; Christensen and Per Lægreid, 2005). The experience of the case studies supported this perspective in that all participants, staff and users, engaged with the topic of trust and cooperation as an important and common sense issue on which they had views. External factors have some relevance to citizen trust, but there is an overwhelming theoretical and empirical case that if the state wants to be trusted, then the most significant and effective tool at its disposal is to be trustworthy.

A qualitatively different challenge to the proposition on trust is to the adequacy and validity of the differentiation of trust articulated by the typology. It was reassuring that the three dimensions were derived from the relational model, and created conceptually independent variables that could be mapped to the core three part definition of trust. It was also reassuring that they aligned with bodies of academic literature on trust (Faulkner, 2007; Banerjee, Bowie and Pavone, 2006; Möllering, 2006; Bijlsma-Frankema and Costa, 2005; Bachmann, 2001; Tyler, 1998; Baier, 1994; Giddens, 1994; Coleman, 1990), producing helpful insights. The structure and categories were also tested in the course of the study process. The typology has been presented in a number of contexts, including both public policy and psychosocial seminars, with positive feedback. 
However, because it is an original construct, built from first principles to be useful to the specific question at hand, it is important to acknowledge the limitations of applying the typology to the messy reality of the citizen/state relationship and identify where it would benefit from more development. There are a number of ways of thinking about this critique. The most obvious is that this study only tests the typology in the context of a universal and a welfare type service. It has yet to be tested in the context of, for example, a highly transactional or automated service (e.g. paying a parking fine) or a coercive service (e.g. the prison system). The argument developed in this study would imply that the prison inmate has a right to a trustworthy prison service, just as the errant motorist should be able to trust the integrity of the fine payment system; but more studies are needed to demonstrate that the typology embraces those and all other citizen/state relationships. Such further studies would also be useful in testing the point made earlier - a key finding of this study is that citizen trust is generated by perceived fairness in the rationing or allocation of a public good as much as by personal self interest in the result. The complexity for the trust typology this issue demonstrates is that the citizen has two trust relationships with the state that need to be reconciled. The first is with the state as a collective in how it develops and applies policy - in effect political and strategic trust. The second is with the frontline of service delivery in translating this policy into action in the interaction with the individual.

The other major challenge to the integrity of the trust typology is that in reducing all aspects of the citizen/state relationship to the subjective trust of citizens, it inadvertently obscures the importance of other key factors as independent variables. These factors include issues such as demographics, the impact of culture and history as well as the particular operational and psychoanalytic realities and constraints of individual service transactions. They also include the action of broader social forces and constructs such as the potentially dominatory impact of gender, race, class and disability on the experience of state activities.

The answer to this critique is not that the trust typology ignores these issues, rather that it subsumes them as contributors to the perception of trustworthiness. To take one example the issue of class and inequality was a major part of the discourse in the HB case study, present as a factor contributing to a sense of citizen distrust in the service. The trust 
typology could bear this weight; and by broadening the conception of trust to include issues of motivation, cognition, power and reciprocity it helped to make such factors transparent and explicit. In addition it provided the means to challenge their impact. A key finding from the HB case study was that to be perceived as trustworthy in the eyes of the claimant the service would need to address any perceptions of conscious or unconscious bias by, for example, each user feeling they were being treated with respect.

However as with the response to the question of whether the typology can be demonstrated to have universal validity across all public services, further studies would be useful in validating the integrating power of trust as argued here. Moreover it is also true that for the purposes of this study, the three dimensions of the typology were sketched with broad brushstrokes. A potential future line of inquiry building from this analysis would be to test and develop the typology with more detailed research into each dimension and how these change for different forms of trust.

\subsection{Critiquing the research method and findings}

In this section I discuss the research method, and challenges to the confidence that can be placed in the findings derived from it. This method was a key aspect of successfully responding to the research questions because of the specific need to access the citizen experience of the 'zone of interaction'. The main challenges are to the appropriateness of the method to the research questions, the representativeness of the case study sample and the objectivity of the data collection and analysis process.

In designing the approach to the field work the relational model and trust typology set the context for the research method. It was necessary to draw on subjective and intersubjective knowledge, and differentiate the forms of trust held by different groups. Another important consideration was repeatability, creating a process replicable by others in different areas of public service. There were two areas of innovation in addressing these requirements. The first was designing a customised form of DAR. The second was developing a systematic approach to generating relational insight from the data (both using an evaluation framework derived from the relational mode in the first case study and the first iteration of the diagnostic tests in the second case study). 
The customised DAR method was assembled from a number of AR schools (Coleman, Deutsch and Marcus, 2014; Heron, 2014; Lorino, Tricard and Clot, 2011; Montoya and Kent, 2011; Shotter, 2010; Reason, 2006; Pettigrew, 2003; Park, 1999; Brydon-Miller, 1997), and specifically designed to articulate and then resolve difference. The method used a structured process to create relational and deliberative knowledge generated by users and frontline staff discussing ways of improving their relationship. An innovative and important aspect of the process was the initial separation of the two sets of participants, enabling each group to find their own voice before meeting the other.

The dynamic dimensions of the relational model (Leonard, 1997; Bakan, 1966) were the foundation for the evaluation framework used to interrogate the data from the first case study. It was then assembled from a number of additional sources, including academic work on intersubjectivity (Benjamin, 2006; Stolorow and Atwood, 2002; Habermas, 1987) and related discourses such as that of 'recognition' (Honneth, 1996; Taylor, 1992; Fraser, 1989). The framework proved valuable in two related ways. Firstly, using the high level categories to group the issues in the housing benefit study helped participants to link related issues, and thereby accelerate shared learning and creativity. Secondly, it enabled an analytic approach to distinguishing the main priorities emerging from the research (the tests of trust played the same role in the second case study, but these are discussed more fully in the next section of this chapter).

The context for the critique that follows are current debates about how to ensure quality in qualitative research, and particularly the value or otherwise of formulaic or checklist type approaches to assessing this quality. Some relativist commentators question the value of any checklist, instead offering quality criteria that focus on testing the credibility of knowledge claims in the context of each individual study (Hammersley, 1998). Others take a detailed and technical approach, looking to the specific use of such techniques as validating results through use of quantitative methods and computer-based evaluation (Seale, 1997). Between these extremes most commentators take a more pragmatic path, using a variety of checklists to interrogate the reliability of the process of research but in a way that is customised to the specific circumstances of each study (Barbour, 2001; Mays and Pope, 2000). The questions that inform the critique in this section borrow most heavily from this latter school, but also embrace some aspects of the others. Synthesising the 
main issues from this literature gives rise to three key challenges particularly pertinent to the quality of the research process within this study - the appropriateness of the DAR method itself, the representativeness of the case study sample and the integrity of the data collection and analysis process. These are addressed in turn below.

There are two related aspects to this challenge on the appropriateness of the DAR method; firstly whether the research question itself was relevant and clear and secondly whether the method was appropriate to finding credible answers (Mays and Pope, 2000). Starting with the research question, it is worth reflecting on how it subtly evolved in the early stages of the study. The first articulation was focussed on the nature of citizen trust, rather than the more precise final formulation around the qualities of the 'trustworthy state'. This latter formulation proved a more forensic way of investigating the issue and was beneficial in forcing a research method focussed on the 'zone of interaction' rather than the traditional study of subjective citizen attitudes alone.

Building on this insight the opening paragraphs of this section described the theoretical thinking behind the design of the DAR process as the means for tapping the deliberative and relational knowledge required. The main practical risks to the approach were that the dialogue would turn out to be one-sided, or that it would be either too anodyne to produce challenging results or alternatively conflict would prevent positive suggestions. However neither risk occurred. The actuality described in chapters 4 and 6 was that both case studies produced thoughtful and engaged discussions arriving at substantive and shared conclusions. Participant feedback was that the two practical steps most important to achieving a positive dialogue were the initial separation of the two groups to allow them room to form their identity and perspective, and also excluding staff with little user or patient contact so as to maintain a focus on the citizen experience (and empower frontline staff to talk freely without worrying about management's sensibilities).

The second challenge to the quality of the research method concerns the sample population participating in the study (Barbour, 2001). The objective was to recruit a citizen group that was sufficiently diverse to contain as full as possible range of views, but without particular interests, or dominant individual voices, skewing the findings. The risks in this respect are whether the makeup of the participant group would introduce bias to the 
results, or omit crucial experience that would have otherwise swayed findings. There are several reasons for wanting to test this issue in respect of this study. Firstly the groups of participants were self-selecting. That might bias the process, for example leading to users motivated because they are particularly happy (or unhappy) with a service. That risk was compounded by sample size. Seven or eight group participants permit reasonable individual participation, which makes for good dialogue but cannot provide the basis for a statistically representative sample of (e.g.) class, gender, age, or ethnic demographics. The main mitigation of these risks was a recruitment process that used a number of different avenues in targeting volunteers. In both cases this was successful in generating a participant group with different views on the service derived from negative as well as positive experiences, and from heavy as well as more occasional use of both services. This proved of considerable value, emphasising the importance of a reasonably heterogeneous group of participants. Future studies should seek to enshrine this as a criterion in the recruitment process for citizen participants.

A further mitigation of the risk of participant bias was the participation of staff. Their wider experience of service users offered a counterbalance to unrepresentative views, although from the staff perspective. Another mitigation, and also a learning point, was the occasional need for assertive facilitation if one participant was threatening to dominate. It was particularly useful to open the debate by systematically going round the table asking each participant for a view on the topic in question. A further learning point was to prepare for workshop sessions with the conscious understanding that it was a deliberate attempt to surface and harness constructive 'tension'. The nature of the exercise was to expose different views between users and staff, and being armed with strategies to manage conflict proved useful (for example clarifying an issue for inclusion in the wider dialogic process rather than immediate resolution). In the event the process produced an engaged debate, with considerable evidence that the dialogic approach helpfully generated relational knowledge that may not have emerged through less deliberative methods. Whilst there cannot be certainty that a different group of participants would have produced similar outputs, the process of group discussion and challenge served to guard against maverick results. 
The second challenge to the sufficiency of the sampling is the limited number of DAR exercises, and whether the results are applicable as intended more generally across the public sector. This is a more fundamental challenge, related to the critique of the trust typology above that questions the generic applicability of the final output of the diagnostic. Therefore it is pursued in the context of the critique of the transferable utility of the final form of the tests of trustworthiness in the next section.

The third test for the quality of the research is the integrity of the data collection and analysis process. This is a question of particular importance to this study because of the use of the evaluation framework (HB case study) and the diagnostic tests (GP case study) to group and then analyse the respective research data. Using such preconceived structures, as opposed to a ' more purist 'grounded theory' (Corbin and Strauss, 1990) approach, in which categories of analysis are derived only after immersion in the data, posed the risks of inadvertently excluding relevant areas of knowledge or directing conversation within topics towards a particular conclusion. This risk was heightened as in each case study there was little opportunity for multiple coding (Barbour, 2001) as a way of gaining independent validation of the interpretation of the data. The process of data analysis was primed to identify elements that did not fit, but this may have been insufficiently rigorous. The danger was that the evaluation process uncovered preconceived findings implicit in the evaluation framework or the diagnostic tests.

There were a number of general safeguards against these risks. Firstly the process of evaluation and the findings were discussed exhaustively with the supervision team and presented to a variety of academic groups and conferences for feedback and challenge. Secondly it should be clear from the narrative in chapters 4 and 6 that the spine of the findings in each case study was the formal report of the DAR participants, and that this was subject to respondent validation in both instances. This was a primary check on the subjective interpretation of the researcher. Thirdly in both case studies the dialogue was framed by open questions about the relationship - seeking to expose what was in the mind of participants without reference to how the data was analysed - in order to ensure no bias. In both case studies the outcomes of the evaluation process were similar. The only outlier data points that could not be attributed within the respective evaluation structures were those that were too vague. However in both cases the evaluation process 
identified inconsistencies in the analytic structures that led to considerable internal restructuring and development of the respective frameworks.

Taking the use of the evaluation framework in the HB case study first, the lack of any major outlier results was not unduly surprising as the headings of the framework were intended to be sufficiently abstract to have universal and comprehensive application. The objective was to be descriptive - to have a map of the terrain from the citizen perspective, rather than a normative compass indicating a particular route. The process also tried to test the comprehensiveness and discreteness of the framework categories. For example mapping previous research within the categories and using them to construct the trust typology provided reassurance they were not obviously flawed or inadequate. Moreover the framework was only used in the second phase of the case study, which started with open questions about how to improve the mutual relationship. Participants were encouraged to think widely about the issues that troubled them, and only once these had been fully established was the material grouped within the framework categories. The rigour of the approach is demonstrated by the impact of the evaluation process on the internal structure of the framework as described in the conclusion to chapter 4 . This outlines how the coding and evaluation of the inductive 'trust elements' was used to refine the structure of the evaluation and expand the definitions of the framework sub-categories. The main impact was to expand the number of headings for the analysis of data germane to the 'zone of interaction', and focus the analysis of this category more specifically on trust as a mechanism of coordination and governance enacted in the reciprocal dynamics of the 'zone of interaction'.

The data collection and analysis within the GP case study followed a similar pattern. The initial diagnostic structure of the six tests of trustworthiness was designed to be comprehensive of the key themes from the HB study. A further test of comprehensiveness was to arrange the tests around the core structure of the trust transaction rather than using the evaluation framework as the template. Once again there were no significant outlier data points, but evidence for the comprehensiveness and integrity of the evaluation can be derived from the impact on the final diagnostic structure, with the final stage of distillation resulting in a tighter articulation of the three themes of trustworthiness. This thread tracks the logic and rationale of the progression of the findings from the nine sub- 
categories of the evaluation framework to the six tests of trustworthiness and ultimately the three themes. This offers a transparent and replicable method with a clear pathway from the analytic structure to the normative findings.

This critique of the data collection and analysis aspect of research method offers both strengths and weaknesses in the context of the literature on quality in qualitative research. There were genuine risks in using preconceived categories of evaluation (though as many commentator point out the risks - and potential for funding - of a completely theory free approach are equally if not more problematic (Barbour, 2001)). The use of multiple coding would have provided additional validation though this was partially offset by rigorous challenge in the supervision process and by the use of internal university workshops to test a sample of findings. Moreover the prioritisation of respondent validation of the formal report from each case study provides an important further level of triangulation to the results. A balanced conclusion is that the data collection and interpretation provides a credible basis for the derivation of the final diagnostic tests - in part because of the safeguards described above, and in part because there is a consistency in the cumulative weight of evidence from the variety of empirical sources from which they have been derived. However as with the other judgments in this section this conclusion can only be interim, pending further case studies done in different service and relational contexts.

This section has outlined the main critiques of the research method, examining its relevance to the research question, the integrity of the sample and the validity of the data collection and analysis process. It has identified a number of learning points, principally around the importance of active facilitation of a dialogic process that will inevitably contain elements of conflict, of the need for diversity in the recruitment of participants and in the value of multiple coding. Moreover the methodological issues in the internal structure of the evaluation framework discussed above also invite further development.

At the same time the analysis has also identified some positive and innovatory aspects that are worth incorporating in future studies of this sort. The DAR process itself was enlightening and tapped relational knowledge. The evaluation framework and diagnostic tests were tested and developed in a number of ways, and provided concrete insight into the data. The cumulative weight of the evidence suggests that the themes identified are 
significant and make a convincing case for the core message that relational issues were important to trust in addition to technical competence. The final conclusion is that the core approach is credible and valuable, but as with a number of other aspects of this study it needs further development and testing in a wider number of service contexts before claims of comprehensive utility can be made. A fruitful way of encouraging such challenge would be for the wider use and testing of the trust diagnostic derived from the method. This is discussed in the next section.

\subsection{Critiquing the utility of the diagnostic}

Thus far this section has critiqued the key theoretical and methodological steps necessary to develop credible answers to the research question. In this section I critique the value of the final output itself - the trust diagnostic that synthesises the factors important to citizens in assessing the trustworthiness of the state. Thus the diagnostic responds to both research questions. Firstly, by articulating the issues of importance to citizens in respect of trust in the state, and secondly presenting them in a form that can be applied in practice to inform the practicalities of the citizen/state relationship.

I develop three challenges to this claim. The first is to the validity of the tests themselves, including their applicability to other aspects of the state. The second is whether they can provide an effective tool for citizens to hold the state to account, focussed on the question of whether they are likely to achieve real change. Finally I question the practicality and costs of the state adopting and responding to the diagnostic.

The two most important steps in developing the diagnostic were firstly structuring it around the trust version of the public value model, and secondly the process of deriving the tests themselves. The diagnostic structure strived for intellectual coherence with the core nature of trust, whilst giving room for the specific factors exposed by the research and in the language of the citizen. Testing the tests in the second case study provided feedback and led to a final simplification of both language and structure. Figure 7.4 illustrates this endpoint, with the overarching themes of respect, responsibility, and consent aligned with the nature of the citizen as trustor, the state as trustee and the interaction with trust as a mechanism for coordination and governance. 
Figure 7.4 The structure of the trust diagnostic

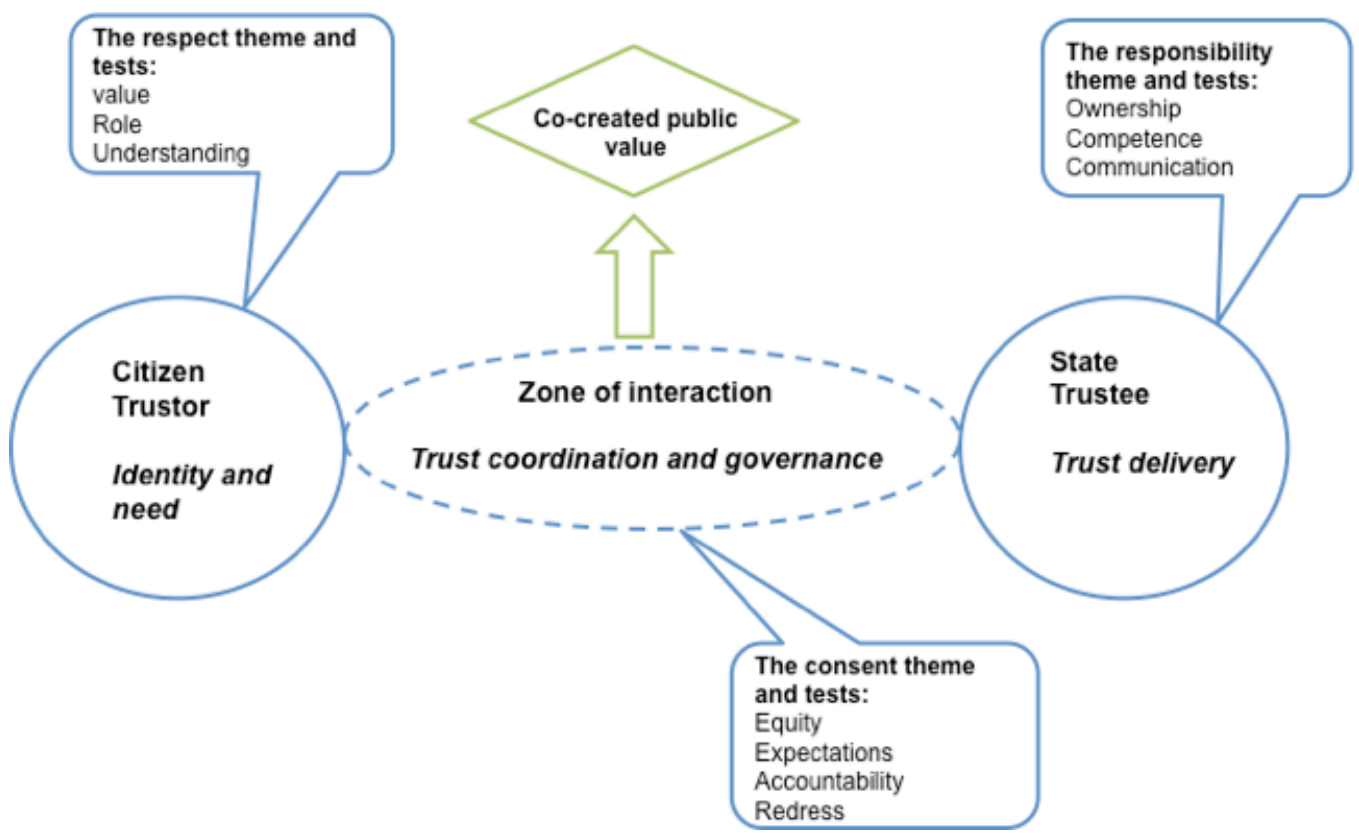

There are several benefits to this approach. Firstly, it is structured yet flexible. Starting from the core elements of the trust relationship provides intellectual rigour, while the hierarchy of themes and tests allows further development. Secondly, simplifying the diagnostic structure within the three themes of respect, consent and responsibility reflects the core messages from the research data, and provides a potent narrative structure accessible to citizens, staff and management.

The first challenge is to the validity of this overarching diagnostic structure and themes. The claim made above is not that it is the only way to organise the results, but that at a practical level the themes have a logic appropriate to the evidence and are generic and communicable. To take each in turn, associating the state as trustee with responsibility is possibly the least contentious. Making responsibility central to the diagnostic is an important variation on the dominant performance model of trust in public policy, adding a sense of ownership to the related concept of technical competence. However, competence too was important to citizens and is therefore aggregated within this heading, along with the importance of effective communication. Making the consent test overt is 
more challenging for the state, but contentious more for the practical implications than intellectual objections. Consent also provides a coherent heading for the empirically derived themes of the importance of redress and transparency of mutual expectations.

Finally, the theme of respect emerges consistently from the data as the governing principle for the citizen's self-perception of their identity as a trustor. It took on some specific connotations during the study. One was that citizen participants often talked of their relationship with the state in the context of a broader reciprocity - for example in an entitlement for a service or activity derived from their participation in the collective (exemplified by paying taxes and voting). They saw themselves as members of the state rather than as external to it. Findings about the importance of the citizen's perception of their value, role and understanding all fall naturally within the category.

A more problematic issue is demonstrating the comprehensiveness of the supporting subtests. The challenge described above to the qualitative and subjective evaluation is relevant. These findings were aggregated empirically by common themes, but were therefore inherently influenced by the evaluation framework. The structured approach to building the analysis provides some reassurance that there is a coherent and consistent body of evidence for the individual tests that have been identified. Moreover they worked as an effective stimulus for constructive discussion.

However the limited application of the diagnostic means it is not possible to demonstrate from this evidence that the tests are complete and applicable across all the public sector. This requires more use of the diagnostic. As discussed above in section 7.3 there are a number of ways of thinking about the segmentation of further case studies. The housing benefit study is an example of a rationed welfare service, in an apparently medium trust environment. The GP study is of a universal service in a high trust environment. An interesting contrast would be a coercive service such a prison or secure mental institution. Other service contexts might include regulatory state functions (e.g. trading standards) or redistributive functions such as taxation. A different structure again would be to consider relationships from the perspective of policy (political and strategic engagements including voting), or in the state's role as a catalyst for action by others, for example in encouraging self help within civic society and material prosperity within the economy. 
This study is intended to stimulate and support such wider analysis, and the proposition it describes is capable of adaptation. The overarching normative themes (respect, consent, responsibility) are proposed as universal, and as yet no service or activity has been found for which these are not appropriate ${ }^{15}$ (though that does not demonstrate sufficiency). However if new learning suggests better umbrella terms in pursuit of trustworthiness, the structure would be strengthened. The formulation also allows more subsidiary questions to be added if generated by further case studies.

The second challenge is whether the tests are genuinely effective. This relates to the study's objective of creating a practical tool for holding the state to account. For example one argument is that the tests are insufficiently exacting; that the drive for a generic structure and headings has led to obvious and anodyne tests. Few people argue that any public service should disrespect its users, ignore the need for consent or refuse to take responsibility for its actions. Most public bodies would no doubt feel they already fulfil these tests, in conjunction with the public service ethic of many frontline workers. The counter-argument is that the DAR process and themes nonetheless generated significant proposals for change, some small and some more fundamental. Indeed an interesting observation is that the micro and macro were often linked in users' minds. It has already been shown how lack of confidentiality in the housing benefit case study was seen as symbolic of a lack of respect.

${ }^{15}$ The most contentious debates in the course of the research have concerned the applicability of trust to coercive services such a prisons and police. However the resolution is usually that compulsion makes trust more not less important. The relationship of trust to the military is an other contentious area. 
It was beyond the scope of this study to assess the implementation of the DAR recommendations, but the more profound recommendations from both case studies aggregate to a radical agenda for change. In both cases there was agreement to establish statements of mutual expectations to create more transparent mutual governance. Both emphasised the structural importance of empowering the frontline; a pre-condition for trust was an empowered agent with whom 'you could do business'. The fragmentation of responsibility was an immediate source of cynicism. Empowerment of this sort requires major structural and process change, with systems aligned on the frontline agent. Amongst other implications, the role of strategic and democratic leadership would need to be defined as setting standards rather than managing production.

Another radical implication concerns embedding consent. Consent was a potent backdrop to much of the discussion, but in the form of dissent, or most apparent when withdrawn. The implication of this test is that sustaining trustworthiness requires public bodies actively to seek out distrust and learn how to turn it to trust. In itself this may well expose issues within all the areas of the tests of trustworthiness. A further challenging implication of resolving distrust is the research finding about the need for adequate and proportionate redress for error. No organisation, and especially not one based on bureaucratic principles, finds it easy to admit mistakes, and this is more fraught in the public sector where compensation to an individual might come at the expense of the collective. Creating a capacity for redress that does not use public resources is one of the main principled arguments for delivery of public services by independent service providers.

There is a further challenge to the efficacy of a diagnostic, which relates to prevailing norms of trust. This study argues that trust can be a potent mechanism for the coordination of social interactions, and can lead to the sort of radical change described above. But as a mechanism it is only effective if continued trust is important to both trustor and trustee. If the norm of trust in use within the state continues to be passive, assuming public trust, and there are few obvious costs to distrust, then citizens' views can be disregarded. So the final question about efficacy is whether the tests are dependent on a sympathetic sponsor, as was the case for both studies in this research. 
A sympathetic sponsor is certainly vital to action. However one additional line of inquiry, raised by this study but not resolved, is whether the tests can be used where there is citizen/state conflict rather than collaboration. One possible development is to investigate whether citizen bodies acting unilaterally can use the tests to give voice to their concerns. For example it is possible to imagine the Grenfell Tower residents using the diagnostic to express their frustration with the local authority during their many conflicts with the Council prior to the disaster. If the tests help legitimise the vocabulary of trust, and articulate distrust more effectively, then they can also help create the conditions for dialogue by increasing the political costs of ignoring citizens. Moreover an enlightened state finding itself in conflict with a group of citizens should want to identify the causes.

The final challenge arises from this analysis of efficacy. Can the costs and risks of the cultural, structural and governance changes implied by the tests be justified? These may be considerable if the transformatory implications described above are correct. Frontline empowerment requires investment for system and process changes. Creating organisational capacity to resolve dissent will increase some transaction costs. The emotional impact of this sort of change will be painful for many, with the redistribution of authority over decisions to the frontline and in many cases away from the professional 'expert'.

Whether these costs are justified depends on the value ascribed to the benefits of enhanced trust. At the start of this chapter I suggested that a key line of inquiry emerging from this research was to quantify the positive benefits of citizen/state cooperation. The potential prize is considerable but remains hard to measure. Anecdotes from each case study have spoken compellingly about the hidden waste in a dysfunctional citizen/state relationship. Examples quoted in the course of this study have shown how conflict reduces public value, adding to running costs and reducing the effectiveness of the service or function (the programme spend). Simply generating better feedback on the effectiveness of services and how to maximise successful consumption would produce major benefits. 


\subsection{Final thoughts and future lines of inquiry}

This critique argues for the coherence of the diagnostic, and the key steps in its development as a response to the research question, and has highlighted some specific points of value in this study. However it also identifies limitations on the knowledge claims that can be made from the current evidence. The assessment of each contribution has the same broad conclusion. The results are emergent; they open up useful lines of inquiry but require additional development and validation. In this concluding section I return to the research questions to summarise the potential implications and value of the findings and identity a number of fruitful future lines of inquiry opened up by the study.

To recap the research questions were to understand the tests in the mind of citizens when assessing the state's trustworthiness (and whether these are different in kind to the those assumed within the agencies of the state), and once identified to establish whether these tests can help structure the citizen/state relationship to encourage a more co-operative interaction. The ambition was explore whether trust, as a mechanism of governance for the relationship, could supplement voice and choice in helping to create a relational paradigm of cooperation rather than compliance.

The emergent proposition from this study offers a positive and potentially potent response, both to the research questions and ambition. The three themes of the diagnostic structure, and their supporting tests, summarise a body of empirical evidence on the nature of the factors that citizens associate with state trustworthiness. By highlighting the importance of the relational qualities of 'respect' and 'consent' as well as 'responsibility' these factors represent a major conceptual step beyond the traditional 'performance model' (Van de Walle and Bouckaert, 2007) of trust within the public sector. Moreover the alignment of these empirical findings with the core nature of the citizen/state trust transaction (the identity of the citizen as trustor, the requirement of the state as trustor and the mechanism of governance for the trust transaction) and the trust typology provides a credible framework for applying and developing these tests in a wider range of citizen/state interactions. The proposition is that these themes are generic to all citizen/state relationships. However this structure provides a coherent framework for further studies to test the completeness of the core themes and the underpinning tests in a wider range of 
citizen/state relationships. This combination of theory and practice offers a persuasive definition of the core characteristics of the trustworthy state from the point of view of citizens.

Moreover this diagnostic structure offers a practical and transparent tool in structuring individual citizen/state interactions. Combining the three themes and tests with the DAR research method has proved effective in tapping relational knowledge within the 'zone of interaction. It offers a simple and insightful tool that can be used to assess the health of a citizen/state relationship and to generate information needed to redesign the delivery of a public service. As it stands the diagnostic questions combined with the DAR process developed in the course of this study represent a practical output that can be readily adopted and applied by public sector managers, or citizen groups, who wish to generate significant insight into the quality of their relationship and the rapid development of options for improving it.

An even more radical vision is for these tests to be embedded in the day-to-day process of service delivery. For example questions on respect and responsibility could conceptually be used in a similar way to the regular 'family and friends' test in the NHS (where patients are systematically asked for feedback on whether they would recommend a service to a loved one). More challenging would be for the state to systematically embrace a stronger version of consent as an effective mechanism of accountability for citizens. In practice this would mean giving citizens the systematic means to voice dissent, and the right for this to be registered and resolved through some independent process of assessment. The process would need to be swift and not onerous, and the issue reviewed by an entity seen as separate from the service. With these provisions in place citizens may not always win such appeals but all the evidence presented here suggests that trust would be enhanced nonetheless simply by knowing their voice had been fully considered. In effect the exchange of trust (requiring the resolution of distrust) would become the key mechanism for the governance of the citizen/state relationship, arguably in a way analogous to the exchange of money in private sector.

This more challenging vision of systematising state trustworthiness offers the prospect of enabling a paradigm shift in the citizen/stage relationship. Embedding the requirement for 
the state to resolve distrust would have prevented many of the conditions of abuse that gave rise to the various public sector scandals alluded to in the course of this study. Moreover enhancing citizen trust would create the conditions for more active feedback on the success of public services in achieving public value, offering huge benefits in reduced waste and more effective services. Finally more active citizen cooperation in the physical coproduction of public services has been shown to offer a step change in public value outcomes, particularly in more complex and behavioural areas of public policy.

The balance of these three types of benefits will likely vary according to the nature of specific public services and interactions, but the proposition that emerges from this study is that there is no part of the state or its activities for which trustworthiness is not appropriate. Whether a service is automated, coercive, involuntary or universal it should avoid abusing its users, maximise feedback on effectiveness and encourage citizen cooperation. This systematic application of the thinking, opening the state to such a shift of accountability to citizens, will require political will as well as management commitment.

More work is required to make the case for the trustworthy state in order to generate this political will. Arising from this study two big themes for further research are particularly evident. The first concerns the diagnostic itself. The case studies investigated two public services with very different relational contexts. The themes and tests to which they have given rise are seemingly generic but the issues they surface are specific to each service. Whether the same generic tests produce similarly interesting results across all areas of the public sector will only be demonstrated by applying the diagnostic more widely. The process of DAR and diagnostic tests are designed for use by any public sector body or citizen group wishing to investigate and improve citizen/state relations. Using the diagnostic in different contexts also offers the potential to aggregate a growing knowledge base of both results and recommendations of mutual value. Wider application will also help distinguish the different ways the diagnostic can be used, for example either as a one off exercise to take the temperature of a relationship, as a tool when redesigning a service, or (more ambitiously) built into the day-to-day governance of a relationship.

The complementary line of enquiry lies in developing a better understanding of the case for, and implications of, adopting the citizen perspective on trust and the trustworthy state. 
It should be possible to quantify the cash and service benefits of cooperation. It also implies a number of qualitative research themes in reconfiguring service delivery around trustworthiness. These include such topics as the psycho-dynamics of trust in the interplay of citizen and state, the ownership and transparency of service and personal information, formal and informal incentives that can be used to structure the interplay, and the impact of technology - for example in the burgeoning phenomenon of mutual citizen/state video surveillance. It also includes approaches to embedding consent and resolving dissent as argued above. The practical aspiration voiced within this study is for citizens to know there is someone 'on their side' within the process of service delivery itself, to whom they can turn in difficulty. This may be one of the reasons that doctors consistently emerge as the most trusted of public sector professionals; patients see them as on their side, and as advocates in securing services from within the broader NHS.

These research themes could be pursued through multiple discrete projects. However an interesting alternative would be for a major pilot project that worked through a full cycle of diagnosis, service redesign, implementation and subsequent evaluation of the quantitative and qualitative benefits - including impact on levels of citizen trust.

I started this thesis with a historical context for the reform of the state. That is also the background for the conclusion. I presented the proposition for trust as part of a paradigm shift from the bureaucratic legacy of the public sector, and the passive user relationships inherent to that organisational technology. Some of the key foundations on which the old paradigm was built, such as citizen deference, are crumbling. At the same time new technologies of organisation are emerging in private and civic society, many adopting more networked and collaborative forms of mutual coordination and governance. It is not possible to predict with certainty how these forces will affect the nature and structure of the citizen/state relationship, but the apparently inexorable decline of public trust in government over the last decades indicates the strain they are putting it under.

This study suggests that there is effective action the state can take to stem the tide. And on the evidence of this study the potential prize is considerable. Better cooperation could reduce operational waste and significantly enhance the outcomes of any public policy requiring citizen action. 
In the longer term the argument may be even more basic. Being trusted by citizens is likely to be the price the state has to pay for continuation of sufficient levels of public funding for the collective provision it currently offers.

\section{Bibliography}

Anon. (2014) British Social Attitudes Survey, 2013 [online]. Colchester, Essex: UK Data Archive. [Accessed 15/5/2017].

Allen, N. and Birch, S. (2015) Process Preferences and British Public Opinion: Citizens' Judgements about Government in an Era of Anti-politics. Political Studies [online]. 63 (2), pp.390-411. [Accessed 4/4/2017].

Allen, N. and Birch, S. (2011) Political Conduct and Misconduct: Probing Public Opinion 1. Parliamentary Affairs [online]. 64 (1), pp.61-81. [Accessed 4/2/2013].

Ames, R.E. and Marwell, G. (1981) Economists free ride, does anyone else?: Experiments on the provision of public goods, IV. Journal of Public Economics [online]. 15 (3), pp.295-310. [Accessed 12/5/2017].

Arnstein, S. (1969) A Ladder Of Citizen Participation. Journal of the American Planning Association [online]. 35 (4), pp.216. [Accessed 17/7/2011].

Arrow, K. (1974) The Limits of Organization [online]. Canada: Norton. [Accessed 04/12/2017].

Axelrod, R. (2012) Launching "The Evolution of Cooperation". Journal of Theoretical Biology [online]. 299 pp.21-24. [Accessed 12/5/2017].

Axelrod, R. (2006) The Evolution of Cooperation [online]. Rev. ed. Cambridge, Mass: BasicBooks. [Accessed 12/5/2017]. 
Axelrod, R. (1997) Advancing the art of simulation in the social sciences. Complexity [online]. 3 (2), pp.16-22. [Accessed 10/3/2017].

Axelrod, R. and Dion, D. (1988) The Further Evolution of Cooperation. Science [online]. 242 (4884), pp.1385-1390. [Accessed 10/09/2012].

Bachmann, R. (2001) Trust, Power and Control in Trans-Organizational Relations. Organization Studies [online]. 22 (2), pp.337-365. [Accessed 10/8/2015].

Baier, A. (1994) Moral Prejudices : Essays on Ethics [online]. United States: [Accessed 16/1/2018].

Bakan, D. (1966) The Duality of Human Existence: Isolation and Communion in Western Man. USA: Beacon Press.

Banerjee, S., Bowie, N.E. and Pavone, C. (2006) An ethical analysis of the trust relationship. In: Bachmann, R. and Zaheer, A., eds. (2006) Handbook of Trust Research. Cheltentham: Elgar, pp.303-317.

Barbour, R.S. (2001) Checklists for improving rigour in qualitative research: a case of the tail wagging the dog? BMJ. 322 (7294), pp.1115-1117.

Barclay, C. (2010) The Truth about Trust in Government. Available from: https://www.opendemocracy.net/charles-barclay-roger/truth-about-public-trust-ingovernment [Accessed 06/06/2017].

Barnes, P.M., Newman, J. and Sullivan, H. (2009) Power, Participation and Political Renewal. Bristol, UK: The Policy Press.

Barry, P. (2009) Beginning Theory: An Introduction to Literary and Cultural Theory [online]. 3rd ed. Manchester: Manchester University Press. [Accessed 19/3/2015].

Bavinck, M., Pellegrini, L. and Mostert, E. (2014) Conflicts Over Natural Resources in the Global South: Conceptual Approaches [online]. 1st ed. London: CRC Press. [Accessed 20/1/2018]. 
Beck, U., Giddens, A. and Lash, S. (1994) Reflexive Modernization: Politics, Tradition and Aesthetics in the Modern Social Order. Cambridge: Polity.

Benjamin, J. (2006) Two-Way Streets: Recognition of Difference and the Intersubjective Third. Differences [online]. 17 (1), pp.116. [Accessed 6/03/2013].

Benjamin, J. (2005) Creating an Intersubjective Reality: Commentary on Paper by Arnold Rothstein. Psychoanalytic Dialogues [online]. 15 (3), pp.447. [Accessed 19/05/2013].

Bijlsma-Frankema, K. and Costa, A.C. (2005) Understanding the Trust-Control Nexus. International Sociology [online]. 20 (3), pp.259-282. [Accessed 19/12/2013].

Blackburn, S. (1998) Trust, Cooperation, and Human Psychology. In: Braithwaite, V. and Levi, M., eds. (1998) Trust and Governance. New York: Sage, pp.28-45.

Blau, P.M. (1964) Exchange and Power in Social Life [online]. London: John Wiley. [Accessed 8/8/2015].

Blind, P., (2007) Building Trust in Government in the Twenty-First Century: Review of Literature and Emerging Issues [online]. online: U.N. [Accessed 07/06/2017].

Bourdieu, P. (1996) Practical Reason : On the Theory of Action [online]. Cambridge: Polity Press. [Accessed 8/7/2011].

Boyle, D. and Harris, M. (2009) The Challenge of Co-Production. London: NESTA.

Bradach, J.L. and Eccles, R.G. (1989) Price, Authority, and Trust: From Ideal Types to Plural Forms. Annual Review of Sociology [online]. 15 (1), pp.97-118. [Accessed 8/8/2015].

Braithwaite, J. (1998a) Institutionalizing distrust, Enculturating trust. In: Braithwaite, V., Margaret, ed. (1998a) Trust \& Governance. New York: Russell Sage, pp.343375. 
Braithwaite, V. (1998b) Communal and exchange trust norms: their value base and relevance to institutional trust. In: Braithwaite, V. and Levi, M., eds. (1998b) Trust and Governance. New York: Sage, pp.46-74.

Breiner, P. (1996) Max Weber and Democratic Politics [online]. [Accessed 9/1/2018].

Brydon-Miller, M. (1997) Participatory Action Research: Psychology and Social Change. Journal of Social Issues [online]. 53 (4), pp.657-666. [Accessed 18/1/2018].

Burchell, G., Gordon, C. and Miller, P., eds. (1991) The Foucault Effect: Studies in Governmentality. with Two Lectures and an Interview with Michel Foucault. [online]. United States of America: University of Chicago Press. [Accessed 05/12/2017].

Cabinet Office (2006) The UK Government's Approach to Public Service Reform. Available from:

http://webarchive.nationalarchives.gov.uk/20070506125953/http://www.cabinetoffice .gov.uk/strategy/downloads/work_areas/public_service_reform/sj_pamphlet.pdf [Accessed 9/1/2018].

Cabinet Office UK Parliament and Government Petitions. Available from: https://petition.parliament.uk/petitions [Accessed 9/1/2018].

Cahn, E.S. (2000) Co-producing justice: the new imperative. The University of the District of Columbia Law Review [online]. 5 (1), pp.105; 105. [Accessed 23/2/2016].

Checkland, P. and Holwell, S. (1998) Action Research: Its Nature and Validity. Systemic Practice and Action Research [online]. 11 (1), pp.9-21. [Accessed 18/4/2017].

Christensen, T. and Per Lægreid (2005) Trust in Government: The Relative Importance of Service Satisfaction, Political Factors, and Demography. Public Performance \& Management Review, [online]. 28 (4), pp.487-511. [Accessed $11 / 5 / 2011]$. 
Clarke, S., 1962-, Hoggett, P. and Thompson, S., 1962- (2006) Emotion, Politics and Society. Basingstoke: Palgrave Macmillan.

Clarke, S. and Hoggett, P. (2009) Researching Beneath the Surface: Psycho-Social Research Methods in Practice. London: Karnac.

Coats, D. and Passmore, E., (2008) Public Value: The Next Steps in Public Service Reform [online]. [online]: The Work Foundation. [Accessed 13/08/2015].

Coleman, J.S. (1990) Foundations of Social Theory [online]. Cambridge, Mass: Belknap Press of Harvard University Press. [Accessed 16/1/2018].

Coleman, P.T., Deutsch, M. and Marcus, E.C. (2014) The Handbook of Conflict Resolution: Theory and Practice [online]. Third ed. San Francisco, CA: JosseyBass. [Accessed 18/1/2018].

Commission on 2020 Public Services, (2010) From Social Security to Social Productivity: A Vision for 2020 Public Services. RSA, 8 John Adam Street: 2020 Public Services Trust.

Cook, K.S., Hardin, R. and Levi, M. (2005) Cooperation without Trust?. New York: Russell Sage Foundation.

Corbin, J.M. and Strauss, A. (1990) Grounded theory research: Procedures, canons, and evaluative criteria. Qualitative Sociology [online]. 13 (1), pp.3-21.

Cudworth, E., Hall, T. and McGovern, J. (2007) The Modern State: Theories and Ideologies. Edinburgh: Edinburgh University Press.

Currall, S.C. and Inkpen, A.C. (2006) On the Complexity of Organizational Trust: A Multi-Level Co-Evolutionary Perspective and Guidelines for Future Research [online]. [Accessed 8/8/2015].

Dasgupta, P. (2009) Trust and cooperation amongst economic agents. Philosophical Transactions of the Royal Society [online]. 364 (1), pp.3301-3309. [Accessed 12/6/2014]. 
Dawes, R.M. and Thaler, R.H. (1988) Anomalies Cooperation. The Journal of Economic Perspectives (1986-1998) [online]. 2 (3), pp.187. [Accessed 12/5/2017].

Dolan, P., Hallsworth, M., Halpern, D., King, D. and Vlaev, I., (2009) Mindspace, Influencing Behaviour through Public Policy [online]. Report number: Discussion Paper.London: Institute for Government. [Accessed 28/9/2011].

Doray, B. (1988) From Taylorism to Fordism: A Rational Madness [online]. France: Free Association Books. [Accessed 19/3/2016].

Dowding, K. and John, P. (2012) Exits, Voices and Social Investment: Citizens' Reaction to Public Services [online]. Cambridge: Cambridge University Press. [Accessed 8/8/2015].

Duffy, B., Downing, P. and Skinner, G., (2003) Exploring Trust in Public Institutions, Report for the Audit Commission. London: MORI Social Research Institute.

Edelman Trust Barometer (2017) Global Report. Available from: http://www.edelman.com/global-results/ [Accessed 15/5/2017].

Engels, F. (1959) Anti-Duhring: Herr Eugen Duhring's Revolution in Science [online]. 2nd ed. Moscow: Foreign Languages Publishing House. [Accessed 13/1//2018].

Etzioni, A. (1995) The Spirit of Community: Rights, Responsibilities and the Communitarian Agenda [online]. London: Fontana. [Accessed 9/1/2018].

European Commission, (2016) Standard Barometer 85 [online]. Report number: 85.Brussels: TNS Opinion and Social. [Accessed 15/7/2017].

Faulkner, P. (2007) A Genealogy of Trust. Episteme [online]. 4 (3), pp.305-321. [Accessed 27/6/2017].

Fehr, E. and Gächter, S. (2000) Fairness and Retaliation: The Economics of Reciprocity. The Journal of Economic Perspectives [online]. 14 (3), pp.159-181. [Accessed 27/2/2013]. 
Fisher, J. (2010) Does One Trust Judgement Fit All? Linking Theory and Empirics. British Journal of Politics and International Relations [online]. 12 (2), pp.161-188. [Accessed 29/6/16].

Fotaki, M. (2014) Can consumer choice replace trust in the National Health Service in England? Towards developing an affective psychosocial conception of trust in health care. Sociology of Health \& IIIness [online]. 36 (8), pp.1276-1294. [Accessed 23/1/2017].

Foucault, M. (1997) Discipline and Punish [online]. Penguin: [Accessed 5/7/2011].

Foucault, M. (1988) The History of Sexuality. London: Penguin Books.

Foucault, M., Senellart, M., Ewald, F. and Fontana, A. ([1977-78] 2009) Security, Territory, Population: Lectures at the College De France, 1977-78 [online]. New York: Picador. [Accessed 7/5/2011].

Fox, R. and Blackwell, J. (2016) Audit of Political Engagement [online]. Audit 13 ed. 40-43 Chancery Lane, London WC2A 1JA: Hansard Society. [Accessed 16/6/2016].

Fox, A. (1974) Beyond Contract: Work, Power and Trust Relations [online]. London: Faber. [Accessed 10/8/2015].

Francis, R. (2013) Report of the Mid Staffordshire NHS Foundation Trust Public Inquiry: February 2013: Executive Summary: Presented to Parliament Pursuant to Section 26 of the Inquiries Act 2005. London: Stationery Office.

Frank, R.H. (2011) The Strategic Role of the Emotions. Emotion Review [online]. 3 (3), pp.252-254. [Accessed 5/12/2017].

Fraser, N. (1989) Unruly Practices : Power, Discourse and Gender in Contemporary Social Theory [online]. Cambridge: Polity. [Accessed 7/7/2011].

Freire, P. (1972) Pedagogy of the Oppressed. Harmondsworth: Penguin. 
Friedman, M. (1977) Capitalism and Freedom. The Freeman [online]. 27 (1), pp.24. [Accessed 26/10/2017].

Frosh, S. (2003) Psychosocial Studies and Psychology: Is a Critical Approach Emerging? Human Relations [online]. 56 (12), pp.1545-1567. [Accessed 13/9/2015].

Fukuyama, F. (1995) Trust : The Social Virtues and the Creation of Prosperity [online]. Hamish Hamilton: [Accessed 28/9/2011].

Gale, J., Binmore, K.G. and Samuelson, L. (1995) Learning to be imperfect: The ultimatum game. Games and Economic Behavior [online]. 8 (1), pp.56-90.

[Accessed 15/5/2017].

Garfinkel, H. (1967) Studies in Ethnomethodology [online]. Eaglewood Cliffs, N. J: Prentice Hall ; Cambridge : Polity Press. [Accessed 8/8/2015].

Gaventa, J. and Cornwell, A. (2006) Power and Knowledge. In: Reason, P. and Bradbury, H., eds. (2006) Handbook of Action Research. London: Sage, pp.71-82.

Giddens, A. (1994) Risk, Trust, Reflexivity. In: Beck, U., Giddens, A. and Lash, S., eds. (1994) Reflexive Modernization: Politics, Tradition and Aesthetics in the Modern Social Order [online]. Cambridge: Polity, [Accessed 8/8/2015 4:46:27 AM].

Giddens, A. (1991) Modernity and Self-Identity: Self and Society in the Late Modern Age [online]. Cambridge: Polity.

Giddens, A. (1990) The Consequences of Modernity [online]. Stanford, Calif: Stanford University Press. [Accessed 7/08/2015].

Giddens, A. (1986) The Constitution of Society: Outline of the Theory of Structuration [online]. Cambridge: Polity Press. [Accessed 15/12/2017].

Gintis, H. (2000) Strong Reciprocity and Human Sociality. Journal of Theoretical Biology [online]. 206 (2), pp.169-179. [Accessed 10/8/2015]. 
Gozzoli, C. and Frascaroli, D. (2012) Managing participatory action research in a health-care service experiencing conflicts. Qualitative Research in Organizations and Management: An International Journal [online]. 7 (3), pp.275-289. [Accessed 19/1/2018].

Greener, I. (2008) Markets in the public sector: when do they work, and what do we do when they don't? Policy \& Politics [online]. 36 (1), pp.93-108. [Accessed 15/12/2017].

Grönroos, C. (2011) Value co-creation in service logic: A critical analysis. Marketing Theory [online]. 11 (3), pp.279-301. [Accessed 20/1/2017].

Güth, W. and Kocher, M.G. (2014) More than thirty years of ultimatum bargaining experiments: motives, variations, and a survey of the recent literature. Journal of Economic Behavior \& Organization [online]. 108 pp.396-409. [Accessed 15/5/2017].

Gyford, J. (1991) Citizens, Consumers and Councils: Local Government and the Public [online]. Basingstoke: Macmillan. [Accessed 8/8/2015].

Habermas, J. (1987) Theory of Communicative Action [online]. Cambridge: Polity. [Accessed 5/7/2011].

Hammersley, M. (1998) Reading Ethnographic Research: A Critical Guide. 2nd ed. London: Longman.

Hardin, R. (2006) Trust. Cambridge, U.K: Polity.

Hardin, R. (2002) Liberal distrust. European Review [online]. 10 (1), pp.73-89. [Accessed 8/8/2015 5:10:39 AM].

Hardin, R. (1998) Trust in government. In: Braithwaite, V., Levi, M., Cook, K.S. and Hardin, R., eds. (1998) Trust and Governance. New York: Russell Sage Foundation, pp.9-27. 
Hayek, F.A. and Caldwell, B. (2014) The Road to Serfdom: Text and Documents [online]. The definitive ed. New York, New York: Routledge. [Accessed 26/10/2017 10:03:44 AM].

Heron, J. (2014) Co-Operative Inquiry. In: Coghlan, D. and Brydon-Miller, M., eds. (2014) The Sage Encyclopedia of Action Research [online]. pp.187-192. [Accessed 18/1/2018].

Heron, J. (1996) Co-Operative Inquiry: Research into the Human Condition [online]. London: Sage. [Accessed 18/1/2018].

Hibbing, J.R. and Elizabeth Theiss-Morse (2001) Process Preferences and American Politics: What the People Want Government to Be. The American Political Science Review [online]. 95 (1), pp.145-153. [Accessed 4/4/2017].

Hirschman, A.O. (1973) Exit, voice and loyalty: Further reflections and a survey of recent contributions. [online]. 1 (13), pp.7-- 26. [Accessed 19/06/2014].

Hirschman, A.O. (1970) Exit, Voice, and Loyalty: Responses to Decline in Firms, Organizations, and States [online]. Cambridge, Mass: Harvard University Press. [Accessed 8/8/2015].

Hirst, P. (1994) Associative democracy. Dissent [online]. 41(2), pp. 241. [Accessed $13 / 8 / 2015]$.

Hoggett, P. (2000) Emotional Life and the Politics of Welfare [online]. Basingstoke: Macmillan. [Accessed 28/9/2011].

Hoggett, P., Beedell, P., Jimenez, L., Mayo, M. and Miller, C. (2010) Working psycho-socially and dialogically in research. Psychoanalysis, Culture \& Society [online]. 15 (2), pp.173-188. [Accessed 15/11/2011].

Hollis, M. (1998) Trust within Reason [online]. Cambridge: Cambridge University Press. [Accessed 8/8/2015]. 
Hollway, W. and Jefferson, T. (2000) Doing Qualitative Research Differently: Free Association, Narrative and the Interview Method. London: SAGE.

Holton, R. (1994) Deciding to trust, coming to believe. Australasian Journal of Philosophy [online]. 72 (1), pp.63-76. [Accessed 16/1/2018].

Honneth, A. (2007) Disrespect : The Normative Foundations of Critical Theory [online]. Cambridge: Polity Press. [Accessed 7/7/2011].

Honneth, A. (1996) The Struggle for Recognition : The Moral Grammar of Social Conflicts [online]. 1st MIT Press ed. Cambridge, Mass: MIT Press. [Accessed 7/7/2011].

Hood, C. (1991) A Public Management for all Seasons? Public Administration [online]. 69 (1), pp.3-19. [Accessed 16/6/2016].

Ipsos Mori, (2016) Ipsos Mori Veracity Index [online]. Online: Ipsos Mori. [Accessed 06/06/2017].

James Jr, H.S. (2002) The trust paradox: a survey of economic inquiries into the nature of trust and trustworthiness. Journal of Economic Behavior and Organization [online]. 47 (3), pp.291-307.

Jessop, B. (2008) State Power: A Strategic-Relational Approach [online]. Cambridge: Polity. [Accessed 8/8/2015].

Jessop, B. (2002) The Future of the Capitalist State [online]. Cambridge: Polity. Jilke, S. (2015) Choice and equality: are vulnerable citizens worse off after liberalisation reforms? Public Administration [online]. 93 (1), pp.68-85. [Accessed 9/1//2018].

Jones, K. (1999) Second-Hand Moral Knowledge. The Journal of Philosophy [online]. 96 (2), pp.55-78. [Accessed 17/1/2018]. 
Kahneman, D. (1986) Fairness as a constraint on profit seeking: entitlements in the market. The American Economic Review [online]. 76 (4), pp.728-741. [Accessed 10/8/2015].

Kelly, G., Mulgan, G. and Muers, S., (2002) Creating Public Value, an Analytical Framework for Public Service Reform. London: Cabinet Office.

Kemmis, S. (2008) Critical Theory and Participatory Action Research. In: Reason, P., ed. (2008) The Sage Handbook of Action Research [online]. London: SAGE Publications Ltd, [Accessed 20/11/15].

Kernaghan, K. (2000) The post-bureaucratic organization and public service values. International Review of Administrative Sciences [online]. 66 (1), pp.92-371. [Accessed 19/3/2016].

Khalil, E.L. (1999) Sentimental fools: a critique of Amartya Sen's notion of commitment. Journal of Economic Behavior and Organization [online]. 40 (4), pp.373-386. [Accessed 9/10/2012].

Le Grand, J. (2007) The Other Invisible Hand: Delivering Public Services through Choice and Competition [online]. Oxford; Princeton, N.J: Princeton University Press. [Accessed 9/1/2018].

Le Grand, J. (2003) Motivation, Agency, and Public Policy: Of Knights and Knaves, Pawns and Queens. Oxford: Oxford University Press.

Leonard, R. (1997) Theorizing the Relationship between Agency and Communion. Theory \& Psychology [online]. 7 (6), pp.823-835. [Accessed 25/5/2017].

Levi, M. (1998) A State of Trust. In: Braithwaite, V. and Levi, M., eds. (1998) Trust and Governance. New York: Sage, pp.77-101.

Lorino, P., Tricard, B. and Clot, Y. (2011) Research Methods for NonRepresentational Approaches to Organizational Complexity: The Dialogical 
Mediated Inquiry. Organization Studies [online]. 32 (6), pp.769-801. [Accessed 18/1/2018].

Lowndes, V. (1997) Change in public service management: new institutions and new managerial regimes. Local Government Studies [online]. 23 (2), pp.42. [Accessed 8/7/2011].

Luhmann, N. (1979) Trust and Power. Chichester: J Wiley.

Lukes, S. (1986) Power [online]. New York: New York University Press. [Accessed 24/5/2017].

Lyons, W.E., Lowery, D. and Hoogland De Hoog, R. (1992) The Politics of Dissatisfaction: Citizens, Services, and Urban Institutions [online]. United States: M.E. Sharpe. [Accessed 8/8/2015].

Mårtensson, P. and Lee, A.S. (2004) Dialogical Action Research at Omega Corporation. MIS Quarterly [online]. 28 (3), pp.507-536. [Accessed 18/1/2018].

Mays, N. and Pope, C. (2000) Qualitative Research in Health Care: Assessing Quality in Qualitative Research. BMJ: British Medical Journal. 320 (7226), pp.50-52.

McEvily, B., Weber, R.A., Bicchieri, C. and Ho, V. (2006) Can groups be trusted? An experiemental study of trust in collective entities. In: Bachmann, R. and Zaheer, A., eds. (2006) Handbook of Trust Research. Cheltenham: Edward Elgar Publishing, pp.52-68.

McKnight, D.H. and Chervany, N.L. (2006) Reflections on an initial trust-building model. In: Bachmann, R. and Zaheer, A., eds. (2006) Handbook of Trust Research. Elgar, pp.29-51.

McKnight, D.H. and Chervany, N.L. (2001) What Trust Means in E-Commerce Customer Relationships: An Interdisciplinary Conceptual Typology. International Journal of Electronic Commerce [online]. 6 (2), pp.35-59. [Accessed 10/8/2015]. 
Moeliono, I. (2005) Uncovering the Hidden Stones : The use of Participatory Action Research for Conflict Resolution in Natural Resource Management Around Projected Areas in Flores, East Nusa Tenggara, Indonesia [online]. [Accessed 20/1/2017].

Moggridge, D.E. (1976) Keynes [online]. London: Macmillan. [Accessed 23/5/2017].

Möllering, G. (2006) Trust, institutions, agency: towards a neoinstitutional theory of trust. In: Bachmann, R. and Akbar, Z., eds. (2006) Handbook of Trust Research. United Kingdom: Edward Elgar, pp.355-376.

Möllering, G., (2005) Understanding Trust from the Perspective of Sociological Neoinstitutionalism : The Interplay of Institutions and Agency [online].

Wissenschaftliche Einrichtungen. MPIfG - Max-Planck-Institut für Gesellschaftsforschung. [Accessed 7/08/2015].

Möllering, G. (2001) The Nature of Trust: From Georg Simmel to a Theory of Expectation, Interpretation and Suspension. Sociology [online]. 35 (2), pp.403-420. [Accessed 7/08/2015].

Montoya, M.J. and Kent, E.E. (2011) Dialogical Action: Moving From CommunityBased to Community-Driven Participatory Research. Qualitative Health Research [online]. 21 (7), pp.1000-1011. [Accessed 23/8/2017].

Moore, M., H. (1995) Creating Public Value: Strategic Management in Government. Cambridge, MA: Harvard University Press.

Muir, R. (2014) The relational state: Beyond marketisation and managerialism. Juncture [online]. 20 (4), pp.280-286. [Accessed 8/8/2015].

Mulgan, G. (2012) Government with the people: the outlines of a relational state. In: Cooke, G. and Muir, R., eds. (2012) The Relational State: How Recognising the Importance of Human Relationships could Revolutionise the Role of the State [online]. [online]: Institute for Public Policy Research, pp.20-34. [Accessed 3rd November, 2015]. 
Newman, J. and Clarke, J. (2009) Publics, Politics and Power : Remaking the Public in Public Services [online]. London: Sage. [Accessed 7/5/2011].

Normann, R. (1991) Service Management: Strategy and Leadership in Service Business [online]. 2nd ed. Chichester: Wiley. [Accessed 07/072017].

North, D.C. (1990) Institutions, Institutional Change and Economic Performance [online]. Cambridge: Cambridge University Press. [Accessed 8/8/2015].

O'Neill, O. (2002) A Question of Trust. Cambridge: Cambridge University Press.

Osborne, S.P., Radnor, Z. and Strokosch, K. (2016) Co-Production and the CoCreation of Value in Public Services: A suitable case for treatment? Public Management Review [online]. 18 (5), pp.639. [Accessed 9/6/2016].

Ostrom, E. (1990) Governing the Commons: The Evolution of Institutions for Collective Action. Cambridge: Cambridge University Press.

Park, A. and National Centre for Social Research (Great Britain) (2008) British Social Attitudes [online]. Los Angeles, Calif; London: SAGE. [Accessed 10/8/2015 10:22:56 AM].

Park, P. (1999) People, Knowledge, and Change in Participatory Research. Management Learning [online]. 30 (2), pp.141-157. [Accessed 19/6/16].

Parker, S. (2008) State of Trust. London: Demos.

Pettigrew, P.J. (2003) Power, Conflicts, and Resolutions: A Change Agent's Perspective on Conducting Action Research Within a Multiorganizational Partnership. Systemic Practice and Action Research [online]. 16 (6), pp.375-391. [Accessed 19/1/2017].

Pettit, P. (1998) Republican theory and political trust. In: Levi, M. and Braithwaite, V., eds. (1998) Trust and Governance. New York: Sage, pp.295-314. 
Piketty, T. (2014) Capital in the Twenty-First Century. London: Harvard University Press.

Powell, W.W. and DiMaggio, P.J. (1991) The New Institutionalism in Organizational Analysis [online]. Chicago: University of Chicago Press. [Accessed 8/8/2015].

Putnam, R.D. (1995) Bowling Alone: America's Declining Social Capital. New York: Simon and Schuster.

Reason, P. (2006) Choice and Quality in Action Research Practice. Journal of Management Inquiry [online]. 15 (2), pp.187-203. [Accessed 15/12/12].

Reason, P. (2003) Pragmatist Philosophy and Action Research: Readings and Conversation with Richard Rorty. Action Research [online]. 1 (1), pp.103-123. [Accessed 11/6/16].

Reason, P. and Bradbury, H. (2006) Handbook of Action Research. London: Sage.

Ripamonti, S., Galuppo, L., Gorli, M., Scaratti, G. and Cunliffe, A.L. (2016) Pushing Action Research Toward Reflexive Practice. Journal of Management Inquiry [online]. 25 (1), pp.55-68. [Accessed 5/1/2017].

Robb, N. and Greenhalgh, T. (2006) "You have to cover up the words of the doctor": the mediation of trust in interpreted consultations in primary care. Journal of Health Organization and Management [online]. 20 (5), pp.434-55. [Accessed 4/4/2017].

Rose, J. (2014) The Public Understanding of Political Integrity: The Case for Probity Perceptions [online]. Basingstoke: Palgrave Macmillan. [Accessed 16/5/2017].

Rose, N. (1996) Inventing our Selves: Psychology, Power, and Personhood [online]. Cambridge: Cambridge University Press. [Accessed 8/7/2011].

Rowe, R. and Calnan, M. (2006) Trust relations in health care--the new agenda. European Journal of Public Health [online]. 16 (1), pp.4; 4-6; 6. [Accessed 4/4/2017]. 
Rowe, G. and Frewer, L.J. (2005) A Typology of Public Engagement Mechanisms. Science, Technology, \& Human Values [online]. 30 (2), pp.251-290. [Accessed 8/8/2015].

Scholz, J.T. and Pinney, N. (1998) Trust, taxes, and compliance. American Journal of Political Science [online]. 39 (2), pp.490-512. [Accessed 8/8/2015].

Schutz, A. (1967) The Phenomenology of the Social World [online]. Evanston: Northwestern University Press. [Accessed 27/6/2017].

Scraton, P. (2013) The legacy of Hillsborough: liberating truth, challenging power. Race \& Class [online]. 55 (2), pp.1-27. [Accessed 9/1/2018].

Seale, C. (1997) Ensuring rigour in qualitative research. The European Journal of Public Health. 7 (4), pp.379-384.

Shotter, J. (2010) Situated Dialogic Action Research: Disclosing "Beginnings" for Innovative Change in Organizations. Organizational Research Methods [online]. 13 (2), pp.268-285. [Accessed 1/5/2018].

Simmel, G. and Wolff, K.H. (1964) The Sociology of Georg Simmel [online]. London: Macmillan. [Accessed 7/08/2015].

Simon, H.A. (1992) Economics, Bounded Rationality and the Cognitive Revolution [online]. Cheltenham: Edward Elgar. [Accessed 19/3/2016].

Simpson, T.W. (2012) What Is Trust? Pacific Philosophical Quarterly [online]. 93 (4), pp.550-569. [Accessed 15/1/2018].

Skinner, Q. (2012) Liberty before Liberalism [online]. Cambridge: Cambridge University Press. [Accessed 8/7/2015].

Stears, M. (2012) The case for a state that supports relationships, not a relational state. In: Cooke, G. and Muir, R., eds. (2012) The Relational State. London: IPPR, . 
Stevenson, A. and Waite, M. (2011) Concise Oxford English Dictionary [online].

Oxford: Oxford University Press. [Accessed 15/5/2012].

Stolorow, R.D. and Atwood, G.E. (2002) Contexts of being: The Intersubjective Foundations of Psychological Life [online]. New York; London: Analytic. [Accessed 19/3/2016].

Swartz, D. (1997) Culture and Power : The Sociology of Pierre Bourdieu [online].

Chicago: University of Chicago Press. [Accessed 28/9/2011].

Taylor-Gooby, P. (2008) Trust and Welfare State Reform: The Example of the NHS.

Social Policy \& Administration [online]. 42 (3), pp.288-306. [Accessed 4/4/2017].

Taylor, C. (1989) Sources of the Self : The Making of the Modern Identity [online]. Cambridge: Cambridge University Press. [Accessed 7/7/2011].

Taylor, C. (1992) Multiculturalism and "the Politics of Recognition" [online].

Princeton University Press: [Accessed 7/7/2011].

Taylor, C. (1991) The Ethics of Authenticity [online]. Harvard: Harvard University Press. [Accessed 7/7/2011].

Taylor-Gooby, P. (2008) Trust and Welfare State Reform: The Example of the NHS. Social Policy \& Administration [online]. 42 (3), pp.288-306. [Accessed 4/4/2017].

Thaler, R.H. (1992) The Winner's Curse: Paradoxes and Anomalies of Economic Life [online]. New York: Free Press. [Accessed 10/3/2017].

The Behavioural Insights Team, (2015) Update Report 2013 - 2015 [online]. London: Behavioural Insights team. [Accessed 15/6/2016].

Thompson, S. (2006) The Political Theory of Recognition : A Critical Introduction. Cambridge: Polity Press. 
Tully, J. (1994) Philosophy in an Age of Pluralism : The Philosophy of Charles Taylor in Question [online]. Cambridge: Cambridge University Press. [Accessed 7/7/2011].

Tyler, T. (1998) Trust and Democratic Governance. In: Braithwaite, V., Margaret, ed. (1998) Trust and Governance. New York: Sage, pp.269-294.

Uslaner, E.M. (2005) Varieties of Trust. European Political Science [online]. 2 (3), pp.43-49. [Accessed 4/4/2017].

Uslaner, E.M. and Brown, M. (2005) Inequality, Trust, and Civic Engagement. American Politics Research. 33 (6), pp.868-894.

Van de Walle, S. and Bouckaert, G. (2007) Public service performance and trust in government: the problem of causality. International Journal of Public Administration [online]. 29 (8), pp.891-913. [Accessed 4/4/2017].

Van de Walle, S., Van Roosbroek, S. and Bouckaert, G. (2008) Trust in the public sector: is there any evidence for a long-term decline? International Review of Administrative Sciences [online]. 74 (1), pp.47-64. [Accessed 4/4/2017].

Wang, N. (2014) Private finance initiative as a new way to manage public facilities: A review of literature. Facilities [online]. 32 (11/12), pp.584-605. [Accessed 10/1/2018].

Waters, T. and Waters, D. (2015) Weber's Rationalism and Modern Society: New Translations on Politics, Bureaucracy, and Social Stratification [online]. First ed. Basingstoke: Palgrave Macmillan. [Accessed 9/1//2018].

Weber, M., Gerth, H.H. and Mills, C.W. (1970) From Max Weber: Essays in Sociology [online]. London: Routledge \& Kegan Paul. [Accessed 7/08/2015].

Webler, T. (2000) Fairness and Competence in Citizen Participation. Administration \& Society [online]. 32 (5), pp.566. [Accessed 8/7/2011]. 
Weerakkody, V. (2009) The diffusion and use of institutional theory: a crossdisciplinary longitudinal literature survey. Journal of Information Technology [online]. 24 (4), pp.354-368. [Accessed 8/7/2011].

Whiteley, P., Clarke, H.D., Sanders, D. and Stewart, M. (2016) Why Do Voters Lose Trust in Governments? Public Perceptions of Government Honesty and Trustworthiness in Britain 2000-2013. The British Journal of Politics and International Relations [online]. 18 (1), pp.234-254. [Accessed 4/4/2017].

Williamson, O.E. (1993) Calculativeness, Trust, and Economic Organization. The Journal of Law and Economics [online]. 36 (S1), pp.453-486. [Accessed 10/09/2012].

Young, I.M. (2002) Inclusion and Democracy [online]. Oxford: Oxford University Press. [Accessed 8/8/2015].

Zeckhauser, R.J. and Bohnet, I. (2004) Trust, risk and betrayal. Journal of Economic Behavior \& Organization [online]. 55 (4), pp.467-484. [Accessed 20/1/2017].

Zucker, L.G. (1987) Institutional Theories of Organization. Annual Review of Sociology [online]. 13 (1), pp.443-464. [Accessed 8/8/2015].

Zucker, L.G. (1986) Production of trust: Institutional sources of economic structure, 1840-1920. Research in Organizational Behavior [online]. 8 pp.53-111. [Accessed 10/07/2017]. 